\title{
Classification and Salt-tolerance of Actinomycetes in the Qinghai Lake Water and Lakeside Saline Soil
}

\author{
Yan Cai \\ College of Resources and Environment \\ Northwest Sci-Tech University of Agriculture \& Forestry \\ Yangling 712100, China \\ College of Resources and Environment \\ Sichuan Agriculture University \\ Ya'an 625014, China \\ Tel: 86-835-2885-776 E-mail: caiyya@126.com \\ Quanhong Xue (Correspond author) \\ College of Resources and Environment \\ Northwest Sci-Tech University of Agriculture and Forestry \\ Yangling 712100, China \\ Tel: 86-29-8709-1321_E-mail: xueqhong@public.xa.sn.cn \\ Zhanquan Chen \& Rong Zhang \\ Institute of Soil and Fertilizer \\ Qinghai Academy of Agriculture and Forestry \\ Xining 810016, China
}

\begin{abstract}
Mesophilic and cryogenic actinomycetes were isolated from water, quagmire soil, lakeside soil and saline wasteland soil in the Qinghai Lake by spreading samples on three kinds of agar media, in which content of $\mathrm{NaCl}$ was $70 \mathrm{~g} / \mathrm{L}$. They were characterized according to routine methods, and detected their salt-tolerance. The results indicated that there were salt-tolerant, mesophilic and cryogenic actinomycetes in quagmire and lakeside soil of the Qinghai Lake and in saline wasteland soil nearby the Qinghai Lake. The amount in wasteland soil was the largest, followed by lakeside and swamp soil. All of the salt-tolerant actinomycetes identified were Streptomyces (92. $6 \%$ of total), and they were all albsporus. And $47.6 \%, 19.0 \%$, and $33.3 \%$ of the tested actinomycetes could tolerant $\mathrm{NaCl}$ concentration at $70 \mathrm{~g} / \mathrm{L}$, $100 \mathrm{~g} / \mathrm{L}$, and $150 \mathrm{~g} / \mathrm{L}$ respectively.
\end{abstract}

Keywords: Actinomycetes distribution, Salt-tolerant, Qinghai Lake

Actinomycetes is an important class of microbial resources, they are important producers of antibiotics and other important bioactive substances. So far, about two-thirds of the world's antibiotics were secreted by actinomyces (Liu Zh. H. ,2002; Liu Zh. H. and Jiang Ch. L.,2004). As the strains with biological activity were found in large numbers, we separated active actinomycete strains more and more difficult from conventional environment (Jiang Ch. L. and Xu L. H., 1997). So that the efficiency of the discovery of new compounds reduced.Halophilic or salt-tolerant actinomycetes are a kind of extreme environment actinomycetes, which are increasingly concerned around the world as research materials of microbial physiology from adverse circumstance. At present, Mikami Y. (1982), Sato M. et al.(1983) Mikami Y. et al. (1985) put on a certain studies of Alkaliphilic and alkali-tolerant actinomycetes and found several antibiotics and enzyme. Wang D. Zh..(1989), Wang L. F. et al. (1993), Liu D. R. et al. (1998) and Liu T. H. et al. (1999) also conducted a preliminary study on actinomycetes in saline-alkali soil, but study on the plateau halophilic or salt-tolerant actinomycetes reported very few. This article had conducted the preliminary study on the actinomycetes in Qinghai Lake and lakeside saline wasteland soil, where altitude was 3200 meter. The purpose was to explore the 
actinomycete ecological distribution characteristics in extreme environment of plateau saline soil, and provide a scientific basis for research, use of the plateau extreme environmental actinomycete resources and protection of ecological environment.

\section{Materials and Methods}

\subsection{Overview of sampling point}

Qinghai Lake is in the Qinghai-Tibet Plateau, where the altitude is 3200 meter and the average annual temperature is around $0{ }^{\circ} \mathrm{C}$.It is the natural closure of inland water, and rich in salts material. As the soil salinization, lakeside vegetation is sparse, and mostly wormwood grass, ice grass and Chinese small iris and other herbs. $\mathrm{pH}$ and salt content of samples analyzed by conventional methods. Table 1 is sampling point overview and samples basic properties.

\section{$<$ Table 1 Basic properties of samples and overview of sampling point}

\subsection{Separation, counting and purification $>>$}

Dilution plate spreading method was used to separate and count (Cheng L. J. and Xue Q. H. ,2000). Separation culture medium were starch casein agar, glycerol asparagine agar and starch ammonium agar, which all added $70 \mathrm{~g} \mathrm{/} \mathrm{L} \mathrm{NaCl}$ in particular (Ruan J. Sh. 1992, Cheng L. J. and Xue Q. H. 2000). The growth temperature and time respectively were $4{ }^{\circ} \mathrm{C}$ for 3 months and $28{ }^{\circ} \mathrm{C}$ for 1 month. Actinomycetes separated were preserved on the corresponding incline after purified by plate line method.

\subsection{Actinomycete identification}

According to the shape and the culture characteristics(Ruan J. Sh.,1992), Actinomycetes were identified to genus. Mycelium shape was observed by buried glass method, and culture characteristics was observed by Gao 1 agar culture medium.

\subsection{Determination of actinomycete salt-tolerance}

Purified actinomycetes were inoculated on medium, in which $\mathrm{NaCl}$ concentrations were $0,50,70,100,150,180,200$, 250 and $300 \mathrm{~g} / \mathrm{L}$ respectively, and observed their growth conditions. The highest $\mathrm{NaCl}$ concentration that the strain could tolerant expressed the strain salt-tolerance.

\section{Results and analysis.}

\subsection{Number of actinomycetes in lakeside soil and lake quagmire}

Although the plateau ecological environment had cold characteristics in general, but numbers of mesophilic actinomycetes in four samples were still far higher than those of cryogenic actinomycetes (from table 2). Average number of actinomycetes from saline wasteland soil was the maximum, whose mesophilic actinomycetes were 1.86 $\times 10^{6} \mathrm{cfu} / \mathrm{g}\left(\right.$ at $\left.28{ }^{\circ} \mathrm{C}\right)$ and cryogenic actinomycetes were $8.55 \times 10^{4} \mathrm{cfu} / \mathrm{g}\left(\right.$ at $\left.4^{\circ} \mathrm{C}\right)$, followed by lakeside soil and quagmire, whose mesophilic actinomycetes were respectively $1.03 \times 10^{3} \mathrm{cfu} / \mathrm{g}$ and $2.75 \times 10^{2} \mathrm{cfu} / \mathrm{g}$. Number of mesophilic actinomycetes in saline wasteland soil was 1805 times higher than that in lakeside soil, and was 6763 times higher than that in quagmire. At $4{ }^{\circ} \mathrm{C}$ and $28{ }^{\circ} \mathrm{C}$ culture conditions, Water of Qinghai Lake were not isolated salt-tolerant actinomycete. You C.F. (1986) believed that actinomycetes liked dry environment, which was possibly an important reason for no actinomycete in water of Qinghai Lake. This study did not isolated cryogenic actinomycetes, in addition to saline wasteland soil.

$<<$ Table 2 Number of actinomycetes in lakeside soil, quagmire, water of Qinghai Lake and saline wasteland soil in Qinghai Lake township>>

\subsection{Classification and composition of actinomycetes in lakeside soil, quagmire and saline wasteland soil}

According to the classification principle of actinomycete, the 27 representative actinomycete strains, which had been separated and purified, were identified and classified. The results were as follows: 25 strains were identified as Streptomyces, and all were albsporus, which were $92.6 \%$ of the representative strains. 2 strains of actinomycete had no sporulation structure in the test medium and were unable to determine their classification status, which were $7.4 \%$ of the representative strains.

So the actinomycete composition of lakeside soil and quagmire of Qinghai Lake and saline wasteland soil in Qinghai Lake township were all sole, that just tallied with their alpine, cold, and high-salt extreme environment. Liu D. R. and Li X. H. (1998) studied on actinomycetes of salt lake in Yuncheng in Shanxi, and included the separated strains in 1 familia and 4 genus, and classified Streptomyces into 11 groups. Lv Zh. T., Zhang L. P., Li Y. H. et al.(2006) studied salty samples from Cangzhou city Hebei province. They isolated 33 moderately halophilic actinmycetes strains and 13 halotolerant actinomycetes strains, which belonged to Nocardiopsis, Streptomyces and a novel genus of Cellulomonadaceae. The actinomycete composition of lakeside soil, saline wasteland soil and quagmire of Qinghai Lake were far simpler than other places, which noted that actinomycete composition in saline soil of plateau ecosystems was different with that of low elevation area. Li W. J.,Tang Sh. K., Wang D. et al.(2004) studied biodiversity of 
moderately halophilic actinomycetes in Xinjiang and Qinghai area, and also found that the variety of halophilic actinomycetes from Xinjiang was much higher than that from Qinghai area.

\subsection{Salt-tolerance of actinomycetes in lakeside soil, quagmire and saline wasteland soil}

Salt-tolerance of 21 actinomycete strains were determined,and the results were as follows: 10 strains could grow on the $70 \mathrm{~g} / \mathrm{L} \mathrm{NaCl}$ medium,which were $47.6 \%$ of the tested strains and scheduled for mild salt-tolerant actinomycetes tentatively; 4 strains could grow on the $100 \mathrm{~g} / \mathrm{L} \mathrm{NaCl}$ medium, which were $19.0 \%$ of the tested strains and scheduled for moderate salt-tolerant actinomycetes tentatively; 7 strains could grow on the $150 \mathrm{~g} / \mathrm{L} \mathrm{NaCl}$ medium, which were $33.3 \%$ of the tested strains and scheduled for mild halophilic actinomycetes.

Wang D. Zh..(1989), Liu D. R. and Li X. H. (1998) believed that the growth of extreme halophilic bacteria requested a high concentration of $\mathrm{NaCl}$ (at least $120 \mathrm{~g} / \mathrm{L}$ ), and the optimal $\mathrm{NaCl}$ concentration was $200 \sim 250 \mathrm{~g} / \mathrm{L}$, and even in saturated $\mathrm{NaCl}$ solution they could grow. Optimal growth salinity of the 21 tested actinomycete strains was $0 \sim 70 \mathrm{~g} / \mathrm{L}$. 7 tested actinomycete strains could endured $150 \mathrm{~g} / \mathrm{L} \mathrm{NaCl}$ and called mild halophilic actinomycete. To sum up, certain amount of salt-tolerant actinomycetes and mild halophilic actinomycete were in lakeside soil, quagmire and saline wasteland soil of Qinghai Lake.

\section{Conclusions}

There were some mesophilic and cryogenic actinomycetes in lakeside soil, quagmire of Qinghai Lake and saline wasteland soil of Qinghai Lake township; Actinomycetes were not detected in Water sample of lake. the salt-tolerance actinomycetes identified were all Streptomyces. $47.6 \%, 19.0 \%$ and $33.3 \%$ of the tested actinomycetes could tolerant the highest $\mathrm{NaCl} 70 \mathrm{~g} / \mathrm{L}, 100 \mathrm{~g} / \mathrm{L}$ and $150 \mathrm{~g} / \mathrm{L}$ respectively. Certain amount of salt-tolerant actinomycetes and mild halophilic actinomycetes were in lakeside soil, quagmire and saline wasteland soil of Qinghai Lake.

\section{Discussion}

In this paper, isolated identified actinomycetes were all Streptomyces by conventional separation culture medium, and quantity of rare actinomycetes (other actinomycetes in addition to Streptomyces) was small or none. For decades, researchers found that rare actinomycetes produced many bioactive substances, including antibiotics (erythromycin, rifampicin, extremadura, foreign erythromycin and so on), enzymes, vitamins and so on. Some antibiotics have been commercialized, and resulted in tremendous social value and economic value (Jiang Ch. L. and Xu L. H.,1997; Liu Zh. H. ,2002; Liu Zh. H. and Jiang Ch. L.,2004). Isolation of rare actinomycetes is the first and the most important step of actinomycetes resource development. Isolation and Screening of rare actinomycetes should choose a suitable medium in addition to choice of special ecological environment as the separation of outside sources. Tang Sh. K., Jiang Y., Zhi X. Y. et al.(2007) thought that separation medium fitting for halophilic actinomycetes was improved ISP5 medium, starch ammonium medium, modified starch ammonium medium. They also thought that we must give full consideration to micro-environment of medium, and simulate salt environmental conditions (including a certain degree of concentration, a certain proportion of complex salt, the special nutrition needs and so on) as far as possible. Only in this way it would be possible to isolate more number of rare actinomycetes.

\section{References}

Cheng L. J., Xue Q. H. (2000). Microbiology Experiment Technology. Publisher: World Books Publication Company, pp: 80-83, 104-105 (in Chinese).

Jiang Ch. L., Xu L. H..(1997). Microbial Resources. Publisher: Science Press, pp:104-200 (in Chinese).

Liu Zh. H.. (2002). Modern Microbiology. Publisher: Science Press, pp:3-35 (in Chinese).

Liu Zh. H., Jiang Ch. L..(2004). Modern Biology and Technology of Actionomycetes. Publisher: Science Press, pp:10-50 (in Chinese).

Li W. J., Tang Sh. K.,Wang D. et al. (2004). A primary study on biodiversity of moderately halophilic actinomycetes in Xinjiang and Qinghai area. Acta Microbiol. Sinica, 44(1):1-7.(in Chinese).

Liu D. R., Li X. H. (1998).Studies on actimycetes population from saltlake of Yuncheng in Shanxi. Acta Microbiol. Sinica, 38(2):137-141. (in Chinese).

Liu T. H., Zhou P. J.. (1999). Halophilic microbes. Microbiology. 26(3):232. (in Chinese).

Lv Zh. T., Zhang L. P., Li Y. H. et al. (2006). Biodiversity of halophilic actinomycetes of Cangzhou salty environments. Journal of Hebei University (Natural Science Edition), 26(1):1-6.

Mikami Y., Miyashita K., Arai T.. (1982). Diaminopimelic acid profiles of alkalophilic and alkaline-resistant strains of actinomycetes. J. Gen. Microbiol, 12(8):1 709-1 712.

Mikami Y.. (1985-1986). Alkalophilic actinomycetes . The Actinomycetes. $19: 176$ - 191.

Ruan J. Sh.. (1992). Foundation of Actimomycete Classification. Publisher: Science Press, pp:18-109 (in Chinese). 
Sato M., Beppu T., Arima K. (1983). Studies on antibiotics produced at high alkaline pH. Agr. Biol. Chem, 47(9): 2019 $-2027$.

Tang Sh. K., Jiang Y., Zhi X. Y.et al. (2007). Separation method of halophilic actinomycetes. Microbiology. 34(2): 390-392. (in Chinese).

You C. F.. (1986). Actinomycete of soil microorganisms. Soil Science Progress, (6): 1-5 (in Chinese).

Wang D. Zh.. (1989). Extreme environment microbes and application.Chinese Journal of Applied Ecology, 6(2):77 - 81. (in Chinese).

Wang L. F., Song Sh. Zh., Ruan J. Sh.. (1993). A study on classification of actinomycetes from saline-alkali soils. Acta Microbiol. Sinica, 33(6):393 - 399. (in Chinese).

Table 1. Basic properties of samples and overview of sampling point

\begin{tabular}{|c|c|c|c|c|c|}
\hline $\begin{array}{c}\text { No. of } \\
\text { samples }\end{array}$ & Sampling point & $\begin{array}{l}\text { Altitude } \\
(\mathrm{m})\end{array}$ & $\mathrm{pH}$ & $\begin{array}{l}\text { Salt content } \\
\left(\mathrm{g} \cdot \mathrm{kg}^{-1}\right)\end{array}$ & Vegetation \\
\hline $15-1$ & $\begin{array}{c}\text { Lakeside of } \\
\text { Qinghai Lake }\end{array}$ & 3230 & 9.38 & 1.90 & wormwood grass \\
\hline $15-2$ & $\begin{array}{l}\text { Quagmire }(0-20 \mathrm{~cm}) \\
\text { of Qinghai Lake }\end{array}$ & 3230 & 9.02 & 5.44 & \\
\hline $15-3$ & Water of Qinghai Lake & 3230 & 9.02 & 4.33 & \\
\hline 17 & $\begin{array}{l}\text { Saline wasteland in } \\
\text { Qinghai Lake township }\end{array}$ & 3081 & 8.62 & 19.6 & $\begin{array}{c}\text { ice grass, } \\
\text { Chinese small iris }\end{array}$ \\
\hline
\end{tabular}

Table 2. Number of actinomycetes in lakeside soil, quagmire, water of Qinghai Lake and saline wasteland soil in Qinghai Lake township(cfu/g)

\begin{tabular}{cccccc}
\hline & No. of sample & Starch casein agar & Starch ammonium & Glycerol asparagine agar & Average \\
\hline Number of & $15-1$ & $1.82 \times 10^{3}$ & $1.01 \times 10^{3}$ & $2.70 \times 10^{2}$ & $1.03 \times 10^{3}$ \\
mesophilic & $15-2$ & $4.12 \times 10^{2}$ & $1.37 \times 10^{2}$ & $2.75 \times 10^{2}$ & $2.75 \times 10^{2}$ \\
actinomycete & $15-3$ & 0 & 0 & 0 & 0 \\
$\left(\right.$ at $28{ }^{\circ} \mathrm{C}$ ) & 17 & $1.38 \times 10^{6}$ & $2.02 \times 10^{6}$ & $2.18 \times 106$ & $1.86 \times 10^{6}$ \\
Number of & $15-1$ & 0 & 0 & 0 & 0 \\
cryogenic & $15-2$ & 0 & 0 & 0 & 0 \\
actinomycete & $15-3$ & 0 & 0 & 0 & 0 \\
$\left(\right.$ at $\left.4{ }^{\circ} \mathrm{C}\right)$ & 17 & $1.20 \times 10^{5}$ & $5.81 \times 10^{4}$ & $7.84 \times 10^{4}$ & $8.55 \times 10^{4}$ \\
\hline
\end{tabular}




\title{
Personnel Characteristics of Maintenance Practice: A Case of High-Rise Office Buildings in Malaysia
}

\author{
Emma Marinie Ahmad Zawawi \\ Centre of Research \& Graduate Studies, Faculty of Architecture, Planning \& Surveying \\ University Technology MARA \\ 40450 Shah Alam, Malaysia \\ Tel: 6-03-5521-1518Ｅ-mail: emmamarinie@salam.uitm.edu.my \\ Syahrul Nizam Kamaruzzaman (Corresponding author) \\ Building Surveying Department, Faculty of Built Environment \\ University of Malaya \\ Lembah Pantai, 50603 Kuala Lumpur, Malaysia \\ Tel: 6-03-7967-6833 E-mail: syahrulnizam@um.edu.my
}

\begin{abstract}
An excellent practice of maintenance management is greatly needed to increase the life cycle of the property and to minimize unexpected breakdowns or deterioration effects. In this respect, the modern maintenance manager will have to rely as much on knowledge of the managerial and social sciences as on the traditional technique knowledge base of building construction and deterioration. Improper conduct and application of maintenance management procedure and systems may result in deteriorating the property itself. Therefore, the performance of the maintenance management operations have to be continuously reviewed and analysed in order to ascertain a high quality service. This study aims to present the personnel characteristics in the current practice of building maintenance management in Malaysia. Questionnaires are distributed to all maintenance personnel on selected buildings. These data are then analysed consequently to produce the in depth understanding of personnel characteristics in current building maintenance practice in Malaysia. This study believe to be valuable in identifying where the practice needed further attention and helped pin point problems areas within building maintenance management.
\end{abstract}

Keywords: Building maintenance, Personnel, High-rise offices, Malaysia

\section{Introduction}

Building maintenance management is a highly complex sphere of operations, involving the interaction between the technical, social, legal and fiscal determinants that govern the use of buildings (Francis et al, 2001). Most people do not realize that a building maintenance system contributes to the income of the company's owning or renting the building. It has become a part of a total performance approach, together with other factors such as productivity, quality, safety, and environment (Groote, 1995). Maintenance performance is generally hard to measure, as one should not only consider quantifiable parameters but also the quality of the performed maintenance and its organization (Armstrong, 1987).

As building in Malaysia is concerned, most buildings are maintained by their own staff instead of hiring contractors (Zawawi, 2006). Buildings such as hotels, hospitals and high-rise offices normally have their own maintenance department managed by a maintenance manager. Zawawi (2006), conducted a building satisfaction survey and found that most occupants considers that the maintenance serviced they received was not in the satisfied point. This involves issues such as lack of maintenance staff, unskilled workers, lack of tools and many more. Thus, this paper aims to assess and identify the personnel characteristics affecting building maintenance efficiency of building maintenance department in Malaysia. Maintenance personnel include maintenance staff or people responsible for maintenance job in the buildings.

\section{Data Gathering/Methodology}

Many of the possible subjects are not always in the office, as they are all moving about within the building, carrying out tasks. This makes interviewing problematic thus, questionnaire was chosen as the method of collecting data. This 
appears to be the most convenient way to obtain highest participation as people would be able to fill in the questionnaire during free time.

For this study, data are gathered from the entire maintenance individuals that are directly involve in maintenance works including repairing and supervising. As this involve all level of maintenance personnel, dual language, Malay and English was used, as this would help in providing better understanding of the questionnaires. The questionnaire was design for the maintenance personnel to fill in their details that includes data of academic qualifications, working experience, age, gender and so on. The maintenance personnel are divided into mechanical, electrical and electronic types. Likewise, the personnel are hierarchically group into engineer, superintendent and technician (Mjema, 2002). Five high-rise buildings located in Kuala Lumpur and Klang Valley were selected for this study. Based on the selected buildings, 76 questionnaires were distributed to all maintenance personnel.

\section{Building Description}

A summary of key building features is shown in the Table 1 . The number of storeys varies from ten to eighteen with a total gross floor area ranging from $6530 \mathrm{~m}^{2}$ to $18100 \mathrm{~m}^{2}$. These buildings are all modern type high-rise office buildings with sophisticated building services installed. All of these buildings operate approximately 8 hours to 10 hours a day.

\section{Discussions of Results}

\subsection{Gender and Working Experience}

From 76 respondents of maintenance staff in high-rise office buildings, males are more likely to be employed in the maintenance department rather than females (Figure 4). Only $7.9 \%$ of the respondents are found to be female. The study has also found that those females employee are most likely to be doing administrative work in the department, such as receiving calls for maintenance requests, filing and other similar tasks. The author strongly believed that having one or two such clerical persons in a maintenance department would be necessary. This is because most females are very familiar with paperwork, including typing, coding and so on.

Working experience is also one of the factors that affect the quality of maintenance system. The survey shown that from the entire 76 respondents in maintenance department, not many of them possesses a long working experience. Figure 2 shows that only $9.82 \%$ of them have 6 to 8 years working experience, and majority of the personnel obtain around 2 to 4 years experienced in that field $(44.70 \%)$. Even though, working experience does not give unswerving impact to the maintenance system but it does affect the quality of works. Peoples with more experience tend to do their work confidently and effectively while less experience peoples may need somebody to assist them.

\subsection{Academic Qualification}

Based on the survey data, most companies do not have full skilled maintenance personnel. Figure shows the percentage of academic qualification of maintenance people in the office buildings. Some of them are high-school leavers that do not posses the necessary skills to do maintenance job. A large number of them are back up with technical certificates as their education level. Only one-fourth of them have suitable qualification such as degrees or diplomas. Degree holders are the managers and those at a higher level. They are not involved in technical issues at all.

Technician and supervisors are among staffs with technical certificate and are considered as skilled staffs that fulfils the building maintenance requirements. SRP, SPM and STPM are those of school's passer, have no basic technical knowledge, and are considered as unskilled staff. Only a few of them have some working experience in this field. These are among the problems faced by most maintenance organisations in Malaysia. Hiring skilled maintenance personnel is difficult. In order to resolve this problem the Building Management Team should provide skill training to those staff without essential academic qualifications. The Stationery Office, (1994) has stated that it is the duty of an employer to ensure that his personnel have the necessary competency to do maintenance work. It is also the responsibility of the employer to provide employees with appropriate training if they are not competent enough to carry out tasks. Competency level should be emphasized because a maintenance department works closely with the building's control system. Moreover, unskilled staff could cause enormous damage to machines and equipment especially in a manufacturing plant, and therefore represent a high risk to the building. In view of this, staff must be carefully select for their knowledge and ability so that they are able to handle matters pertaining to plant equipment and other maintenance matters. Staff evaluation systems, staff motivation programmes and staff trainings are an effective ways to improve employees' maintenance skills and should be practiced more often to bring out the best out of them.

Faculty of Civil and Construction and Faculty of Architecture, Planning and Surveying of University of Technology MARA (UiTM, 2007) offers building services courses that provide students with knowledge and understanding on the principle of electrical and mechanical engineering. The courses emphasizes on the supervision of electrical system and different types of mechanical equipments that are commonly use in building. The operation and maintenance of the equipments are also taught to the students. Students will also learn the electrical wiring regulations and building service systems. Similar courses are also offered by two polytechnics in Malaysia but only at diploma levels. Some of the 
syllabuses are included in one or two subjects under architecture, building or real estate courses. Besides that, the National Vocational Training Council (NVTC, 2006) of Malaysia also provides and coordinates skill-training strategies and programmes to keep up with Malaysia's technological and economic development needs. The objectives are to establish a coordinated skill training system attuned to Malaysia's development goals and needs, to promote the development of skill training; and to certify skills competency. These facts clearly show that the standard of technical and skill training must be upgraded to fulfil the required standard. The Ministry of Education and related parties should consider ways to improve this situation. Introducing a technical skill programme or short-term courses on technical skills is one of the possible solutions.

\subsection{Flexibility of the Personnel}

Besides not having enough skilled maintenance staffs, most company also have lack number of maintenance staffs. Table 2 below list the number of staffs in the maintenance department in office buildings in Malaysia. The table shows that staffs are able to fix and repairs the entire maintenance request but will be over worked to maintain quite a large area. It is also important for every maintenance manager to study the minimum number of staff employed. This is to avoid overworked staff, which might affect the quality of the system. Chan et al., (2001) proposed the Manpower Utilisation Index to be used as an indicator to reflect how well the maintenance workforce has been utilised. This is useful in identifying whether the maintenance workforces is over, fully or under utilised, and for assessing the general productivity of the maintenance personnel. The size of building and the number of staff available are important factors that should be studied deeply.

Small simple buildings and large complex buildings might require different amount of maintenance work. The ratio of average request for repair daily or weekly to the number of maintenance work force would help management to predict whether the maintenance team is able to run the maintenance system effectively or not. The business function will dictate the maintenance needs. To ensure that an organisation achieves its business function with maximum efficiency, a clear understanding of maintenance need is required (Smith and Tate, 1998).

\subsection{Organization Structure}

Evaluation on maintenance personnel includes the way they communicate in the department. This would affect the efficiency of the maintenance system in the building. A good arrangement of organisation structure will help the maintenance department to manage the building without too much hassle. Most buildings in Malaysia have their organization structure but the problem it is not displayed for everyone to see. It is important for staffs to know their organization structure because it tells more about the responsibilities and provide staffs with the knowledge in seeking further assistance. An observation in most buildings in Malaysia found that most staffs are confused with its own position in the department and facing difficulties in finding the correct person to report. At the end, many unresolved requests and complaints has been store up. Maintenance staff should be clearly brief on the position, jobs, and responsibilities before any works can be executed.

Each maintenance personnel should know his or her responsibility in the department. Documented description of the job responsibility will help each person perform work better. A responsible job is one which the value of job outcomes is highly sensitive to the worker's input. A responsible worker is not closely monitored during the production process, but after the outcome of his work is evaluated, credits will be given for a well done job or blames if the job is poorly done. The degree of responsibility may be measured by the variation in the value of job outcomes over the feasible range of worker's effort. Management should prepare and explain the responsibilities of the staff due to their position in the department. This is to avoid any disputes between the employees over the jobs assigned. Therefore, when there is a request for maintenance work at a certain area, the person in-charge of that area will immediately take up the job.

Management of maintenance can also comprise more than the control activities associated with each item of equipment and can be addressed broadly under the headings of 'technical' and 'control' (BS 8210). Effective maintenance management minimized the cost associated with the non-availability of an engineering service (CIBSE, 2000). Maintenance manager must be able to manage the team as well as having sufficient knowledge of health and safety regulation and other requirements that are necessary to the departments. It is the responsibility to the manager to bring a satisfaction condition not only for the occupants but also to the staffs for not burden on overworked.

\section{Conclusions}

Building maintenance management is a highly complex sphere of operations, involving the interaction between the technical, social, legal and fiscal determinants that govern the use of buildings (Lee et al, 2001). An excellent practice of maintenance management is greatly needed to increase the life cycle of the property and to minimize unexpected breakdowns or deterioration effects. In this respect, the maintenance personnel will have to rely as much on knowledge of the managerial and social sciences as on the traditional technique knowledge base of building construction and deterioration (Smith, 1992). Improper conduct and application of maintenance management procedure and systems may result in deteriorating the property itself. 
Effective building maintenance can be achieved through a well-organized management, skilled maintenance personnel and a good organization structure (Smith, 2004). In this study the maintenance personnel requirements in Malaysia has been evaluated and the finding shows that many parties should be involved in enhancing the standard. The building Management Team as well as the Ministry of Education Malaysia and the Ministry of Human Resource should take note that prompt actions are really needed to build up the level of maintenance technology in Malaysia. The key factors described in this paper would hopefully be applied to provide guidance and references for better building maintenance management system for Malaysia.

\section{References}

Armstrong, J., (1987). "Maintaining Building Services, A guide for Manager." BSRIA, Technical Notes pp.17-131.

BSI, (1986). BS 8210: Guide to Building Maintenance Management. British Standards Institute, UK.

CIBSE (2000), Guide to ownership, operation and maintenance of building services, Chartered Institute of Building Services, UK.

El-Haram, M.A \& Horner, M.W. (2002) Factors affecting housing maintenance cost. Journal of Quality in Maintenance Engineering, Vol. 8, No. 2, pp 115-123.

Francis W.H and Yik, W.L, Lee, C.K.Ng (2002) Building Energy efficiency and the remuneration of operation and maintenance personnel. Facilities, Vol.20, pp 406-413.

Grooted, P. De. (1995). Maintenance Performance Analysis: A Practical Approach. Journal of Quality in Maintenance Engineering Vol.1, No.2, pp 4-24.

K.T. Chan., R.H.K. Lee, and J. Burnett.(2001) Maintenance Performance : A case study. Facilities Vol.19, No.13/14, pp 494-503.

M. H. Smith. (1992). 'Decisions in Maintenance', Technical Note TN 14/92, BSRIA.

Mjema, E.A.M. (2002). An analysis of personnel capacity requirement in the Maintenance department by using a simulation method, Journal of Quality Maintenance, Vol.8, pp. 253-273.

NVTC, (2006) National Vocational Training Council of Malaysia. [Online] Available: http://www.nvtc.gov.my (July 15, 2007)

Richard A. Smith. (2004). 'How to Develop and Implement A successful Maintenance Skills Training Program'. [Online] Available: www.plantmaintenance.com/articles/Assessing_Maintenance_Training_Needs.pdf (August 27, 2007)

Smith, M. and Tate, A. (1998). 'Maintenance Programme Set-Up', Application Guide AG 1/98, BSRIA

The Stationery Office, (1994). The Construction (Design and Management) Regulation: Statutory Instrument 199,4 No. 3140, London.

UiTM, (2007). UiTM Prospectus, University Technology MARA, Malaysia.

Zawawi, E.M.A. (2006). The development of guidelines for the Management of Building Maintenance in Malaysia. The University of Manchester, UK. [Unpublished thesis]

Table 1. Details of high-rise office buildings

\begin{tabular}{|c|c|c|c|}
\hline Building & Building Location & Building Gross Floor Area & No. of Maintenance \\
\hline Building A & Shah Alam, Selangor & 18100 & 40 \\
\hline Building B & Shah Alam, Selangor & 10934 & 5 \\
\hline Building C & Subang, Selangor & 6530 & 4 \\
\hline Building D & Kuala Lumpur & 12300 & 6 \\
\hline Building E & Kuala Lumpur & 14000 & 21 \\
\hline
\end{tabular}




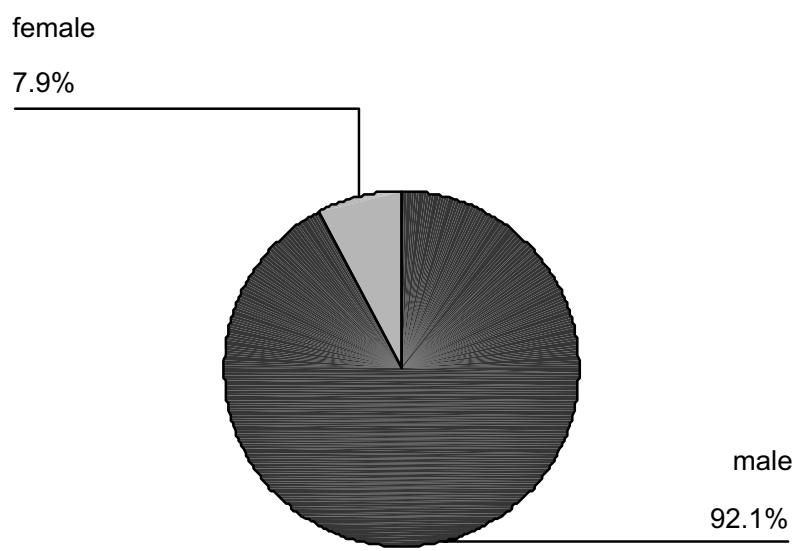

Figure 1. Staff Gender

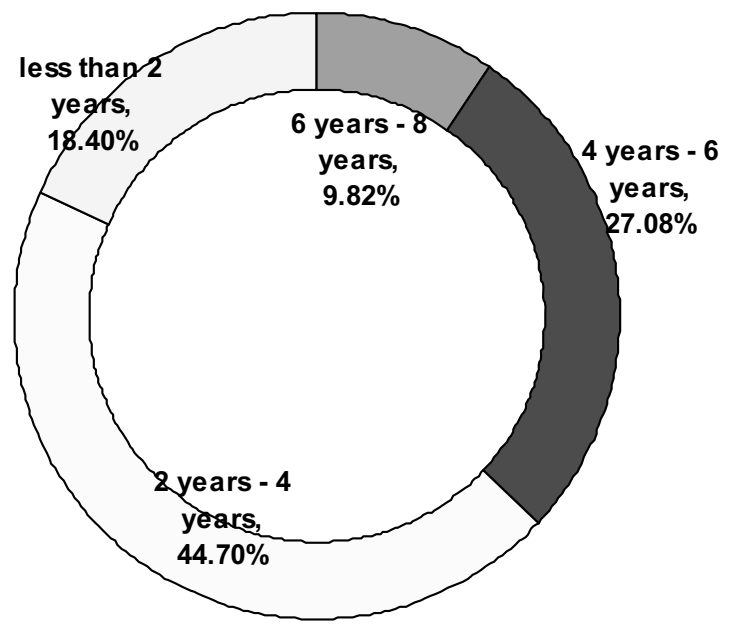

Figure 2. Job experience

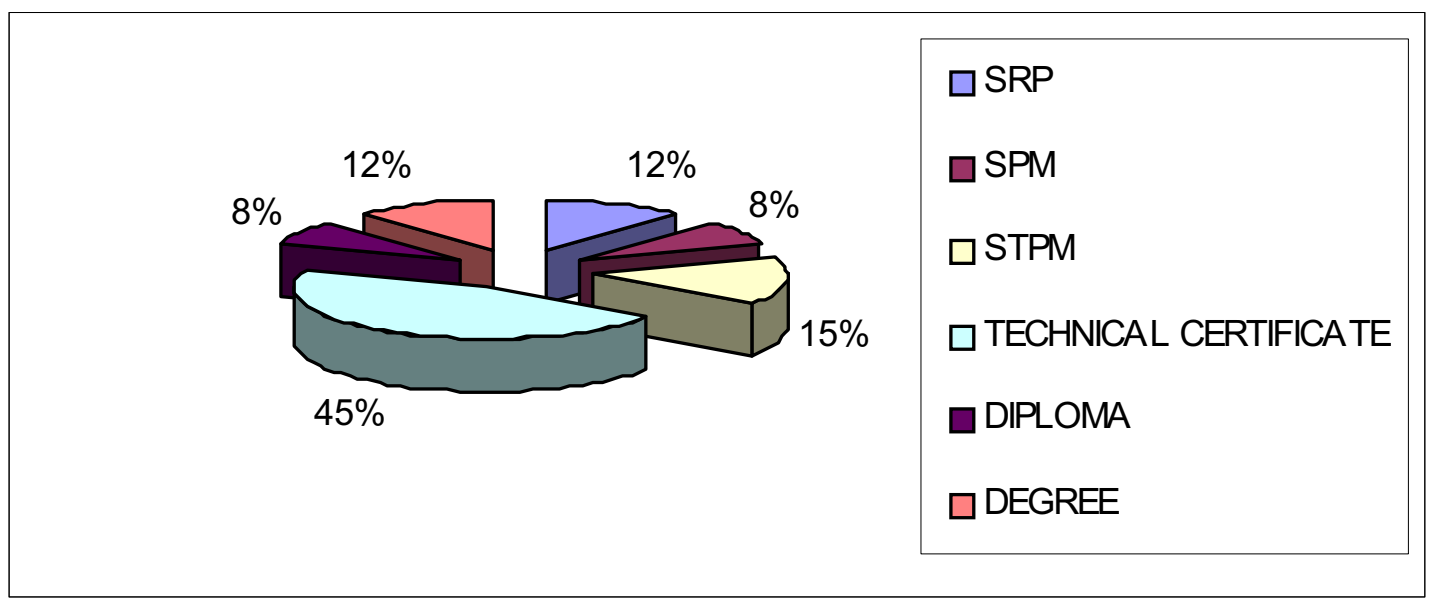

Figure 3. Percentage of academic qualification of maintenance people in office buildings 


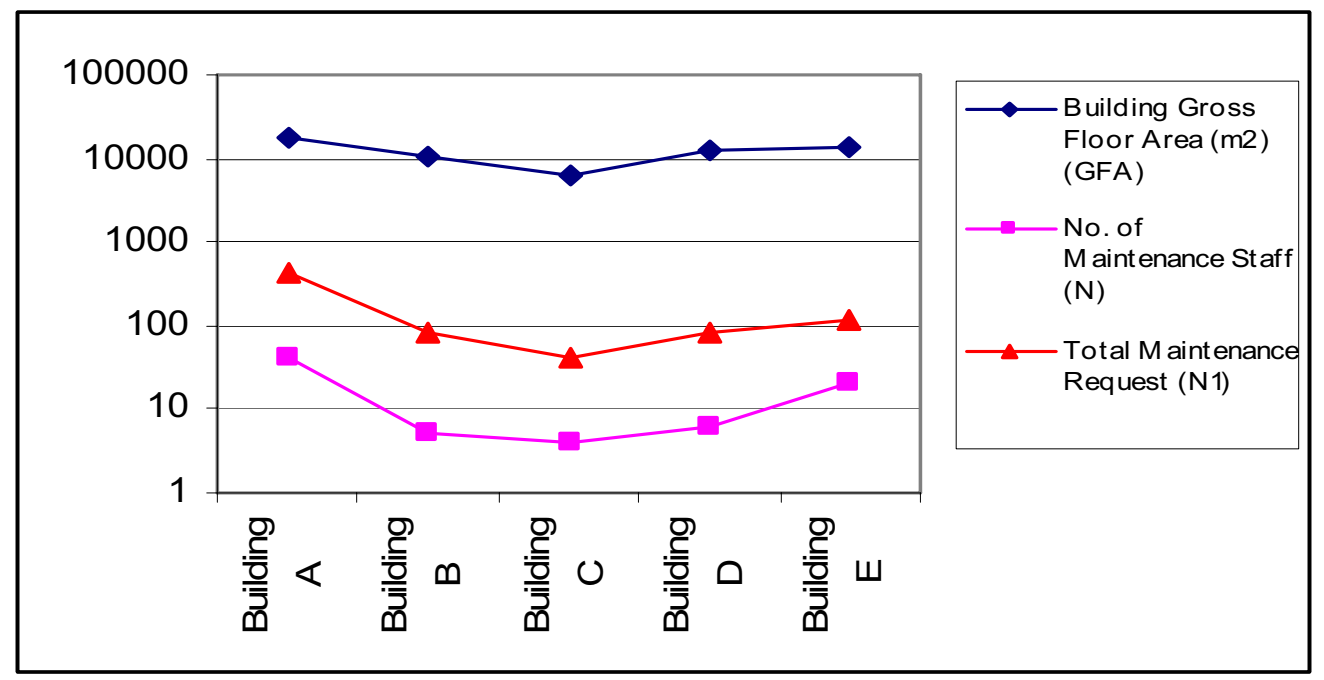

Figure 4. Building size, number of staff and requests demand

\section{$\mathrm{MUI}=\quad$ Maintenance hours spent on maintenance works in a period Total maintenance hours available for maintenance in the same period.}

Equation 1. Manpower Utilisation Index (MUI), (Chan, et al., 2001). 


\title{
Current Situation of Energy Consumption in Guangzhou Railway Station and Analysis on the Potential of Energy Conservation
}

\author{
Kai Fu \& Zhihui Deng \\ School of Mechanical Engineering \\ Southwest Jiaotong University \\ No.111 $2^{\text {nd }}$ Ring Road North Section 1, Chengdu 610031, China \\ E-mail: fk16@163.com
}

\begin{abstract}
According to the questionnaires about the energy consumption situation of Guangzhou railway station, information regarding to the situation of electricity consumption, gas consumption and gas consumption in the station during last two years has been gathered, which serves as the basis for analysis and research, focusing on several main parts of energy consumption in the station like the air-conditioning system and illumination, as well as their components and mutual influence. By gathering and analyzing the data, it has been found that there exist some improper waste phenomena in the designing, daily operation and maintenance of the systems mentioned above in the station. A series of measures for energy saving are brought forward in the paper.
\end{abstract}

Keywords: Railway station, Energy consumption, Air-conditioning system, Energy-conservation

\section{Introduction}

With the rapid development of economy in China, demand for energy is constantly growing. Meanwhile, the conflicts between the shortage of energy and economic growth have become increasingly conspicuous. Buildings, an indispensable part in people's life, with their multiple comprehensive functions, consume energy of a large amount (Jiang, 2005, p.30-31) in modern information and economic society. As large-scale public constructions, railway stations have the common characteristics of other public constructions, for example, automation of equipment, office automation, and communication modernization etc, while it has its own uniqueness as a transportation hub. Public constructions of this kind have their own characteristics like large space, high ratio of windows and walls; high turnover rate of the staff; complex lighting etc. As a result, the consumption of electricity, gas and water is further increased, posing more difficulties in energy conservation. However, Energy-saving design standards for public buildings reported that there still exist huge potential for energy saving. Therefore, the extra-consumption caused by these specialties is a key in the research and analysis on energy-saving of the railway station.

This paper makes an in-depth analysis on the various energy consumption of the Guangzhou railway station. The survey applies the method of direct interview, and collects data through the completion of pre-designed questionnaires which includes basic information of constructions, detailed information about the air-conditioning system, lighting system and power equipment system, the variety of energy usage in the past two years. The basic information includes the building age, areas of major parts, function and use. The details of the air-conditioning system, lighting system and power equipment system include the types of main equipment, model, power, and other technical indicators, as well as the daily management of the maintenance staff. At last, the characters of energy consumption in the station will be analyzed based on these daily operation data. And correspondent plans for energy conservation will be suggested so as to serve as a reference for the energy saving in the station.

\section{Architectural profile and features}

\subsection{Architectural profile}

Guangzhou Railway Station has 4 floors and $36 \mathrm{~m}$ high on the ground and the total building area is $22,360 \mathrm{~m}^{2}$. The first floor on the ground is used for the ticket hall, the waiting room and the entrance hall; the second floor for the waiting room; the third for offices; the fourth for equipment space. The building has inside and outside window shade, ordinary single-layer glass windows of aluminum alloy.

\subsection{Air-conditioning system situation}

The air-conditioned area is $17,020 \mathrm{~m}^{2}$. Air-conditioned region includes waiting room, the hall on the second floor, office 
space, guest rooms, ticketing centers, maternal and child rooms, customs inspection room, which, except the office space, adopt the Fan Coil Unit and Fresh air Unit system, and offices adopt the Split-type air-conditioning. The cold source is the two-centrifugal-water-cooled unit with same specifications. The system uses two pipes and a pump to control water system. Each unit is equipped with a chilled water pump and a back-up one. See the main equipment in Table 1.

\subsection{Ventilation system}

The entrance hall in the railway station uses mechanical ventilation.

\section{Analysis on the energy consumption in Guangzhou railway station}

\subsection{Monthly energy consumption}

See monthly electricity consumption (2006) of Guangzhou railway station in Figure 1.

It can be seen from Figure 1 that the largest electricity consumption was in August; electricity consumption decreased during September to December; from March to July the electricity consumption had no great change; the lowest electricity consumption was in January, and the electricity consumption in February increased greatly compared with that in January. This relates to Guangzhou's climate and the actual situation of the railway station. According to the weather data since the founding of China, the annual average temperature of Guangzhou is $21.9^{\circ} \mathrm{C}$, with July as the month whose average temperature is $28.4^{\circ} \mathrm{C}$, highest in the year. Although temperature is low in January, the average temperature is still above $13^{\circ} \mathrm{C}$. Temperature difference between the lowest and highest in a year is $15^{\circ} \mathrm{C}$. The maximum power consumption in August was due to the fact that the hot weather in summer caused higher indoor heat load than in other months, and a sudden increase of electricity consumption in February was due to the increase of passenger flow in the station before and after the Spring Festival, and the staff changes led to dramatic changes in the indoor loads.

\subsection{Analysis on the structure of building energy consumption}

To get a clear understanding of the electricity consumption of various systems in Guangzhou railway station, the station is divided into four parts: air-conditioning, lighting, power equipment and lifts. The ratio of electricity consumption by four parts is shown in Figure 2.

As can be seen from Figure 2, the energy consumption of air-conditioning system is the largest, accounting for 53\% of the total energy consumption. This is due to the climate characteristics of Guangzhou which decides that the air-conditioning system should run throughout the year, and nearly all interior construction adopts the Fan Coil Unit and Fresh air Unit system. This results in its large total energy consumption. Next is the electricity consumption of power equipment. The station has many lifts and elevators, so it accounts for the relatively large proportion. Lighting takes the minimal share of only $6 \%$, and this is due to the large-scale use of energy-saving lamps and a more reasonable distribution in the station

In order to do further analyze energy consumption of air conditioning, Figure 3 shows the energy consumption ratio of various parts in air-conditioning system.

It is shown in Figure 3 that centrifugal water-cooled unit shares the largest part, reaching $45 \%$. The proportion of pumps and mechanical ventilation is more or less the same, $21 \%$ and $19 \%$ respectively. The ratio of FCU in air-conditioning system is the least.

\section{Analysis on the potential of energy saving}

It can be found through the above analysis that the air-conditioning, lighting, power equipment, and elevators are four major parts of the electricity consumption. Based on the running record of the year and other relative data analysis about the air-conditioning system, lighting system and office equipment, there exists irrationality and waste of energy in design, operation and management of the air-conditioning system, power equipment system, and then there is great potential for energy conservation. Improving the running and management of lighting, office equipment .etc is also an important energy-saving method.

\subsection{Energy-saving of the air-conditioning system}

Air-conditioning system is the largest part of energy consumption. According to the analysis on the parts of air-conditioning system, we can see that hot and cold source is the largest part of power consumption of the air-conditioning system. Therefore, choosing cold and hot source unit with high COP value plays a key role in improving energy-efficiency of the air-conditioning system. Secondly, air-conditioning system also needs to improve everyday operation and maintenance. The pumps are more consumptive of energy, so we can switch to the combined operation of a variable frequency pump and a general water pump. This method is secure, stable and easy for management, and the running of water pump can be changed in accordance with the changes of the construction load so as to improve the operation of air-conditioning system to save energy. 


\subsection{Energy-saving in power equipment system}

The power equipment system is the second largest part in electricity consumption, so choosing energy-saving equipment and improving the system's management and maintenance are major ways for reducing the building energy consumption.

\subsection{Energy-saving in lighting system}

Generally speaking, the lighting load in railway station is rather large, and this is a very important aspect on building energy-efficiency. Take the waiting room in Guangzhou railway station as an example. The area of the waiting room is $7020 \mathrm{~m}^{2}$. There are about 1297 energy-saving lamps and 818 fluorescent tubes in the room. The lighting load per unit area is about $4.1 \mathrm{~W} / \mathrm{m}^{2}$, slightly higher than the railway passenger station building design codes. Though the building uses a large number of energy-saving lamps, it's not enough, and the design and control system is unreasonable. Therefore, we should choose a new type of energy-saving light source instead of fluorescent tubes, use intelligent lighting control system, improve the management and utilization of the system, optimize the quality of electricity, and save lighting electricity to achieve the best lighting effect. In addition, to enhance and train the staff's awareness of energy-saving is an important measure to reduce the power consumption (Zhang, 2006).

\section{Conclusion}

Through analyzing the whole-year situation of building energy consumption in Guangzhou railway station, we can find that: (1) the air-conditioning, lighting, power equipment, elevators constitute the four major parts of the electricity consumption. (2) Energy consumption of the lighting system in Guangzhou railway station is relatively small, but there is potential for further improvement, so more attention should be paid to it. (3) Energy consumption of the air-conditioning in Guangzhou railway station is the largest, and the energy consumption of the hot and cold source unit accounts for $45 \%$ in the energy consumption of air conditioning. This is a key point in energy saving. (4) There exist irrationality and waste phenomena in the design, operation and management of air-conditioning, lighting and power equipment. It proves that there is great potential for energy conservation.

\section{References}

Yi Jiang. (2005). Current building energy consumption in China and effective energy efficiency measures. $H V \& A C$, 2005, 35(5): 30-31.

Construction Ministry of PRC. (2005). Energy-saving design standards for public buildings. China Building Industry Press.

Railways Ministry of PRC, Construction Ministry of PRC. (1996). Railway passenger station building design codes.

Liying Zhang. (2006). Energy-saving on Railway Lighting System. Ningxia Machinery, 2006, 01.

Table 1. Main air-conditioning equipment in Guangzhou railway station

\begin{tabular}{|l|l|l|}
\hline Equipment Name & Power & Number \\
\hline Centrifugal Water-cooled Unit & Cooling capacity $3059 \mathrm{kw}$,electric power $530 \mathrm{kw}$ & 2 \\
\hline Freezing Water Pump & Rated Power $90 \mathrm{kw}$ & 3 \\
\hline Cooling Water Pump & Rated Power $90 \mathrm{kw}$ & 3 \\
\hline Fan Coil Unit & Total Power $494.825 \mathrm{kw}$ & 124 \\
\hline Tank Lifting Air-conditioner Unit & Rated Power $3 \mathrm{kw}$ & 1 \\
\hline
\end{tabular}




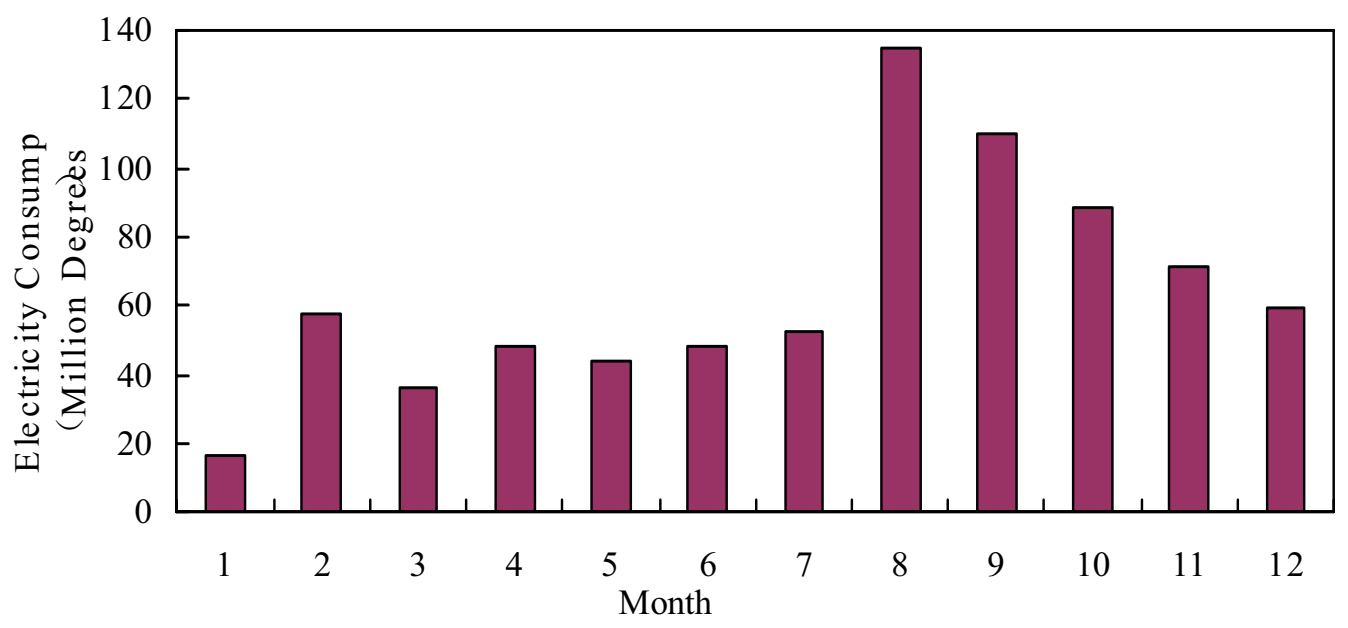

Figure 1. Monthly Electricity Consumption

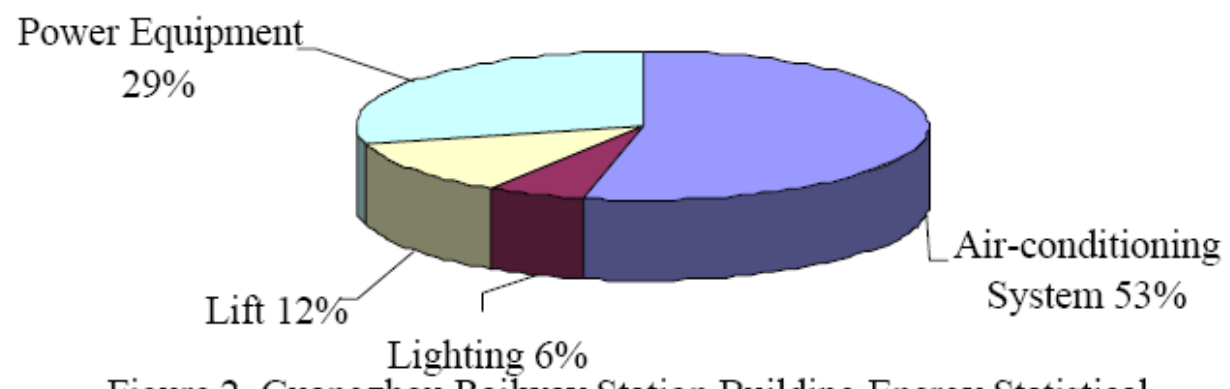

Figure 2. Guangzhou Railway Station Building Energy Statistical

Classification

Mechanical

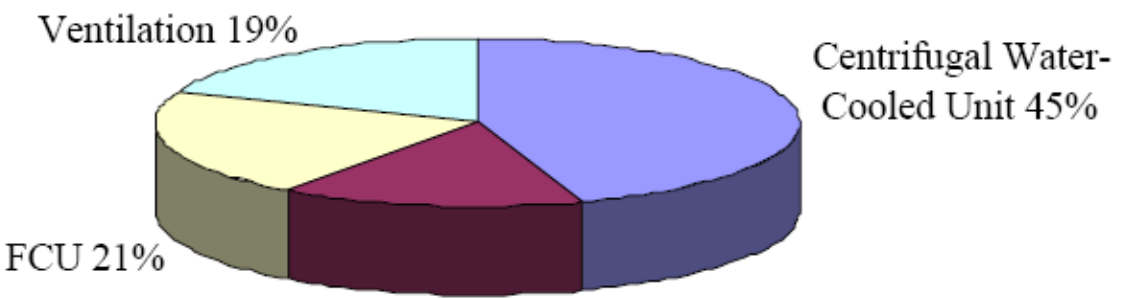

Freezing and

Cooling Pump15\%

Figure 3. The Energy Consumption Ratio of the Various Parts of Airconditioning System 


\title{
Vascular Epiphytes Diversity
}

\section{at Pusat Sejadi, Kawang Forest Reserve, Sabah Malaysia}

\author{
Andy Russel Mojiol \\ School of International Tropical Forestry \\ Universiti Malaysia Sabah
}

Locked Bag 2073, Kota Kinabalu 88999 Sabah, Malaysia

Tel: 6-088-320-118Ｅ-mail: rmojiol@yahoo.co.uk

Anna Merlyn Aloysius Jitinu

School of International Tropical Forestry

Universiti Malaysia Sabah

Locked Bag 2073, Kota Kinabalu 88999 Sabah, Malaysia

Tel: 6-088-320-118Ｅ-mail: dz_anna86@yahoo.com

Audrey Adella

School of International Tropical Forestry

Universiti Malaysia Sabah

Locked Bag 2073, Kota Kinabalu 88999 Sabah, Malaysia

Tel: 6-088-320-118 E-mail: schumey_adel@yahoo.com

Gloria Muring Ganang

School of International Tropical Forestry

Universiti Malaysia Sabah

Locked Bag 2073, Kota Kinabalu 88999 Sabah, Malaysia

Tel: 6-088-320-118 E-mail: little_gloria12@hotmail.com

Narbet Nasly

Sabah Forestry Department, Locked Bag 68

90009 Sandakan, Sabah

Tel: 6-088-320-118Ｅ-mail: narbert68k@yahoo.com.my

\begin{abstract}
Vascular epiphyte category as well as diversity of epiphytic was studied in Pusat Sejadi, Kawang Forest Reserve Papar Sabah. Five randomly sampling plots of $50 \mathrm{~m} \mathrm{x} 40 \mathrm{~m}(0.2 \mathrm{ha})$ were presented for 1 ha of the forest for the purposed of data collection. The result showed that 3 types of phorophytes (host tree) on which the vascular epiphyte attached to: standing tree, dead standing tree and fallen tree (deadwood). The standing and dead standing tree were subdivided into 3 zones which known as basal part, trunk and canopy to analyse the species richness. A total of 137 numbers of individual species with 2 groups (Angiosperm and Pteridophyte), 7 families and 15 species were found growing epiphytically on the phorophytes. According to the Shannon - Weiner biodiversity index analysis, it showed (H') was 0.98 which the vascular epiphytes were diverse, although they were not equally abundant based on the calculated value of Evenness Index $(\mathrm{E}=0.36)$. The species richness also less with $\mathrm{I}_{\text {Margalef }}=2.8$. Pteridophytes (ferns) contributed more significantly to species diversity. Vascular epiphytes were more diverse in standing and fallen tree. In standing tree, fewer species were found on the tree trunk (4 species) than in the basal ( 5 species) and crown or canopy ( 5 species). Aspleniaceae and Polypodiaceae were 2 families consisted of more species which each of it had 4 species. Four species were found presented on all types of phorophytes: Asplenium nidus, Nephrolepis spp. Arcypteris irregularis and Microsorum musifolium. Asplenium nidus was the commonest species presented in all plots with good adaptations in any conditions of the forest whether in shady, partially or fully sun.
\end{abstract}


Keywords: Vascular epiphytes, Diversity, Shannon-weiner, Pusat sejadi and kawang forest reserve

\section{Introduction}

There are in fact up to 25000 species of vascular epiphytes alone that occur mainly in tropics (Zotz and Hietz, 2001). Epiphyte forms a major component of the diversity of tropical forests (Gentry and Dodson 1987; Kelly et al., 2003). The shrub layer epiphytes are normally dependant on large mature trees that have upon them an abundant epiphyte community, which feeds the shrub layer below with seeds and asexual plant material, whose role it is to colonise the sub strata (Goddings et al., 2006). Vascular epiphytes share few qualities beyond occurrence in tree crowns that identify them as a single ecological type, primarily because their phylogenetic origins and life styles in forest canopies are diverse (Benzing, 1987).

Epiphytes are extremely important elements of the flora (they represent about 10\% of all plant species globally), (Neider and Barthlott, 2001). Epiphytes are responsible for much of the biotic diversity that makes humid tropical forests the most complex of all the world's terrestrial ecosystems (Gentry and Dodson, 1987). The aims of this study are to determine the category type of vascular epiphytes species found at Pusat Sejadi, Kawang Forest Reserve and to analyse the diversity of vascular epiphytes species at three different host trees: standing tree, dead standing tree and fallen tree.

\subsection{Study Site}

Pusat Sejadi, Kawang Forest Reserve is located in Kinarut Papar, Sabah which is approximately $30 \mathrm{~km}$ from Kota Kinabalu city. The topography of this forest is about $6 \mathrm{~m}$ to $610 \mathrm{~m}$ asl and with approximately 1550 ha large in area and its terrain is hilly with slopes sometimes reaching $25^{\circ}$. The main vegetations of this forest reserve are $19 \%$ of primary forest which the floras consist the mixture of dipterocarp species, $69 \%$ of secondary forest, $8 \%$ for shrubs and another $4 \%$ of open spaces area (Joseph et al., 1998).

The study site for the preliminary survey of vascular epiphyte was only took place in the area of Pusat Sejadi, Kawang Forest Reserve which is mark by a black box on the Kawang Forest Reserve map on the Figure 3.1 above. Approximately $80 \%$ of Pusat Sejadi's forest is secondary forest and its geographical is pretty hilly.

\section{Methods}

A sampling plot of $50 \mathrm{~m}$ x 40m (0.2ha) was developed. Five (5) randomly selected plots were established to cover spatial variability. These plots covered a hectare $(1 \mathrm{ha})$ of the area of Pusat Sejadi. All vascular epiphytes species that found in each plot were recorded either epiphyte that found in standing tree, dead standing tree or fallen tree (deadwood). A binocular was used to identify species that was located high above the tree. This method is described by Gradstein (1992), Ground Base Inventory (GBI) using binoculars and sampling of fallen branches, is inadequate to assess the diversity of the epiphyte communities.

All the vascular epiphytes species that were found in Pusat Sejadi were divided into its group or category type to achieve the first objective of the study and the recorded data were computed by using three indices (Shannon - weiner diversity index, Evenness index and Margalef's diversity index) to calculate the diversity of vascular epiphyte that attached to the types of phorophytes and respecting to the zones of the standing and dead standing trees.

\section{Results}

\subsection{Category type of vascular epiphytes species}

There were 36 totals of host trees (phorophytes) which represent the 1 ha area of the forest. The hosts of standing trees are 18 trees, 4 trees of dead standing trees and 14 phorophytes for fallen trees. Upon completion of the survey, however, a total of 137 numbers of individual species of vascular epiphytes representing 7 families (with one is unidentified) were found growing epiphytically on the trees either in standing trees, dead standing trees or fallen trees. Based on the collected data, it showed a variation in the appearance of vascular epiphytes in all plots.

There were two categories or groups of vascular epiphytes that had been collected and analysed and those were Angiosperm and Pteridophytes. Two families of Angiosperm; Araceae and Orchidaceae while five families in the group of Pteridophytes which one of it was unidentified. Those families were Aspleniaceae, Blechnaceae, Oleandraceae and Polypodiaceae.

\subsection{Composition of vascular epiphytes species}

Family of Aspleniaceae and Polypodiaceae took a big portion of the percentage of composition or communities of vascular epiphytes species present in Pusat Sejadi, Kawang Forest Reserve. While Araceae and Blechnacea had the lowest percentage of species present.

\subsection{Diversity}

According to the results of three indices (Shannon - Weiner index, Evenness index and Margalef's index) that had been calculated in all types of different trees, it shows that standing trees had the highest value of H' and E, while fallen trees had the highest value of $1_{\text {Margalef }}$ and for dead standing trees it had the lowest value of all three of the indices. 
The values of the three indices were obviously different between the zones of the standing and dead standing trees especially in the canopy zone. The result on Figure 5 shows that the diversity (H') and the evenness (E) values are the

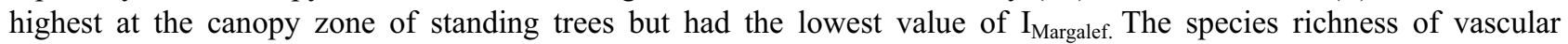
epiphytes is less at canopy zone even though its diversity is highes

The results below show that at the canopy zone, there are no values of the three indices and these make the major difference of the diversity of vascular epiphytes in the canopy of standing trees and dead standing trees.

\section{Discussion}

\subsection{Diversity of vascular epiphytes at different types of phorophytes}

The study revealed the vascular epiphytes communities dominated by the division of Pteridophyta especially the two families of ferns: Aspleniaceae and Polypodiaceae. They were the commonest species that can be found in the three different categories of host trees. Asplenium species have been noted for their abundance in tropical forest throughout the world (Ellwood and Foster, 2004). Polypodiaceae was also the most diversified family in the tropical rain forest (Zapfack et al., 1996).

The vascular epiphytes at Pusat Sejadi, Kawang Forest Reserve were more diverse and distributed more equally at the standing trees rather than at dead standing trees and fallen trees but at the fallen trees, the species richness of vascular epiphytes were highest than the other two of phorophytes. Based on the datasheet of all plots, it showed that in Plot 3 and Plot 4, more number of individual species of vascular epiphytes presence. Both of these plots contain many of large trees which diameter is greater than $60 \mathrm{~cm}$ and also a lot of fallen trees were present to these plots. Tree size relates to several factors that contribute to epiphyte establishment and growth.

Larger trees are likely, on average, to be older, allowing more time to capture spores (Cummings, 2006). In Pusat Sejadi, Kawang Forest Reserve, the large tree that rich with vascular epiphytes attached to it was Kompassia excelsa. Plot 4 and Plot 5 were rich in fallen trees which these phorophytes may be suitable habitat for most of vascular epiphytes that can be found in Pusat Sejadi Kawang Forest Reserve. Vascular epiphytes that preferred to the shady and moderate sunlight were mostly grow in the fallen trees because the surround areas of which these fallen trees lied are covered by the canopy layers which the sunlight indirectly reach to the surface of forest floor.

\subsection{Comparison between the canopy zone of standing and dead standing tree}

The values of the three indices were obviously different between the zones of the standing and dead standing trees especially in the canopy zone. The species richness of vascular epiphytes is less at canopy zone even though its diversity is highest and according to Kelly et al., (2004) during his study at La Montana, vascular species richness was sharply reduced in the upper zones.

Even though the species richness is less, still the vascular epiphytes communities were very abundant in the canopy zone rather than at base and trunk of standing trees based on the present of number of individual species in the canopy of standing trees. This is because the presence of branches in the canopy layer, it may result accumulation of dusts which encouraging epiphytic plants to grow. Large branches and crotches at the bases of reiterated trunks provide platforms for debris accumulation (Sillette, 1999).

There were less of vascular epiphytes attached at the canopy zone of a dead standing tree rather than the standing tree. This may be the reason of the absent of foliages of the dead phorophyte which discourage the accumulation of humus and subsequently prevent the formation of the vascular epiphyte and besides, a dead standing tree is not as efficient as a standing tree in up taking water resources which water is the major component for vascular epiphytes to grow.

\section{Conclusion}

All 15 species of vascular epiphytes present in Pusat Sejadi. Kawang Forest Reserve are Asplenium nidus, Arcypteris irregularis, Nephrolepis spp, Philodendron martianum, Stenochlaena milnei, Asplenium tenerum, Asplenium spp.1, Asplenium spp.2, Dendrobium crumenatum, Dendrobium anosmum, Bulbophyllum careyanum, Platycerium superbum, Microsorum musifolium, Pyrrosia lanceolata and Species 1 is unidentified. According to the calculation of ShannonWeiner index, the vascular epiphytes in Pusat Sejadi, Kawang Forest Reserve were diverse with the value of 0.98. The epiphytic plants were not equally abundant according to the value of Evenness index 0.36 and the species richness was less which it was only 2.5 value of Margalef' index.

\section{Acknowledgment}

We are grateful for the co-operation and permission of the Kota Kinabalu Forestry Department Sabah for the permit to do a study in Pusat Sejadi, Kawang Forest Reserve. We are also very much indebted to various people who have helped in data collection directly or indirectly in accomplishing this study especially to the staffs of School of International Tropical Forestry, Universiti Malaysia Sabah. The data collection would have been difficult without their support and help. 


\section{References}

Benzing, D. H (1987). Vascular Epiphytism: Taxonomic Participation and Adaptive Diversity. Annals of The Missouri Botanical Garden, Vol. 74, No. 2 (1987), Pp. 183-204.

Cummings, J., Martin, M., and Rogers, A. (2006). Quantifying the Abundance of Four Large Epiphytic Fern Species in Remnant Complex Notophyll Vine Forest on the Atherton Tableland, North Queensland, Australia. Cunninghamia (2006) 9(4): 521-527.

Ellwood, M.D.F. and Foster, W.A. (2004). Doubling The Estimate Of Invertebrate Biomass In A Rainforest Canopy. Nature 429: 549- 551.

Gentry, A. H and Dodson, C. H. (1987). Diversity and Biogeography Of Neotropical Vascular Epiphytes. Annals Of The Missouri Botanical Garden (74): 205 - 233.

Goddings, H., Greenwood, J., and Turnbull, A. (2006). Vascular Epiphyte Diversity Within The La Chonta Forestry Concession, Bolivia. Project Bosque, University Of Edinburgh and The University Of Uppsala.

Gradstein, S. R. (1992). The Vanishing Tropical Rain Forest As An Environment For Bryophytes And Lichen In A Changing Environment In Bates J. W. and Farmer A. R, Eds. Bryophytes and Lichens In A Changing Environment. Oxford, United Kingdom: Clarendon Press.

Gradstein, S.R., Nadkarni, N.M., Kromer, T., Holz, I., and Noske, N. (2003). A Protocol for Rapid and Representative Sampling of Vascular And Non - Vascular Epiphyte Diversity of Tropical Rain Forest. Selbyana (2003) 24(1): 105 111.

Joseph Tangah, Rueben Nilus and Robert, C. Ong. (1998). Kajian Status Hutan Simpan Domestik Di Sabah. Sandakan Sabah: Pusat Penyelidikan Perhutanan. Unpublish.

Kelly, D. L., Tanner. J., Lughadha. E. M. and Kapos, V. (1994). Floristics and Biogeography of A Rain Forest In The Venezuelan Andes. J. Biogeogr. 21:421 - 440 .

Neider, J. and Barthlott, W. (2001). Epiphytes and Canopy Fauna of The Otonga Rain Forest (Ecuador). Books on Demand: Vol 2 Of 2.

Sillett, S. C. (1999). Tree Crown Structure and Vascular Epiphytes Distribution In Sequoia Sempervirens Rain Forest Canopies. Selbyana 20(1):76-9.

Zapfack, L., Nkongmeneck, A. B., Villiers, J. F., and Lowman, M. (1996). The Importance Of Pteridophytes In The Epiphytic Flora Of Some Phorophytes Of The Cameroonian Semi-Deciduous Rain Forest. Selbyana 17: 76 - 81.

Zotz, G. and Hietz, P. (2001). The Physiology Ecology of Vascular Epiphytes. Journal Of Experimental Botany. 52(364): $2067-2078$.

Table 1. Systematic partitioning of species of vascular epiphytes

\begin{tabular}{|c|c|c|c|}
\hline GROUP & FAMILY & SPECIES NAME & No. of ind.sp \\
\hline \multirow[t]{4}{*}{ ANGIOSPERMS } & Araceae & Philodendron martianum & 2 \\
\hline & \multirow[t]{3}{*}{ Orchidaceae } & Bulbophyllum careyanum & 2 \\
\hline & & Dendrobium anosmum & 5 \\
\hline & & Dendrobium crumenatum & 18 \\
\hline \multirow[t]{11}{*}{ PTERIDOPHYTES } & Aspleniaceae & Asplenium nidus & 43 \\
\hline & & Asplenium spp. 1 & 5 \\
\hline & & Asplenium spp. 2 & 3 \\
\hline & & Asplenium tenerum & 1 \\
\hline & Blechnaceae & Stenochlaena milnei & 2 \\
\hline & Oleandraceae & Nephrolepis spp & 18 \\
\hline & \multirow[t]{4}{*}{ Polypodiaceae } & Arcypteris irregularis & 12 \\
\hline & & Microsorum musifolium & 7 \\
\hline & & Platycerium superbum & 5 \\
\hline & & Pyrrosia lanceolata & 10 \\
\hline & Unidentified & Species 1 & 4 \\
\hline
\end{tabular}




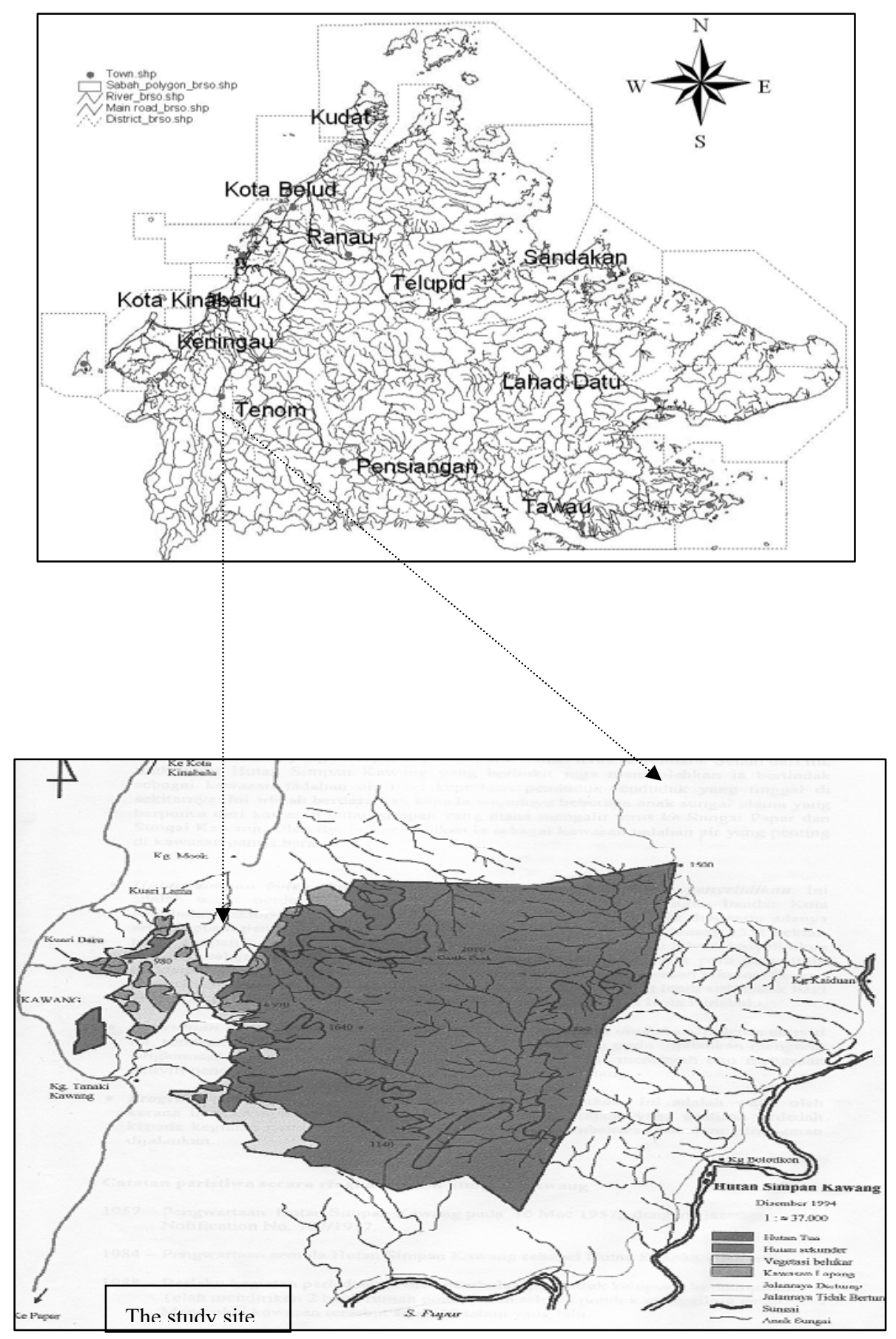

Figure 1. Kawang Forest Reserve map

(Source: Joseph et al., 1998) 
The host trees (phorophytes) of standing and dead standing tree were subdivided into three zones.

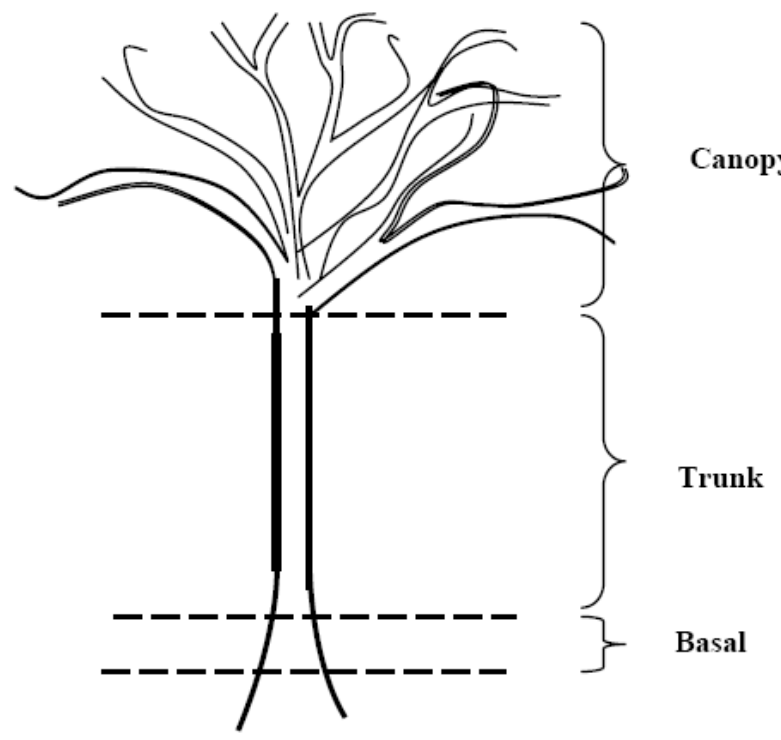

The tree was subdivided into three (3) zones:

a) Zone 1 - Basal, from the ground to the diameter at breast height (dbh)

b) Zone 2 - Trunk, from the dbh to the first branch

c) Zone 3 - Canopy, from the first branch to the tip of the tree

Figure 2. Subdivision of the phorophyte into vertical zones

Source: Kelly et al., (2003), modified

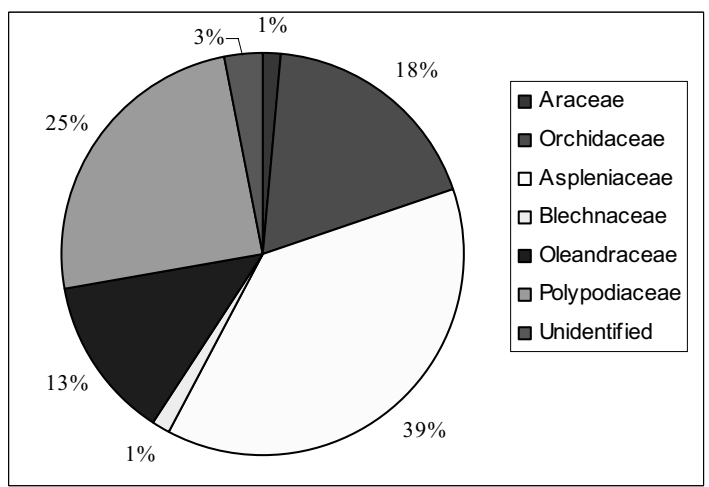

Figure 3. Percentage distribution of vascular epiphytes composition

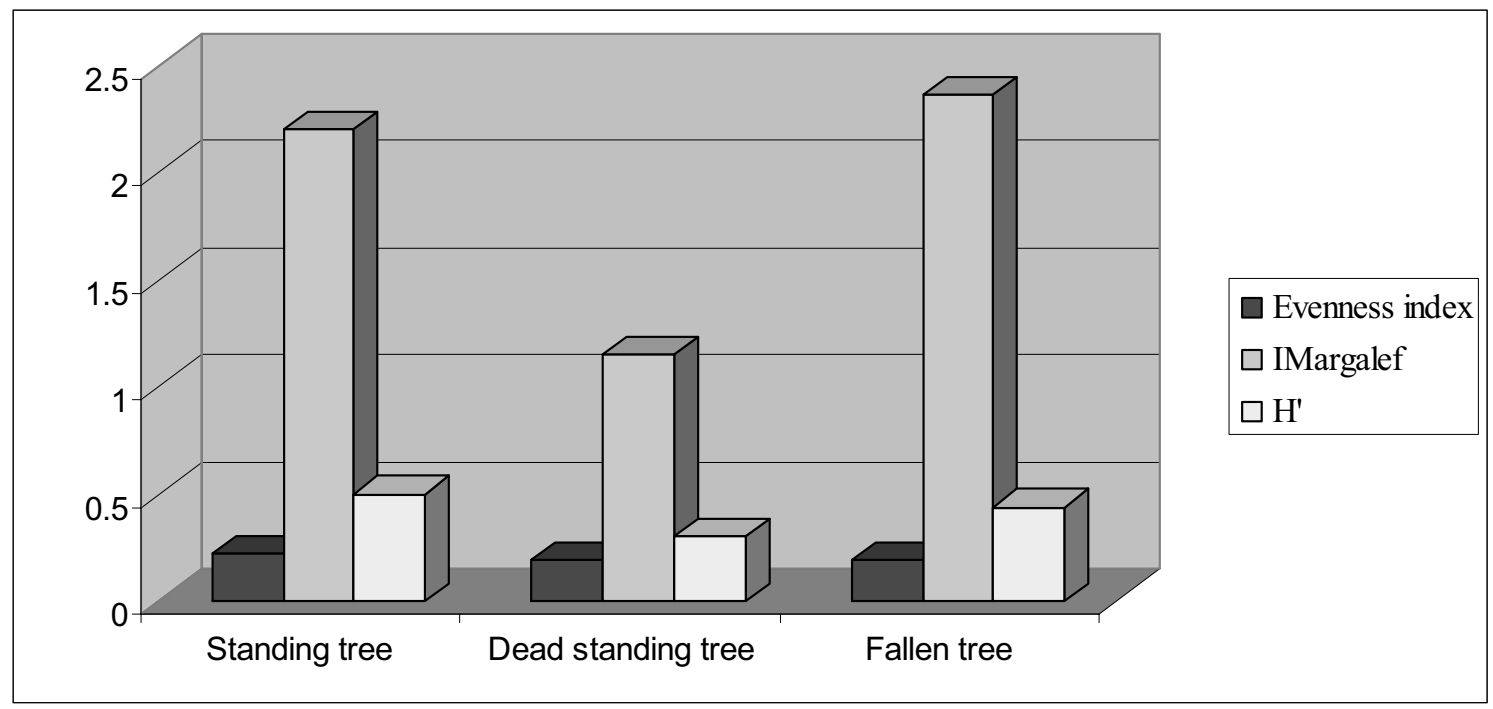

Figure 4. The result of three indices of diversity respecting to three zones of standing tree 


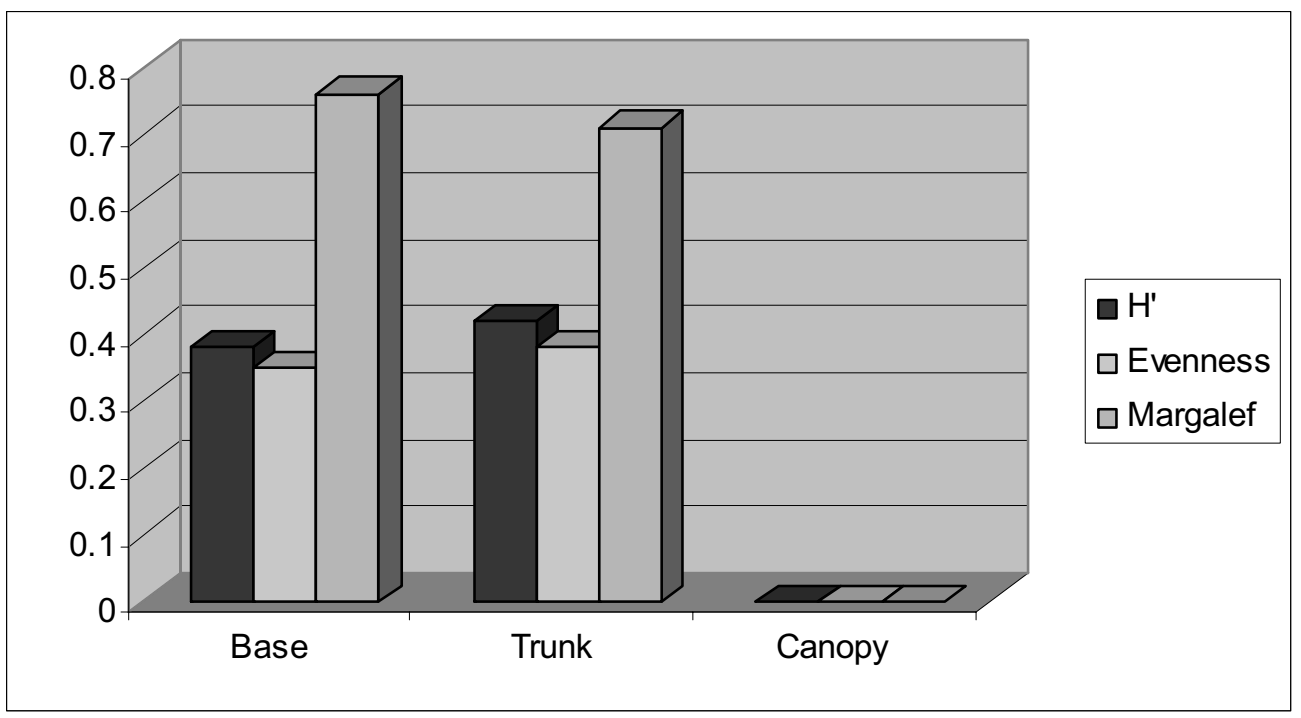

Figure 5. The result of three indices of diversity respecting to three zones of dead standing tree 


\title{
Nontraditional Diplomacy---Chinese Ecological Diplomacy
}

\author{
Jingwei Liu \& Tianyang Sun \\ College of Humanities and Social Sciences \\ Northeast Forestry University \\ Harbin 150040, China
}

Tel: 86-451-8219-2162Ｅ-mail: nefuliujingwei@hotmail.com

\begin{abstract}
From a traditional point of view, a country's diplomatic position and principles are determined by the political environment and military circumstances. The global ecological environment, which has worsened since 1970s, is now paid great attention to by people all over the world. The eco-environmental problem has gradually become one of the most important factors that affect the international relations nowadays. Besides nontraditional diplomacy in culture, trade and security aspects, China is now carving out a new way in nontraditional diplomacy---ecological diplomacy. It greatly impels China to break through the traditional diplomatic thinking and try a new diplomatic strategy.
\end{abstract}

Keywords: Chinese Ecological Diplomacy, Bottleneck, Prospect

\section{The Development of Chinese Ecological Diplomacy}

Since 1960s, people all over the world have attached great importance to the relationship between human and nature. The contamination accident of Guanting Reservoir, which happened in March, 1972, impelled the Chinese government to pay attention to the ecological environment. Three months later, the Chinese Environmental Protection Department contacted with the International Environmental Protection Organization. In June, 1972, the Chinese government organized a big delegation to take part in United Nations Conference on the Human Environment, which was held in Stockholm, the capital of Sweden. This was the first important international conference that China had taken part in since she re-joined the United Nations, which embodied that Premier Zhou Enlai set great store by the environment and international relations. Moreover, it was considered as the beginning of the Chinese ecological diplomacy. The Declaration of Human Environment, which was published in that conference, has an epoch-making significance to the history of human environment movement.

China has been actively taking part in the international discussion on eco-environment since the middle of 1980s. Based on the UN Conference on Environment and Development, some diplomatic activities on ecological problems, such as submit diplomacy, conference diplomacy, treaty diplomacy and expert diplomacy have developed rapidly. China, as well as some developing countries, played an important role in that conference. In the $16^{\text {th }}$ conference of Environmental Protection Committee of State Council, which was held in October, 1989, the Ministry of Foreign Affairs was admitted to the Environmental Protection Committee and participated in the decision-making of foreign environmental policies. The international department and legislation department of the Ministry of Foreign Affairs assigned specialists to take charge of the environmental affairs. What's more, environmental problems were included in the agenda, which embodied that government attached great importance to the environmental foreign affairs.

After 1990, a series of international pacts and documents on environmental problems were published, such as Rio de Janeiro Declaration on Environment and Development, The $21^{\text {st }}$ Century Agenda, Statement on Forest Problems, United Nations Framework Convention on Climate Change, Convention on Biological Diversity, which symbolized that the harmonious development between human and nature had become global common sense.(Zhou, 2007) Especially on the World Environmental Development Conference in 1992, on behalf developing countries, China put her foot down some viewpoints that were put forward by developed countries in the interests of themselves. In the negotiation on Framework Convention on Climate Change, China clearly pointed out that the Responsibility Sharing theory, which was brought forward by the western countries, was unfair and unpractical. The fact is the emission from the developed countries is luxurious, but for the developing countries, that is for survival. China was consistently appraised by the developing countries. More and more developing countries considered China as a reliable friend and it greatly promoted the friendship between China and other developing countries.

In 2008, the Ministry of Environmental Protection was founded. As a flourishing big country, China is now taking more and more responsibility on the global environment. The voice and viewpoints of the Chinese government and academe are of great importance to the world on global eco-environmental problems. 


\section{The Bottleneck of Chinese Ecological Diplomacy}

It has been 30 years since the Reform and Open Policy was published. During this period, China has accomplished fruitful economic achievement, in which the western countries had spent more than 100 years. However, more than 100 years' eco-environmental problems of the western countries were reflected in China's 30 years, too. China's ecological environment is supervised and paid great attention to by the whole world, especially in the bidding process of 2008 Beijing Olympic Games. For all countries, especially the developed countries, as long as they restrict China by means of environmental problems, their candidates will get votes, especially from the left-wing. China's ecological diplomacy are now facing great challenges.

\section{The Chinese Environmental Threat Theory}

As global warming becomes the focus of the whole world, the Chinese Environmental Threat Theory heats up. The so-called Chinese Environmental Threat Theory is that China is the main threat of global warming and will be the biggest greenhouse gas emissions country. Consequently, China must take on responsibility to reduce its greenhouse gas emissions as developed countries. In the developed countries' point of view, population problem and resource consumption problem of the developing countries are the main environmental threats to the international society. For example, the article Who Will Feed China, written by Lester Brown, is a typical ecological threat theory against developing countries. It becomes an important basis for many developed countries and related international organizations to criticize and censure China's ecological problems.

Nevertheless, $15 \%$ of the developed countries' population controls more than $85 \%$ resources of the whole world. Moreover, they carry out ecological colonialism based on their rules. Actually, global warming is the result of greenhouse gas emissions since Industrial Revolution. Undoubtedly, most of the greenhouse gas emission comes from the developed countries. China's greenhouse gas emissions have been gradually increasing since 1980s. That is only a small proportion. Consequently, according to this, it is unfair and unreasonable to require China to take on the corresponding responsibilities and obligations. From another perspective, it is a good way for some developed countries to distract the world's attention and relieve pressure by pushing China to the front and requiring China to take on the same responsibilities in the excuse of economic aggregate and development speed.

\section{Green Barrier}

Green Barrier is the shortened form for Green Trade Barrier (also called Environmental Protection Barrier, Ecological Barrier or Environmental Trade Measures). The definition of Green Barrier is that in the name of protecting ecological environment and human health, a country set discriminatory or unnecessary trade barrier against importation from foreign countries in order to restrict importation and protect trade.(Pan, 2002)

The gap in technology and economic development between developed countries and developing countries is the main factor that impels the green barrier greatly develops. Because of the difference in productivity level, especially on the consideration of both resource protection and economic profits, some environmental and trade contradictions do exist between developed countries and developing countries, which continuously sharpens as the international economic situation develops. Developed countries use this kind of different environmental standards that result from economic level differences in two aspects. On one hand, transfer pollution industries to developing countries while grabbing raw materials from them, which worsens developing countries' environment; on the other, take environmental problems as new trade barriers to set off developing countries' comparative advantage in resource and cheap labor and restrict their economic development to keep leading position in international multilateral economic and trade fields.

Ostensibly, based on some public legislation, such as international convention and laws, Green Barrier complies with sustainable development and human health development. However, exporters can't foresee its contents and changes.

After join in WTO, China, the biggest market, opens its door to the world. And the world market gives opportunities to the Chinese products, too. As a WTO member, China is both a big trade country and an environmental country. Not only should China complies with environmental clauses and specifications, but also accept many international criteria on trade and environment. For now, the majority of the restricted products are from electromechanical and textile industries, but in the future, the automobile industry will be restricted as well. We lost $\$ 31.7$ billion in electromechanical export to Europe only because two environmental protection articles on electro mechanism that were released by EU in 2005, which was $71 \%$ of the total electromechanical export to Europe. Consequently, China's ecological diplomacy takes on great responsibility in trade and environmental problems, but the Green Barrier is too difficult for China to cope with.

\section{Foreign Capital Importation and Independent Development}

What can foreign capital bring us? The introduced environmental protection project may be advanced that what we had before, but it will never be the most advanced. Some environmental protection projects are introduced in order to solve employment problems, but actually, they lag the real environmental protection. As a matter of fact, developed countries have never fulfilled their commitment to transfer environmental protection technology and capital to the developing 
countries. For years, the only thing they have transferred is device, but not the technology. Government always makes an excuse that technology belongs to enterprise itself and enterprise possesses its patent. Domestic enterprises pay out ecological cost and cheap labor, but actually, they only pay pill for the developed countries' environment and resource.

Compared with other countries, we still have great deficiency in environmental protection and the technology of ecological control. Take climate change for example. Various kinds of evaluation reports written by IPCC are playing a more and more important role in international environmental convention activities. However, compared with developed countries, we have fewer experts take part in writing reports and fewer documents are quoted. We don't have strong scientific evidence to protect our countries' interests. As a result, we not only face more pressures in climate change activities, but also in ecological diplomatic activities. Our environmental protection enterprises which possess independent intellectual property and scientific research projects are still in the primary development phase.

\section{Prospect of Chinese Ecological Diplomacy}

The functionality of ecological diplomacy is far more important than political nature. How to protect the domestic resource while taking on a big country's responsibility is the spirit of ecological diplomacy.

\section{Build up Green Image and Promote Soft Power}

Recently, Soft Power is widely accepted and applied in international politics and communication. People domestic and abroad all agree that the improvement of comprehensive national strength should not only be reflected in hard power, such as economy, technology and national defense, but also in soft power, such as policy, culture and ecological environment. The essence of soft power is a country's image and influence. (Huan, 2006, p.147) The stronger the soft power is, the more international influence it will be and vice versa.

\section{Actively Cope with Green Barrier and Create Better Environment}

To break through green trade barrier, developing countries cannot expect that developed countries would willingly help them. They should take part in the international trade and environmental business actively to create better external environment for economy and trade. Moreover, developing countries need to actively cope with various kinds of trade barriers to strengthen their power in international trade negotiation and resist being imposed country system and policies.

Currently, ecological diplomacy has been an important means for the developed countries to expand green trade. In the international trade and cooperative ecological diplomacy, China should take on positive measures, expand green industries, improve the quality of green products and break through the green barrier to guarantee that our green products can successfully come into the international market. What's more, we need to gain the initiative, make research for international trade and environmental management and fully use diplomatic means to counterattack various kinds of green trade barriers.

\section{Widen Capital and Technical Channel, Encourage Independent Development}

China is a big manufacturing country, but not a strong manufacturing country. Many products in the world are based on the biggest world factory---China. The high consumption of resource and energy leads to our energy deficiency and environmental pollution. The National Science and Technology Support Plan, which was published in February, 2007, brought forward to transform 'Made in China' to 'Green Manufacturing' by putting the 'Key Technology and Equipment of Green Manufacturing' project into effect.

The 'Key Technology and Equipment of Green Manufacturing' project requires us to reduce the resource consumption and environmental pollution to break through the international green trade barrier. Moreover, we need to put forward a set of key technology and equipment for green manufacturing products and actualize some demonstration projects to improve our green manufacturing ability and the proportion of products and technology of independent intellectual property.

Up to the end of 2007, China has already had more than 1000 environmental cooperative projects with UN and other international organizations. What's more, science and technology cooperation, technical transfer and various kinds of environmental projects and research have been implemented between China and a great number of countries, which play a key role in widening the channel to introduce foreign capital and technology and encouraging independent development of environmental protection enterprises.

\section{Conclusion}

The functionality of China's ecological diplomacy is far more important than its political nature. On one hand, China cannot banish the international moral justice to develop. This will greatly damage her image. On the other, China should not abandon her rights to develop, too. As the biggest developing country, China greatly impels the whole world to develop with her. China's ecological diplomacy should not only protect her own development benefits in the negotiation on international environmental conventions to guarantee the long-term development strategic to be successfully 
implemented, but also make contribution to the global environmental protection.

We should make clear the purpose of joining in the international organizations. China's ecological diplomacy should not only make good use of international rules, but also resist unreasonable international ecological system and create new mechanism and rules.

The research on China's ecological diplomacy theory and ecological environment still has a long way to go. Ecological diplomacy theory must be based on absorbing the advantage of developed countries' related theories and considering China's condition to guarantee China's leading position in the ecological diplomacy. Meanwhile, we should make more research on the statistics of ecological environment to gain initiative in the process of ecological diplomacy, actively participate in multilateral negotiation on ecological environment, especially on the global climate change, to get ready for the new round negotiation to safeguard China's development rights and interests.

\section{References}

Huan Qingzhi, (2006). International Comparisons on Environmental Politics Jinan: Shandong University Press. P.147
Pan
Haiping,
(2002).
Green
Barriers.
[Online]
Available:

http://news.xinhuanet.com/fortune/2002-04/17/content_361465.htm (July 7, 2007).

Zhou Shengxian, (2007). Build an ecological civilization. People's Daily. 24 December 2007. 


\title{
Long Term Shoreline Oscillation and Changes of Cauvery Delta Coastline Inferred from Satellite Imageries
}

\author{
R. Sathyanarayan Sridhar (Corresponding Author) \\ Department of Civil Engineering \\ Coimbatore Institute of Technology \\ Coimbatore- 641014, India \\ Tel: 91-422-2574071_E-mail: sridharsathyanarayan@hotmail.com \\ K. Elangovan \\ Department of Civil Engineering \\ PSG College of Technology \\ Coimbatore- 641004, India \\ P. K. Suresh \\ Institute of Hydraulics and Hydrology \\ Poondi- 602 023, India
}

\begin{abstract}
Coastal zone is highly volatile ecosystem which is always in adjustments. Loss of shore line will cause severe impact on human life and as well as their properties. Remote sensing is a reliable technique to study the historical shoreline changes. Therefore in this paper long term shoreline oscillations of Cauvery delta shorelines at Poompuhar, Tharangambadi and Nagapattinam were studied using satellite imageries and the same was physically observed at the above three locations with the help of reference pillars and compared mutually. It was observed that the shoreline at Poompuhar is under accretion at the rate of $1.79 \mathrm{~m} /$ Year and other shoreline stretches at Tharangambadi and Nagapattinam were under erosion at $0.4888 \mathrm{~m} /$ Year and $0.4985 \mathrm{~m} /$ Year respectively. It was also observed that the remote sensing study qualitatively matches with the physical observation for all the three coastal stretches of the study area.
\end{abstract}

Keywords: Shoreline oscillation, Coastal Erosion, Remote sensing, Cauvery delta

\section{Introduction}

Coastal zone, a dynamic eco system is a transition between land and sea. It is always in adjustments to maintain equilibrium with changes in the nature. Coastal development is one of the main lifelines for socio- economic progress. The Cauvery delta coastline (central east coast of Tamilnadu, India) between Kollidam river mouth to Nagapattinam was worst affected during $24^{\text {th }}$ December 2004 Tsunami.

Tamilnadu has the shoreline extending to a length of $990 \mathrm{~km}$ in east and is straight in most of the places (Gurugnanam, 2000). This shoreline has always been in adjustments to maintain equilibrium with changes in operating process of both land and marine origin since 6000 years B.P (Meijerink, 1971). This changes in shoreline, whether natural or man-made, affects wetland ecosystem and socio- economic developments. The old history states that the central east coast of Tamilnadu had lost many coastal towns and villages due to coastal erosion (Kaliasundaram et. al, 1991). Like any other geomorphic processes, coastal erosion or accretion is highly episodic and dominated by major natural events like Super cyclones, Tectonic activity, Tsunami and other climate changes besides manmade activities like construction of break waters, jetties etc.

Therefore it is very essential to understand the amount of erosion and accretion to conceive a master plan for socioeconomic developments and proper coastal zone management to utilize the coastal area optimally. 
In this context, shoreline oscillation and changes of Cauvery river delta coastal stretches at Poompuhar, Tharangambadi and Nagapattinam has been studied in this paper from 1975 to 2005 using Satellite images and compared with physically observed data from 1979 to 2004 .

\section{Study Area}

The Cauvery delta shoreline (Central east coast of Tamilnadu) lies between $10^{\circ} 45^{\prime} 00^{\prime \prime} \mathrm{N}$ latitudes to $11^{\circ} 47^{\prime} 30^{\prime \prime} \mathrm{N}$ and $79^{\circ} 49^{\prime} 00^{\prime \prime} \mathrm{E}$ to $79^{\circ} 53^{\prime} 00^{\prime \prime}$ E longitudes and covers the coastal districts of Nagapattinam (Tamilnadu) and Karaikal (Pudhucherry).The significance of the study area is increased due to existence of historical Towns of Poompuhar and Tranqobar and Minor Ports at Nagapattinam, frequent floods often devastated the ecosystem in the proposed study area and as many as 11 rivers merging into bay of Bengal in this region. In this proposed study coastline stretches at Poompuhar, Tharangambadi and Nagapattinam has been studied for shoreline oscillation.

\subsection{Poompuhar Shoreline Stretch}

Poompuhar is a small coastal village located $22 \mathrm{~km}$ northeast of Mayiladuthurai Town in Nagapattinam District lies at $11^{\circ} 07^{\prime} 00^{\prime} \mathrm{N}$ Latitude and $79^{\circ} 52^{\prime} 00^{\prime \prime} \mathrm{E}$ Longitude. This village was once major port and trade city for Chola Kingdom and was called Kaveripoompattinam. River Cauvery joins the Bay of Bengal at distance of about 400m south of this village. Shoreline length of $1950 \mathrm{~m}$ was selected for observation at Poompuhar with 7 Coastal Monitoring Stations.

\subsection{Tharangambadi Shoreline}

Tharangambadi is situated about $30 \mathrm{~km}$ East of Mayiladuthurai and $32 \mathrm{~km}$ North of Nagapattinam and lies at $11^{0} 01^{\text {, }}$ $00^{\prime} \mathrm{N}$ Latitude and $79^{\circ} 51^{\prime} 00^{\prime}$ " E Longitude. This city was under Danish administration in Pre Independence period. Shoreline observation was conducted for a length of $760 \mathrm{~m}$ with 4 observation pillars. This place had been exposed to severe cyclones during 1972, 1977 and 1993.

\subsection{Nagapattinam Shoreline}

Nagapattinam is the district head quarters of Nagapattinam District with geographical location of $10^{\circ} 46^{\prime} 00^{\prime \prime} \mathrm{N}$ Latitude and $79^{\circ} 51^{\prime} 00^{\prime}$ " E Longitude. This city having a minor port at Koduvaiyaru River mouth and presently developmental activities (construction of break waters) are in progress in the port area. Total length of observation was $4270 \mathrm{~m}$ with 8 numbers of observation pillars.

\section{Objective of the Present Study}

Present study mainly focused on the following objectives,

1) To find the change in shoreline positions of Nagapattinam, Tharangambadi and Poompuhar over period of time (1975 to 2005) using multidated satellite imageries, SOI Toposheet, GPS survey and physical observations.

2) To quantify the rate of erosion and accretion of the study area between 1975 and 2005.

\section{Methodology}

Survey of India Toposheet for the year 1975 (Fig.1) was used as base map and IRS IA LISS II image (1990), IRS IC LISS III (2000) and IRS P6 LISS III (2005)(Fig 2- Fig 4) were used for delineation of coastline during respective years. The satellite data received from NRSA Hyderabad with radiometric corrections and the same was has been geometrically corrected using ENVI 4.2 software and verified with ground truth. Then the shorelines had been digitized for further analysis.

For field monitoring of shoreline oscillation in three shoreline stretches at selected locations, permanent coastal point pillars erected by Public Works Department, Government of Tamilnadu at Poompuhar, Tharangambadi and Nagapattinam were used as benchmark pillars (Fig.5). The exact locations of these points were observed and respective latitude and longitude were recorded using (Fig.6) LEICA GS5+ Dual frequency Global Positioning System (DGPS). Then the coastline was monitored from this pillar points every month and average coastline oscillation was computed in season wise during South West Monsoon (Jul-sep), North east Monsoon (Oct-Dec) and Fair-weather Period(Jan-May) . Archival coastline oscillation data of the study area since 1978 had been obtained from Institute of Hydraulics and Hydraulics Structures, Poondi and the same was used in the analysis.

\section{Results and Discussions}

A thematic map comprising of Base map with over lapped shoreline vectors for the years $(1975,1990$ and 2005) were prepared to analyse the shoreline erosion/ accretion in the study area and the same was furnished in Table.1. In the remote sensing study, it reveals that the Poompuhar Coastal stretch was in accretion with a net annual rate of $2.12 \mathrm{~m} /$ year. The coastal stretches of Tharangambadi and Nagapattinam were recorded as erosional shorelines with an average rate of $-3.06 \mathrm{~m} /$ Year and $-2.96 \mathrm{~m} /$ Year respectively. 
Qualitatively, physical observation of shoreline oscillation yields a good agreement with remote sensing data but differs in quantitative analysis. In the physical observation (Table.2), Poompuhar had been recorded as an accretioanl coast with average rate of $1.79 \mathrm{~m} /$ year which was found true during ground truth study.

The Tharangambadi shoreline and as well as Nagapattinam shoreline emerged as erosional coasts with an average rates of $-0.49 \mathrm{~m} /$ Year and $-0.50 \mathrm{~m} /$ Year respectively. The long term shoreline oscillation observation from selected reference pillar at Poompuhar, Tharangambadi and Nagapattinam was furnished in Fig. 7.

This overestimation in the remote sensing data was due to the coarser resolution satellite imageries and the same can be brought to fairly accurate to the field observation by making use of high resolution images.

\section{Conclusions}

Based on this study it can be conclude that remote sensing technique will be useful in long term qualitative monitoring of shoreline oscillations. Further the remote sensing study has a good agreement with the physical observation of shoreline oscillation. The coastal stretch at Poompuhar were in accretion and quite suitable for tourism like activities whereas Nagapattinam and Tharangambadi shorelines were in erosion and require attention from coastal authorities. The difference of rate of erosion/ accretion between the remote sensing study and physical observation was due to the coarser resolution of satellite images.

\section{Acknowledgements}

The authors acknowledges the Department of Science and Technology, Government of India for their Funding under FAST TRACK scheme and the Director, Institute of Hydraulics and Hydrology, Poondi for sharing their archival data on shoreline oscillations.

\section{References}

Gurugnanam, B., Gokulakrishnan, R., Ramkumar, T., and Manoharan, K., (2000). Coastal Zone Dynamics of the central part of east coast, Tamilnadu- A case study through integrated remote sensing. Marine remote sensing Applications (Eds.: Ramachandran S), pp235-249.

Kaliasundaram. G, Govindasamy. S and Ganesan. R, (1991). Coastal erosions and accretions. Coastal zone management (Tamilnadu State, India) (Eds.: Natarajan R, Dwivedi S. N and Ramachandran S), Ocean data centre, Anna university, Madras, pp.73- 82 .

Meijerink, A. M. G. (1971). Reconnaissance survey of the Quaternary Geology of the Cauvery delta. Journal of Geological Society of India, 12: pp 113- 124.

Table 1. Shoreline Oscillations Observed from Satellite Imageries

\begin{tabular}{|c|c|c|c|c|c|c|c|c|}
\hline \multirow[b]{2}{*}{ Location } & \multicolumn{2}{|c|}{ Year } & \multirow{2}{*}{ 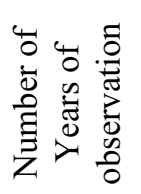 } & \multirow{2}{*}{$\begin{array}{l}\text { Maximum } \\
\text { Shore line } \\
\text { Oscillation } \\
\text { in } m\end{array}$} & \multirow{2}{*}{$\begin{array}{l}\text { Minimum } \\
\text { Shoreline } \\
\text { Oscillation } \\
\text { in } \mathrm{m}\end{array}$} & \multirow{2}{*}{$\begin{array}{c}\text { Average } \\
\text { Shoreline } \\
\text { Oscillation in } \\
\mathrm{m}\end{array}$} & \multirow{2}{*}{$\begin{array}{l}\text { Rate in } \\
\mathrm{m} / \text { Year }\end{array}$} & \multirow{2}{*}{$\begin{array}{l}\text { Average } \\
\text { rate in } \\
\mathrm{m} / \text { Year }\end{array}$} \\
\hline & From & To & & & & & & \\
\hline Poompuhar & 1975 & 1990 & 15 & 56 & 37 & 46.50 & 3.10 & \multirow{3}{*}{2.12} \\
\hline Poompuhar & 1990 & 2000 & 10 & 42 & 35 & 38.50 & 3.85 & \\
\hline Poompuhar & 2000 & 2005 & 5 & -38 & 32 & -3.00 & -0.60 & \\
\hline Tharangambadi & 1975 & 1990 & 15 & -95 & -12 & -53.50 & -3.57 & \multirow{3}{*}{-3.06} \\
\hline Tharangambadi & 1990 & 2000 & 10 & -56 & -8 & -32.00 & -3.20 & \\
\hline Tharangambadi & 2000 & 2005 & 5 & -36 & 12 & -12.00 & -2.40 & \\
\hline Nagapattinam & 1975 & 1990 & 15 & -52 & -33 & -42.50 & -2.83 & \multirow{3}{*}{-2.96} \\
\hline Nagapattinam & 1990 & 2000 & 10 & -67 & -38 & -52.50 & -5.25 & \\
\hline Nagapattinam & 2000 & 2005 & 5 & -27 & 19 & -4.00 & -0.80 & \\
\hline
\end{tabular}

- sign indicates erosion 
Table 2. Physically Observed Shoreline Oscillations

\begin{tabular}{|c|c|c|c|c|c|}
\hline Location & Year & $\begin{array}{c}\text { Average Initial } \\
\text { Shoreline Position (m) }\end{array}$ & $\begin{array}{l}\text { Average Final Shoreline } \\
\text { Position (m) }\end{array}$ & $\begin{array}{l}\text { Erosion/ } \\
\text { Accretion }\end{array}$ & $\begin{array}{c}\text { Average Rate in } \\
\mathrm{m} / \text { Year }\end{array}$ \\
\hline Poompuhar & 1979 & 27.99 & 23.11 & -4.88 & \multirow{26}{*}{1.7938} \\
\hline Poompuhar & 1980 & 23.11 & 19.71 & -3.40 & \\
\hline Poompuhar & 1981 & 19.71 & 31.01 & 11.30 & \\
\hline Poompuhar & 1982 & 31.01 & 55.04 & 24.03 & \\
\hline Poompuhar & 1983 & 55.04 & 59.18 & 4.14 & \\
\hline Poompuhar & 1984 & 59.18 & 46.80 & -12.38 & \\
\hline Poompuhar & 1985 & 46.80 & 41.96 & -4.84 & \\
\hline Poompuhar & 1986 & 41.96 & 49.63 & 7.67 & \\
\hline Poompuhar & 1987 & 49.63 & 55.07 & 5.44 & \\
\hline Poompuhar & 1988 & 55.07 & 47.01 & -8.06 & \\
\hline Poompuhar & 1989 & 47.01 & 58.55 & 11.54 & \\
\hline Poompuhar & 1990 & 58.55 & 54.57 & -3.98 & \\
\hline Poompuhar & 1991 & 54.57 & 55.79 & 1.22 & \\
\hline Poompuhar & 1992 & 55.79 & 41.82 & -13.97 & \\
\hline Poompuhar & 1993 & 41.82 & 39.63 & -2.19 & \\
\hline Poompuhar & 1994 & 39.63 & 33.48 & -6.15 & \\
\hline Poompuhar & 1995 & 33.48 & 58.31 & 24.83 & \\
\hline Poompuhar & 1996 & 58.31 & 77.80 & 19.49 & \\
\hline Poompuhar & 1997 & 77.80 & 77.83 & 0.03 & \\
\hline Poompuhar & 1998 & 77.83 & 73.82 & -4.01 & \\
\hline Poompuhar & 1999 & 73.82 & 78.02 & 4.20 & \\
\hline Poompuhar & 2000 & 78.02 & 80.95 & 2.93 & \\
\hline Poompuhar & 2001 & 80.95 & 74.28 & -6.67 & \\
\hline Poompuhar & 2002 & 74.28 & 70.39 & -3.89 & \\
\hline Poompuhar & 2003 & 70.39 & 70.05 & -0.34 & \\
\hline Poompuhar & 2004 & 70.05 & 74.63 & 4.58 & \\
\hline Tharangambadi & 1979 & 35.02 & 38.52 & 3.50 & \multirow{13}{*}{-0.4888} \\
\hline Tharangambadi & 1980 & 38.52 & 32.40 & -6.12 & \\
\hline Tharangambadi & 1981 & 32.40 & 17.38 & -15.02 & \\
\hline Tharangambadi & 1982 & 17.38 & 25.82 & 8.44 & \\
\hline Tharangambadi & 1983 & 25.82 & 31.87 & 6.05 & \\
\hline Tharangambadi & 1984 & 31.87 & 23.58 & -8.29 & \\
\hline Tharangambadi & 1985 & 23.58 & 23.60 & 0.02 & \\
\hline Tharangambadi & 1986 & 23.60 & 27.37 & 3.77 & \\
\hline Tharangambadi & 1987 & 27.37 & 32.01 & 4.64 & \\
\hline Tharangambadi & 1988 & 32.01 & 24.33 & -7.68 & \\
\hline Tharangambadi & 1989 & 24.33 & 25.80 & 1.47 & \\
\hline Tharangambadi & 1990 & 25.80 & 24.67 & -1.13 & \\
\hline Tharangambadi & 1991 & 24.67 & 19.12 & -5.55 & \\
\hline
\end{tabular}


Vol. 2, No. 1

\begin{tabular}{|c|c|c|c|c|c|}
\hline Tharangambadi & 1992 & 19.12 & 19.55 & 0.43 & \\
\hline Tharangambadi & 1993 & 19.55 & 27.21 & 7.66 & \\
\hline Tharangambadi & 1994 & 27.21 & 19.70 & -7.51 & \\
\hline Tharangambadi & 1995 & 19.70 & 22.28 & 2.58 & \\
\hline Tharangambadi & 1996 & 22.28 & 28.35 & 6.07 & \\
\hline Tharangambadi & 1997 & 28.35 & 22.72 & -5.63 & \\
\hline Tharangambadi & 1998 & 22.72 & 22.19 & -0.53 & \\
\hline Tharangambadi & 1999 & 22.19 & 25.00 & 2.81 & \\
\hline Tharangambadi & 2000 & 25.00 & 26.98 & 1.98 & \\
\hline Tharangambadi & 2001 & 26.98 & 32.84 & 5.86 & \\
\hline Tharangambadi & 2002 & 32.84 & 45.76 & 12.92 & \\
\hline Tharangambadi & 2003 & 45.76 & 34.41 & -11.35 & \\
\hline Tharangambadi & 2004 & 34.41 & 22.31 & -12.10 & \\
\hline Nagapattinam & 1979 & 40.48 & 39.92 & -0.56 & \multirow{26}{*}{-0.4985} \\
\hline Nagapattinam & 1980 & 39.92 & 44.06 & 4.14 & \\
\hline Nagapattinam & 1981 & 44.06 & 55.22 & 11.16 & \\
\hline Nagapattinam & 1982 & 55.22 & 49.15 & -6.07 & \\
\hline Nagapattinam & 1983 & 49.15 & 48.93 & -0.22 & \\
\hline Nagapattinam & 1984 & 48.93 & 40.08 & -8.85 & \\
\hline Nagapattinam & 1985 & 40.08 & 46.18 & 6.10 & \\
\hline Nagapattinam & 1986 & 46.18 & 48.24 & 2.06 & \\
\hline Nagapattinam & 1987 & 48.24 & 66.19 & 17.95 & \\
\hline Nagapattinam & 1988 & 66.19 & 52.96 & -13.23 & \\
\hline Nagapattinam & 1989 & 52.96 & 64.64 & 11.68 & \\
\hline Nagapattinam & 1990 & 64.64 & 68.15 & 3.51 & \\
\hline Nagapattinam & 1991 & 68.15 & 66.18 & -1.97 & \\
\hline Nagapattinam & 1992 & 66.18 & 46.26 & -19.92 & \\
\hline Nagapattinam & 1993 & 46.26 & 54.64 & 8.38 & \\
\hline Nagapattinam & 1994 & 54.64 & 38.91 & -15.73 & \\
\hline Nagapattinam & 1995 & 38.91 & 46.14 & 7.23 & \\
\hline Nagapattinam & 1996 & 46.14 & 47.41 & 1.27 & \\
\hline Nagapattinam & 1997 & 47.41 & 49.89 & 2.48 & \\
\hline Nagapattinam & 1998 & 49.89 & 46.41 & -3.48 & \\
\hline Nagapattinam & 1999 & 46.41 & 50.82 & 4.41 & \\
\hline Nagapattinam & 2000 & 50.82 & 58.91 & 8.09 & \\
\hline Nagapattinam & 2001 & 58.91 & 57.1 & -1.81 & \\
\hline Nagapattinam & 2002 & 57.1 & 47.37 & -9.73 & \\
\hline Nagapattinam & 2003 & 47.37 & 35.81 & -11.56 & \\
\hline Nagapattinam & 2004 & 35.81 & 27.52 & -8.29 & \\
\hline
\end{tabular}




\section{Fig.1 Survey of India Topo Sheet of the Study area in 1975}

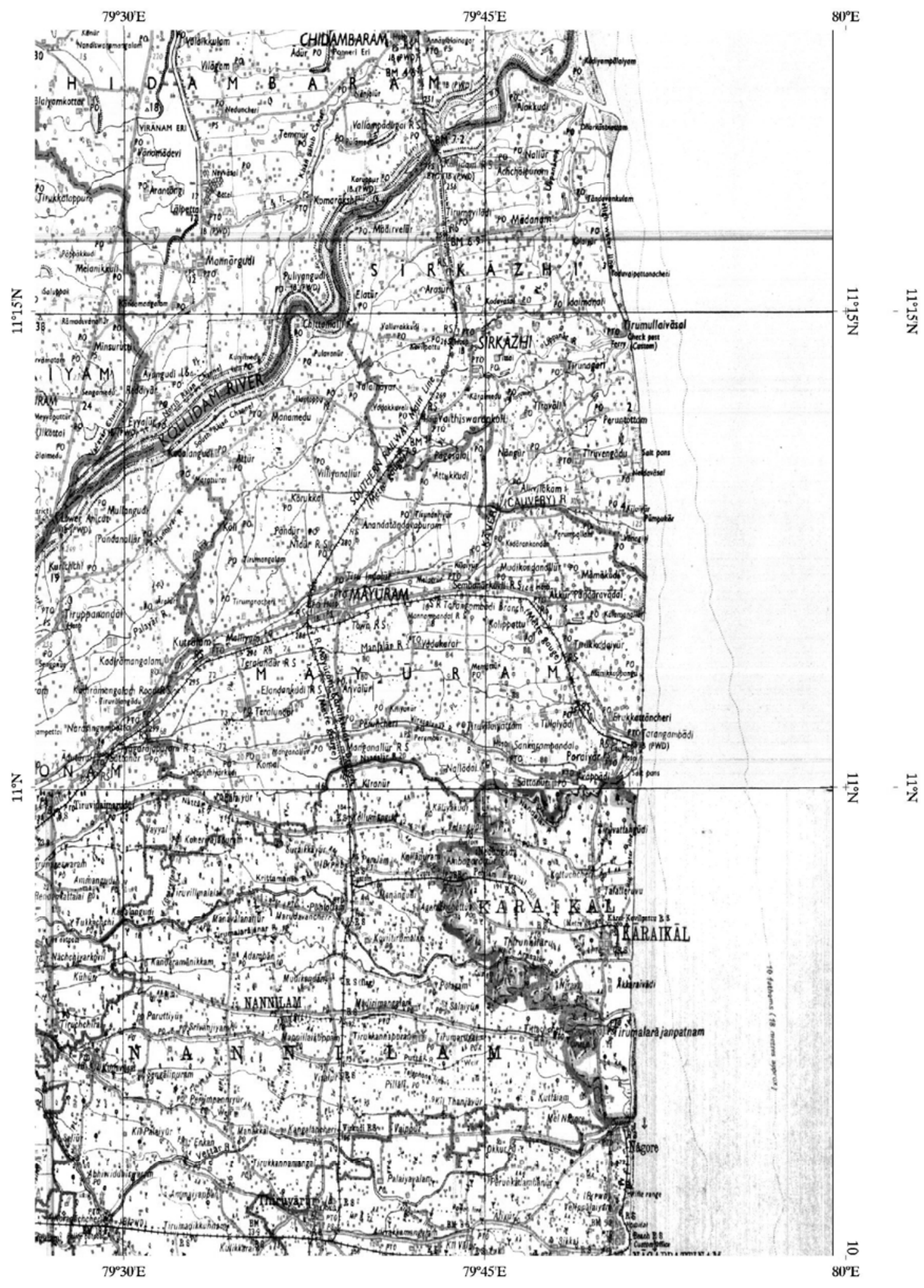

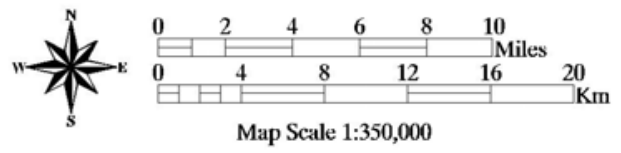


Fig.2 IRS-1A-LISS II- 1990 Image of Study Area

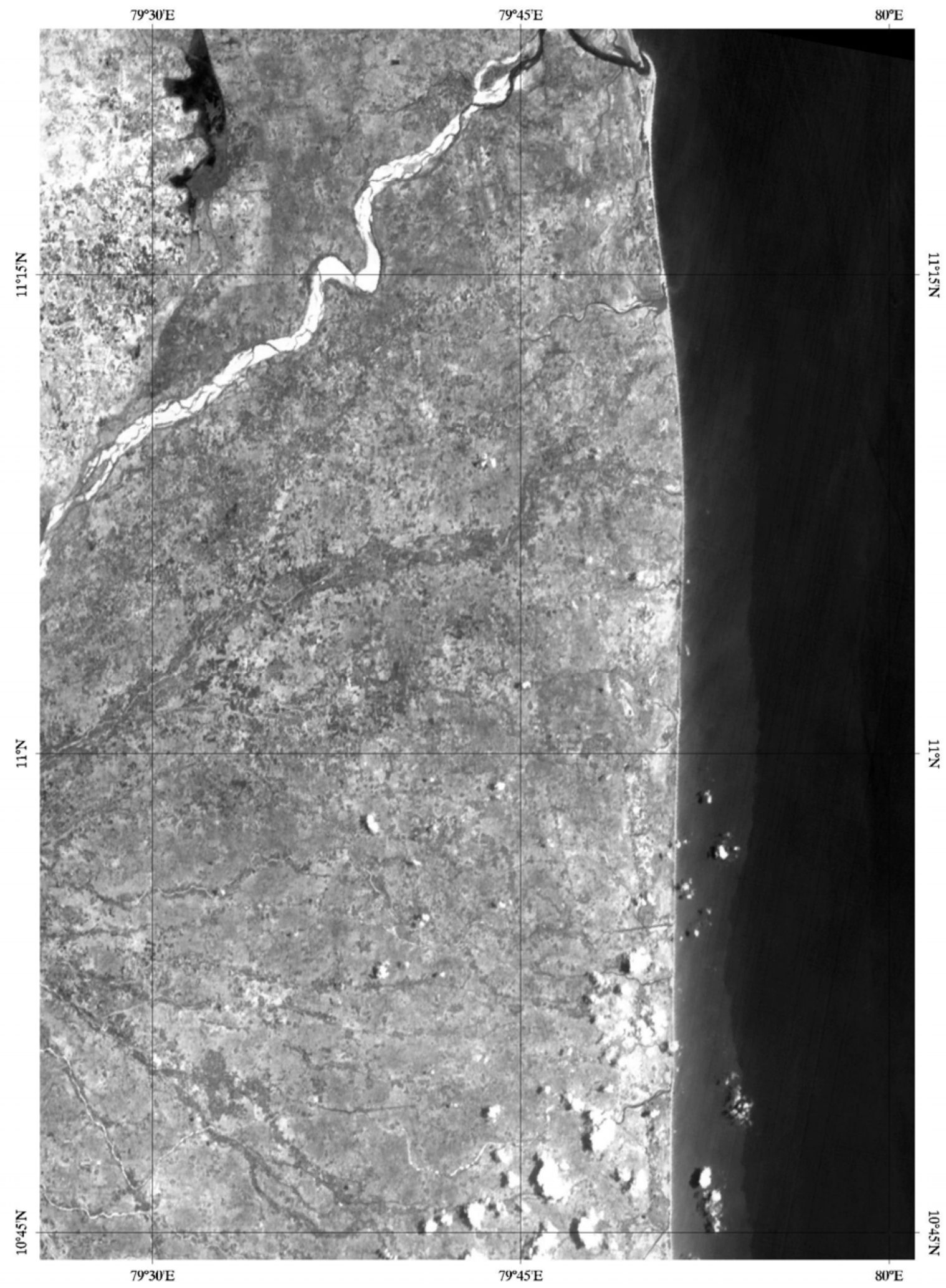

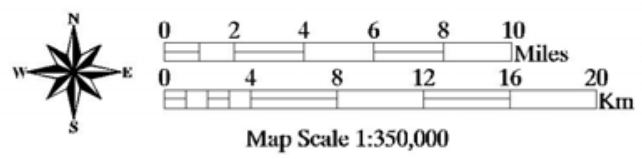




\section{Fig.3 IRS 1C LISS III -2000 Image of Sudy Area}

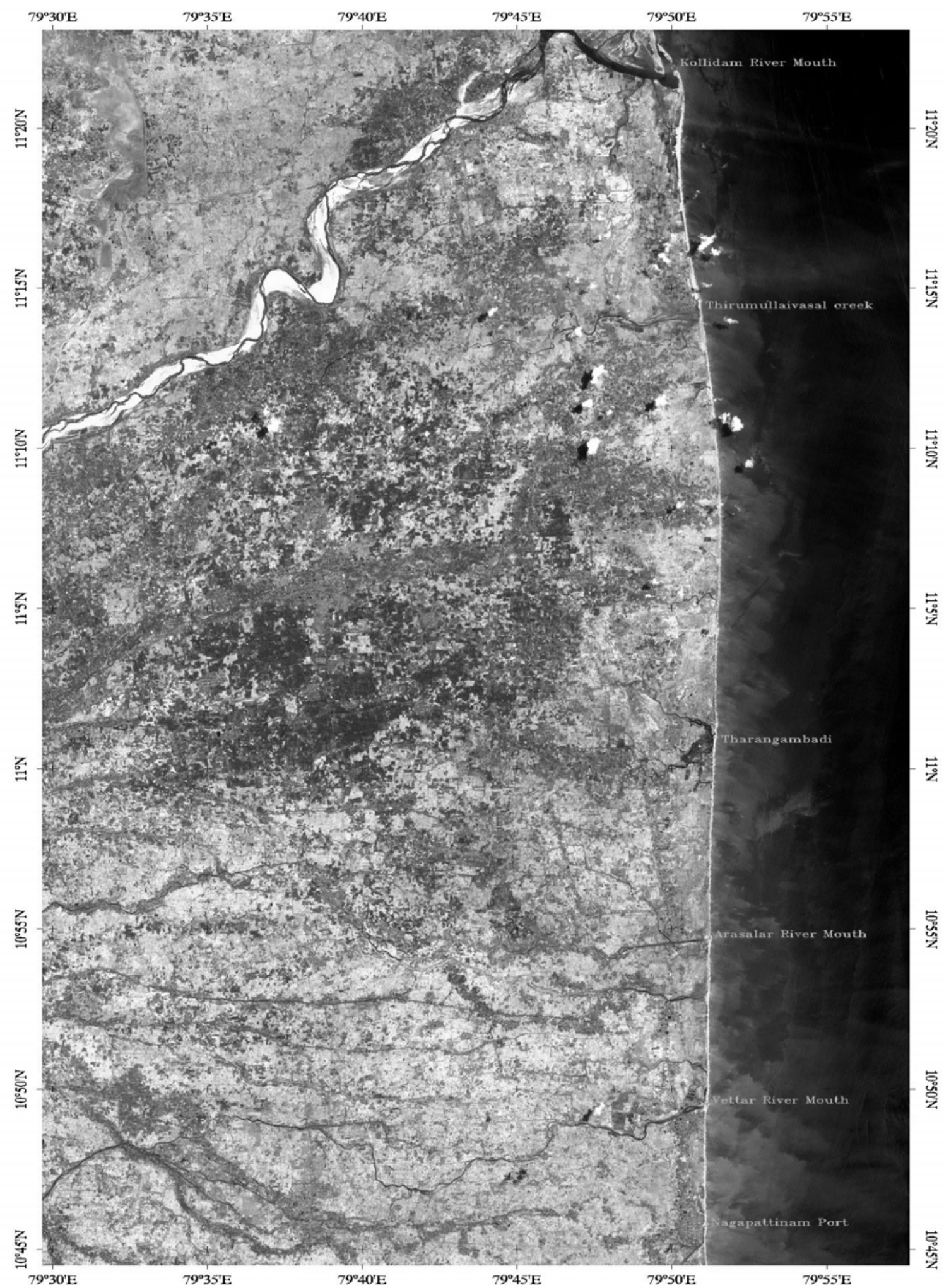

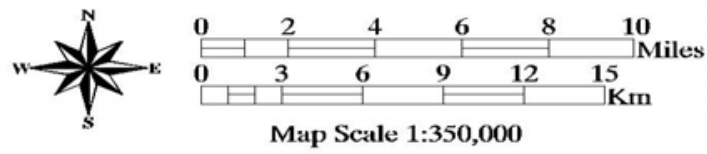




\section{Fig.4 IRS- P6- LISS III - 2005 Image of Study Area}

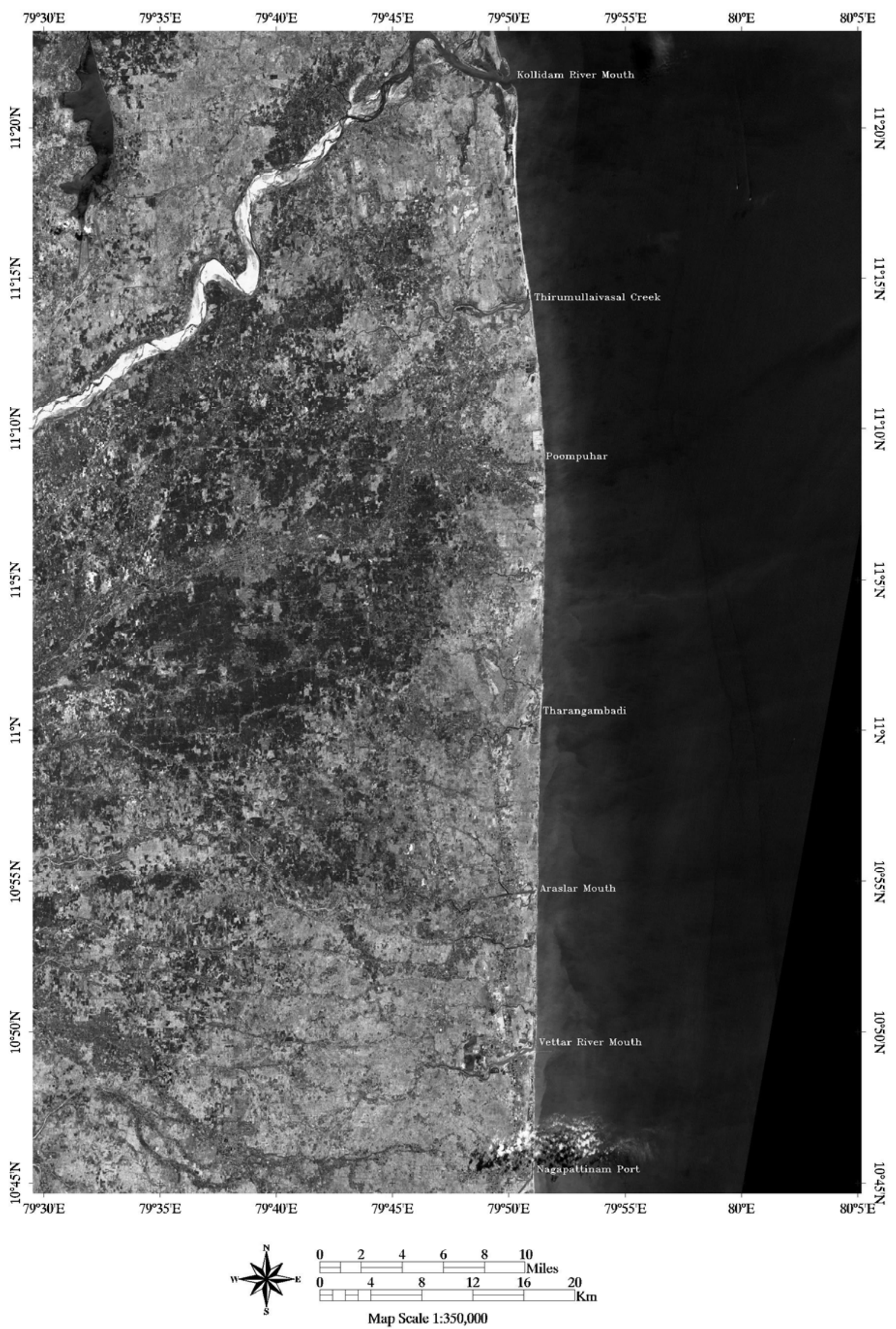




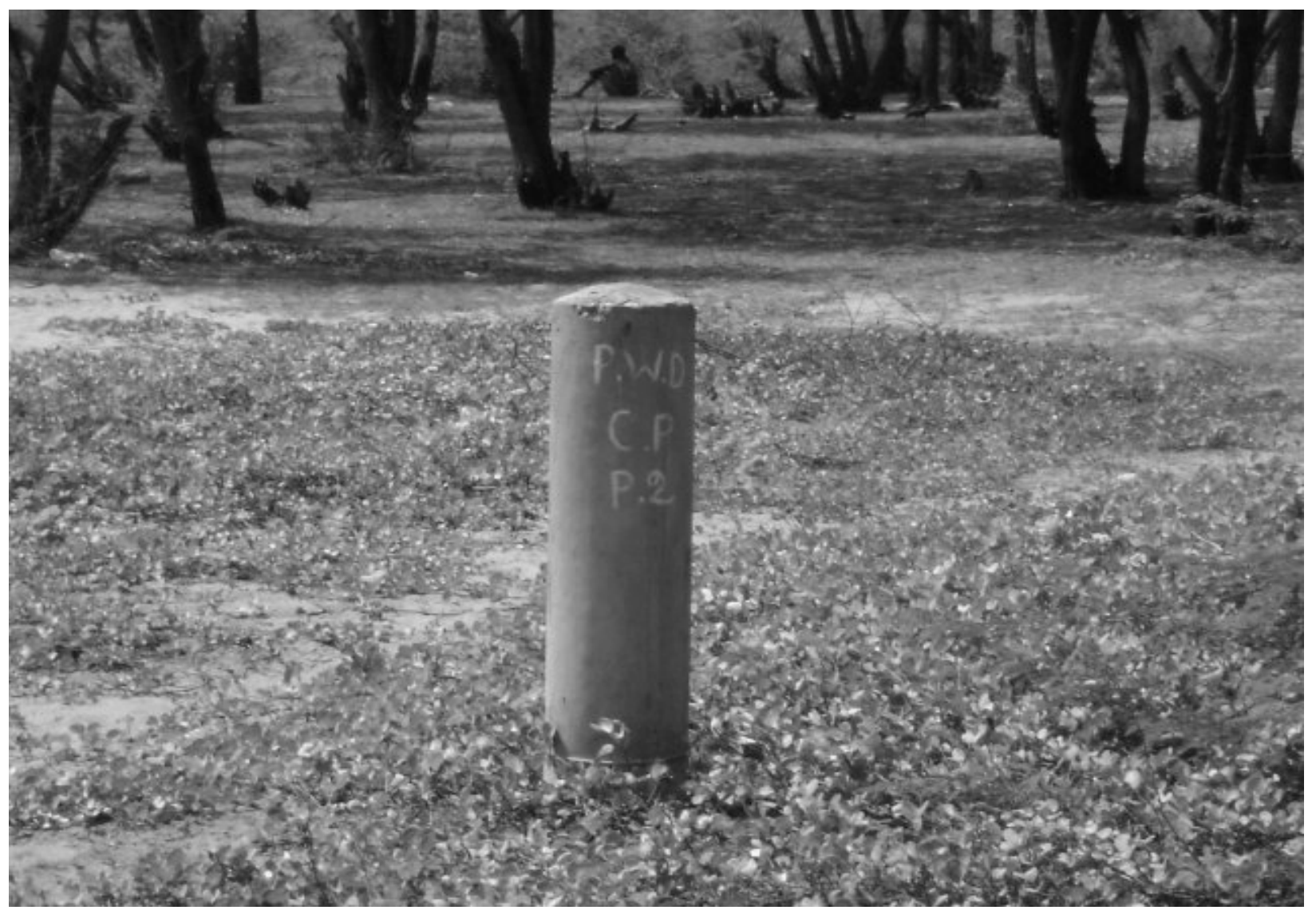

Figure 5. Coastal reference Pillar at Poompuhar

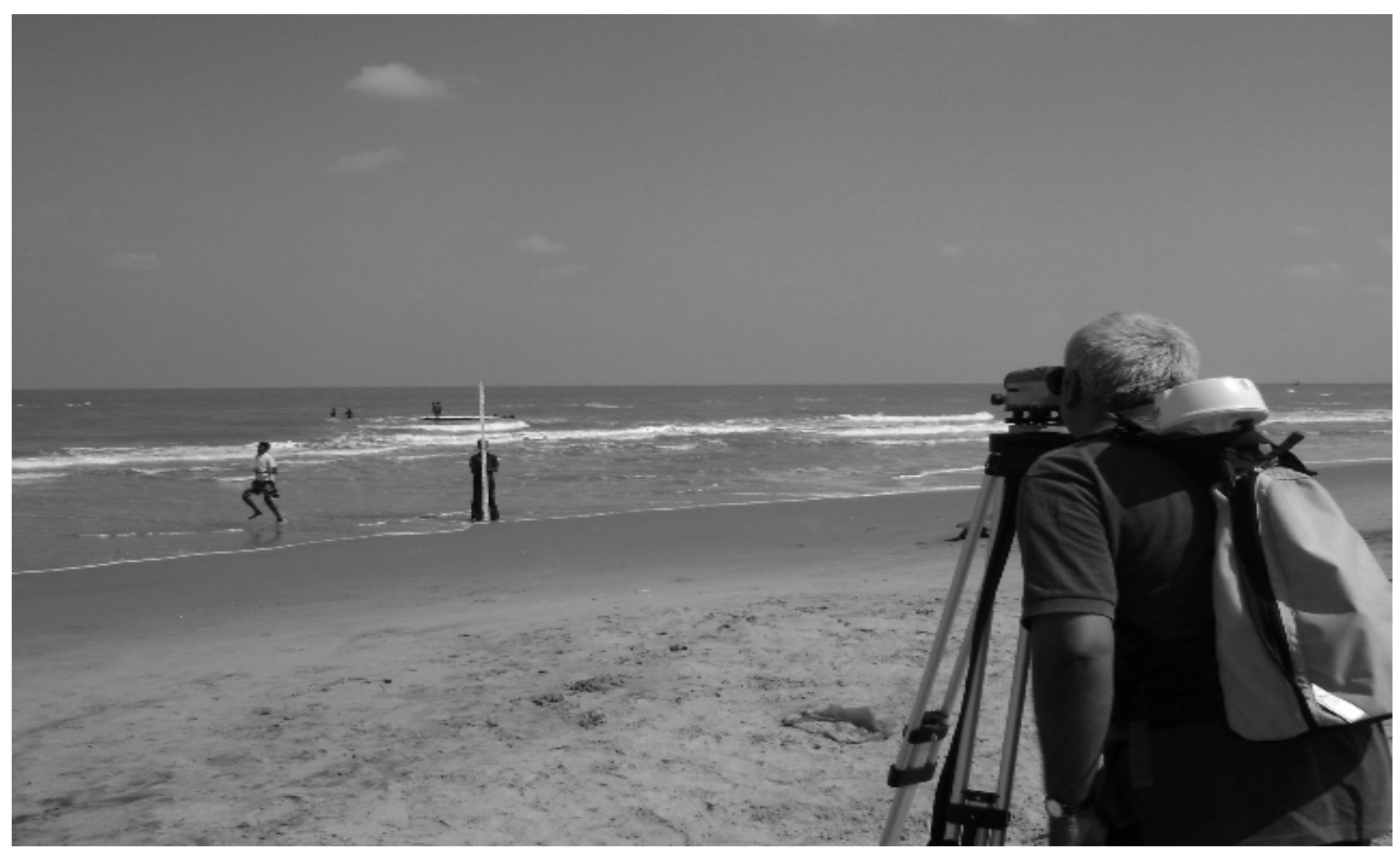

Figure 6. Coastal Survey with DGPS and Auto Level 
P1

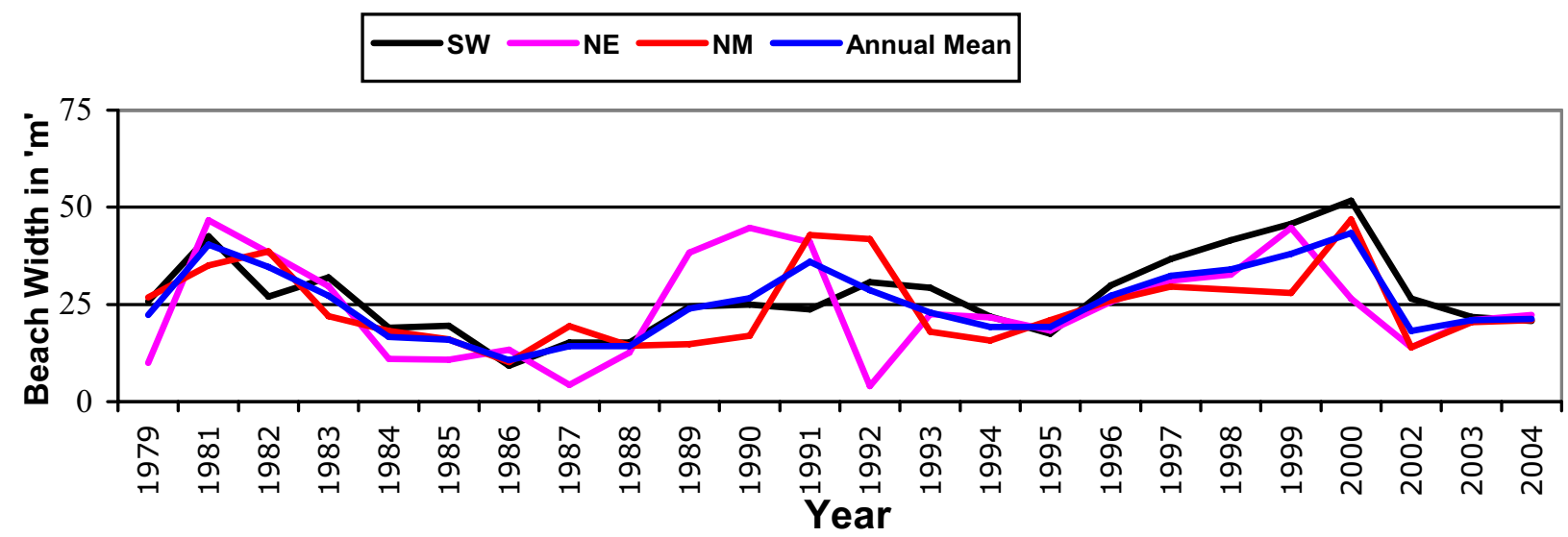

(a)

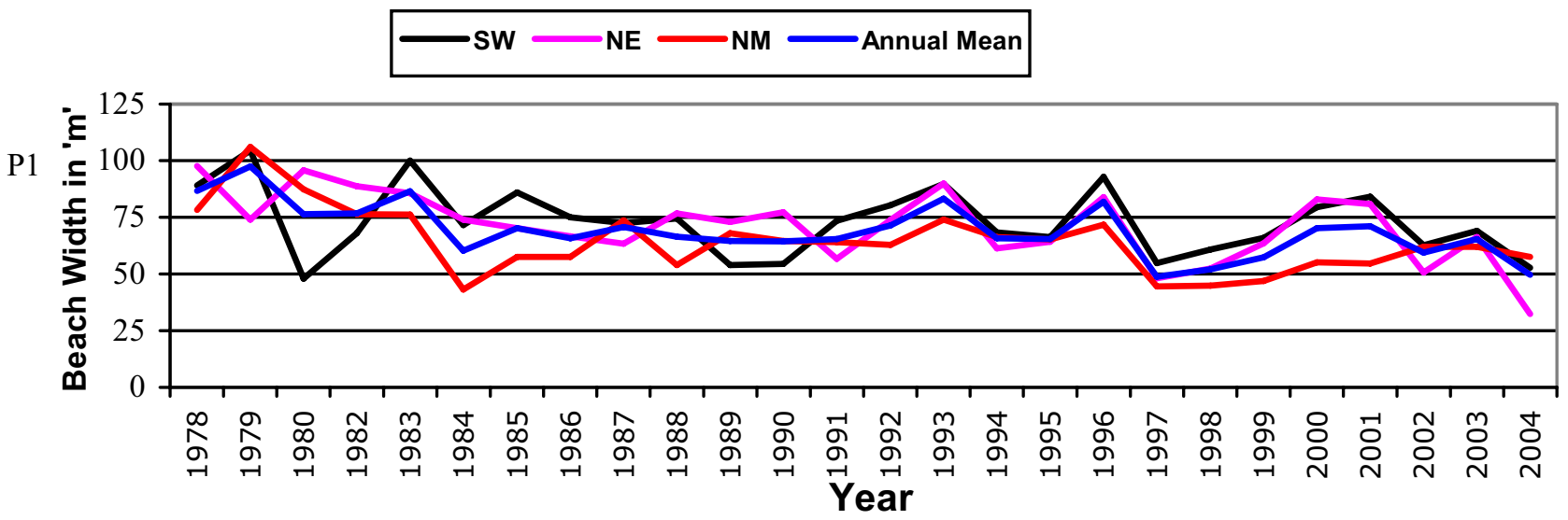

(b)

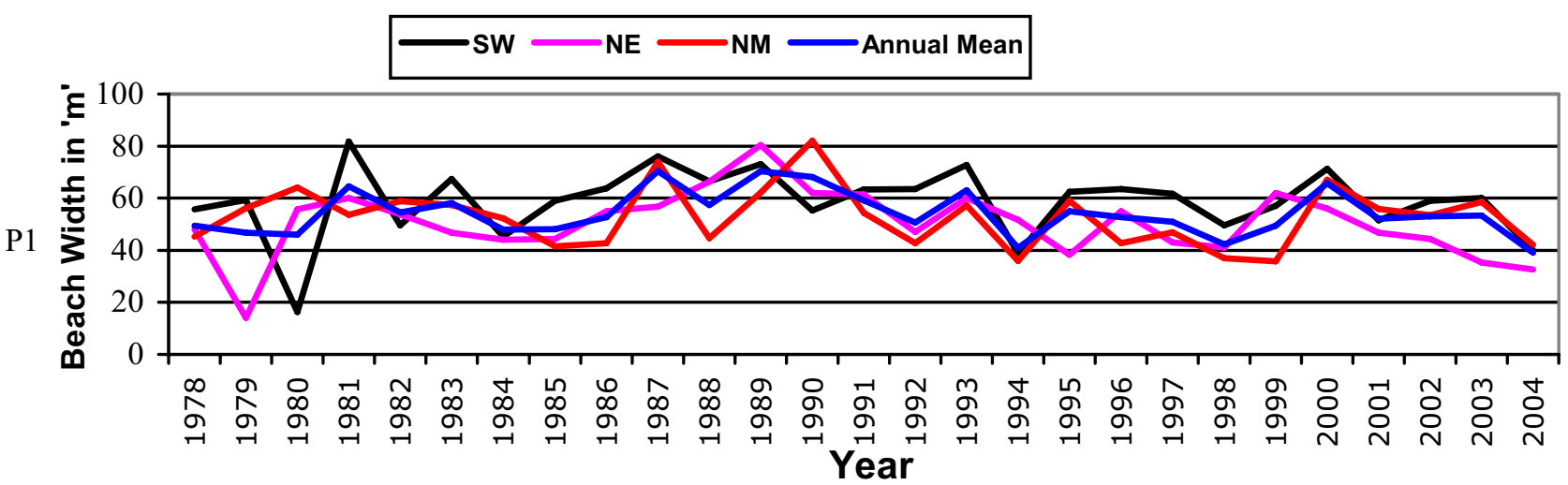

(c)

SW- South West Monsoon, NE- North East Monsoon NM- Fair weather Period

Figure 7. Shoreline Position from Reference Pillar during Different Seasons at

a). Poompuhar,

b). Tharangambadi and c). Nagapattinam 


\title{
Research on Evaluation Index System of Enterprise Innovation Culture Based on Sustainable Development
}

\author{
Chunyan Shao \\ School of Accounting \\ Shandong Economic University \\ Jinan 250014, China \\ E-mail: haichangli@126.com
}

\begin{abstract}
This text introduced the necessity of establishing an index system of evaluating innovative culture in enterprise in the view of sustainable development by analyzing the relationship between innovative culture and sustainable development, and then established an index system of evaluating innovative culture based on sustainable development. This is beneficial to enhance the core-competitiveness of enterprise.
\end{abstract}

Keywords: Sustainable development, Innovation culture, Evaluation index system

\section{Introduction}

Schumpeter's "Innovation Theory" pointed out clearly that innovation is the essence of economic development. Innovation culture in enterprise is the value view in which innovation is the part and core of employees' lives. It is created and shaped in activities of innovation and innovation management in order to adapt to the rapid development of market competition. It can motivate the staff to innovate and develop their conscious awareness of innovation gradually so that they can innovate constantly and try their best to innovate. Innovation culture in enterprise is the source of innovation, and the premise and pilot of technological innovation, system innovation and management innovation. It is need to nurture innovation spirit, innovation awareness and innovation thinking to develop innovation culture so that it can provide spiritual motivation and intellectual support, and break the factor of culture that impedes the innovation of enterprise culture, that is, innovate the cultural environment. In a word, innovation culture should affect innovation subject and improve the innovation capacity of enterprises to promote the sustainable development in economy of enterprise. As a result, the enterprise culture of innovation is critical to the development of enterprise. So it is more and more important for enterprises to evaluate the level of innovation culture. In order to evaluate the innovation culture of enterprise it is required to construct reasonably the index system of evaluating innovation culture of enterprise. The text is to construct the evaluation index system of evaluating innovation culture in enterprise from the perspective of sustainable development, and then evaluate the level of innovation culture in enterprise on this basis. This can promote enterprise to understand its level of innovation culture and enhance its competitiveness.

\section{The necessity of constructing the evaluation index system of evaluating innovation culture in enterprise from the perspective of sustainable development}

The sustainable development of enterprise refers to that the development of enterprise is a kind of long-term and stable behavior, by no means a temporary and short-term one. The core of sustainable development in enterprise is to accommodate the enterprise with the environment and achieve the constant innovation, strengthen management, and then achieve its existence. Therefore the sustainable development of enterprises can not do without continuous innovation and the continuous innovation can not do without the support of innovation culture of enterprise.

\subsection{The innovation culture in enterprise is a prerequisite for sustainable development.}

Modern society is a competitive society and the market is an ever-changing market. So any enterprise must continue to innovate based on market conditions in order to occupy the market continuously, gain the profit continuously and achieve sustainable development. The core of innovation in enterprise is the innovation of culture, and the innovation of technology and management is followed. Only innovation culture is fundamental to maintain the continuous innovation in enterprise. The construction of innovation culture in enterprise is to create a favorable environment suitable for innovation features and fit for innovation law in order to achieve for innovation. On this basis, enterprise puts up technological innovation and product innovation continuously in order to get higher earnings, and thus achieved sustainable development. Therefore it can be said that enterprise culture of innovation is a prerequisite for sustainable development in enterprise. 


\subsection{Sustainable development is the purpose and basis for the building of innovation culture in enterprise.}

The ultimate goal of the development of any enterprise is survival, development and profitability, so that it can achieve sustainable development. This requires enterprise to carry through continuously the construction of innovation culture, to go along technical innovation and product innovation, to produce marketable products, and then it can obtain favorable economic benefit. So it can be said that sustainable development is the purpose of building innovation culture in enterprise; On the other hand, only the enterprise has a favorable economic benefit and can achieve sustainable development can the enterprise has the ability to build innovation culture constantly. So the sustainable development is also the basis of building innovation culture in enterprise.

\subsection{The innovation culture and sustainable development in enterprise complement each other and promote each other.}

The construction of enterprise innovation culture serves the economic development of enterprise and is a prerequisite for sustainable development of enterprise; At the same time, the purpose of building enterprise innovation culture is to achieve sustainable development. Only sustainable development can utilize efficiently the production of the construction of enterprise innovation culture, or the construction of enterprise innovation culture will lose its carrier and significance. Sustainable development is the foundation of building enterprise innovation culture. Through sustainable development enterprise has accumulated valuable experience in building enterprise innovation culture and has accumulated the necessary capital for innovation, which will be propitious to the building of enterprise innovation culture. Therefore, the building of enterprise innovation culture and sustainable development go hand in hand. They promote each other and work together to serve enterprise.

The aim of enterprise innovation culture is to achieve sustainable development, so it is necessary to study the evaluation index system of enterprise innovation culture from the perspective of sustainable development. This paper is to build the evaluation index system of enterprise innovation culture from the perspective of sustainable development in order that the evaluation index system of enterprise innovation culture is more practical.

\section{The evaluation index system of enterprise innovation culture from the perspective of sustainable development}

It is necessary to establish the evaluation index system of enterprise innovation culture reasonably in order to evaluate the overall level of enterprise innovation culture objectively, accurately and completely. In order to make the evaluation index system of enterprise innovation culture serve the building of the enterprise innovation culture better, this article is to construct the evaluation index system of enterprise innovation culture in such four aspects as innovation environment, innovation subject, innovation content and independent innovation from the perspective of sustainable development.

\subsection{Innovation environment}

Innovation environment is a set of factors that is conducive to innovation. It is a set of all material factors and intangible factors which is favorable for innovation. Enterprise innovation environment is important condition to ensure enterprise to promote innovation culture. So it can be used to measure the level of enterprise innovation culture. Innovation environment includes physical environment and immaterial environment.

\subsubsection{Physical environment}

Physical environment mainly includes infrastructure, labor, human resource, engineering level and other material factors.

\subsubsection{Immaterial environment}

Immaterial environment mainly includes social systems, social psychology, social customs, legal systems, social morality, political policies and other immaterial factors.

\subsection{Innovation subject}

The index to measure innovation subject in enterprise includes innovation concept, innovation consciousness, innovation spirit and innovation thinking, and so on.

\subsubsection{Innovation concept}

One of the constituent elements of enterprise innovation culture is the atmosphere in which everyone is innovating whenever. Innovation concept is just formed in such an atmosphere. So the innovation concept of innovation subject will help enterprise to measure the level of innovation culture.

\subsubsection{Innovation consciousness}

Innovation consciousness is a kind of high-level mental reflection of an objective reality. It is produced in the course of practice needs in social life of community and individuals according to the motive of discovery and invention. In this practice people show their intention, desire and idea in order to regulate and adjust their directions of activities. Enterprise innovation consciousness is the most direct spiritual strength that decides the innovation ability of enterprise. It will help people to shape such advanced concepts as deploitation consciousness, opening awareness and so on. It can 
also help enterprise form democratic enterprise culture. So innovation consciousness can be used to measure the level of enterprise innovation culture.

\subsubsection{Innovation spirit}

Innovation culture is essentially a people-oriented culture whose center is people. All the fruits of innovation in enterprise are to serve humanity so that people can live a more convenient and more comfortable life. Consequently, as the important features of innovation culture, people-oriented culture pays attention to the innovation value of and innovation contributions of every member, to the idea and advice of the staff, to the most democratic activities on the widest sense, to the demand at all aspects and all levels of the staff, and to staff exercising their powers fully within their authority. Therefore, the innovation spirit of innovation subject can measure the level of innovation culture in enterprise.

\subsubsection{Innovation thinking}

The most core part of innovation culture is innovation values, while the inclusive thought of encouraging innovation and tolerating failure is an essential part of innovation values. Because innovation means risks and uncertainties, that is, the possibility of failure, the innovation culture should put more emphasis on encouraging innovation and spurring the employees' innovative behavior and tolerate their failure in innovation, which will help to maintain the innovation enthusiasm of the staff so that they can maximize their professional skills and develop their innovation thinking so as to the success of innovation. Therefore, the status of the innovation thinking ability of innovation subject can reflect the level of enterprise innovation culture.

\subsection{Content of innovation culture}

The index to measure the content of enterprise innovation culture includes innovation values, innovation system and innovation incentives, and so on.

\subsubsection{Innovation values}

Enterprise innovation culture provides innovative values for enterprise. The core of enterprise culture is values, and the values of innovation culture advocates change and is progressive. Shaping the innovation values is a process that all the members of the organization understand all the connotations of innovation, build innovative thinking, realize the process of innovation and treat the outcome of innovation reasonably.

\subsubsection{Innovation system}

Enterprise innovation culture provides innovative system for enterprise. To maintain long-lasting capability of innovation and improve the efficiency of innovation in enterprise, it is necessary to build corresponding system which is the basis of carrying out innovation acts. The innovation activities are uncertain and there is no specific rules and regulations to follow, but as the organizer and manager of innovation activities, it is need for enterprise to establish a set of matching system in order to get the most fruit of innovation in the lowest cost. In short, the building of system is an integral part of innovation culture, and it is an important safeguard for an organization to develop its continuous ability of innovation.

\subsubsection{Innovation incentives}

Enterprise innovation culture requires enterprise to adopt incentives to promote innovation. In addition to an increase in wages and promotion, the incentive for innovation action can create a variety of Honor in recognition of foster innovation and build up heroes to strengthen innovation positively in order to encourage people to innovate.

\subsection{Independent innovation}

Enterprise innovation culture constitutes the driving force of enterprise innovation in culture. In particular, enterprise innovation culture is the premise to enhance the ability of independent innovation in such aspects as spirit, idea and values; is the foundation of improving the ability of independent innovation from the perspective of system; is the systemic "software" to construct the system of enterprise innovation from an environmental viewpoint. Therefore, the core of innovation in enterprise is the innovation of culture which is followed by the innovation of science and technology, technology and products.

\subsubsection{Scientific and technological innovation}

With the arrival of the era of knowledge economy, the competition of science and technology is more and more intense, and the ability of technological innovation has become the core competitiveness of enterprise. The source and power of scientific and technological innovation comes from the innovation culture of enterprise. Therefore, the level of scientific and technological innovation in enterprise can reflect the level of innovation culture of enterprises.

\subsubsection{Technology Innovation}

At present, with the deepening of reform and development in China's society, economy and technology, technological 
innovation has become the conditions of survival, the basis of development and the source and means of improving the core competitiveness in enterprise. While the foundation of technological innovation is the innovation of enterprise culture, so the level of technological innovation can reflect the level of enterprise innovation culture.

\subsubsection{Product innovation}

Technological innovation is critical to enterprise. The embodiment of technological innovation is product innovation, that is, high-quality products can be produced in low cost in enterprise through technological innovation. Therefore, the level of product innovation can similarly, reflect the level of enterprise innovation culture.

Specifically, the evaluation index system of enterprise innovation culture is established as that in the table 1 .

\section{Conclusion}

The evaluation index system of enterprise innovation culture in the table can be established from the perspective of sustainable development and give full consideration to all factors of impacting enterprise innovation culture. So the evaluation of the level of enterprise innovation culture in the right way on this basis is objective, accurate and complete, and can encourage enterprises to understand their own situation of evaluating innovation culture so as to take further measures to improve their own level of innovation culture and improve the competitiveness of enterprise.

\section{References}

Chen, yiyuan. (2007). Innovation culture: the cultural driving force of independent innovation. Fujian Tribune. Humanities and Social Sciences Version. 2007.3:131-134.

Li, jiashou. (2007). Cultivation of Enterprise Innovation Culture. China Business(research on economic theory). 2007.12:24-27.

Ma, yide. (2007). Research on four models of enterprise innovation culture. Economy in length and breath. 2007.11:89-90.

Ning, qingqing, Bao, buyun and Yao, xuexin. (2007). Discuss on enterprise innovation culture and the cultivation of the core competitiveness in enterprise. Productivity Research. 2007.15:116-118.

Ren, shuliang. (2000). Technology innovation and innovation culture in enterprise. Reform of Economic System. 2000.5:93-96.

Sun, lizhi. (2008). The role and cultivation of innovation culture in the construction of innovation system in district. Market Modernization. January, 2008:318-319.

Tang, wei, Jiang rifu and Lu, meng. (2007). Summmary of research on evaluation theory on ability of technology innovation in enterprise. Science \& Technology Progress and Policy. 2007(5):195-200.

Zhang, hengrong. (2007). Attention on the role of enterprise innovation culture in promoting independent innovation. Private science and technology. 2007.6:4-6.

Table 1.Evaluation Index System of Enterprise Innovation Culture

\begin{tabular}{|c|c|c|}
\hline \multirow{12}{*}{$\begin{array}{l}\text { Level of Enterprise } \\
\text { Innovation Culture }\end{array}$} & \multirow{2}{*}{ Innovation environment } & Physical environment \\
\hline & & Immaterial environment \\
\hline & \multirow{4}{*}{ Innovation subject } & Innovation concept \\
\hline & & Innovation consciousness \\
\hline & & Innovation spirit \\
\hline & & Innovation thinking \\
\hline & \multirow{3}{*}{ Content of innovation culture } & Innovation values \\
\hline & & Innovation system \\
\hline & & Innovation incentives \\
\hline & \multirow{3}{*}{ Independent innovation } & Scientific and technological innovation \\
\hline & & Technology innovation \\
\hline & & Product innovation \\
\hline
\end{tabular}




\title{
International Migration, Remittances and Development
}

\author{
Hasan Mahmud (Corresponding Author) \\ Department of Sociology \\ Atish Dipankar University of Science and Technology \\ Faisal Tower, Gulshan-2, Dhaka, Bangladesh
}

Tel: 88-02-9891904Ｅ-mail: mahmud.soc@gmail.com

Md. Abdus Sabur

Department of Science and Humanities

Military Institute of Science and Technology

Mirpur Cantonment, Dhaka-1216, Bangladesh

Tel: 88-02-8019950Ｅ-mail: saburshajal@yahoo.com

\author{
Sharmin Tamanna \\ Department of Anthropology \\ University of Dhaka, Dhaka-1000, Bangladesh \\ Tel: 88-02-8615583Ｅ-mail: stamanna86@yahoo.com
}

\begin{abstract}
The increasing remittance flows to the labor sending developing countries in recent years have generated huge optimism in the contemporary development discourse about the possibility of development at the grassroots levels which has been an overwhelming challenge for the development actors for decades. However, the realization of such potential proves difficult due to a lack of common understanding of the phenomenon of labor migration and its causes and consequences. This study focuses on the existing literature on international labor migration, its causes and consequences with a view to identify a common line of theorizing about the issue in question.
\end{abstract}

Keywords: International migration, Migration theories, Migration and development, Transnationalism

\section{Introduction}

"Today, the impact of remittances is recognized in all developing regions of the world, constituting an important flow of foreign currency to most countries and directly reaching millions of households, totaling approximately 10 per cent of the world's population.... The driving force behind this phenomenon is an estimated 150 million migrants worldwide who sent more than US $\$ 300$ billion to their families in developing countries during 2006, typically US\$100, US\$200 or US\$300 at a time, through more than 1.5 billion separate financial transactions" (IFAD, 2007). These funds have generated startling optimism for development, particularly for effective grassroots economic development in the rural areas in the developing countries that present some of the greatest challenges to financial inclusion. However, we need to address all the complex dynamics of motives and usages of remittances to realizing the development potentials of remittances both in the host and home countries (Brown, 2006) which requires a review of our understanding of the reasons for, and impact of, migration in the developing countries. In the discourse of International Migration (or more precisely, International Labor Migration), various works are found where the researchers attempted to theorize about people's movement and ensuing consequences over last few decades. The main focuses in these studies are measuring the extent of international labor migration, defining its dominant characteristics, and particularly evaluating its contribution to socio-economic development (Goss \& Lindquist, 1995). Nevertheless, those researchers are thought of being distracted by the adoption of incompatible theoretical approaches and selecting diverse context and wide range of variables for empirical studies, and consequently, those studies resulted in further ambiguity. The situation in evaluating the consequences of international labor migration has become further complicated by the researchers' preferential emphasis on national economies, communities, or households as unit of analysis (Kearney, 1986). This paper is an attempt to understand the causes behind individuals' movement across national borders and their remittance practices, 
and the developmental implications of these for the labor-sending Third World countries through a review of existing literature.

\section{Theories of International Labor Migration}

"It is argued that at present there is no single, articulate theory of international migration, but a muddle of models, analytical frameworks, conceptual approaches, empirical generalizations, simple notions, and only seldom pieces of real theory segmented by disciplinary boundaries"(Arango, 2000). However, a review of the literature on migration recognizes two distinct approaches to the study of international labor migration: Functional approach and Structural approach.

\subsection{Functional Approach}

The functional models of international migration derive from neoclassical development economics which defines migration as a process of transferring surplus labor from an agricultural economy to the urban industrial sector, providing for economic growth and a psychosocial reorientation of the migrant in the process. This is a micro-social perspective in that it views migration as an aggregation of individual decision making and moving abroad. The different models that fall within functional camp are following:

\subsubsection{Neoclassical Macroeconomics}

This is considered to the oldest and best-known theory of international migration which has been developed originally to explain labor migration with regard to economic development (Lewis, 1954; Ranis \& Fei, 1961). However, this approach makes methodological individualism in that "individuals make rational decisions to maximize their utility on the basis of available knowledge of objective conditions, or in the case of migration that they migrate in response to the wage differences that result from uneven distribution of returns to the factors of production" (Goss \& Lindquist, 1995:320). According to this approach, international migration is stimulated by geographical differences in the supply of and demand for labor. It conceptualizes countries with large endowment of labor relative to capital as having low equilibrium market wage, whereas countries with a limited endowment of labor relative to capital as having high equilibrium market wage. This differential influences workers to move from low-wage countries in the third world to the high-wage countries in the developed world, and from rural to urban areas within a particular country. This theory predicts that the continuous movement of workers over a certain period will result in an increase in the supply of labor and decrease in the wage in capital-rich countries and regions, while economic growth in the source regions, attained by remittance together with the return of skilled migrants, will gradually eliminate the spatial inequalities and difference in wages. Thus, equilibrium is reached at one point. However, Massey et. al. (1993) find it too restricted to reflect only on the cost of international movement, pecuniary and psychic. There are instances that rural-urban and international migration has increased in many contexts, despite the high levels of unemployment and underemployment in the urban-industrial economies. Also the predicted economic development is unseen in the source regions.

\subsubsection{Neoclassical Microeconomics}

To overcome the limitations of the neoclassical macroeconomic model, Harris \& Todaro (1970) hypothesize that individuals take action rationally to the perceived differentials in wages and the expected probability of securing employment, instead of actual opportunities, and hence they travel despite the fact that opportunities for wage labor are more constrained. This behavioral modification is a sensible move in that this recognizes individual agency; yet this model suffers from "lack of distinctiveness and explanatory value due to its recognition of nonequilibrating tendencies in migration and inclusion of imperfect information and supra-individual decision making" (Kearney, 1986:335). Further, Cadwallader (1992) argues that this model reduces migrants- a social category that is structured by gender, ethnicity and social class- to mere embodiment of labor power, and thus fails to adequately address the political and other structural barriers to mobility.

Massey et. al. (1993) argue that, through the simple and compelling explanation of international labor migration, neoclassical economics has turned out to be prominent in shaping public discourse on migration and providing the intellectual foundation for immigration policy. Goss \& Lindquist (1995) criticize the functional approach becoming policy-making orthodoxy for international migration in a time when developing countries are trying to reduce or redirect the flow of rural-urban migration due to its apparent disequilibrating tendencies and inefficiencies. This fact is reflected in the migration policy of many Asian countries that encourage their citizens to seek income opportunities overseas with the belief that the host country is provided with a supply of cheap labor while the sending country gains foreign exchanges in the form of remittance. This also gives a relief from domestic unemployment and acts as a political safety valve, though temporarily (Ellerman, 2005). It is anticipated, however, that the increased rates of domestic savings and the deployment of new skills by the returning migrants will convert into productive investment and creation of new job opportunities in the long run.

The reality in most of the labor sending countries in the third world does not conform to the predictions of neoclassical model that views migration as a temporary phenomenon likely to decline with the equilibrating effects through 
development in the sending countries. From a review of empirical studies on Philippines and some other developing countries, Goss \& Lindquist (1995) have identified three inconsistencies with this model: first, overseas earnings are invested less in productive enterprises than expended to repay debts, purchase land and housing or daily subsistence needs, and finance conspicuous consumption reflecting the better off status of the migrants and their families in the home country. Such patterns of spending remittance do not generate economic develop and new job opportunities, but rather often create inflation. Secondly, the ironical fact is that most of the migrants have already been employed in their home country before moving out. Thus, migration seems to have little impact on domestic unemployment reduction, or sometimes even exacerbating the situation. Thirdly, the wages in the Philippines have not increased as a result of huge overseas migration, nor has employment abroad lead to the acquisition of new skills since most migrant take-up low-paying, unskilled jobs shunned by the workforce of the host country.

\subsection{Structural Approach}

The structural approach focuses on the macroeconomic processes that produce socio-spatial inequalities and constrain the life chances of individuals as members of specific social classes in particular place. It explains migration in terms of the exploitative political and economic relationship between sending and receiving countries. This macro-social approach does not conceptualize migration as merely the result of the aggregation of individual decisions and actions, but rather the product of objective social and spatial structures that produce the necessary conditions for labor migration. A review of literature generally identifies three closely related but distinct structural models of international labor migration. These are: neo-Marxist dependency theory, world system theory, and modes of production theory.

\subsubsection{Neo-Marxist Dependency Theory}

Emanating primarily from the Latin American scholars, this theory argues that labor migration is stimulated by the uneven spatial development resulting from colonial and neocolonial political and economic relationships between the developed capitalist economies and their underdeveloped peripheries. As such, migration is viewed not only as a response to the existing imbalanced situation, but also a social process that reinforces it. Migration, as Amin (1974) argues, represents a spatial transfer of value greater than the return to the individual in remitted wages, because it selectively captures only the most productive and educated workers from the underdeveloped countries or regions. This view is best represented by the dual labor market theory (Piore, 1979) which argues that international labor migration is caused by a permanent demand for immigrant labor inherent in the economic structure of developed nations. Structural inflation, declining status associated with lower-level jobs, economic dualism and shifting demographic trends have generated a gap in the lowest strata in the labor market in developed countries. Being guests in these societies, the migrant workers from the underdeveloped countries are attracted to those jobs comparing the absolute value of their wages in developed countries with that in their home country where it improves the migrants' status and economic condition. However, scholars in this approach are criticized for their focus on the historical processes and exploitation through unequal exchanges rather than the existing social relations of production in the home country (Kearney, 1986). They are also seen to be reluctant to the differences among the source countries as well as the contradiction between different social classes within them (Wood, 1982).

\subsubsection{World System Theory}

The world system theory addresses, at least partially, the first problem with the dependency model in explaining the existing social relations in the source countries. Building on Wallerstein (1974), this model posits that "the penetration of capitalist economic relations into peripheral, noncapitalist societies creates a mobile population that is prone to migrate abroad" (Massey et. al., 1993: 444). According to this theory, migration is a natural outgrowth of the dislocations and disruptions caused by capitalist development. With the expansion of capitalism over larger parts of the world, the influence and control of market is also extended over land, raw materials and labor within the peripheral regions, creating a vast mobile population. The material and ideological links along with the investment capital usher these dispossessed masses from the underdeveloped countries to the global cities in developed countries to take up low-paying jobs at the bottom of the occupational hierarchy (Sussen 2001). However, this approach fails to take into account how distinct noncapitalist social relations in the periphery affect the transfer of value incorporated in the migrant workers' labor power (Goss \& Lindquist, 1995).

\subsubsection{The Modes of Production Theory}

With an acknowledgement of the historical significance of colonialism, this approach argues that precapitalist forms of productions often coexist with capitalism under conditions of uneven development in the peripheral regions. As a result, individuals and households are caught up in various forms of production relations and may be found in motion between them, and hence necessitating migration. In such situations, value is channeled through 'super-exploitation', where individuals work in sectors of capitalist market but part of the reproduction of their labor is provided by noncapitalist sectors (i.e. extended family, or government subsidized education and healthcare services). Shrestha (1988) shows how the penetration of capitalist social relations in rural Nepal dislocates the farmers from agricultural land, forces them to 
turn into wage laborers depending on the sale of their labor power. The scarcity of capital and underdeveloped nonfarm sectors result in extremely limited alternative employment opportunities, and consequently, many migrate- particularly in the face of rapid population growth- to the urban regions or if affordable, to developed countries.. However, members of the local elite are seen to choose migration as a means to attain more political and market authority and to diversify risk. In a study of Filipino construction workers in the Middle East, Gibson and Graham (1986) identify the emergence of the New International Division of Labor that attempts to reduce production costs by espousing favorable conditions of production, particularly cheap, unorganized labor. Given the inability in certain production system to relocate capital from its specific sites of production, i.e. agriculture, construction, retail and social services, multinational capital draws workers from underdeveloped countries like Philippines. Hence, they argue, the migration of Filipino workers to Middle East (construction and service), Europe (domestic and other services), Japan (entertainment and cultural works) and East Asian NIEs (domestic services).

It is argued that the mode of production approach explains the role of migration in the historical process of articulation of the domestic economy with the capitalist economy (Kearney, 1986). Although the penetration of capitalist social relations undermine domestic economy, the reproductive sphere remains at least partly integral within the domestic economy which bears the responsibility for the long-term reproduction of migrant labor. Thus, the tie of exploitation shifts from the wage laborer to the households and community and a concern with the microeconomics of kinship relations that ensures the reproduction of labor under conditions of articulation. It is also argued, given the sensitivity of this approach to local processes and the productive and reproductive strategies of households and communities, that "this provides some bridges for spanning the gulfs in levels of analysis by theorizing migration, production and reproduction at the local level, shaped by and as a response to, global economic conditions" (Kearney, 1986:352). In spite of its attention to the local agency and some other valuable theoretical and empirical contributions, this approach fails to articulate the concepts of household and community that play the vital of reproduction of migrant workers (Goss \& Lindquist, 1995).

In sum, it can be argued from the discussion above that both the functional and structural approaches reduce migration to mere responses of individuals to the wage differential determined by the market forces, or inequality between the home and host countries stimulated by a difference in the level of socio-economic development. As such, migration connotes the circulation of labor power embodied in the individuals and thus the social, cultural, political and institutional dimensions of the phenomenon are subordinated to an economic logic (Schiller et. al., 1992). The situation exacerbates with regard the conflicting and contradictory conclusions that these two approaches draw. While functional approach conceives of migration as a temporal process and a way towards equilibrium with the economic development of the source regions by means of remitted wages and new skills embodied in returnees, thus making migration a 'win win game', structural approach considers migration as a somewhat more permanent phenomenon and a 'zero sum game' (Tanner, 2005) that propels underdevelopment in the source regions and reinforce it, and hence the widening of the existing inequality between the developed and underdeveloped regions.

\subsection{Integrative Approaches to International Migration}

The theoretically fragmented literature and the conflicting conclusions that conceptualize migration as either the cumulative result of individual decision or a manifestation of a social structure imposing behavioral constraints on individuals provoke the need for a comprehensive view of the migration process and its role in development examining concurrently the origin and destinations, and reflecting on both historical and contemporary processes. Examples are the new economic approach, the system approach and the network approach.

\subsubsection{The New Economic Approach}

By incorporating the larger social unites, typically households and communities, that are interested in risk minimization rather than in profit maximization, the new economic approach elaborates the decision making role of microeconomic functional models (Stark, 1991). This approach conceptualizes migration as a household strategy focused not so much to maximize income as to diversify sources of income, in order to minimize risks- i.e. unemployment, loses of income, crop failure, etc. and slacken constraints, given the imperfections that plague credit and insurance market in sending country (Stark and Tylor, 1989). The strength of this approach lies in the fact of its integration of migration decision making with migrants' remittance behavior and households' remittance use. Since the primary motivation for migration is to overcome risk and credit constraints on local production from market failures, migration and remittance should positively influence local income-generating activities. This approach also broadens the analysis of migration by placing it in broader community context, especially associating household's migration decision to its relative position within the income distribution of the community. However, the premises of this model depend on the fact that other things- i.e. market imperfections- remain equal and unchanged. Unfortunately, such other things are not equal or static and thus the predictive power of this approach suffers failure to certain extent, especially in explaining the patterns of remittance expenditure as observed- for instance, in Bangladesh where the remittances receiving families are found spending on activities other than income generation (Rahman, 2000). It is also difficult to figure out the influence of 
market imperfection and risk on international migration from the role of other income and employment variables (Massey et. al., 1993) and thus rendering empirical investigation difficult, if not impossible.

\subsubsection{The Migration Systems Approach}

The systems approach focuses on the stable international migration systems that comprise both the macro and micro linkages between different places. These systems are characterized by relatively intense exchange of goods, capital and people between certain countries and less intense exchanges between others (Massey et. al., 1993). While the macro-level relations include political systems, economic dominance/dependency, immigration policy and cultural/linguistic associations, the micro-level relations include friendship and kinship resulting from the geographic dispersion of populations. Accordingly, migration is conceptualized as sequential process of decision making, transition and adaptation by the individual made within the context of general political-economic and specific social relationships at each stage (Fawcett \& Arnold, 1987).

Both the aforesaid models emphasis 'household' as the unite of analysis which falls somewhere between the individual and society, thus exposing potential as "a means to account for both the aggregation of the actions of individual decision makers and the structuring of constraints upon behavior by the global or national economy" (Goss \& Lindquist, 1995:326). According to these approaches, the household unite is conceived as it is in the conventional economics and sociology of developing countries, that is, the primary unit of production and reproduction characterized by single utility function and acting in the pursuit of collective goal. As Boyd argues, "migration of individual members or the entire household unit represents a strategy at the household level to achieve a fit between resources such as land or capital, the consumption needs of its members and the alternatives for generating monetary and non-monetary income" (Boyd, 1989:645). Thus migration results from the 'very precise calculation' of utility and collective decision making by the household unit in order to respond to the contingencies emerging from external environment and/or international configuration of the household unit so as to diversify income and minimize risk, and to enhance capital accumulation.

However, Goss and Lindquist (1995) have identified some problems with such a conceptualization of household unit. First, poor households often fail to reflect the strategic notion of household envisioned by the literature and are also least able to draw out members' cooperation due to their limited power to apply sanctions on those turn aside. Secondly, the substitution of the notion of the rational, calculating individual by the rational, calculating household obscures the social processes behind decision making and individual interests within the household, and thus repeats the errors of voluntarism (or altruism) in neoclassical approaches to social explanation. Thirdly, from a feminist point of view, such a unified notion of the household mystifies the intra-household stratification by gender and generation, and chokes out the voices of the underpowered- usually the female and young. Finally, the meaning and determination of primary loyalty makes it difficult to precisely identify the household as 'decision-making unit' since distant kin or non kin members are sometimes found sharing the daily budget. They further argue that while such an isomorphic conception of household unit is applicable in the Western societies, it does not fit in more traditional societies in the third world. Thus ethnographic studies observe individuals pursuing their own individual interests, sometimes compromising the collective interest, and sometimes overtly confronting it (Phillips, 1989). Others have also noted that the prospects of adventure are particularly important for young members- both male and female (Rigg, 1989), and that individual perceptions of relative deprivation rather than household consumption may stimulate migration (Stark, 1984).

\subsubsection{Migrant Network Theory}

Massey, et al. (1993) attempts an extensive review of the diverse approaches that have been used in the study of international migration and builds up a new approach called 'migrant network theory'. This network concept has not come out from network analysis, but rather from the studies of social adaptation that examine the effect of massive population shifts within Third World nations after World War-II (Gurak \& Caces, 1992). According to this theory,

"migrant networks are sets of interpersonal ties that connect migrants, former migrants, and nonmigrants in origin and destination areas through ties of kinship, friendship, shared community origin. They increase the likelihood of international movement, because they lower the costs and risks of movement and increase the net returns to migration" (Massey et al.,1993:448).

The migrant networks embody a kind of social capital that individuals can draw on to lower the cost and the extent of uncertainty involved in the process of international migration. As networks establish links between individuals in both the origin and destination areas, migrants are able to benefit from these connections in both areas. Researchers observe that networks provide would-be migrants information about available destinations, contacts with the gatekeepers, and sometimes with funds for travel and other fees. At the areas of destination, networks provide assistance in securing housing and employment, a means of cultural continuity and communication with the community of origin.

Much of the scholarship on international migration recognizes the existence and functioning of strong ties among the migrants that constitute migrant networks. Under the auspices of improved transportation and communication technologies, migrants are now capable of maintaining continued relations with their community members back in 
home country (Glick-Schiller, et al., 1992). As such, most of the migrant communities now construct and maintain connections beyond nation-states that contain flow of money, information, and other resources along with people across borders and entail one-time return migration, repeat migration, and circular migration, as well as migration of settlements (Waldinger and Fitzgerald, 2004).

The network approach posits that the connections are essentially based on the membership within a particular kin-group, community or locality. However, migration networks do not include every individual in a certain community or locality. Goss and Lindquist (1995) observe in Philippines that migration networks function selectively in granting access to the members in the community. Krissman (2005) criticizes the restrictive nature of composition and function of networks and observes participation of 'exogenous actors' in the migrant networks both in the home and host countries which Massey-model overlooks by designating as 'nonmigrants' or 'friends of migrants'. He divides these 'outsiders' or non-hometown participants in two groups: one group of actors consists of individuals working for any of a number of government agencies engaged in formal recruitment; the other group includes promoters and beneficiaries of informal recruitment, i.e. employers and their supervisory staff, various types of intermediaries and other agents who receive pay and/or sinecures. He also criticizes the notion of symmetrical relations among network participants in this approach and argues that much of these relations are asymmetrical that facilitate functioning of the whole network. Collyer (2005) in his study of the Algerian Asylum-Seekers observes that the pre-entry and post-entry controls imposed by the state of France have restricted the functioning of the existing networks for new migrants, and these individuals, as a consequence, creatively seek recourse to weak ties- i.e. smugglers, or Muslim communities from other countries- to manage relocation to the UK. Aguilera (2005) finds while the patriarchal family structure keeps Puerto-Rican women from actively engaging in the networks, the weak ties with individuals out side of the network helped them get better jobs.

\section{Migration and Development}

By now, it has been recognized by scholars that international migration has profound impact on development in the receiving countries through remittances. Taylor et. al. (1996) argue that the direct effect of remittances is the contribution to national income, while the indirect effects include the shift in production stemming from the withdrawal of labor, easing foreign exchange constraints, and enhancing domestic savings and investments. Jennings \& Clarke (2005), emphasizing on the 'multiplier impact' of remittances in Nicaragua, observe that a significant portion of remittances are saved, invested in family-business and agricultural inputs, and education and health all of which have profound influence on national development. De Haas (2005) also agrees that remittances contribute significantly to development and living conditions in sending countries. However, he comments that the recent 'remittances euphoria' is an exaggeration, because unattractive investment environment and restrictive immigration policies which interrupt circular migration prevents the high development potentials of migration from being fully realized.

\subsection{Migrants and Development}

Going beyond the classic economic logic of greater income, Brown (2006) observes that migrants move abroad and remit money for various other reasons and these motives have considerable political implications, too. As such, realizing the development potentials of remittances need to address all these complex dynamics of motives and usages of remittances both in the host and home countries. In an attempt to identify the complexity of motives and usage involved in remittances practices, Goldring (2004) finds three different types of remittances with different motives: remittances as wage or salary that is sent by the circular migrants or sojourners to support relatives; remittances as investment that is sent during a trip or brought back upon return and spent on land purchase or building a home; and remittances as capital that is deliberately saved to invest in specific productive venture. She argues that development has to be defined more broadly to include social, community, and political dimensions and the influence that different types of remittances have on each of these dimensions. From a transnational perspective, Sana and Massey (2005) observe in their study of the patterns of remittances sending to the home communities in Mexico, Dominican Republic, Nicaragua, and Costa Rica that the rationale behind remitting involves kin solidarity, reciprocal obligations, yearning for social recognition, and profit seeking. As such, remittances may be used, not only for risk diversification or investment, but also for family subsistence, human capital investment, small- and middle-scale businesses, or land purchase, or other social intangible.

\subsection{Institutions and Development}

The remittance practice does not only involve motives of the migrants who send money back but also other agencies concerned with development according to their own interests. As (Seddon, 2004) observes, the government aims to have a control over the flows of remittances because it wishes to fund its foreign exchange with the tax acquired from these flows, the multilateral development agencies (i.e. WB, IMF, ADB, etc) are interested because these flows outstrip FDI and foreign aid, and thus seem hold potential for constricting their role in development, while some other agenciesboth political and nonpolitical- who suspect a considerable amount of remittances flows going to funding for terrorist and other illegal affairs want to hold back such infamous funding. Contrary to the much acclaimed idea of temporary 
labor migration as a developmental path that many national governments espoused after WW-II, for example, TurkeyEllerman (2005) identifies some adverse impacts of such migration on the development of the sending countries. He argues that migrants are not the poorest of the sending regions and they do have certain human and social capital, and also remove financial capital when they move out. This leads to a loss in absolute terms in the sending regions, and the selective nature of labor migration further exacerbates this loss. He also argues that the labor-sending countries in the developing south are fraught with multiple social problems and observe calls for reform frequently. The ruling elites in these countries use migration as an efficient tool to circumvent the pressure for reform with a view to perpetuate their domination. However, he also identifies some potential, though limited in scope, of the return migration in setting up non-agricultural rural development.

\subsection{Transnationalism and Development}

Although scholars are yet to agree on the developmental impact of migration in the labor sending countries, researchers in the field of transnationalism strongly advocate the belief in remittances, including both monetary and non-monetary forms of remittances, as a potent source of development. Defining transnationalism as the grassroots activities conducted across national borders by actors in civil society, independent of, and sometimes in opposition to official directives and rules, Portes, et al (2007) observe a novel element in the contemporary processes of migration- the frequent and durable participation of immigrants in the economic, political, and cultural life of their countries, which requires regular and frequent contacts across national borders. Contrary to the earlier notion, this study finds that transnational activities are more common among the better-established, better-educated, and wealthier migrants. They also argues for an impressive possibility of these transnational activities to aggregate into an important feature of the contemporary process of "counter-globalization" that runs opposite to the multinational logic of corporate capitalism. Hence these activities promise opportunities at least to slow down the partition of the world into the increasingly rich and the desperately poor.

Overall, the recent development discourse is inundated with studies that applaud the positive impacts of remittances on national development when the improvements in public goods i.e. health and education are considered. However, these improvements cannot be considered as positive contributions towards national development for these only leads the whole country to the trap of further dependent on international migration. From a perspective of "common good", Deneulin (2006) suggests that a sound national policy that generates conditions for common goods to exist is a prerequisite to ensure the sustainable positive impacts of remittance on national development, which will allow the individuals not only to enjoy the goods to realize themselves, but also will empower them to create those goods for themselves as a part of their community life. Common goods do not lie in the sum of the social arrangements which allow individuals to be healthy or educated (like free primary education or basic services), but lies in the conditions of possibility for these arrangements to emerge (like the norm that dictates that everybody has the right to have education and health services). Therefore, favorable national policy that allows all individuals to participate in community life with sufficient power to generate common goods is crucial to ensure the positive impacts of remittances on national development.

\section{Conclusion}

International migration has been exhibiting remarkable potential for development for the labor sending countries in the third world because of the notable increase in the flows of remittances nowadays. However, this potential does not automatically translate into reality. What is required to grasp this possibility for development is to take into consideration all the dynamics of structures and functions, possibilities and limitations that the migrants are exposed to and act upon.

It has already been recognized by scholars that considerable development in our understanding of the perplexities of migration has been attained (Arango, 2000). Yet, the diversity of the forms and processes revealed by empirical studies and the dynamism manifested by the ever-changing context thwart theory building. Perhaps the greatest intricacy in migration study lies in its extreme multiplicity, in terms of forms, types, processes, actors, motivations, socio-economic and cultural contexts, and so on. In such a confounding state, a careful investigation into the whole issue of migration, remittances and development of the sending countries has become an imperative, especially for the scholars in the labor sending countries in the south which aspire to develop by prudent use of migration remittances.

\section{Bibliography}

Agulera, M. B. (2005) “The Impact of Social Capital on the Earnings of Puerto Rican Migrants," The Sociological Quarterly, 46:569-592.

Amin, S. (1974). "Introduction,” Modern Migration in West Africa. (Ed) Amin, S. London: Oxford University Press.

Arango, J. (2000). “Explaining Migration: A Critical Review,” International Social Science Journal, 165:283-296. 
Boyd, M. (1989). "Family and Personal networks in International Migration," International Migration review, 23(3):638-670.

Brown, S. S. (2006). “Can Remittances Spur Development? A Critical Survey”, International Studies Review, 8: 55-75.

Collyer, M. (2005). "When Do Social Networks Fail to Explain Migration? Accounting for the Movement of Algerian Asylum-Seekers to the UK," Journal of Ethnic and Migration Studies, 31(4):699-718.

Dahinden, J. (2005). "Contesting Transnationalism? Lessons from the Study of Albanian Migration Networks from Former Yugoslavia,” Global Network 5 (2):191-208.

De Haas, H. (2005). "International Migration, Remittances and Development: Myths and facts", Third World Quarterly, 26(8): 1269-1284.

Deneulin, S. (2006). "Individual Well-being, Migration Remittances, and the Common Good" in The European Journal of Development Research, 18(1): 45-58.

Ellerman, D. (2005). "Labor Migration: A Developmental Path or A Low-Level Trap?," Development in Practice, 15(5): 617-30.

Fawcett, J., and F. Arnold (1987). "Explaining Diversity: Asian and Pacific Migration System.” In Pacific Bridge: The New Immigration from Asia and the Pacific Islands. Eds J. Fawcett and B. Carino. New York: Center for Migration Studies.

Gibson, K. and J.Graham (1986). "Situating Migrants in Theory: The Case of Filipino Migrant Construction Workers," Capital and Class 3:131-149.

Goldring, L. (2004). "Family and Collective Remittances to Mexico: A Multi-dimensional Typology", Development and Change, 35(4): 799-840.

Goss, J., and Bruce Lindquist (1995). “Conceptualizing International Migration: A Structuration Perspective," International Migration review 29(2):317-351.

Gurak, D. T., and F. Cace (1992). "Migration Networks and the Shaping of Migration Systems." In International Migration Systems. Ed. M.M. Kritz et al,. Oxford: Oxford University Press.

Harris, L. R., and Micheal P.Todaro (1970). "Migration, Unemployment and Development: A Two-Sector Analysis," American Economic Review, 60:126-142.

IFAD (2007). Sending Money Home: worldwide remittances flow to developing countries, Rome: International Fund for Agricultural Development (IFAD).

Jennings, A. \& M. Clarke (2005). “The Development Impact of Remittances to Nicaragua”, Development in Practice, 15(5): 685-691.

Kearney, M. (1986). “From Invisible Hand to Visible Feet,” Annual Review of Anthropology, 15:331-361.

Krissman, F. (2005). "Sin Coyote Ni Patron: Why the 'Migrant Network' Fails to Explain International Migration," International Migration Review, 43(4):167-194.

Lewis, O. (1954). Five Families. New York: Basic Books, Inc.

Massey M. D. et al. (1993). "Theories of International Migration: A Review and Appraisal," Population and Development Review, 19(3):431-466.

Nohria, N. (1992). "Introduction", in Networks and Organizations: Structure, Form and Action, N. Nohria and R.G. Eccles (eds.), Boston: Harvard Business School Press.

Phillips, L. (1989). “Gender Dynamics and the Rural Household Strategies," Canadian Review of Sociology and Anthropology, 26(2):294-310.

Piore, M. (1979). Birds of Passage: Migrant Labor in Industrial Societies. Cambridge: Cambridge University Press.

Portes, A. et al (2007). "Immigrant Transnational Organizations and Development: A Comparative Study", International Migration Review, 41(1): 242-281

Pries, L. (2004). "Determining the Causes and Durability of Transnational Labor Migration between Mexico and the United States: Some Empirical findings,” International Migration 42(2):3-38.

Rahman, Md. Mizanur (2000). "Emigration and Development: The Case of a Bangladeshi Village," International Migration, 38(4):109-130.

Ranis, G., and J.C.H. Fei (1961). “A Theory of Economic Development,” American Economic Review, 51:533-565. 
Rigg, J. (1989). "International Contract Labor Migration and the Village Economy: the Case of Tanbon Don Han, Northern Thailand." Paper of the East-West Population Institute, No.112. Honolulu, HI.

Sana, M \& D. S. Massey (2005). "Household Composition, Family Migration, and Community Context: Migrant Remittances in Four Countries", Social Science Quarterly, 86(2): 509-528.

Sassen, S. (2001). Global City ( $2^{\text {nd }}$ ed). Princeton: Princeton University Press.

Schiller, N. G., et al. (1992). "Transnationalism: A New Framework for Understanding Migration," Annals of the New York Academy of Science, 645:1-24.

Seddon, D. (2004). "South Asian Remittances: Implications for Development", Contemporary South Asia, 13(4): 403-420.

Stark, O. (1991). The Migration of Labor. Cambridge: Basil Blackwell.

1984 "Discontinuity and the Theory of International Migration," in KYKLOS 37(2):206-222.

Shrestha, N. (1988). "A Structural Perspective on Labor Migration in Underdeveloped Countries," Progress in Human Geography, 12(2):179-207.

Tanner, A. (2005). "Brain Drain and Beyond: Returns and Remittance of Highly Skilled Migrants”. Working Paper\#24, Global Commission on International Migration, Geneva.

Taylor, E.J., et. al.(1996). "International Migration and National Development", Population Index, 62(2): 181-212.

Waldinger, R. and D. Fitzgerald (2004). "Transnationalism in Question”, American Journal of Sociology, 109(5): 1177-95.

Wallerstein, I. (1974). The Modern world System: Capitalist Agriculture and the Origins of the European World Economy in the Sixteenth Century. New York: Academy Press. 


\title{
Study on the Ban on Free Plastic Bags in China
}

\author{
Xiufeng Xing \\ School of economy and trade \\ Qingdao Technological University \\ Qingdao 266520, China \\ E-mail: xxfqd@126.com
}

The research is financed by Shandong Social Science Planning Programme.No.08JDD013

\begin{abstract}
On Jun $1^{\text {st }}, 2008$, the production, sale and use of plastic shopping bags 0.025 millimeters thick or thinner will be banned in China under a State Council decree, and retailers will be prohibited from providing customers with free plastic bags, which is called by the general public the ban on free plastic bags (or plastic limit order). Since the implementation of the policy, the use of plastic bags has decreased dramatically, meanwhile, the public awareness of environmental protection has also been enhanced. Nevertheless, there still leaves much to be desired, for instance, some plastic bags provided to the consumers do not meet the national standards, and auxiliary bag without carrying function has been double-charged. According to Polluter pays principle, coupling with the means of product charge, the paper analyzes the impact of the ban, evaluates on its results and then puts forward some relevant measures on the above basis.
\end{abstract}

Keywords: Ban on free plastic bags, Polluter pays principle, Corporate social responsibility, Resources-saving and Environmental-friendly society

\section{Analysis on the ban on free plastic bags in China}

Chinese ban on plastic bags consists of two regulations: the compulsory national standard of plastic bags and the management of compensation for the use of plastic shopping bags in retail establishments. The former stipulates that the plastic bag should be no less than 0.025 millimeters thick, while the latter requires that the selling price of the plastic bags be higher than operating costs. In addition, on Jul $10^{\text {th }}, 2008$, Chinese Ministry of Commerce, National Committee of Development and Reform, and State Association of Industry and commerce made a joint supplementary provision which expand the scope of application, according to which restaurants and bookstores are included.

\subsection{Analysis on the relationship between product charge and use of plastic bags on the basis of polluter pays principle}

The Polluter Pays Principle (PPP) is a principle where the polluting party pays for the damage done to the natural environment. The basic tenet of PPP is that the price of a good or service should fully reflect its total cost of pollution control. The PPP is the chief economic principle for environmental policy including product charges. With respect to product charges, this generally refers to the charge for a product that generates emission or discharge in the course of production and consumption to raise the price level. The purpose is to reduce product use and manufacture less pollution product and raise the capital for pollution prevention or treatment. Tax difference is a special case of product charges which means to make additional positive or negative charges on the product levied according to its different environmental impact.

In theory, through the use of price signals and tax difference in accordance with PPP, it is conductive to change people's plastic bags dependence gradually, form the habit of reuse plastic bags, and thus reduce the discharge and harness cost of "white pollution".

\subsection{Brief analysis on the enforcement and its policy effects on the ban on plastic bags}

If carried out effectively, the ban will make a fundamental impact on all aspects of China economy and society: from the perspective of micro level it will change the public awareness of environmental protection; from the perspective of middle-level, it will change dramatically to the production industry of plastic bags; from the perspective of macro level, namely from the perspective of the whole society in China, it will definitely help the construction of resources-saving and environmental-friendly (or eco-friendly)society and sustainable development. In other words, it can improve the ecology system and save a lot of expenditure on pollution control, in the meantime, the public awareness of environmental protection and corporate social responsibility will be enhanced, which are the main intention of the 
policy. The subject on corporate social responsibility has been studied previously. (Carroll, 2007, pp.122-131).

\section{Evaluation on the results of the ban on free plastic bags}

\subsection{Evaluation of the results on the ban on free plastic bags}

Stage results obtained are as follows. (1) Wang (2008,p.3) reported that the ban worked well in circulation in shopping malls and supermarkets, and the total use of plastic bags had reduced two-thirds roughly by Jul $12^{\text {th }}$. (2) Public awareness of environmental protection has been somewhat improved than before, customers or consumers come to accept the charge on plastic bags and bring their own carrying bags with them when shopping.

\subsection{Problems existing}

The outstanding problems include: (1) Markets is the most difficult place to carry out the policy. Traders often have 2 kinds of plastic bag, one of which meets the national standard and is only used to cope with the inspection, while the other is thinner than 0.025 millimeters which should have been prohibited from providing to consumers. Compared with the supermarkets which offer standard plastic bags, it is the markets that provide consumers free Ultra-thin plastic bags that become the body of the "white pollution". (2) Plastic bags provided by a small number of commercial enterprises are far from the national standard. Though Chinese Ministry of Commerce, National Committee of Development and Reform, and State Association of Industry and commerce made a joint supplementary provision on Jul $10^{\text {th }}, 2008$, which stipulated that from October of 2008, plastic bags without specific Logo should be terminated. At present, some business enterprises still use the sub-standard auxiliary bag (or pre-packaging roll bag), for example, the bags have no such Logo as "for food use", "QS", enterprise information, and the thickness is thinner than the required standard. Besides, there exists problem like repeated charges (or double-charged) on the consumers on standard bag, the higher the price of the goods, the more charges paid shifted to the business. The expensive fresh good is a good case in point, for the weight of bags hasn't been subtracted from the total weight. Obviously, the purchase cost of the bags has been shifted to the customers covertly and the retailers make money from the deal accordingly. (3)There is lack of effective substitute for plastic bag. Non-woven cloth bag is now accepted widely. Actually non-woven cloth is plastic which is not biodegradable and will result in huge consumption on non-renewable resources such as oil. It can be used as transitional goods but should avoid excessive use so to prevent it from being another source of white pollution after plastic bag. (4) The ban wants for supporting measures. The single-fee system can't guarantee the effective fulfillment of the goal; both consumer and shop are bound to pay for the environment. To all-round implement the ban on free plastic bags, supporting measures on controlling plastic pollution should be released accordingly.

\section{Policy suggestions on the perfection of the ban on free plastic bags in China}

The purpose of the release of the ban on free plastic bags is to improve the awareness of the public on environmental protection, eliminate white pollution, and build up the resources-saving and eco-friendly society gradually. To fulfill the aim, several measures including restriction, substitution and reclamation must be taken.

\subsection{Implement the form of deposit or refund to encourage or restrain the production and use of plastic products}

As mentioned above, one role of product charge is to reduce the product use and the other is to raise the fund. Actually tax difference can be views as a special case of the former, whose purpose is to generate stimulation function by positive or negative charge to raise or cut the price level. Given the real situation of the ban, the paper suggests that tax difference be carried out at an appropriate time to intensify the policy impact. The deposit-refund system originally means when the potentially pollutant product is sold, a deposit should be charged simultaneously, and the deposit will be refunded only after the buyer return the residues to the designated collecting system so to avoid pollution. Presently China only recollects solid residues such as beer bottle, but to the author's viewpoint, the deposit-refund system can also be extended to the recyclable plastic bags. By doing so we can improve the environmental protection awareness of the public step by step without increase the burden on consumer, while the social cost of the system is shared by government, production and commercial enterprises to shoulder the social responsibility. For the purpose of harness the white pollution and the realization of the resources-saving and eco-friendly society, Chinese governments should take appropriate way to subsidize those manufactures which meet the environmental protection standard in production and research link and those reclaim waste plastic enterprises. Meanwhile, repeated charges (double-charged) on the consumers should be rectified seriously.

\subsection{Develop the qualified substitutes as soon as possible}

Qualified substitutes must be developed as quickly as possible, as to plastic bags which don't meet certain standard, particularly the auxiliary bag, supervisions and punishment must be strengthened until the product is standardized. Fu (2008,p.13)has reported that the qualified substitutes include biodegradable plastic bag, qualified cotton bag with carrying function and paper bag made of recyclable paper. At present, paying for the plastic bag by general public is the only way to practice the ban on free plastic bag, while other measures such as using the tax preferential policy to manufacture biodegradable plastic bag and qualified cotton bag haven't been introduced. Some experts point out that 
only a small portion of plastic bags can be partially biodegradable under certain condition. The totally biodegradable plastic bag is less competitive than the non-biodegradable or partially biodegradable ones for its high-tech, high production cost and small scale. In this case, government should issue relevant policy to encourage and stimulate the research and produce of the totally biodegradable plastic bag.

\subsection{Strengthen the life cycle assessment of plastic bags}

Life cycle assessment is the assessment of the environmental impact of a product in a cradle-to-grave approach. It is also known as life cycle analysis. Through life cycle assessment a comparison can be made of the environmental performance of products and services in order to choose the least harmful one. The theory of life cycle assessment has been studied previously. (Theo de Bruijn, 2007, pp.312-313).According to this theory, through the life cycle analysis all the pollution from the stage of production, use, reclamation of plastic bags should all be taken into account. It is impossible to eliminate plastic bag in China for the time being, what can be done is to change people's attitude towards plastic bag progressively through market-oriented approach to reduce the use, say make recharge or refund to those carrying his own bag when shopping. As for the reclamation, it is the producers and retailers that are responsible for the whole cycle of the product; this is also the key of the polluter pays principle. It is crucial to build up the complete environmental management system.

\subsection{Make efforts on environmental education for general public in China}

The environmental education in China starts late and the public are not actively participated as those in developed countries. According to a survey conducted in 2007 by China Environmental Culture Promotion Association to 9011 residents aged from 18 to 65 cross 31 provinces nationwide, although environmental pollution ranked second among the nine most concerned questions, $66.9 \%$ of people argue that China confront serious environmental problems, only $13.7 \%$ think they play an important role in the process of environmental protection, nearly half people don't think they are of great importance. The survey shows that awareness on environmental protection is lacking for Chinese people and the responsibility on environmental protection rely much on government. Though the ban on plastic bag has been put into practice for several months, some consumers still lack the consensus on the relationship between the meaning of the ban on free plastic bag and environmental protection and the use of the charge. After carrying out their social responsibility respectively, government and relevant enterprises should seize the opportunity to make propaganda for environmental protection, improve the public's awareness, and narrow the environmental education gap between history and present so to speed up the construction of resources-saving and eco-friendly society.

\section{References}

Fu, Zimei. (2008). Only With Various Measures Can the Aim of Ban on Free Plastic Bag Be Fulfilled. People's Daily. 16 June 2008.

Wayne, Visser, \& Dirk, Matten (2007). The A to Z of Corporate Social Responsibility. In Carroll, Archie, Corporate Social Responsibility. England: John Willey \& Sons, Ltd. pp.122-131.

Wayne, Visser, \& Dirk, Matten (2007). The A to Z of Corporate Social Responsibility. In Theo de Bruijn, Life Cycle Assessment. England: John Willey \& Sons, Ltd. pp.312-313.

Wang, Mingfeng. (2008). One Month after the Implementation of the Ban on Free Plastic Bag: "How Much Does the White Pollution Reduce?" People's Daily Overseas Edition. 12 July 2008. 


\title{
Challenges of Sustainable Physical Planning and Development
}

$$
\text { in Metropolitan Lagos }
$$

\author{
'Leke Oduwaye \\ Department of Urban and Regional Planning \\ Faculty of Environmental Technology \\ Olabisi Onabanjo University \\ Ibogun Campus \\ Tel: 234-80-5998-6906Ｅ-mail: leodwa@yahoo.com
}

\begin{abstract}
Currently the concept and adoption of sustainable development is one of the most commonly adopted in recent time. This paper therefore examines the application of the concept in the physical development process in Lagos State. It delves into literature on physical development efforts with discussions on planning legislations from the colonial period to the present time in Lagos State all aimed at resolving the myriad of problems confronting physical and environmental development in the state. Existing problems identified in the paper are classified into physical/environmental, cultural/sociological, managerial and legislative problems. Efforts towards sustainable development in other parts of the world are examined upon which suggestions are presented on how sustainable physical development can be achieved in Lagos State. Among specific suggestions offered by the paper include need for public participation in planning, capacity building, integration of information technology into planning practice and that planning should not be commercialized.
\end{abstract}

Keywords: Sustainable development, Physical development, Urban management, Environment, Planning, Development

\section{Introduction}

Sustainable development concept is a shift from mere sustained growth of a society to the level whereby such growth does not jeopardize the need of the future generation. Sustainable development is predicated on the articulation and incorporation of environmental and human needs in the pursuit of economic growth and development objectives (Aina, et al, 1992). It however has human, soci-economic and physical development dimensions. This paper is concerned primarily with the environmental and physical dimension of the concept of sustainable development.

Early literature on sustainable development did not lay much emphasis on physical dimension of the concept but it later became apparent that sustainability cannot be achieved in other facets of human development without the compliment of the physical environment. Thus sustainable physical development came into the debate. The early debates were on the need to create "green cities" (Leff, 1990). While some definitions linked social and economic development to environmental development, the World Health Organisation (1992) opined was that sustainable urban development should be concerned with the achievement of more productive, stable and innovative economies at low resource use. The definition by the World Commission on Environment and Development (1987) which emphasized meeting the "needs of the present generation without compromising the ability of future generation to meet their own needs became the popularly embraced definition. This paper attempts to evolve strategies for sustainable physical development in Lagos State, Nigeria.

The paper also presents inherent problems of physical planning and the place of physical planning in the attainment of sustainable development. The nature of physical and environmental problems in Lagos State are examined and existing policies and laws influencing physical development in Lagos are evaluated to ascertain their shortcomings. At the global level, city development and management strategies are examined with examples from the UN-HABITAT efforts in Colombo (Sri Lanka), Johannesburg (South Africa) and Santo Andre/ABC Region (Brazil).

The paper finally advances presents policy recommendations for Lagos State which include integration of socioeconomic goals with physical planning, unicity urban council and administration, e-planning and privatization of 
municipal services, and capacity building. Other recommendations include need for innovative approaches to environment management, exhibition and replication of best practices, annual awards for best practices and from development control (Permit) to development management.

\section{Sustainable development and human settlement}

Basically the concept of sustainable development is an attempt to articulate and incorporate environmental and human needs in the pursuit of economic growth and development. It is a process of change in which the exploitation of resources, investments, application of technology and institutional change are in harmony and enhances both current and future potential to meet human needs and aspirations (Adeyinka, 2005). The World Commission on Environment and Development (WCED, 1987) known as "Our Common Future" defines sustainable development as one that meets the need of the present without compromising the ability of the future generations to meet their own needs. More prominenced was given to the concept of sustainable development due to its emergence as one of the key resolutions of the United Nations Conference on Environment and Development (UNCED) held at Rio de Janeiro in 1992 and seconded by the Habitat Conference at Istanbul, 1996, who emphasis were on the need for sound environmental management in order to achieve the objectives of sustainable development.

At the global level Agenda 21 of the Earth Summit concern for sustainability of cities is at two levels, first at the global level it involve a range of issues concerning long term sustainability of the earth. Secondly, at the local level it involves the possibility that urban life may be undermined from within because of congestion, pollution, waste generation and their accompanying social and economic consequences.

Therefore sustainability in the broad area of physical development particularly, human settlements goes beyond conventional concerns as better social conditions, equity and better environmental standards, to issues such as concern for the impact of city-based production and consumption activities within and outside of the city (Adeniji, 1998). In the area of human settlement basic yardsticks of sustainability as established by the United Nations Centre for Human Settlements (UNCHS), 1996 are quality of life of inhabitants, scale of non-renewable resource use, extent of recycling and re-use, the scale and nature of renewable resource use, waste emanating from production and consumption activities as well as the impact of these wastes on environmental health and ecological systems. It adopts equity, socially responsive policies at both local and regional levels.

Specifically to achieve sustainable physical development in the less developed world the United Nations Conference on Environment and Development (The Earth Summit) Agenda 21 outlined eight programmes (Johnson, 1993) as outlined below:

- $\quad$ Promotion of adequate shelter for all;

- Improvement of human settlement management;

- $\quad$ Promotion of sustainable land use planning and management;

- $\quad$ Promotion of integrated provision of environmental infrastructure;

- $\quad$ Promotion of settlement planning and management in disaster-prone areas;

- $\quad$ Promotion of sustainable construction industry activities and

- $\quad$ Promotion of human resource development and capacity-building for human development.

\section{The place of physical planning in the attainment of sustainable physical development}

Physical planning like other areas of human endeavour has a credible role to play if sustainable physical development is to be achieved in any society. Urban planning has a central role in achieving sustainability (Wellbank, 1994). Though urban planning is a service and does not necessarily result directly into goods (Jiriko, 1998). It is judged by its product i.e. the outcome of the implementation of the planning provisions and programmes. It provides a plan-document to be used for physical development of the human habitat. By implication urban planning provides the led system for "building" the environment which is fundamental for the attainment of sustained control and development of the environment. Physical planning documents are vehicles for environmental development in the immediate term and set the direction of future growth. This is achieved through the use of a plan diagram backed-up with many legislative guidelines and administrative reports. Therefore sustainable physical development and management of human settlement hinges greatly on the effectiveness of physical development plans. This involve the reconciliation of land uses, provision of the right site for the right use, control of development, provision of facilities, services and public goods, preservation, protection and conservation of resources, preservation of heritage among others. Planning has a positive catalytic role to play (McDonic, 1986) towards achieving sustainable development. Planning provide a plan-led system. Such plans provide sustainable and best sites for various human activities. To a very high level, physical planning forecast and projects activities relationships through a planning process which involve evaluation, thus such plan stands a good chance of promoting sustainable development. 
In summary for societal stability and quality environment based on equity the need for physical planning can be outlined as follows (Adesanya, 1998).

- $\quad$ As physical development occurs, it most often have severe impacts on land and water resources and on the atmosphere, thus the need to take advance action to prevent potential damages.

- $\quad$ Pressure of population growth and urbanization most often have adverse implications on the supply of adequate shelter, infrastructure and services, therefore the need to plan for them.

- The poor most often do not have access to suitable shelter, and most often lack security of land tenure, the need to protect their interest.

To overcome these problems physical planning provide compatible land uses, ensures orderly development, equitable land distribution, provide functional and visually pleasing environment and satisfactory services in a sustainable manner.

\section{The Study Area and Associated Environmental and Physical Development Challenges}

Lagos State was created on May $27^{\text {th }} 1967$ when Nigeria was restructured into 12 States. Before this period Lagos municipality was under the administration of the Federal Government through the Federal Ministry of Lagos Affairs as the regional authority. The city of Lagos was under the Lagos City Council. The regions of Ikeja, Agege, Mushin, Ikorodu were under the former Western Region. Lagos State lies approximately between longitude $2^{\circ} 42^{\prime} \mathrm{E}$ and $3^{0} 42^{\circ} \mathrm{E}$ and latitude $6^{0} 22^{\prime} \mathrm{N}$ and $6^{0} 52^{\prime}$. The state is located on the South-Western part of Nigeria with the southern boundary of the state framed by about 180 kilometer along Atlantic coastline while the northern and eastern boundaries are framed by Ogun State. The Republic of Benin formed the western boundary. The state is the smallest state in Nigeria in land area with an area of about 358,861 hectares or 3577sq.km (Odumosu, 1999). This represents only 0.4 percent of the entire area of the country. This size accommodates about 10 per cent of the entire 140 million appropriate population of the country. The state is also the most urbanized in Nigeria (Ayeni, 1979). Only about 5 per cent of the state total population are of rural areas. This has serious consequences on land use planning in the state especially in urban areas. It also has great implication on infrastructure such as housing, water supply, storm drainage, roads, electricity, telephone, waste management and other socio-economic, cultural and administrative issues. Ironically except for Abuja, Lagos stand out to be the best served with infrastructural facilities in the country yet it is where these facilities are most inadequate due to the high population density. The state is also the most affluent in spite of its small size.

\subsection{Physical and Environmental Challenges in Lagos State}

Physical and environment challenges in Lagos can be viewed from both socio-economic and environmental perspectives. Increase in the urban population has resulted in the proliferation of slums and shantytowns. The proliferation of these shantytowns results in the unwieldy expansion of the urban centres, which poses a major planning problem as the provision and management of roads, drainage and sewage systems among other infrastructure proves very difficult. Furthermore, shantytowns generate a high rate of poverty, diseases and epidemics, environmental pollution, urban conflicts and crime as typified by Mushin, Ajegunle, Isale Eko, Makoko, Oshodi, Ojo and Orile amongst others. Addressing the problems of the Lagos Metropolis requires a holistic approach. The prevalent problems are physical/environmental, cultural/sociological and managerial. [Mabogunje (1981), Egunjobi (1999), Olayiwola (2000), Oduwaye and Ogundele (2006)]. Incidentally, UN-Habitat (2004) outlines these problems to be the major challenges to poverty reduction in Nigeria. Therefore, these issues must be the fulcrum for any meaningful intervention to the urban development problems of Lagos State.

Physical and Environmental Challenges: Physical and environmental challenges in Lagos State include conflicting land uses such as the infiltration of commercial land uses on housing as the case in Festac town; compete succession on Allen Avenue and Awolowo roads; poor aesthetics and unsightly cityscape, high building density and high rate of building collapse such as the recent one at Ebute Metta, and invasion of informal shanties in planned areas. Infrastructure problems include narrow and poorly constructed roads, mostly without provision for drainage. Other environmental problems include traffic congestion, pollution (Noise, atmospheric and water), flooding and ocean surge etc. These problems are particularly prevalent in areas that are inhabited by the poor. Due to the rapid population expansion and rapid urbanization being witnessed in the metropolis, more people, especially the poor are inhabiting ecologically vulnerable areas such as Ijeh, Amukoko, Makoko amongst others. Atmospheric pollution is high in Olusosun and Ojota; Ajegunle and Orile are prone to flooding while building collapse is high in Ketu, Ebute Metta, Ajegunle and Orile. Although the Lagos State Public Health Bye law recommends a room occupancy rate of 2 persons per room, as at 2004, occupancy rates vary from 1.4 in low density Apapa to 3.6 in medium density Surulere and 8.0 in high density Mushin (UNDP/LASG) See Table 1. 


\subsection{Sociological and cultural challenges}

Prevalence of miscreants i.e. area boys, crime and juvenile delinquency, ethnic clashes, high population density, political violence, public ignorance and apathy, environmental health crises are common. All these issues are dominant in the shanty towns. Area boys are mainly located in the slums of Mushin, Oshodi, Ketu, Onipanu, Yaba, Shita and Isale Eko. Land disputes and extortion, usually accompanied by widespread violence are quite common among the Omo-Oniles of Ajah and other emerging settlements around the metropolis. Ethnic clashes usually occur in the shantytowns of Idi-Araba and Ladipo-Mushin. Environmental health crises are quite common in low income areas. High incidence of sexually transmitted were recorded in the low income settlements of Ipodo-Ikeja and Tolu-Ajegunle (Nwokoro and Okusipe, 2002). Political skirmishes are also widespread in low income areas. Crime is also higher in the low income areas of Agege and Somolu, compared to the middle and high income areas of Surulere, Apapa and Eti Osa.

\subsection{Environmental management challenges}

This includes legislative bottlenecks, technical inadequacies and lack of manpower, lack of public participation and corruption. Furthermore, the loopholes in the Land Use Decree of 1978 are yet to be revised, close to three decades later; selective implementation of the Urban and Regional Planning Decree 88 of 1992, paucity of qualified officers on the field and the inability of government to remunerate workers adequately. Community participation is also not fully implemented. Planning is still basically "for the people", rather than being "with the people". Therefore, planning ends up not being unsustainable as the people do not feel a sense of responsibility to their environment. Furthermore, the problems of the Lagos Metropolis are compounded because Lagos is a city that does not have citywide administration. There is an overlap of functions and activities by all levels of governments, and consequently, friction, conflicts and waste of public funds. If constituent local governments of a large metropolis plan and manage their own sections of the area, there are bound to be conflicts and narrowness in outlook. Overlap of functions of the various environmental management agencies is also an issue. The case of Lagos State Traffic Management Authority, Federal Road Safety Corps and Federal Road Maintenance Agency is an example. The populace has also lost confidence in their elected representatives and so many of them do not have a sense of responsibility to their environment or communities. Vandalism and destruction of government projects are quite pronounced, especially in the slums and shanties. It is obvious that in the Lagos Metropolis, Ikorodu, Epe and Badagry among other urban settlements in Lagos State, poverty has a dire effect on the general environment.

In summary the major challenges confronting physical planning and development in metropolitan Lagos include the following communication gap, non-integration of socio-economic goal with physical development planning objectives, fragmentation of planning and planning related agencies, low level of application of information technology in the planning process, and need to showcase good practices.

\section{A review of efforts towards achieving orderly physical development in Lagos State}

The major approach towards land use control in Lagos State has been legislative. The application of legislative instruments as guides to Town Planning in Lagos State is classified in this paper into colonial and post-independent periods. Prior to these periods, planning was under the control of traditional rulers and chiefs.

\subsection{Colonial town planning legislations (1854-1960)}

Town planning in Lagos can be traced to the colonial period, that is, before 1854 when the British took over the administration of the country. The milestone statement of Sir Richard Burton in 1863 in his book on West Africa in which he suggested steps to be taken to clear the "Lagos Stables" that "that the site of Lagos is detestable" constitutes what could be termed the beginning of the first physical plan for Lagos (Aduwo, 1999). Also in 1873, as part of measures to ensure a clean environment in Lagos, the acting Colonial Surveyors gazetted that "Householders and owners of unoccupied lands throughout the town are requested to keep the streets clean and around their premises, by sweeping them at least once in a week as well as cutting and clearing away bush and grass and removing other sources of nuisance (Aduwo, 1999).

In 1866, Governor Moloney, a botanist established a Botanical Garden at Ebute Metta. Between 1899 and 1904 a Sanitary Board of Health was established by Governor MacGregor who was a physician. The Board was established to advice the Governor on many township improvement schemes. MacGregor could also be remembered for his concern with the problem of water supply, prevention of malaria and other diseases.

The 1902 Planning Ordinance empowered the Governor to declare areas to be European Reservations with Local Board of Health of their own. Their duties were to preserve and improve the health of the reservation areas. The Public Health Ordinance was promulgated in 1908 under the Lagos Municipal Board of Health in order to improve environmental health conditions. In 1917, the Township Ordinance No. 29 was promulgated which made Lagos the only first class city in Nigeria with a Town Council. 
The provision in the 1917 Township Ordinance did not allow for appreciable improvements of the Native Towns. This nonchalant attitude of the colonial government to the planning of Lagos Island and native settlements led to the disaster which preceeded the introduction of a planning ordinance to cover the Native Area of Lagos Island. The high population density of Lagos Island given in 1928 as 90193 (71.5\%) of the city total on a land area of 4.4. square kilometer or $7 \%$ of the total land area of the city (Olomola, 1999) led to overcrowding, unhealthy housing and spread of diseases. This led to two terrible plagues in Lagos, the post-world War 1 influenza epidemic which claimed many lives followed by the Bubonic Plague between 1924 and 1930 which led to the enactment of a planning ordinance of 1928, the Lagos Town Planning Ordinance which also witnesses the creation of the Lagos Executive Development Board (LEDB). The 1928 Ordinance covers only the colony of Lagos. The LEDB major task was the vetting and approval of building plans. The Board also doubled as a housing authority. It was empowered to undertake comprehensive land use planning, replanning, improvement and general development of Lagos territory. The first major assignment of the LEDB was the reclamation and replanning of part of Oko-Awo and Idumagbo in Lagos Island.

\subsection{Post-independent town planning legislations (1960-Date)}

By 1972, the LEDB became defunct when the Ikeja Area Planning Authority (IAPA) was created in 1956 by the Western Nigeria Government, Epe Area Planning Authority (EAPA) merged with the LEDB to form the planning nucleus of the Lagos State Development and Property Corporation (LSDPC) in 1972. The LSDPC had the power to acquire, develop, hold, sell, lease and let any movable and immovable properties in the state.

With the creation of Lagos State in 1972, remarkable town planning efforts particularly in the area of legislation has been made. In 1973, the Lagos State Town and Country Planning Law, cap 133 was enacted with deliberate effort to assemble existing planning laws under the new act. They are Western Regional Law No. 41 of 1969; Town and Country Planning Amendment Law; the Lagos Local Government Act 1959-1964 cap. 77; the Lagos Town Planning (compensation) Act 1964; the Lagos Executive Development Board (Power) Act 1964, the Lagos Town Planning (Miscellaneous provision) Decree 1967; the Lagos State Town Planning (Miscellaneous Provision) Decree 1967 and the Town Planning Authorities (Supervisory Power) Edict 1971. After 1972, other town planning laws that have been promulgated in Lagos State are Town and Country Planning (Building Plans) Regulations LSLN; No. of 1982 Guidelines for Approval of Layout, LSLN NO. 6 of 1983; Town and Country Planning Edict 1985 and Town and Country Planning (Building Plan) Regulations 1986. All the laws outlined above had various shades of successes and failures. It was with the aim of improving on the past planning legislations that the 1998 Lagos State Urban and Regional Planning Edict No. 2 was formulated in order to incorporate and correct problems identified in the past legislations. It is also significant to note that the Lagos 1998 Planning Edict itself was derived from the Nigerian Urban and Regional Planning Law Decree 88 of 1992 which is the only comprehensive Law covering the whole country after the 1946 Town and Country Planning Law. The most significant features of the 1992 law is that it provides for a federal planning framework by recognizing the three tiers of government (local, state and federal) as the basis of physical planning. The 1992 law empowers each level of government with specific planning responsibilities.

Despite the laudable efforts of the Lagos state 1998 planning law, and the commencement of its implementation which started more than seven years ago, there are many emerging problems. Some of these problems identified in the process of implementing the Lagos 1998 Planning Edict can be highlighted as those associated with system development of an innovative idea, yet some are self-inflicted human problems created by the administrators and implementers of the laws. These problems include the need for the implementation of the 1992 planning law at federal level, frequent dissolution of the Board at State level and the LPA's at local level, lack of full autonomy by the LPAs need to establish necessary departments at LPA level, inability of LPA to implement enforcement orders, lack of adequate working tools and need for staff retraining. Other problems identified are inter-departmental conflicts, top-sided revenue sharing formula and the need to expand the area of operational coverage of LPA and unethical composition of LPA board membership.

Major Highlights of the new 2005, Lagos State Official Gazette No. 25 Vol. 38 are stated in the following session of this paper.

- $\quad$ The Lagos State Physical Planning and Urban Development shall be responsible for all Physical Planning and Urban Development in Lagos State.

- $\quad$ The law made provision for the creation of an authority made up of the following;

(a)

The Lagos State Physical Planning and Development Authority

(b)

(c)

The Lagos Urban Renewal Authority and

Any other agency as may be established

- $\quad$ The Ministry shall when required, delegated to the Authority specific responsibilities and functions for implementation. 
- The Ministry shall be responsible for preparation and approval of the following hierarchies of plans: Regional, sub-regional, master and urban centre plans.

- The Ministry shall provide technical assistance to all government Ministries and Agencies on physical planning matters.

- $\quad$ The Lagos State Ministry of Physical Planning and Development Authority shall be responsible for: processing and issuance of all building development permits and ensure compliance, with the express approval of the Governor acting through the Commissioner establish District Town Planning Offices. Also acting through the Commissioner and co-operation of the Local Government Councils establish Local Planning Offices (LPO) at Local Government levels. The LPOs are to refer any plan prepared by it to the Ministry for the purpose of obtaining the approval of the Commissioner.

- $\quad$ The Lagos State Urban Renewal Authority shall identify, prepare and implement areas approved for upgrading and redevelopment. It shall hold, administer and maintain government acquired properties within redevelopment or renewal project areas.

- The Ministry shall have powers to regulate the operations, and the Authority.

- The Development Authority shall have powers to exercise operational control and supervision over its Constituents District Town Planning Offices and Local Planning Offices.

- $\quad$ Every physical planning agency in Lagos State shall with the approval of the Commissioner set up programme for the preparation and review of Development Plans.

- $\quad$ For the purpose of preparing Development Plans, the Ministry or the Authority shall from time to time invite relevant stakeholders including Ministry/Agencies, Non-Governmental Organisation, professional bodies and individuals for the purpose of considering any matter relating to physical planning and urban development.

- $\quad$ A draft Development plan shall be made available for public inspection for a period of 28days. Such plan(s) shall be advertised in at least two daily newspapers and the public is allowed to raise objection/comments on the plan.

The new law to provide for the administration of physical planning is relatively new, therefore it is assumed that the promoters of the law base its emergence on the improvement of previous planning laws in Lagos State, especially the 1998 Lagos State Urban and Regional Planning Edict. It is therefore too early to comment on the likely problems that will emerge but it appears that the intent of the law to centralise planning power within the Ministry is against the spirit of democratic system on one hand and the concept of bringing planning close to the local level and the community.

Perhaps due to these inadequacies, a new law has been enacted for the "Administration of Physical Planning, Urban and Regional Development, Establishment and Functions of Physical Planning and Development Agencies" in Lagos State (Lagos State Official Gazette No. 25, Vol. 38 of 2005).

\section{City development strategies and management: lessons from urban management (UMP / UN-HABITAT) experience}

\subsection{The city development strategy (CDS)}

The City Development Strategy (CDS) is one of the key approaches within the Cities Alliance, a coalition of cities and their development partners, committed to address urban poverty reduction as a global committed public policy issue in 1999. The main Consultative Group Members are the UN-HABITAT and the World Bank, Association of Local Authorities and Governments (www.citiesalliance.org). The CDS is fundamentally about participatory decision-making. It provides cities with framework for sustainable and equitable pro-poor policies, strategies and actions (UN-HABITAT, 2002).

On the other hand the Urban Management Programme (UMP) is based on three basic principles of enablement, participation and capacity building. It involve empowering local authorities and other partners through enabling legal and institutional frameworks, all which are necessary conditions for CDS exercise. The local level and local authorities role must be genuine, resulting in local ownership of the process. The goals of CDS process include solid institutional and technical capacity building, collective vision and strategy, improved governance and management increased investment and systematic sustained reduction in urban poverty. Initially when the Cities Alliance was launched in 1999, the concept of CDS was not well defined, though cities generally undertake city development strategy of some sort even through the use of the Master Plans or Strategic Plans, thus the initial lack of clarity about the difference between the CDS promoted by the Cities Alliance from existing city planning and development activities. This was later clarified through the World Bank Draft Urban Strategy Paper that called for making cities "Competitive, Bankable, Livable and Managable". Thus the emerging paradigm of a CDS identified by Cities Alliance is:

"A collective vision for the city that is responsive to its comparative strengths and advantages in the national and regional context, a vision that is "owned" by the city and all the stakeholders, and provides an agreed strategic 
framework for growth and poverty reduction, and identified action areas with assigned roles for each stakeholder group" (UN-HABITAT/UMP, 2002)

The CDS is focus to making cities work means development process through participatory processes. It is expected that cities governed and managed well can improve the efficiency with which scarce resources are allocated. Such cities can also improve their efficiency of administration, services and expanded productivity sectors. Cities that understand their competitive position and more wisely and quickly to capitalise on their comparative advantage can expect enormous economic returns.

\subsection{The urban management programme (UMP)}

The Urban Management Programme is one of the largest urban global technical assistance programme of the United Nations system. The programme in partnership with all levels through regional and sub-regional offices, develops, applies and shares urban management knowledge. The UMP undertook 120 city consultations in 57 developing countries in Africa, the Arab States, Asia and Latin America and the Caribbean between 1997-2001. During this period the programme, through consultation process; local governments are encouraged to engage in constructive dialogue with stakeholders and involve them in decision-making. Local and regional partner institutions are encouraged to build adequate support with government and stakeholders groups. The stronger the partnership the better the result.

While the CDS and UMP are complimentary and both target towards sustainable city development with poverty reduction and participation actions are the core values, but only varies in scale. The CDS takes definite economic views and clearly target poverty reduction. The UMP city consultation also focuses on poverty reduction but with broader sectoral and thematic entry points of participation.

\subsection{Some examples of CDS programms carried out by UN-HABITAT/UMP}

Seven CDS programme recently completed by the UN-HABITAT are Bamako (Mali), Cuenca (Ecuador), Colombo (Sri Lanka), Johannesburg (South Africa), Santo Andre (Brazil), Shenyang (China), and Tunis (Tunisia). This paper discusses the case of Colombo, Johannesburg and Santo Andre, the three which constitute the first generation of CDS.

\subsubsection{Colombo, Sri Lanka}

Sri Lanka is a densely populated island nation of 18 million people; with a per capital income of about $\$ 670$ with about $20 \%$ of her household living below poverty line, high level of insecurity, lack of land tenure, discrimination from service providers, exclusion, difficult living environment and lack of access to basic services. Despite this the country has a good record of human development indicators such as 72 years life expectancy, infant mortality rate of 16 and 90 per cent literary level. Through with history of remarkable political unrest and ethnic unrest, Liberalized trade, deregulated foreign investment, export based industrialisation and privatisation policy.

Colombo comprises of the city and its adjoining municipalities, it accounts for about $20 \%$ of the national population, $44 \%$ of the GDP and $80 \%$ of industrial establishments. The city had high level of traffic congestion, competition from other sea ports in the region and absence of integration of the formal and the informal sectors. City development is cross-sectoral with conflicting and overlapping roles by multiple agencies.

The CDS for Colombo therefore involve work at the level of the three municipal councils, coordinated into a larger CDS. The three main objectives of the Colombo CDS are:

- $\quad$ A Comprehensive development framework

- A Strategic Action Plan based on the comprehensive framework and

- $\quad$ The adoption of the elements of the Strategic Action Plan by development agencies.

The Colombo CBS was stakeholder led by an NGO, SEVANATHA. The poor and marginalized were represented by leaders of Community Development Councils. Several meetings, interviews and consultative meetings were held, thematic reports on economic potentials, poverty and development efforts prepared through which shared vision emerged and the City Development Framework Guidance developed. The guidance finally formed the framework being used by local governments to establish sustainable mechanism.

\subsubsection{Johannesburg, South Africa}

South Africa is a middle-income bracket for developing country with a modern industrial sector and well-developed infrastructure operating alongside a subsistence informal sector (UN-HABITAT, 2002). The Greater Johannesburg Metropolitan Council (GJMC) contributes $11 \%$ to national GDP. The city is sharply divided into the white and poor African settlements with the former enjoying a high standard of infrastructure and service while the later have limited access to basic services. Crime and violence is a serious problem in the city. The new Municipal Structure Act led to the establishment of a single "unicity" council headed by one executive mayor. There is increase in responsibilities for the new GJMC in the face of declining financial resources. 
To solve this problem, the GJMC device two major strategic plans to drive the city transformation called iGoli 2002 and iGoli 2010. IGoli 2002 is a medium-term strategy focused on the city's financial, institutional and service delivery challenges aimed at restoring the city financial health. It created ten independent service provider companies, a core administration and eleven regional administrations. IGoli 2010 is a long-term vision to drive the city into a globally competitive position. Majority of the GJMC works were with sound technical and financial modeling, using specialist consultants from the private sector. Though iGoli proposal many times had negative effects on local communities, despite this the iGoli 2002 recorded significant successes, while iGoli 2010 have been cited for a lack of adequate consultation, participation, sensitivity to workers and consumers, accountability and transparency. These are areas of challenges to be addressed in the Johannesburg experience.

\subsubsection{Santo Andre/ABC Region, Brazil}

The ABC Region composed of seven municipalities of over 2 million people. It contained the majority of the multinational firms in the car-manufacturing sector and concentration of other industrial firms. By 1990s the region started to suffer from pollution, lack of land, aggressive federal fiscal de-concentration policies, macro-economic shocks, overvalued exchange rates, trade balance deficits and high interest rates, thus informal sector employment is on the rise. The chamber of the Greater ABC Region was created with the participation form the public, private and civil society sectors. Through this Chamber, the Regional Development Agency was formed. When the UMP city consultation process was put, extremely rich and dynamic learning process among stakeholders has been achieved.

The New Partnership for Africa Development (NEPAD) cities programme, which is a UN-Habitat response to the Maputo Declaration of the Africa Union Assembly is aimed at reaping the benefits of cities and towns as places of opportunity and prosperity for all African people (Lagos Megacity, 2004). The NEPAD forum recommended three imperatives for urban development in Africa which are: enhancing good urban governance, improving physical infrastructure and promoting access to among the urban poor. The NEPAD initiative is new and its effect has been slow in Africa.

\section{Policy recommendations for Lagos State towards sustainable physical planning and development}

Until recently, much of the development planning efforts in Nigerian rest largely on economic planning with very little regard to the implications of economic and social policies on physical planning (Adeniji, 1998). For few towns with master plans to guide their development there has been insignificant citizen involvement in the mist of rapidly changing socio-economic circumstances, thus making it extremely difficult to achieve the provisions of such plans. The results of this are settlements based on unsustainable yardsticks. This calls for a more dynamic approach which will not only be the use of the plan-design but with adequate support of appropriate management strategies. Such approach should be derived from the unique local situation from the area concerned. Based on this, the paper suggests the need to give consideration to the following in the attempt to achieve sustainable physical development in Lagos State.

An area where major efforts has been made in the Lagos State land use legislations is on provisions for public participation. What is presently lacking in that the public is not aware of these provisions. In order to benefit from the laudable efforts of governments through the various existing laws put in place to guide sustainable environmental development in general and enhancement of citizen participation, there is need to promote active participation of community leaders and planning advocacy practice. There is need for creative planning by professionals whereby forward planning involving wholistic view should be adopted rather than the present piece meal and sectoral planning approach.

The stakeholders in environmental development consist of many professionals groups, residents and entrepreneurs. All stakeholders should be encouraged to participate in the process of planning. To achieve this planners should be ready to stimulate, communicate and educate these stakeholders in order to make things happen. Stakeholders are government, professionals, non-governmental organizations amongst others. This should be the consultative role of not only the town planners but also the architect, lawyers, surveyors, engineers, among core professionals involved in environmental management. To win the support of the busy entrepreneurs the information disseminations system should show high degree of transparency and un-ambiguity. In this process of multi-background participation for example the businessmen should be encouraged to offer part-time services at either board or committee levels to use their experience in order to enrich the physical environment. The business sector has the financial and corporate resources which it can deployed to support local public sector officials who are involved in community base projects. They could also be involved in the initiation of research on environmental problems such as traffic congestion, slum upgrading, water supply amongst others in neighbourhoods. Industrial sector could sponsor environmental related programmes on television, radios and the print media. The industrial sector can also sponsor new methods of building and research in sustainable building products, while the business sector should sponsor media since this gives them an opportunity to market their products. This will be a means of educating the public on awareness, their roles, and available opportunities amongst others. 
Since physical planning should aim at enriching the economic potentials of the people, it is important to locate land use where they can be of benefit to the people. This is not to say that we have to go back to the pre-industrial period when industries and residential areas co-exist but there is need to plan in such a way that employment should not necessarily be too far away from residential areas so that city dwellers will not have to spend larger proportion of their income on journey to work. This will require deeper researches on urban land economy. This is required if planning is to contribute to savings and improvement of quality of life.

Land use should be re-examined to take care of the informal land use especially within housing. The present rigidities and inefficiencies of public land administration hare resulted in a situation where high proportion of city population with limited economic capacity to pay for public housing have been engaged with the development of illegal and informed housing. This is a global phenomenon. For instance in Pakistan (UN, 1998) the informal or illegal land market provides land at a cost that is affordable by many low-income households, with the advantage of immediate possession and no paper work. Standards for plots sizes and infrastructure adjust to the capacity to pay. The lesson learnt here is that public land administration should make provisions to take care of this type of situation. The present public land administration especially that of land acquisition has the negative effect of contributing to land shortages rather than land availability. Planning should be pro-poor as not planning for them makes them contravene laws while trying to make shelter or tenure available for themselves.

There is need to bring the control of settlement under one major umbrella and this could be achieved through a mayorality system whereby all areas in a city-state like Lagos under the Lagos Megacity will be under a single local administration. This might be difficult in a situation where the existing local government are entrenched in the constitution but the merit of this should be examined. This will eliminate the present situation where there is conflicting and overlapping responsibilities between the local government authorities in the State and between various agencies of government concerned with environment planning and management, land use development and provision of infrastructure among other efforts towards the goal of sustainable physical development in Lagos State.

There is no doubt that information revolution is sweeping across the globe. This will determine not only the way cities are managed but now they will proper and grow. Cities without the ability to cope with the modern age information system are destined to fall hopelessly behind and doomed to fail in an increasingly competitive world. Tokyo alone has as many telephones as all of Africa (Dennis, 1995). This has serious implication on the growing information gap, between the "information rich" and the "information poor" nations. Access to information technology is important not only on how a city is managed but it is important on how local leaders communicate with their constituents.

Majority of Nigerian urban centres lack access to new technologies such as satellites, high-speed and low-cost computers, fibre optics, and other innovations that make possible links between and among people. Fortunately government regulations affecting broadcasting, print media and telecommunication, have been relaxed through privatization. This is a step in the right direction toward dissemination of information but only first class cities, mainly the early sets of regional capitals and those created up the early 1970's are benefiting from this level of information consumption. Therefore there is lack of facts for planning, unreliable information and poor information support to top decision-makers in medium and low order cities.

Nigerian cities information strategies for development in the new global system must emphasize their connectivity, their information capacity and their ability to manage social integration. Cities switched-off the global information network system will be marginalized and ultimately impoverished. Therefore adequate infrastructure of telecommunications, transportation and information system is a must for to sustain her leading role as the pole of wealth creation for her territories. Integration with the information system will enhance the ability of city managers at all levels to generate and process information knowledge required to propel the cities. Local and community level meetings at the ward and citywide levels are required as means of information flow. This will play important role in promoting communication between government and the citizens. There is need to get information technology consultants involved in the identification of information requirements of each settlement in Lagos State.

Specific programmes such as "right to quality environment campaign" should be initiated at all levels of government to emphasis that quality environment is a right along with food, education, clothing and employment. Children environmental issue programmes and exhibitions in schools should be encouraged to tailor the minds of the children to their critical role in identifying solutions to environmental problems, thus influencing their development as they are highly vulnerable.

The concept of advocacy in planning should be given consideration in Lagos State physical planning efforts especially through the formation of partnership by multidisciplinary group such as the town-planners, architects, surveyors and the lawyers coming together to form environmental advocate groups and consultants. This could also be done in form of non-governmental associations. Among the major merits of the advocacy planning concept are availability of richer ranges of plans, exposing government planners to expert criticisms, aiding the disadvantaged, education of the client and the government on planning. The politicians should be encourage by advocate group as the former could serve 
as invaluable planning agent because they form the bulk of representatives of the community at all levels of government decision making. Thus, they are vital tools as advisers and presenters of planning information. Advocacy groups should also organize talk-shops with interests groups such as market women, drivers union, and other trade groups across the strata of the society during which people are to be educated about their roles, opportunities and how to contribute to make the environment livable. There is need to integrate the effort of theorist, government officials, private practitioners and private managers. These sectors will require a meeting point to exchange ideas. The thinkers whose theories are providing the intellectual brain for environmental planning and the investors whose investment affect and propel development should share ideas.

The process of capacity building should involve human resources development and institutional development in the area of urban governance, integrated environmental planning and management, awareness and involvement of local communities, promoting partnerships, capacity building of actors and stakeholders and replication of best practices. Also in order to make planning proposal acceptable to the people and carry them along it should be recognized that different environment are structurally different and cannot accommodate standardized formula or rigid methodologies. To manage the diverse physical, geographic, socio-economic, cultural, political factors necessitate pragmatic approaches. Therefore there is need for appropriate technologically choice of strategies. Affordability, user friendliness, ease of operation and maintenance of services should be considered when undertaking technology, choice for infrastructure and services. This call for shifting from generalities into specific plans based on consumers needs, resources and carrying capacity of the consumers and environmental resources.

The place of communication and information are critical in this millennium. Effective flow of information and improved communication facilities will affect the physical environment in at least two unprecedented ways (Laquian, 1996). Externally the potential advantages include improved communication with other parts of the state and other levels of government, communities and institutions. Internally, the advantage include the potential to improve land registry data bases, land use monitoring, traffic management improved public relations and possibility of increasing municipal revenues through more detailed monitoring of properly taxes. The above illustrations show that the information revolution will not only determine how modern settlements are to be managed but how they will prosper and grow. This shows that there is need for the state government to invest in information technology both in the areas of infrastructure and human capacity building. This should include capacity development and equipment in Geographical Information System. Planning agencies should be equipped with adequate vehicles, equipment, and good working environment. This will reduce corruption and give job satisfaction.

City management department should be created at local government levels as nearly all local government headquarters in Lagos State have matured to urban status. At this level the urban management unit should initiate participatory planning process whereby residents will be engaged in revitalization of their neighbourhoods rather than the traditional approach of waiting for the government to rehabilitate infrastructure facilities for them. This will lead to a shared vision of the future of the citizen. This approach will also require regularly scheduled public meetings to motivate the residents about their role in shaping the future of their neighbourhoods. Among other issues of concern which such neighbourhood forum should discuss are enterprises, fostering awareness on environmental issues such as waste collection, landscaping etc. All these local initiative programmes based on participatory planning and community-based development processes naturally adapt to the dynamics of the local economy which is a way of ensuring sustainable revitalization efforts.

A major step toward achievement of sustainable development is the organization of sustainable practice exhibition through joint cooperation of the private sector and all levels of government. The exhibition will involve the identification, documentation and dissemination of best practices in improving the living conditions and environments in different parts of Lagos State. Such best practice may be inform of actors initiatives or projects that have led to tangible improvements in the quality of live and the living environments of the people in a sustainable way. Such exhibition will expose physical planning managers and communities to actors in other communities outside their areas and from this they will have opportunities to draw from such programmes that could be applied or adapted into their own communities.

The levels of success achieved in Lagos State are quite commendable when consideration is given to the fact that the Federal Government and many States of the Federation have not commenced the implementation of the 1992, Nigerian Urban and Regional Planning Law. It is however, necessary to mention the fact that event though the LPAs have been created, they have not been equipped with the necessary tools for them to achieve the expected results. For example, none of the LPAs have been able to establish the necessary departments. What all of them are presently engaged with is development control. This has grave consequences on the environment as planning is presently being done without facts at the LPAs level in Lagos State.

Lack of equipment and human resources with the later in the area of quantity of planners and quality of knowledge required to cope with emerging contemporary requirements for successful public institution planning practice are 
among the emerging problems. Generally, since planners are majorly trained in the area of management of resources especially on human resources and industrial relations, it is now critical in the planning practice of Lagos State as the State population is highly polarised in the area of social, economic and cultural compositions of Lagosian. To cope with the complexity of these divergent backgrounds will require sound knowledge of human resource management, public relations and industrial relations. Town planners should also realize that this is a political dispensation and therefore there is need to learn how to operate with political leaders. This is presently lacking as most planning schools are yet to introduce courses to take care of these needs to their curricular.

It appears as an irony that the act of physical planning that is town planning which has its nucleus as reconciling land use demand with the primary objective of protecting public interest is being viewed as an act expected to generate profit. This appears to be contradiction to the basic principle of planning, which is expected to guide land use in order to support the efficiency of the urban and rural socio-economic and technical systems. This is expected to invariably lead to the enhancement of land use values. Such enhancement of land use values is also expected to lead to increase in betterment and tenement rates and other taxes and rates by Government. The present situation where the operation of the LPA is expected to generated a lot of money through assessment charges could lead to stunted urban physical growth and improvement and in many cases the development of illegal structures, because if the town planning rates are too high and arbitrary people are likely to result into embarking on illegal development especially in the urban fringes.

There is need to identify and celebrate best practices in planning. This could be spearheaded by the Lagos State Chapter of the Nigerian Institute of Town Planners in collaboration with allied professional groups and organizations. Also higher educational institutions may be in position as part of the organizers but the problem is that they too could be given awards in their area of planning practice which is teaching, research and publication. Such award should cut across many areas such as the best consultant of the year in environmental planning, best project proposal, best advocacy group, best government agency, best friendly environment, best sustainable environment, best new neighbourhood etc. This will go a long way in stimulating positive competition among players in the environmental planning within Lagos State.

To achieve, the basic aim of sustainable physical development in the State the planning approval (permit) stage is a major determinant of the prospects of the environment. Though this has recently been termed planning permit; whereas the actual demand of the complex situation is that of management of planning approval or project for which permits are obtained since the planning permit is not the end in itself. It must be seen within the context of managing change in order to achieve the greatest benefit. Therefore the signifier of this new thinking is that development control (permit) should be changed and practiced as "development management". This should be supported with the adoption of the new practices that this change implies.

The internet has brought many services into the home at the touch of a button (RTPI, 2006). Access into cyberspace will assist planning in making faster and more efficient decisions. This will be achieved through the e-planning concept. E-planning programme will assist strategic planning, pre-application information, appeals, enforcement and monitoring. This will be done through the Planning Portal which provides a one-stop shop for free online planning information and services. The Portal can be accessed by local planning authorities, planning agents and the public to apply for planning permission, fund information on development proposal and appeals or dig out details of government policy and research. A starting point is perhaps the efforts of the Lagos State Planning Information Centre (LASPIC). The intent of LASPIC is not only to be used for ensuring compliance with development regulation. It is also to ensure that data about permitted development could be monitored (Alade-Ojomo, 2005). The LASPIC database when launched can be accessed through internet and intranet from the Lagos State Ministry of Physical Planning and Urban Development, Lagos State Physical Development Authority, all the District Offices and Local Planning Authorities (Oduwaye and Dekolo, 2005). The cyber planning -Portal system allow for easy submission of application and it will contains a wealth of information, and it will be cheaper and reduces human factors such as delay and corruption.

Land information is a critical element towards achieving sustainable physical environment, therefore there is need for free access to land information by the public at the touch of a computer button. This will provide invaluable information that will guide individuals, consultants, government and all stakeholders in environment planning and development. Like the Portal Planning merit, it will also eliminate human problems especially mis-information, delay and corruption.

\section{Conclusion}

This paper has presented a fairly elaborate issues concerning sustainable physical development with emphasis on its application in Nigeria and in Lagos State in particular. This has been done within the backdrop of the concept of physical development, planning, planning problems and sustainable development. It also presented the relationships between physical planning, the need for sustainable develop and how physical planning can be used to achieve sustainable development. It also reviewed efforts towards sustainable physical development in Nigeria and Lagos State upon which policy recommendations are presented on how sustainable physical development can be achieved in Lagos State. 


\section{References}

Abram, C. (1971). The Language of Cities, New York: Avon Books.

Adeniji, J. (1998). Future challenges of sustainable physical development in Nigeria in K. Adeniji and V.I. Ogu (eds) Sustainable physical development in Nigeria._Ibadan: NISER pp $227-279$.

Adesanya, S. (1998). The physical development dimension of the sustainable development challenge in Nigeria in K. Adeniji and V.I. Ogu (eds). Sustainable physical development in Nigeria. Ibadan: NISER: pp 78- 92.

Adeyinka, S.A. (2005). The challenges of global planning legislation for sustainable urban development in Nigeria in A. Fadare et al (eds), A Conference proceeding in Globalisation Culture and the Nigeria built environment._Vol. II Ile-Ife: O.A.U. $389-394$.

Aduwo, A. (1999). Historical preview of town planning Lagos in A.M. Laseni (ed)_Urban and regional planning in Nigeria: A collection of readings_Lagos: NITP: Lagos Chapter.

Alade-Ojomo, O. (2005). GIS: The rationale for the establishment of the Lagos State Planning Information Centre in L. Oduwaye and S. Dekolo (eds). A Workshop proceedings on GIS application in Urban and Regional Planning. Lagos: NITP Lagos Chapter $58-69$.

Ayeni, B. (1979). Concepts and Technologies in Urban Analysis. London: Croom Helm.

Dennis, E.E. (1995). The city in the age of information. Urban Age 3(1) 13 - 16.

Egunjobi, L. (1999). The gasping city. Inaugural Lecture, University of Ibadan.

Habitat 1996: The urbanizing world: Global report of human settlement. Oxford: UNCHS and Oxford University Press. Laguian, A. (1996). Who wants to be President when you can be a Mayor? Urban Age: New York: World Bank.

Leff, E. (1990). The global context of the greening of cities in D. Gordon(ed). Green Cities ecological sound approaches in urban space. Black Rose Books.

Mabogunje, L. (1981). Econometric analysis of housing trait prices in a Third World City. Regional Sciences. 26: 533-547.

Nwokoro, H.C. and O.M. Okusipe (2002). Urban Health and Urban Infrastructure: A Spatial Analysis of Low-Income Communities in Lagos Metropolis. The City in Nigeria, OAU Ile-Ife, 378 - 383.

Nigeria Police Crime Report, (2005).

Odumosu, T. (1999). Location and Regional Setting of Lagos State. Lagos State in Maps. Balogun T., T. Odumosu and K. Ojo (eds). Ibadan;Rex Charles.

Oduwaye, L. (1998). Towards sustainable urban management in Nigeria in the next millennium. A proceeding of the $29^{\text {th }}$ Annual Conference of the Nigerian Institute of Town Planners Makind: pp 14-21.

Oduwaye, L. (2000). Strategies for achieving orderly physical development in Lagos State. A workshop proceedings on Towards a better socio-economic and physical environment for urban and rural areas of Lagos State: Lagos: Frontline Consultants pp $64-81$.

Oduwaye, L. and S. Dekolo (2005). GIS applications in Urban and Regional Planning. L. Oduwaye and S. Dekolo (eds) A Workshop proceedings on GIS Applications in Urban and Regional Planning Lagos: CPD NITP Lagos State Chapter: $1-20$.

Oduwaye, L. (2006). Citizen participation in environmental planning and management in Nigeria. Journal of Human Ecology 20(1): $91-99$.

Oduwaye, L. and K. Ogundele, (2006). Environmental Hazards in Metropolitan Lagos. A Conference proceedings on Conflict Resolution and Environmental, Economics, Department of Estate Management University of Lagos.

Oduwaye, L. and T.O. Lawanson (2006). Poverty and environmental degradation in the Lagos metropolis. A conference proceedings on Urban and Regional Planning in the context of the Millennium Development Goals. Department of Urban and Regional Planning, Federal University of Technology, Minna.

Olayiwola, L.M. (2000). Technique for achieving sustainable development for Towns and cities in Osun State: $A$ workshop proceeding on Urban Planning and Sustainable Development in Osun State. Frontline Consultants. 1 - 15.

Olomola, A.O. (1999). Historical Preview of Town Planning in Lagos Before 1929 in Urban and Regional Planning in Nigeria: A collection of Readings. $\quad$ ed Laseni, A.M. Lagos: NITP.

RTPI, (2005). The RTP Planning Awards, London: RTPI. 
RTPI, (2006). Planning by Portal. Planning Renaissance Delivery and Implementing Planning Reform. London: RTPI 6- 7 .

UNCHS, (1996). An Urbanizing World: Global Report on Human Settlements. Oxford: Oxford University Press.

UN-Habitat, (2002). City Development Strategies: Lessons from UMP/UN-HABITAT Experiences. UMP Series 29. Narobi; UN-HABITAT

WCED, (1987). Our Common Future, Oxford: Oxford University Pres.

WHO, (1992). Report of the Panel on Urbanization: World Health Organisation Commission on Health and Environmental, Geneva: WHO.

Lagos State Government Publications

- $\quad$ Town and Country Planning Law Cap 188 of 1985

- $\quad$ Town and Country Planning (Building Plan) Regulation Cap 188 of 1986

- Town and Country Planning (Governing Conditions for Development of Estate by Private Developers) Regulation Cap. 188 of 1990.

- $\quad$ The Lagos Urban and Regional Planning Board Edict No. 2 of 19998

- $\quad$ New Towns Development Authority Law Cap 135 of 1983

- $\quad$ Neighbourhood Improvement and Property Corporation Cap. 82 of 1990

- $\quad$ The Lagos State Transport Corporation Law Cap 104 of 1977

- $\quad$ Lagos State Parking Authority Law, Cap 95 of 1980

- $\quad$ Lagos State Urban Renewal Board Law Cap 196 of 1991

- $\quad$ Lagos State Environmental Pollution Control Law Cap 46 of 1989

- Lagos State Environmental Sanitation Law of 2000

- $\quad$ Lagos State Park Commission Law of 1985

- $\quad$ Lagos State Rent Edict of 1997

- $\quad$ Lagos State Land Use Charge Law No. 11, of 2001.

- $\quad$ Lagos State Official Gazette No. 24, Vol 38 2005: A Law to provide for the Administration of Physical Planning, Urban and Regional Development in Lagos State, Establishment and Function of Physical Planning and Development Agencies.

- Lagos State Ministry of Economic Planning and Budget 2004: State of Lagos Megacity and other Nigerian Cities. LSMEPB, LSMPUD and the UN-HABITAT, Nigeria. 


\title{
Study on the Law Regulations about Circular Regions
}

\author{
Boyu Zhu \\ Law School, Shandong University of Technology \\ Zibo 255049, China \\ Tel: 86-533-2782279 E-mail: zhuboyu123@126.com \\ Muwen $\mathrm{He}$ \\ Law School, Shandong University of Technology \\ Zibo 255049, China \\ E-mail:sdhmw@163.com
}

\begin{abstract}
The circular region takes the pollution prevention as the start, takes the material circular flow as the character, takes the sustainable developments of society, economy and environment as the final objective, utilize the resource and energy to the largest extents, and reduce the pollution discharge. The circular regions needs powerful legal guarantee and we should strengthen the law regulations for the circular economic province from following aspects, i.e. constituting the legislation program of the circular economic province, using foreign and domestic advanced experiences and constituting comprehensive legislation to develop the circular economy according with the practice of the province, perfecting the policies and law regulations system about sustainable utilization, establishing the policies and law regulations system about circular economy in the agricultural domain, strengthening the legal construction of green packaging, establishing the policies and law regulations system of the consumption mode about sustainable development, perfecting the policies and law regulations system about human resource reasonable utilization and raising money, and strengthening the law execution force and increasing the effect of law regulation.
\end{abstract}

Keywords: Circular economy, Circular region, Circular economic province, Law regulations

The law regulation layer of circular economy is the important part of the legal construction of circular economy, and it can be spread on following four layers including circular enterprise, ecological industrial park, circular city and circular region (Zhu, 2007, P.228). The regional development is different with the growth of enterprise, the development of part and the city, and it has its special rules. The regional circular economy is the higher-layer circular economy and it comes down to numerous administration regions and departments, and various regions and main bodies have complex benefits. The construction of the regional circular economy needs more powerful legal guarantees because of its characters of comprehension, integration, complexity and long-term.

\section{Circular region and its characters}

The circular region is the production that circular enterprise, circular industrial park and circular city extend to large region, and it establishes various industrial ecological chains in one region and various domains of the first, second and third industries through changing he regional production mode, consumption mode and management mode and adjusting the regional industrial structure, and uniformly organizes regional production, consumption, waste disposal and regional management as the ecological network system. The circular region takes the pollution prevention as the start, takes the material circular flow as the character, takes the sustainable developments of society, economy and environment as the final objective, utilize the resource and energy to the largest extents, and reduce the pollution discharge. It is the concrete embodiment that the circular economic theory is applied in the region. The circular region has four factors, i.e. industrial system, urban infrastructure, human ecology and social consumption. First, the circular economic industrial system taking the industrial intergrowth and material circulation as characters should be established. Second, the infrastructures including water cycle utilization protection system, clean energy system and clean public traffic operation system should be built. Third, the human economic construction which takes up with green planning, green view and green construction should be implemented. Fourth, the green sales and green consumption should be advocated and implemented.

The regional circular economy is the circular economy which is implemented on the higher layer and in the larger range based on the enterprise circular economy, industrial park circular economy and urban circular economy have been realized, and it is the based of social circular economy. On the regional layer, the development of the circular economy 
has following characters. First, through the adjustment of regional structure, the ecological industry and the ecological agriculture should be developed depending on original industrial bases to promote the establishment of the production and consumption circular system, the material circulation and the energy gradient utilization among industries and in the interior of the region, and establish the circular region from points to face. Second, relatively complete production, consumption and cycle system should be established in the region. According to the principles of "quantity reducing, reutilization, resource", establish the circular enterprise, circular ecological industrial park and circular city, exert the regional resource advantages, develop the ecological agriculture or ecological touring, and advocate the sustainable consumption. Realize the material circulation and waste utilization among enterprise and various circular cities in the circular region. The associations among the first, second and third industries will be more extensive, and the ecological industrial network will be more complex and stable. Third, the construction of circular region is to adjust the structure, reasonable utilize resource in the larger range, and fully exert local advantages and develop stably (Feng, 2004, P.242-243).

\section{Law regulations of circular economic province}

The circular region is the production that circular enterprise, circular industrial park and circular city extend to large region, so we take the circular economic province as the example to study the law regulations of circular region.

\subsection{To establish the legislation program of circular economic province}

A legislation program according with the demand of local construction could powerfully promote the science, system and balance of the regional legislation program. The construction of the circular economic province comes down to every walk of life, and it needs large law regulation system to support it. So when we make the legislation program, we should not only combine useful legislation with prediction legislation, but pay attention to the cover face of legislation in order to avoid that some relationships with marginal characters which needs to be adjusted are not be regulated correspondingly. We also should correctly deal with the relationship between local region and other legislations, and try to avoid the cross repetition and conflicts among legislations.

\subsection{To constitute policies and law regulations of circular economic province}

2.2.1 Using foreign and domestic advanced experiences and constituting comprehensive legislation to develop the circular economy according with the practice of the province

Many foreign counties such as Germany, Japan and US are developing the circular economy, and they have established relatively perfect legal system of circular economy. In China, many provinces such as Liaoning, Zhejiang and Shandong had early developed the construction of circular economic province, and they all begun to constitute relative laws about circular economy. Because the construction of the circular economic province is largely influenced by the natural condition and social condition, so the regional law regulations should be adjusted measures to local conditions and put the principles and systems about the construction of circular economic province into effect.

In China, because the construction of circular economic province in various places just begun, the comprehensive legislation with local characters has not been constituted. At the same time, with the development of the construction of circular economic province, the social composing, benefit relation, human idea and behavior mode, and living mode in the circular economic province will be largely changed, but the existing legal resources of China has not adapted the requirements of new changing social relationship to the laws. The best method to solve this problem is to constitute the local comprehensive legislation of the circular economic province, which can make the national policies about the circular economy accord with the local characters, and comprehensively regulate many problems such as the principle, objective and management system of the local circular economic province. So according to the practice of the province, the "Circular Economic Province Construction Byelaws" should be constituted, which can ensure the long-term character, integrality and continuity of the strategic layout of the circular economic province by the legal form.

\subsubsection{Perfecting the policies and law regulations system about sustainable utilization}

First, establish uniform resource management system. According to the concrete conditions of the province, make the total layout of the provincial territory resources development utilization and protection, strengthen the managements for the water resources, mine resources, land resources and forest resources, and ensure the effective utilization of the territory resources. Reasonably develop the water resource, completely push the principle of "water conservation" and establish the water-conservative society. Third, aiming at different resources, implement the ecological construction engineering. For example, constitute the protection layout of water resource, protect the water environment of the fountain, forbid to found pollution enterprise at the fountain, turn the fountain green and enhance the self-restraint ability of the fountain (Liu, 2005, P.445).

\subsubsection{Establishing the policies and law regulations system about circular economy in the agricultural domain}

The ecological crisis faced by Chinese agriculture includes not only environment pollution, but population explosion, environment and resource damage, energy deficiency and insufficient food supply (Bian, 2000, P.80-85). Therefore, we 
should not only father and protect the natural ecological environment and save energies, but develop the production by finite resources and enhance the output of various farming products, produce more abundant and higher quality products, and supply increasing population and fulfill material demands of continually increasing.

We should establish the agricultural clean production system through the legislation. For a long-term, the clean production is limited in the domain of industrial production, and it is rarely mentioned in the domain of agricultural production. With the severity of the environment pollution and damage from the agricultural production and the rising of green agriculture, we should confirm the agricultural clean production system in the agricultural legislation, and apply the comprehensive environmental protection strategy of pollution prevention into the agricultural production engineering and control the pollution from the headstream. Through producing and using the green farming productions (such as green fertilizer, green pesticide and green mulch) which is friendly to the environment, we can improve the agricultural production technology, reduce the agricultural pollution, ensure the quality of farming products and reduce the risk of agricultural production to the environment and human. Through measures of pollution charge, pollution-discharge right trade and environment revenue, we can enhance the restriction of environment cost and gradually make the environment costs internalized. To implement the agricultural clean production and the good circular economy, we should regulate the law regulations such as pollution-discharge right trade, green technology standard, green environment symbol system, green packaging system, green sanitation quarantine system, ecological revenue and green allowance system to promote the clean production through relative legislations (Jiang, 2003, P.13).

The relative encouragement systems should be confirmed through the legislation. The relative encouragement and assistance systems should be constituted, which can make farmers and relative enterprises voluntarily participate in the circular economic activities and benefit from these activities in the agricultural domain. We can use the foreign blacklist system for reference. The blacklist system means the legal system which is implemented to protect the environment and control the pollution through forbidding or limiting the lagged products, technologies, skills and projects with much resources consumption and serious pollution, and it is the system which indirectly encourages the green industry through limitation regulations.

In addition, we should also confirm the substitute disposition system through the legislation. The "Prevention and Control of Environmental Pollution by Solid Wastes of the People's Republic of China" had regulated the administration substitute disposition system of dangerous waste, and we can consider extending the application of the substitute disposition system, and regulate that the agricultural producers especially the agricultural collective economic organizations could sign the agreements with the professional pollution disposition enterprise according to the market operation mode, and consign and pay professional enterprise to father the pollution. So the pollution enterprises can dispose the pollutions through exterior professional environment protection establishments, and environmental protection departments would charge and supervise the pollution prevention and offer necessary services (Le, 2003, P.27).

\subsubsection{Strengthening the legal construction of green packaging}

At present, the special legislation about the packaging is still blank. Though in recent years, some policies about the packaging come on in succession, but because they lack in the compelling sanction, they could not exert large function, and the environmental protection consciousness in China is still lower, and some limited even forbidding packaging materials are still produced and used in China, which make some exported commodities suffer losses because of falling short of foreign environment protection laws. We should manage the production, circulation and usage of package through the legislation as soon as possible, and promote the development of green packaging by legal measures.

And we should establish concrete indexes to promote the reclaim utilization of packaging resources. The voluntary reclaim should be combined with paying reclaim to make the reclaim utilization of packaging resource integrated into the environment protection. At the same time, we should legally promote the design of green packaging and study the new materials.

\subsubsection{Establishing the policies and law regulations system of the consumption mode about sustainable development}

Under the condition of market economy, we should standardize the consumption behaviors and control the consumption needs through perfecting policies and laws to make the scale and intension of consumption harmonize with the update ability of resource and the load of environment and instruct the establishment of the consumption mode of the sustainable development. For a long term, human cognition to consumption only emphasizes its social and economic functions, and ignores the potential ecological influences of human consumption. Therefore, we should fully advocate the ecological consumption, which can not only enhance civic ecological consciousness and ecological responsibility sense, but promote the ecologization of production mode and the ecologization of decision-making management, and help to promote the good circulation of the social economic system (Wang, 2004, P.296).

2.2.6 Perfecting the policies and law regulations system about human resource reasonable utilization and raising money

To perfect the legal guarantee system of human resource reasonable utilization, we should establish a set of system 
introducing, holding and cultivating talents according to the national preferential policies. The talent free flow principle should be confirmed through the legislation to create opportunities for attracting and utilizing exterior talents. The normal investment and effective usage of education capitals should be guaranteed and the provincial education should be largely developed through the legislations.

The financing mechanism is the material guarantee for the construction of the circular economic province and the market environment with high capital return is the important condition to attract capitals, which needs confirm many encouragement policies and preferential policies by the legal form to make investors invest without the trouble in the rear. For the construction of infrastructures, we should encourage the participation of private capitals, and encourage foreign and domestic big enterprise to construct the projects by the project system and the mode of BOT. For the construction of non-infrastructures, the nation should endow the province certain revenue exemption right to encourage foreign and domestic investors' investments. We also should adopt more flexible forms such as plan examining and approving, land and mountain contract to attract social capitals. And for the projects which accord with the industrial policies of the circular economic province, we should extend the limitation of market admittance and implement the revenue preferential policies.

\subsection{Strengthening the law execution force and increasing the effect of law regulation}

The executions of law regulations by law enforcement agencies and employees are very important in the construction of the whole circular economic province. And in the present and later period, we should mainly solve following problems.

(1) Strengthening the construction of the law enforcement agencies and teams. Following measures should be adopted, i.e. developing and strengthening the legislations of the administration management organizations and institutions, standardizing the administration behaviors of the government, enhancing the efficiency and perfecting the administration decision-making program, making the training layout and plans, constituting the post criterion, and comprehensively enhancing tipstaffs' professional quality and operation level.

(2) Strengthening the function of the government. The leaders' legal consciousnesses of various layers governments should be first enhanced, and they should seriously run the state by law. At the same time, the law enforcement departments in the government should be severe with them own and fully enhance the law enforcement level.

(3) Perfecting the supervision mechanism of the law enforcement. First, the supervision to the implementation of the construction layout of the circular economic province should be strengthened. We should mainly supervise the investment of the capitals, the implementation of the objective responsibility in the circular economic province, and the perfection of the environment quality. Second, the various-layer power institutions should strengthen the supervision of the law enforcement, and supervise and urge the government to increase the law enforcement power, and maintain the dignity of the law and promote the implementation of the law.

\section{References}

Bian, Yousheng et al. (2000). Theory and Practice: Foreign and Domestic Ecological Agriculture Comparison. Beijing: China Environmental Science Press. P.80-85.

Feng, Zhijun. (2004). Introduction of Circular Economy. Beijing: People's Publishing House. P.242-243.

Jiang, Weiyu. (2003). On the Legislation of Clean Production and Benign Circulate Economy. Law Science Magazine. No.5. P.13.

Le, Xiaofang, Luan, Shengji \& Wan, Jinbo. (2003). Study on the Innovation of Chinese Rural Environmental Policies. China Environmental Management. No.3. P.27.

Liu, Guotao. (2005). Green Industry and Green Industry Law in the Construction of Conservation-conscious Society. Beijing: China Legal Publishing House. P.445.

Wang, Rusong. (2004). Theory and Practice of Hainan Ecological Provincial Construction. Beijing: Chemical Industry Press. P.296.

Zhu, Boyu. (2007). Legal System about Circular Economy. Beijing: People's Publishing House. P.228. 


\title{
Timor Mountain Gum Improvement Program in Eastern Thailand
}

\author{
Mandy Maid (Corresponding author) \\ School of International Tropical Forestry \\ Universiti Malaysia Sabah \\ Locked Bag No 2073, 88999 Kota Kinabalu, Sabah, Malaysia \\ Tel: 60-88-320-000-8602 E-mail: Mandy21@ums.edu.my \\ Suree Bhumibhamon \\ Mae Fah Luang University Botanical Garden \\ 333 Moo1, Thasud Muang, Chiang Rai 57100, Thailand \\ Tel: 66-53-916-0278 E-mail: suree@mfu.ac.th
}

The research was supported by Thai Plywood Company-Lad Krating Plantation for the establishment and maintenance of the experiments and technical support.

\begin{abstract}
Timor Mountain Gum (Eucalyptus urophylla S.T. Blake) is an important eucalypts species for pulp and chip wood production in Thailand because of its rapid growth and suitability for hybridization. The 16 year-old provenance trials compared 19 natural seed sources in four blocks replication from the islands of Timor, Flores, Alor, Lomblen, Wetar, and Pantar. Seeds were collected from selected plus trees of the provenance trials to establish $F_{1}$ progeny test which comprise of 80 half-sib families in 12 blocks replication. In both experiments there were significant differences of growth performances and morphological characteristics among seed sources. A lowland provenance from Mt. Lewotobi, Flores indicated best growth in both the provenance trials and progeny test. The experiments implied that individuals from the island of Timor and Flores were the best performing. Therefore, these should be considered in the next selection process for breeding strategy to optimize plantation productivity.
\end{abstract}

Keywords: Eucalyptus urophylla, Provenance, Progeny, Variation

\section{Introduction}

Eucalypts contribute substantially to Thailand's 3.09 million ha (FAO, 2007) of forest plantations for the production of wood fuel, sawn wood, poles, and pulp for paper and paperboard. The eucalypts are not only important industrial species, but also made significant economic contribution to the income of small-holders. The most common species planted is Eucalyptus camaldulensis, E. urophylla and E. deglupta. The current status of eucalypts as commercial forest plantation species is the result of a series of field trials and testing that was conducted intensely throughout the country since the 1940s. Significant achievements in eucalypts tree improvement research in Thailand were attributed to a series of cooperation between the Thai Royal Forest Department and international agencies. The most notable effort was the preliminary planting of 15 Eucalyptus species with pulpwood potential in four experimental stations. Then, the Thai-Danish Pine and Fast-growing Tree Improvement Project (1972) and an ACIAR-CSIRO Forestry and Forest Products (1985-1986) supported project led to the establishment of ex-situ gene conservation stands of selected species prominently E. brassinana, E. camaldulensis, and E. urophylla in Surin. The later trial confirmed the suitability of E. camaldulensis and E. urophylla for planting in most parts of Thailand (Pousajja, 1993; Luangviriyasaeng, 2003).

Recent observations indicated that some eucalypts species and provenances may be susceptible to pest and diseases such as shoot blight and progressive canker, which causes chronic defoliation, reduction in growth rate and the loss of merchantable volume. Subsequently, tree improvement programs of eucalypts in Thailand will have to seriously consider the selection and screening programs for resistance towards pest and diseases (Pongpanich, 1998). Eucalypts hybrid breeding is actively being pursued for this purpose. This paper will describe the improvement and breeding activities for E. urophylla as one of the most promising species. In addition for the establishment of short rotation forest, the species is potentially suitable for windbreaks and soil salinity control whereby these problems are prevalent in some parts of Thailand. 


\section{Materials and Methods}

\subsection{Experimental site}

The experiments were established at Lad Krating Plantation of Sanam Chaikhet District in Chachoengsao province. It is located on a relatively flat area (altitude $80 \mathrm{~m}$ ) about $90 \mathrm{~km}$ east of Bangkok, Thailand at latitude $13^{\circ} 42^{\prime} \mathrm{N}$ and longitude $101^{\circ} 06^{\prime} \mathrm{E}$. Mean annual temperature is $28^{\circ} \mathrm{C}$ and mean annual rainfall is $1,220 \mathrm{~mm}$ with a dry period occurring between Novembers to February. Soil is sandy clay loam of the Clayey-skeleton, Kalinite, Aeric Kanhapustult Series.

\subsection{Experimental design}

The provenance trials which were established in 1988 compared 23 natural seed sources from the islands of Timor, Flores, Alor, Lomblen, Wetar, and Pantar (Table 1). The provenance trials were laid out in Randomised Complete Block Design (RCBD) of four replicates which consists of five rows of four columns each. Each plot was planted with five rows of five trees at $4 \times 4 \mathrm{~m}$ spacing.

The seeds from 188 selected plus trees from the E. urophylla provenance trials were planted and tested for initial survival and growth rates. Subsequently, the best performing 80 half-sib families were selected from the 188 plus trees to establish the progeny tests (Table 1) in May 2002. The progeny test was laid out in RCBD with 12 replicates each consisting of 10 rows by eight columns. Each plot was planted with four rows of four trees with a spacing of $1 \mathrm{x}$ $2 \mathrm{~m}$. Both experiments were protected by rows of shelterbelts and weeding was carried out at least once a year. The progeny stand was thinned by phenotypic selection in October 2004 and June 2005 by $50 \%$ selection at each time. The final thinning will convert the progeny tests to a seedling seed orchard.

\subsection{Assessment}

The provenance trials were assessed periodically at the ages of 6, 8, 10 and 16 years old. The first assessment of the progeny test was carried out at 3 years old. For both experiments the height $(\mathrm{Ht})$, diameter at $1.3 \mathrm{~m}$ above ground $(\mathrm{dbh})$, diameter at ground level (dgl), crown diameter $(\mathrm{Cr})$ and stem straightness were measured. Bark characteristics were also assessed for the provenance trials. Narrow sense family heritability $\left(\mathrm{h}_{\mathrm{f}}^{2}\right)$ was estimated from the half-sib progeny test using the formula by Zobel and Talbert (1984):

$$
\begin{gathered}
h_{f}^{2}=-\ldots{ }^{2} \\
h^{2}{ }_{f}=1-1 / F
\end{gathered}
$$

Where:

$$
\begin{array}{ll}
\sigma_{\mathrm{f}}^{2} & =\text { Variance among families } \\
\sigma_{\mathrm{e}}^{2} & =\text { Error variance } \\
\mathrm{n} & =\text { Number of individuals per family } \\
\mathrm{F} & =\text { F-ratio of families from ANOVA }
\end{array}
$$

The phenotype and genotype values of progenies were calculated with the following formula by Falconer (1960):

$$
\mathrm{G}=\mathrm{h}^{2} \times \mathrm{P}
$$

$$
\begin{gathered}
\text { Mean value of families }- \text { Total mean average } \\
\text { P }=\text { Total mean average }
\end{gathered}
$$

Where:

$$
\begin{aligned}
\mathrm{G} & =\text { Genotypic value }(\%) \\
\mathrm{h}^{2} & =\text { Heritability } \\
\mathrm{P} & =\text { Phenotypic value }(\%)
\end{aligned}
$$




\subsection{Data analysis}

Variation of tree growth performances were analysed using the Analysis of Variance (ANOVA) using SPSS statistical software (SPSS Inc., 2002). The Duncan's New Multiple Range Test (DNMRT) was used to compare means of the various characteristics among the provenances. Narrow sense family heritability was calculated for the progeny stand.

\section{Results And Discussion}

\subsection{Survival and growth}

The mean survival percentages of E. urophylla in the provenance trials (Table 2) was high ( $>75 \%$ ) during the first 10 years, but decreased sharply after that (54.3\% at 16 years). Survival in the progeny trials (Table 3$)$ at age three years old was very high at $97.3 \%$. This indicates that at this site, the species is very suitable for the establishment of short rotation plantation. However, two provenances (Mt. Mandiri, Flores; Lelogama, Timor) had more than $70 \%$ survival at 16 years and may be considered for sawn timber production. The provenances that had the lowest survival (Mt. Wulogai, Flores; Mt. Mutis, Timor; Mt. Lakaan, Timor) originate from areas above $1500 \mathrm{~m}$ altitude which performs poorly in the lowland tropics (Faridah Hanum and Maesen, 1997). Furthermore, the altitudinal level was positively correlated with provenance $(0.324, p \leq 0.01)$ and negatively correlated with survival $(-0.457, p \leq 0.01)$. Significant differences $(p \leq 0.01)$ between the provenances (Table 2) and families (Table 3) occurred at all ages.

The species attain its greatest height increment during the first six years $(18 \mathrm{~m})$ and the subsequent 10 years height increment was only $7 \mathrm{~m}$ in the provenance trials. Its progenies attain even greater mean height increment at $12.1 \mathrm{~m}$ at three years old. Provenance (Mt. Lewerok, Flores; Mt. Lewotobi, Flores; Kalabahi, Alor) which are of lowland origin $(<1200 \mathrm{msl})$ had the best height implying a genetically inherent characteristics. There were significant differences $(\mathrm{p} \leq 0.01)$ between the provenances and families at all ages.

Diameter at breast height (Dbh) and diameter at ground level (Dgl) have similar increment trend as height for both experiments. The greatest mean Dbh increment for the provenance trials was during its initial six years of $16.3 \mathrm{~cm}$, and subsequent 10 years was followed with Dbh increment of $7.2 \mathrm{~cm}$. In the first three years of progeny testing establishment mean Dbh was $10.4 \mathrm{~cm}$. There were significant differences $(\mathrm{p} \leq 0.01)$ between provenances and families at all ages for both characteristics. Provenance from Mt. Lewotobi, Flores was the best in terms of Dbh and Dgl. Pearson's correlation analysis revealed positive correlations $(0.05<\mathrm{R}<0.92)$ amongst all growth characteristics of $E$. urophylla progenies and was statistically significant $(\mathrm{p} \leq 0.01)$.

Analyses of variance for crown diameter and stem form were also performed for the progeny tests (Table 3). Mean crown diameter was $1.9 \mathrm{~m}$. There were significant differences $(\mathrm{p} \leq 0.01)$ between families for crown diameter and stem form. Fig. 2 shows that the distribution of stem forms in the provenance trials have less than $20 \%$ of straight stem trees, but ANOVA showed insignificant differences between the provenances. In the progeny tests more than $80 \%$ were straight stem, which could be attributed to the selection process that favoured straight stem and high clear bole. However, it could be argued that during the initial fast growth phase the trees tend to develop straighter stem and due to the closer planting arrangement in the progeny tests compared to wider-spaced provenance trials which have led to growth competition.

In general, the results of the provenance trials indicated that some lowland provenances of narrow altitudinal range from the islands of Flores, Alor, Lomblen had good growth at the experimental site. Conversely, provenance from high altitudinal sources (Wetar Island) did not perform well here. Brazil (Scanavaca and Garcia, 2003) and China (Wei and Borralho, 1998) had been actively working on the improvement and breeding of E. urophylla from the island of Flores which provides most of their planting material for the plantation industry. The achievements in tree improvement program have been fruitful in Brazil since some lowland landraces were found to be superior to their more recently introduced wild relatives.

\subsection{Heritability estimates}

Heritability (Table 3) was moderately high for all growth traits (height 0.61 , Dbh 0.77 , Dgl 0.74, crown diameter 0.51, stem form 0.51 ) with the exception of survival (0.30). Survival may not be a heritable character but was highly influenced by environmental factors. On average, phenotypic and genotypic value comprised of more than $80 \%$ and less than $60 \%$ respectively for height, Dgl, crown diameter and stem forms for most growth characteristics. Thus, selection process based on phenotypic characteristic can be reliable. Most fast growing species show to a great extent moderate to high heritability for the most important growth traits in the first three years of active growth which should be taken advantage for early selection to increase volume growth. Slow-growing temperate species such as pines generally have lower heritability compared to fast-growing species. In Pinus caribaea var hondurensis heritability was 0.10-0.24 and in P. elliottii was 0.20, although hybrid pines fared better (0.44) (Powell and Nickles, 1996). Long-lived E. marginata also showed very low heritability of growth traits (0.06-0.13) (O'Brien et al., 2007). Heritability assessment should be carried out periodically because some study points to enhanced heritability with increased ages up to its rotation age. For example, heritability of growth traits of E. camaldulensis in Thailand ranged 0.63-0.74 at 6 
months to 0.83-0.90 after 1 year (Pipatwattanakul, 1996), and similarly in E. urophylla trials in Veracruz, Mexico heritability increased with age at the individual (0.25-0.52) and clone mean levels (0.81-0.93) (Sánchez et al., 2005; Borje-de la Rosa et al., 2005). As research progresses with specific breeding objectives, future studies will have to include the heritability of other traits such as wood properties and flowering characteristics as other research indicated that these traits are strongly inherited (Atipanumpai, 1989).

\section{Conclusion}

Provenance trials and progeny tests of E. urophylla in Eastern Thailand showed significant morphological and growth variations. Heritability estimates was moderately high for all growth traits. The wide genetic content of the species provides opportunity to optimize plantation productivity and enhanced wood properties. Improvement and breeding plan should concentrate on lowland provenance from the islands of Flores, Alor and Lomblen.

\section{References}

Atipanumpai, L. (1989). Acacia mangium: studies on the genetic variation in ecological and physiological characteristics of a fast-growing plantation tree species. Acta Forestalia Fennica 206, 92.

Borja-de la Rosa, A., Vargas-Hernandez, J.J., Lopez-Upton, J., and Ignacio-Sanchez, E.. (2005). Genetic parameters for growth and wood density in juvenile Eucalyptus urophylla S.T. Blake. Agrociencia (Montencillo), 39(4),469-479.

Falconer, D.S. (1960). Introduction to quantitative genetics. Oliver and Boyd, Edinburgh.

Faridah Hanum, I. and van der Maesen, L.J.G. (Eds.). (1997). Plant resources of South-East Asia No. 11: auxiliary plants. Prosea Foundation, Bogor, Indonesia. pp.140-144.

FAO. (2007). State of the world's forest 2007. FAO, Rome. pp.111.

Luangviriyasaeng, P. (2003). Eucalypt planting in Thailand, pp.28-31. In J.W. Turnbull, ed. Proceedings of an international conference, Eucalypts in Asia. ACIAR Proc. No. 111.

O’Brien, E.K., Mazanec R.A. and Krauss. S.L. (2007). Provenance variation of ecologically important traits of forest trees: implications for restoration. Journal of Applied Ecology, 44,583-593.

Pallett, R.N. and Sale, G. (2004). The Relative Contributions of Tree Improvement and Cultural Practice toward Productivity Gains in Eucalyptus Pulpwood Stands. Forest Ecology And Management, 193,33-43.

Pongpanich, K. (1998). Diseases of Eucalyptus in Thailand and options for reducing their impact, pp.47-52. In Hutacharern, C. and Nair, K.S.S. (Eds.) FORSPA Publication: 30/2002. Proceedings of the IUFRO/FAO workshop on forest management in tropical forest plantations. Chanthaburi, Thailand.

Pousajja, R. (1993). Eucalypt plantation in Thailand, pp.213-223. In Kashio, M. and White, K. (Eds.) FAO/RAPA Publication 1996/44, Regional Expert Consultation on Eucalyptus, Vol. II. Bangkok, Thailand.

Powell, M.B. and Nickles, D.G. (1996). Genetic parameter estimates and predicted breeding values for diameter, height, and stem straightness of Pinus elliottii, Pinus caribaea var hondurensis and their $\mathrm{F}_{1}$ hybrid, pp.169-172. In Dieters, M.J., Matheson, A.C., Nickles, D.G., Harwoods, C.E. and Walker, S.M. (Eds.). Proceedings QFRI-IUFRO Conference, Tree Improvement for Sustainable Tropical Forestry. Queensland Forestry Research Institute, Gympie.

Wei, X. and Borralho. N.M.G. (1998). Genetic control of growth traits of Eucalyptus urophylla S.T. Blake in South East China. Silvae Genetica 47,2-3

Sànchez, E.I., Hernandez, J.J.V., Upton, J.L. and de la Rosa, A.B. (2005). Genetic parameters for growth and wood density in juvenile Eucalyptus urophylla S.T. Blake. Agrociencia 39(4),469-479

Scanavaca Jr., L. and Garcia, J.N. (2003). Potential de melhoramento genético em Eucalyptus urophylla procedenteda Ilha Flores. Scientia Forestalis 64:23-32.

SPSS Inc. (2002). SPSS for Windows Version 11.5. SPSS Inc., U.S.

Zobel, B.J. and Talbert, J. (1984). Applied Forest Tree Improvement. John Wiley \& Sons Inc., New York. 
Table 1. Details of Eucalyptus urophylla seed sources for the provenance trials (1988) and progeny tests (2002) at Lad Krating Plantation, Thailand

\begin{tabular}{clcccc}
\hline $\begin{array}{c}\text { Provenance } \\
\text { No. }\end{array}$ & \multicolumn{1}{c}{ Provenance } & $\begin{array}{c}\text { Altitude } \\
(\mathbf{m})\end{array}$ & $\begin{array}{c}\text { Latitude } \\
(\mathbf{S})\end{array}$ & $\begin{array}{c}\text { Longitude } \\
(\mathbf{E})\end{array}$ & $\begin{array}{c}\text { No. of } \\
\text { families }\end{array}$ \\
\hline 1 & Mt. Egon, Flores & $400-890$ & $8^{\circ} 36^{\prime}$ & $122^{\circ} 28^{\prime}$ & 9 \\
2 & Mt. Wulogai, Flores & $1140-1240$ & $8^{\circ} 33^{\prime}$ & $121^{\circ} 48^{\prime}$ & 3 \\
3 & Mt. Wokoh, Flores & $850-900$ & $8^{\circ} 33^{\prime}$ & $122^{\circ} 36^{\prime}$ & 5 \\
4 & Mt. Lewerok, Flores & $500-550$ & $8^{\circ} 15^{\prime}$ & $122^{\circ} 40^{\prime}$ & 3 \\
5 & Mt. Mandiri, Flores & $500-650$ & $8^{\circ} 30^{\prime}$ & $122^{\circ} 54^{\prime}$ & 2 \\
6 & Mt. Lewotobi, Flores & $450-550$ & $8^{\circ} 22^{\prime}$ & $123^{\circ} 39^{\prime}$ & 8 \\
7 & Mt. Kerbau, Lomblen & $420-820$ & $8^{\circ} 22^{\prime}$ & $123^{\circ} 36^{\prime}$ & 3 \\
8 & Mt. Boleng, Flores & $915-1025$ & $8^{\circ} 21^{\prime}$ & $123^{\circ} 35^{\prime}$ & 1 \\
9 & Kalabahi, Alor & $450-850$ & $8^{\circ} 10^{\prime}$ & $124^{\circ} 41^{\prime}$ & 2 \\
10 & Ampui, Alor & $800-1200$ & $8^{\circ} 10^{\prime}$ & $124^{\circ} 41^{\prime}$ & 4 \\
11 & Mt. Sirung, Pantar & 760 & $8^{\circ} 26^{\prime}$ & $124^{\circ} 03^{\prime}$ & 6 \\
$12^{*}$ & Mt. Mutis, Timor & $800-2200$ & $8^{\circ} 34^{\prime}$ & $124^{\circ} 11^{\prime}$ & 2 \\
13 & Mt. Delaki, Pantar & $680-780$ & $8^{\circ} 26^{\prime}$ & $124^{\circ} 03^{\prime}$ & 2 \\
14 & Mt. Wasbilla, Pantar & $750-800$ & $8^{\circ} 34^{\prime}$ & $124^{\circ} 14^{\prime}$ & 9 \\
15 & Remexio, Timor & $800-930$ & $8^{\circ} 35^{\prime}$ & $125^{\circ} 41^{\prime}$ & 3 \\
$16^{* *}$ & Hatuloi, Wetar & 250 & $7^{\circ} 54^{\prime}$ & $125^{\circ} 58^{\prime}$ & 1 \\
18 & Lelogama, Timor & $1200-1300$ & $9^{\circ} 34^{\prime}$ & $124^{\circ} 20^{\prime}$ & 7 \\
19 & Ermera, Timor & $500-1400$ & $9^{\circ} 13^{\prime}$ & $125^{\circ} 40^{\prime}$ & 6 \\
22 & Ililaku, Wetar & $350-550$ & $7^{\circ} 54^{\prime}$ & $125^{\circ} 58^{\prime}$ & 1 \\
23 & Mt. Lakaan, Timor & $1350-1550$ & $9^{\circ} 34^{\prime}$ & $124^{\circ} 05^{\prime}$ & 2 \\
\hline
\end{tabular}

* $\quad$ Provenance died out

** Provenance excluded from analyses (no replication)

Table 2. Results from the analyses of variance for growth characteristics of Eucalyptus urophylla provenance trials periodic assessment at Lad Krating Plantation

\begin{tabular}{|c|c|c|c|c|c|c|c|c|c|}
\hline $\begin{array}{c}\text { ASSESSMENT } \\
\text { PERIOD }\end{array}$ & & \multicolumn{2}{|c|}{6 years } & \multicolumn{2}{|c|}{8 years } & \multicolumn{2}{|c|}{10 years } & \multicolumn{2}{|c|}{16 years } \\
\hline $\begin{array}{l}\text { SURVIVAL } \\
\text { Trial mean (\%) }\end{array}$ & & \multicolumn{2}{|c|}{85.1} & \multicolumn{2}{|c|}{79.7} & \multicolumn{2}{|c|}{75.3} & \multicolumn{2}{|c|}{54.3} \\
\hline Source of variance & d.f. & $\mathrm{ms}$ & $\mathrm{F}$ & $\mathrm{ms}$ & $\mathrm{F}$ & $\mathrm{ms}$ & $\mathrm{F}$ & $\mathrm{ms}$ & $\mathrm{F}$ \\
\hline Replication & 3 & 342.10 & $4.91 *$ & 371.56 & $5.22 * *$ & 576.89 & $8.09 * *$ & 544.77 & $3.93 *$ \\
\hline Provenance & 22 & 426.62 & $6.21 *$ & 497.92 & $7.00 * *$ & 915.78 & $2.84 * *$ & 1230.31 & $8.87 * *$ \\
\hline Residual & & 69.66 & & 71.12 & & 71.34 & & 138.70 & \\
\hline \multicolumn{10}{|l|}{ TOTAL HEIGHT } \\
\hline Source of variance & df & $\mathrm{ms}$ & $\mathrm{F}$ & $\mathrm{ms}$ & $\mathrm{F}$ & $\mathrm{ms}$ & $\mathrm{F}$ & $\mathrm{ms}$ & $\mathrm{F}$ \\
\hline Replication & 3 & 7.49 & $5.07 * *$ & 5.20 & $1.70^{\mathrm{ns}}$ & 6.60 & $3.22 *$ & 46.09 & $10.82 * *$ \\
\hline Provenance & 22 & 10.51 & $6.21 * *$ & 19.61 & $6.42 * *$ & 13.06 & $6.37 * *$ & 12.69 & $2.98 * *$ \\
\hline Residual & & 1.48 & & 3.05 & & 2.05 & & 4.60 & \\
\hline \multicolumn{10}{|l|}{ Dbh } \\
\hline Trial mean $(\mathrm{cm})$ & & \multicolumn{2}{|c|}{16.3} & \multicolumn{2}{|c|}{17.7} & \multicolumn{2}{|c|}{18.9} & \multicolumn{2}{|c|}{23.6} \\
\hline Source of variance & df & $\mathrm{ms}$ & $\mathrm{F}$ & $\mathrm{ms}$ & $\mathrm{F}$ & $\mathrm{ms}$ & F & $\mathrm{ms}$ & $\mathrm{F}$ \\
\hline Replication & 3 & 2.52 & $1.21^{\mathrm{ns}}$ & 2.02 & $2.21^{\mathrm{ns}}$ & 1.80 & $1.85^{\mathrm{ns}}$ & 110.87 & $7.29 * *$ \\
\hline Provenance & 22 & 5.51 & $2.64 * *$ & 5.50 & $6.01 * *$ & 5.21 & $5.35 * *$ & 24.55 & $1.61^{* *}$ \\
\hline Residual & & 2.08 & & 0.91 & & 0.97 & & 15.20 & \\
\hline \multicolumn{10}{|l|}{ Dgl } \\
\hline Trial mean $(\mathrm{cm})$ & & \multicolumn{2}{|c|}{19.6} & \multicolumn{2}{|c|}{21.2} & \multicolumn{2}{|c|}{22.6} & \multicolumn{2}{|c|}{29.8} \\
\hline Source of variance & df & $\mathrm{ms}$ & $\mathrm{F}$ & $\mathrm{ms}$ & $\mathrm{F}$ & $\mathrm{ms}$ & $\mathrm{F}$ & $\mathrm{ms}$ & $\mathrm{F}$ \\
\hline Replication & 3 & 4.62 & $4.22 * *$ & 3.65 & $2.87 *$ & 4.24 & $3.21 *$ & 26.72 & $9.73 * *$ \\
\hline Provenance & 22 & 5.72 & $5.32 * *$ & 7.52 & $5.92 * *$ & 8.00 & $6.05 * *$ & 10.70 & $3.90 * *$ \\
\hline Residual & & 1.09 & & 1.27 & & 1.32 & & 2.74 & \\
\hline
\end{tabular}


Table 3. Results from the analyses of variance for growth characteristics of 3-year old Eucalyptus urophylla progeny tests at Lad Krating Plantation

\begin{tabular}{|c|c|c|c|c|c|c|c|c|c|c|}
\hline \multirow[t]{2}{*}{$\begin{array}{l}\text { Source of } \\
\text { variation }\end{array}$} & \multirow[t]{2}{*}{ df } & \multicolumn{2}{|c|}{$\begin{array}{c}\text { Survival } \\
(\%)\end{array}$} & $\begin{array}{l}\text { Total Height } \\
\text { (m) }\end{array}$ & \multicolumn{2}{|c|}{$\begin{array}{l}\text { Dbh } \\
(\mathrm{cm})\end{array}$} & \multicolumn{2}{|c|}{$\begin{array}{l}\mathrm{Dgl} \\
(\mathrm{cm})\end{array}$} & $\begin{array}{l}\text { Crown diam. } \\
\text { (m) }\end{array}$ & Stem form \\
\hline & & $\mathrm{ms}$ & $\mathrm{F}$ & $\mathrm{ms}$ & $\mathrm{ms}$ & $\mathrm{F}$ & $\mathrm{ms}$ & $\mathrm{F}$ & $\mathrm{ms}$ & $\mathrm{ms}$ \\
\hline Replicate & 11 & 0.29 & $2.27^{\mathrm{ns}}$ & $115.453 .8^{* *}$ & 6.98 & $6.20 * *$ & 18.4 & $12.4^{* *}$ & $3.6125 .62 * *$ & $20.047 .45^{* *}$ \\
\hline Family & 79 & 0.84 & $1.43^{* *}$ & $2.6^{* *}$ & 4.10 & $4.42 * *$ & 5.23 & $3.84 * *$ & $0.342 .05^{* *}$ & $5.562 .07 * *$ \\
\hline Residual & 89 & 0.42 & & 3.0 & 0.93 & & 1.35 & & 0.17 & 2.68 \\
\hline Mean & & & 7.3 & 12.1 & & 0.4 & & 3.8 & 1.9 & - \\
\hline $\mathrm{h}_{\mathrm{f}}^{2}$ & & & 30 & 0.61 & & .77 & & .74 & 0.51 & 0.52 \\
\hline
\end{tabular}

Ns Non-significant

* $\quad$ Significant differences $(\mathrm{p}<0.05)$

** Highly significant differences $(\mathrm{p}<0.01)$

Dbh: Diameter at breast height; $\quad$ Dgl: Diameter at ground level;

$\mathrm{h}_{\mathrm{f}}{ }^{2}$ : Family heritability

(a)

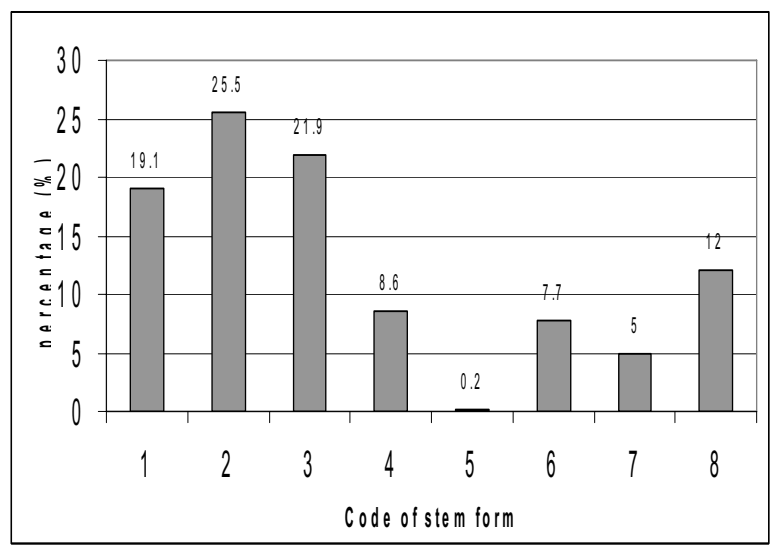

(b)

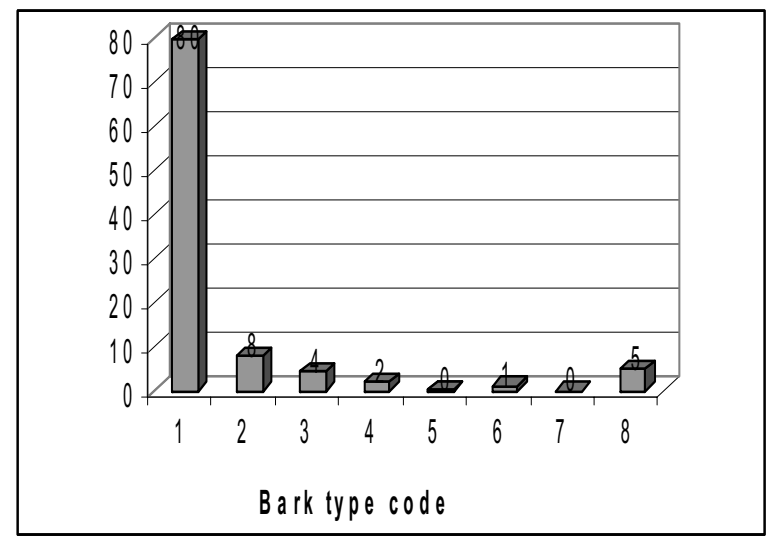

Stem forms: 1 Straight; 2 Curved; 3 Twisted, 4 Leaning, 5 Two Stem, 6 Two top, 7 Nested, 8 Short bole

Figure 1. Distribution of stem form in each experiment.

(a) Distribution of stem form in the provenance trials.

(b) Distribution of stem form in the progeny tests. 


\title{
Multiple Time Scales Analysis of Precipitation in Hotan, China
}

\author{
Jiqing Lv \\ Graduate student for Master Degree, Xi'an University of Technology \\ Xi'an 710048, China \\ Tel: 86-29-82312028_E-mail: lvjiqiang0721@gmail.com \\ Bing Shen \& Shuhong Mo \\ Faculty of College of Water Resources and Hydropower Engineering \\ Xi'an University of Technology \\ Xi'an 710048, China
}

\begin{abstract}
The wavelet transform and detrended fluctuation analysis (DFA) were introduced briefly. Then DFA and discrete wavelet were used to analyze the fluctuation characteristics of precipitation in Hotan from 1954 to 2003. It was shown by analysis with the methods of de-trend fluctuation and wavelet transform that the precipitation in Hotan will decreased in near future for several years, and will last 21 months at least.
\end{abstract}

Keywords: Hotan, Precipitation, DFA, Wavelet analysis

\section{Introduction}

Wavelet analysis is a subject which developed on the basis work of Y. Meyer, S. Mallat and I. Daubechies in 1986, as the epoch-making development results of Fourier analysis. P. Kumar and Foufoula-Gegious introduced orthogonal wavelet transformation to hydrology in 1993, which has made considerable achievements, mainly in the time-scale hydrological analysis, and so on. In 1993, P. Kumar and Foufoula- Gegious studied the space-scale precipitation and vibration characteristics by means of orthogonal wavelet transformation, which shows that there is a variety of components in the precipitation scale of the self-similarity and the time scale (You Wei-hong et al., 1999).

De-trend fluctuation analysis (DFA) is widespread in physics, chemistry, biology and other natural phenomena and even the climate system, in particular the considerable power measurement function which can be used to examine the complexity of the sequence of rainfall, as the basis theory and the law Practical ways in semi-arid area of rainfall research. Peng (C K Peng et al., 1993) etc. introduced the DFA approach in testing of related properties in long-chain molecules, and soon be used in many fields, such as DNA sequencing, physiology, the stock market, cloud structure, economic time series, and physics. It can also be used in climate research. DFA has a significant advantage in analysis of trends and the composition of the noise sequence scale, which depicts the relevant characteristics of the object sequence, and so on. But analysis on the de-trend fluctuation and long-range correlation to describe the characteristics of rainfall is in its infancy (Penzel et al., 2003)

Hotan oasis is located on the southern margin of the Tarim Basin in Xinjiang, the region precipitation is scarce, evaporation is dramatic, light-rich geothermal resources, belong to a typical continental arid climate(Shen Bing et al., 2003). Irrigated oasis and natural desert oasis form the green corridor which is the basic element of socio-economic development and the ecological environment development of Hotan Area. Water resources is the basic elements of survival and sustainable development for the region (Abdirahman. Halik et al., 2006). In this paper, the changes in the characteristics of precipitation from 1954 to 2003 are studied by means of wavelet and de-trend fluctuation analysis.

\section{Methods}

\subsection{Wavelet theory}

Wavelet theory outlined in the climate signal function $\mathrm{F}(t)$ of the continuous wavelet transform, said:

$$
W_{f}(s, \tau)=\int_{R} f(t) \bar{\psi}(s, \tau) d t
$$

Where, $W_{f}(s, \tau)$ is the wavelet coefficient. The wavelet can be defined as $\left|W_{\mathrm{f}}(s, \tau)\right|^{2}$ to reflects the energy size of the signal amplitude. In practical applications, time series are often discrete, the discrete form is: 


$$
W_{f}(s, \tau)=\Delta t \sum_{i=1}^{n} f(i \Delta t) \psi\left(\frac{i \Delta t-b}{a}\right)
$$

Wavelet coefficients can reflect variation characteristics of the system in the time scale corresponding to the period of rainfall. The positive wavelet coefficients correspond to the period of rainfall on the high side, the negative wavelet coefficients correspond to the period of the low rainfall (Huang Qing-qing et al., 2007). Morlet wavelet functions were selected as the generating function in this paper.

2.2 The detailed formulae description of detrended fluctuantion analysis was given as follows:

Here $X_{i}$ is the time series, $i=1,2,--; N$

$$
\bar{X}=\frac{1}{N} \sum_{i=1}^{N} X_{i}
$$

First, the series is integrated

$$
Y(i)=\sum_{i=1}^{N}\left(x_{i}-\bar{x}\right)
$$

The integrated series is separated into $N_{h}$ boxes with equal length $h$. That is $N_{h}=\operatorname{int}(N / h)$. And no overlaped segments are in the boxes.

In order to make full use of the data, we do the separated step from tail to head again. So, $2 N_{h}$ segments are obtained altogether.

Next, for each interval $v, v=N_{h}+1 \ldots 2 N_{h}$. Here $Y_{h}(i)$ is the fitting line for segment $v$.

$$
Y_{h}(i)=Y(i)-P_{v}(i)
$$

Then the de-trend fluctuation function is:

$$
F(h)=\sqrt{\frac{1}{2 N_{h}} F^{2}(v, h)}
$$

Finally,repeating the procedure described above. If time series $X_{i}$ is of long range correlation, then

$$
F(h) \sim h^{a}
$$

The index $\alpha$ is called generalized DFA exponent, which reflects the sequence of long-range correlation.

The scale index $\alpha$ meaning (Luciano Telesca et al., 2004 \& Ping Zhou et al., 2007):

a) $1>a>0.5$, if the DFA exponent is between 0.5 and 1 , the change trend will continue as the the former.

b) $0<a<0.5$, If its DFA exponent is less than 0.5 , the serie is a antipersistence sequence.

c) If the DFA exponent equals 0.5 , the series is a random sequence.

\section{Results and Conclusions}

Changing trend analysis of precipitation time series

The results show that the distribution of long year average precipitation in the Hotan has an obvious annual variation as shown in Figure 1 and Figure 2. The annual average precipitation was $35.7 \mathrm{~mm}$ (from 1954 to 2003), and changed from $3.4 \mathrm{~mm}$ (1985) to $100.9 \mathrm{~mm}$ (1987), there is a increasing trend from 1975-2003, but a slow decreasing trend before 1975.

\subsection{DFA analysis of Hotan precipitation series}

Figure 3 is the Cumulative differential curve of precipitation time series. Figure 4 is the generalized Hurst exponents $a$ using DFA Method, where $a_{1}=0.596, a_{2}=0.4081$.

The scaling index $a_{2}=0.4081$, shows that the series is a anti-persistence sequence in large-scale. And the precipitation will reduce in large-scale; $a_{l}=0.596$, which shows that the decreasing trend will continue at least 21 months.

\subsection{Wavelet analysis of Hotan precipitation time series}

The curves of wavelet variance(Figure 5) shows that primary cycles of annual precipitation in past 50 years are separately 27, 13 and 4 years. The wavelet transformation coefficient (Figure 6) shows that 13 years cycle mainly existed before the 1990s and then reduced. The 27 years and 4 years period existed between the mid-1950s and the early 21 st century. These express that the time series of annual precipitation in Hotan has gone through the process that small size year cycle weaken while mid-sized and large years cycle enhanced in the past 50 years. In particular the wavelet transformation coefficient of quasi-27-year period is developing.

The positive wavelet coefficients correspond to the period of rainfall will increase and the negative wavelet coefficients 
correspond to the period of low rainfall. Hotan in recent years, a 27-year period of negative wavelet coefficients is developing, which indicates the future may be less precipitation in the region.

\subsection{Conclusion}

It was shown by analysis with the methods of de-trend fluctuation and wavelet transform that the precipitation at Hotan will decrease in near future for several years, the trend will be lasting for, at least, 21 months.

\section{References}

Abdirahman. Halik, \&Kirimja. (2006). Study on water resources utilization and ecological environmental building of Hotan river Xin jiang. Areal research and development,25, 111-114.

Peng C K,Buldyrev SV,\&Havlin S,et al. (1994). Mosaic organization of DNA nucleotides. Phys Rev E,49,1685,1689.

Huang, Qing-qing,\&Huang,Mao-dong et al. (2007). Meizhou in the last 50 years of rainfall characteristics. Guangdong Meteorology, 29, 37-38.

Luciano Telesca,Gerardo Colangelo, \& Vincenzo Lapenna et al. (2004). Fluctuation dynamics in geoelectrical data: an investigation by using multifractal detrended fluctuation analysis. Physics Letters A, 332, 398-404.

Penzel,T.,Kantelhardt, J.W.,Grote, L.,Peter, \& J.H., Bunde. (2003). A Comparison of Detrended Fluctuation Analysis and Spectral Analysis for Heart Rate Variability in Sleep and Sleep Apnea. IEEE Trans Biomed Eng, 50, 43-1151.

Zhou, Ping, Li, Feng, Liu, Wen-Yan and Yang, Miao. (2007). Fractal analysis in normal EEG and epileptic EEG of rats. IFMBE Proceedings, 1266-1269.

Shen, Bing, Huang, Ling-mei et al. (2003). Study on the water cycling characteristics of Hotan oasis during the second half of last century. Hydraolic Engineering, 5, 78-83.

You, Wei-hong, Qi, Ming-hui, Duan, Xu. (1999). Wavalet tarnsforms' applications to researches on model of short range. Plateau Meteorology, 18, 39-46.

Van der Geer,J., Hanraads, J. A. J.,\&Lupton R. A. (2000). The art of writing a scientific article. Journal of Scientific Communications, 163, 51-59.

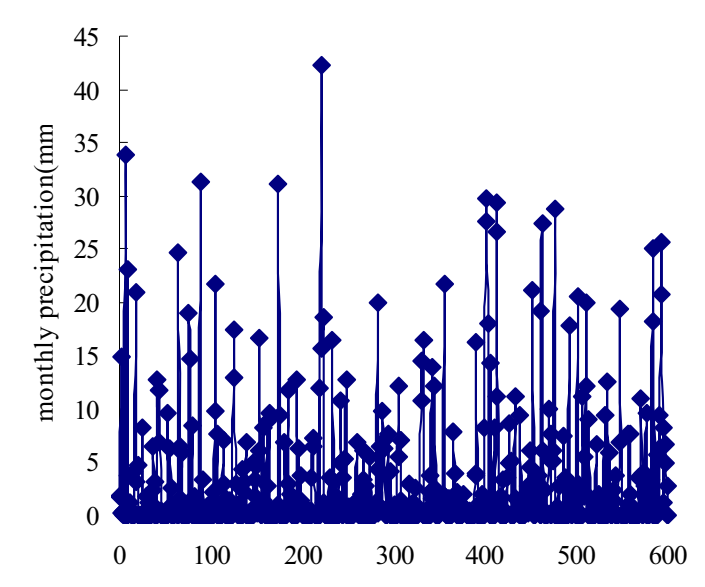

Figure 1. Monthly series process of precipitation in Hotan

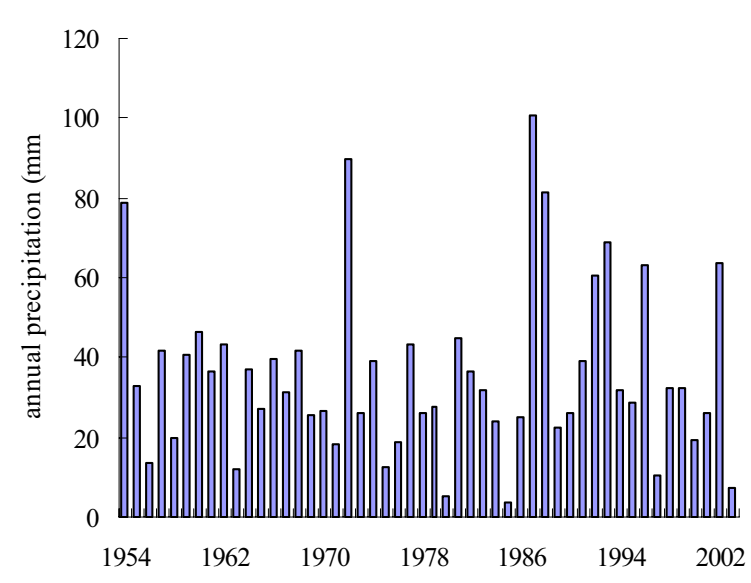

Figure 2. Yearly series process of precipitation in

Hotan 


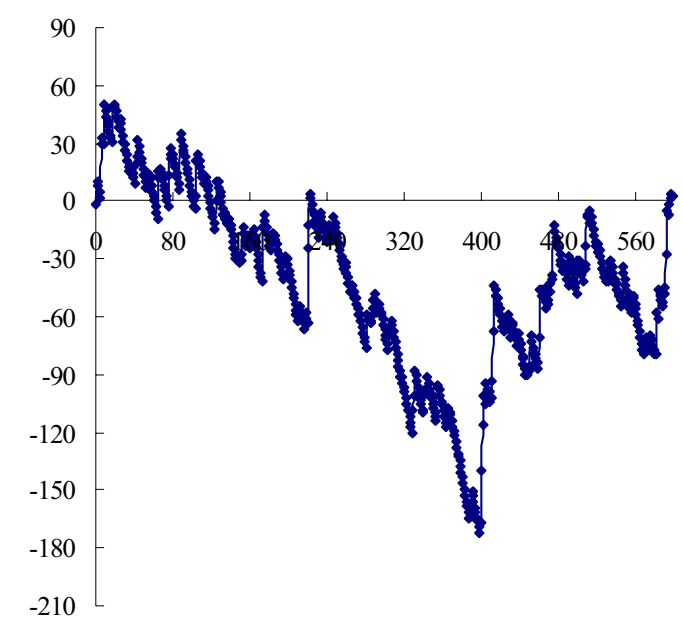

Figure 3. Cumulative differential curve of precipitation series

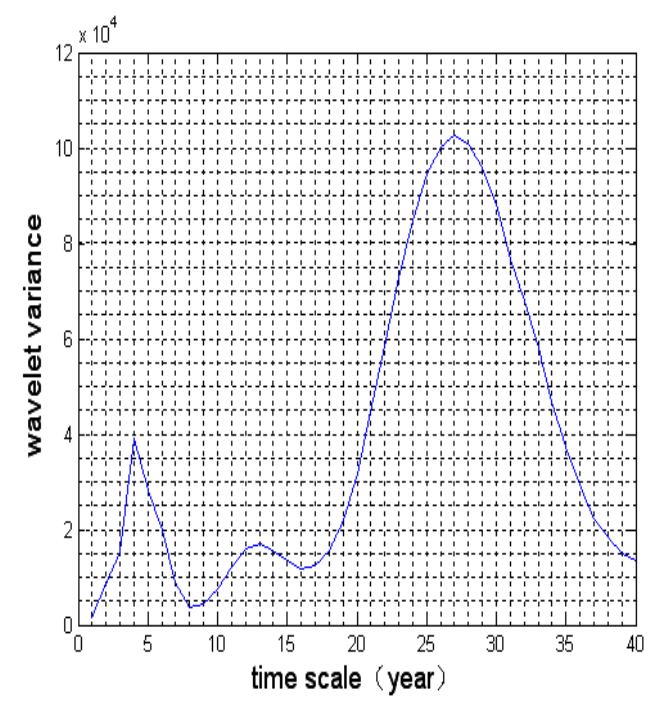

Figure 5. wavelet variance diagram

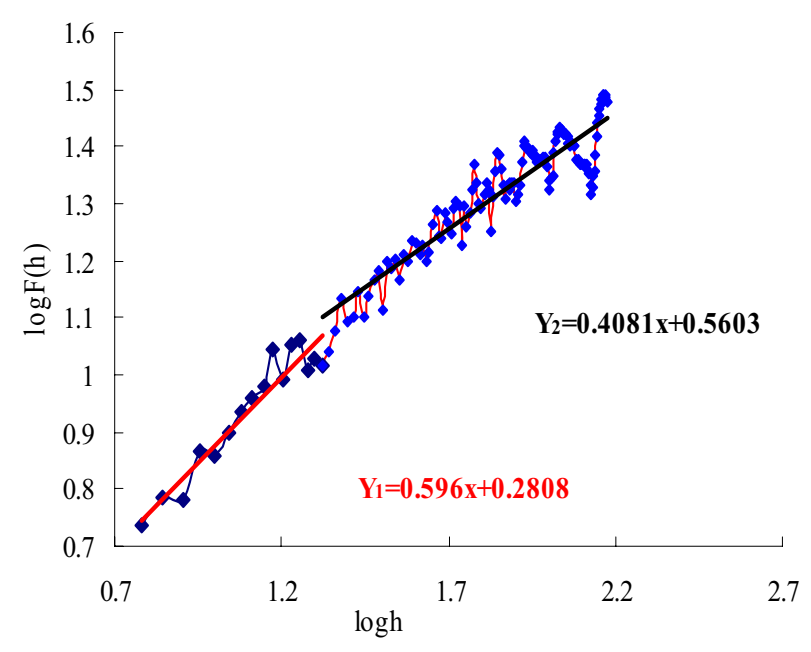

Figure 4. The detrended fluctuation of the precipitation series

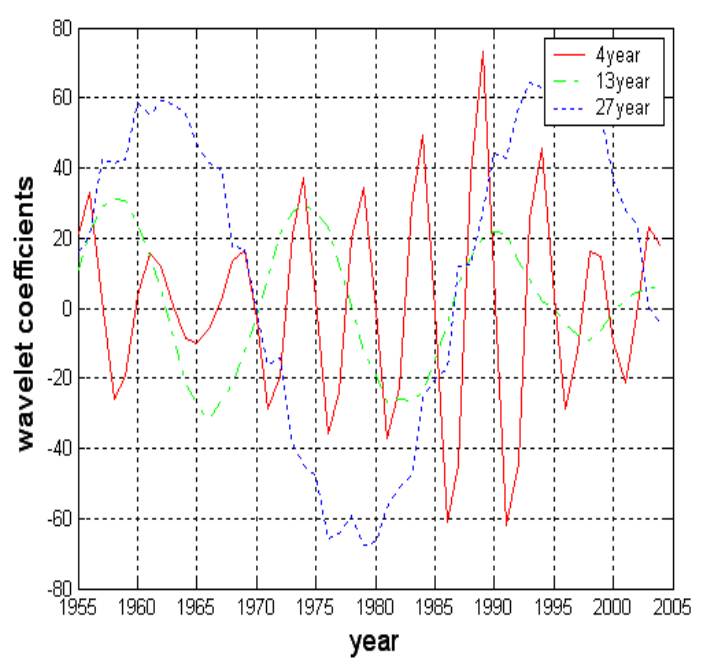

Figure 6. wavelet transformation coefficient diagram 


\title{
Post Occupancy Evaluation towards Indoor Environment Improvement in Malaysia's Office Buildings
}

\author{
Natasha Khalil \& Husrul Nizam Husin \\ Department of Quantity Surveying, Faculty of Architecture, Planning \& Surveying \\ University Technology of MARA Perak, Malaysia
}

Tel: 60-5-374-2000_E-mail: natas582@perak.uitm.edu.my, husrul820@perak.uitm.edu.my

\begin{abstract}
The indoor environmental factors considered in office building must be determined in order to meet user's requirement. Disruption of indoor environment may constitute to reduce occupants' efficiency and work productivity. Therefore, Post-occupancy Evaluation (POE) is a prominent tool that able to indicate satisfaction and comfort level needs by building occupants as lessons learned to identify problems in indoor environment. By using occupants as benchmark of evaluation, the potential of improving the indoor environment in buildings is enormous. With relation to the title, the main purpose of this study is to provide recommendation to improve quality of indoor environment in office building, by analytical study on the level of effort and phases of conducting POE and determining occupant's satisfaction level. The survey used in conjunction with physical measurements to determine how environmental factors affect occupants' perceived comfort and productivity levels, and a benchmarking example of using the survey to establish how new buildings are meeting a client's design objectives. It is recommended that the application of POE is prioritized as strategic level decision making and emphasized as continuous activity in environmental evaluation.
\end{abstract}

Keywords: Post Occupancy Evaluation, Office Buildings, Indoor Environment, Comfort Level

\section{Introduction}

In the current situation where people concerns about sustainability environment, building occupants seek to obtain comfort and efficiency in their office. Occupants demand to have priority in terms of comfortability to use and utilize the facilities and services as it must be fit for purpose of the user. Work productivity of workers may be demotivated and interrupted due to poor environmental conditions. The question is, how to ensure that the indoor environment of the building is met the user's satisfaction? Is the building element and facilities fit for the user's purpose and well function? Post Occupancy Evaluation (POE) is one of strategic implementation of analysis on building sustainability after occupancy. POE has been defined by Zimring and Reizenstein (1980) as examination of the effectiveness for human users of occupied design environment.

POE systematically analyses a particular environment to gain understanding of the impact it as on occupants of a building and its environment, hence how it facilitates or inhibits daily activities of the occupants. Information of the building's condition is gained by reviewing what the occupants' feel and how they response to their needs by use and occupy the building. Among the benefits gathered from POE is it helps to identify successful design features to repeat (Watson,2003), identify problems to mitigate or reduce, improve building environment and performance (Vischer,2002; Hewitt et. al, 2005), fine tune completed buildings, identify redundant or unnecessary building features, empower users to negotiate building issues and others.

Sekhar, Tham \& Cheong (2002) pointed that occupant surveys and interviews with the building manager would provide additional information, which represent the evaluation of the users of the building. This paper is therefore purposely to determine occupants' satisfaction in terms of indoor environment, namely i) level of cleanliness, ii) visual comfort, iii) thermal comfort, iv) air movement, and v) noise pollution. This study is limited to the building occupants in one building only.

\section{Problem Statement}

The climate of Malaysia referring to Yuan (1987) can be classified as warm-humid equatorial, characterized by high temperatures and humidity. Air temperature averages within 22 and 32 degree Celsius with small annual and diurnal ranges. It is continually near but seldom exceeds normal skin temperature. The location of Malaysia which is under tropical climate region is naturally hot and a humid climate. Seeing this situation, majority of office buildings in Malaysia served air-conditioning and mechanical ventilation systems to maintain a thermally comfortable indoor environment. Rapid development of office building which is normally located in the city area incorporates issues in 
terms of cleanliness, noise and air pollution. According to Cheong and Chong (2001), the provision of comfortable indoor environment for the occupants is the only aspect in achieving better indoor air quality. Chemical pollutants, volatile organic compound, noise pollution or pollutant contaminants are among of factors that can have impact on the quality of indoor environment. Pollutant emissions from human activities, building materials, air handling units, etc. in the form of both living and dead material take place continuously in any type of buildings.

Over the last 20 years, a range of POE methods have been developed and their systematic application has demonstrated a huge potential not only to reduce the financial and environmental costs, but also to improve the quality of life, comfort and productivity of building (Nicol and Roaf, 2005). All these factors place constraints on the ventilation design, and if this is poor, it can lead to the deterioration of indoor air quality, thermal comfort and disrupt work productivity of building user.

\section{Research Objectives}

The introduction and the problem statement above led to the formulation of the author's study objectives. The objectives for this study are:

i) To determine occupants' satisfaction and perception level in their office buildings; in terms of indoor environment i.e. thermal comfort, air movement, visual comfort, noise pollution and cleanliness.

ii) To suggest and recommend ways to improve office indoor environment

\section{Research Methodology}

Generally, there are 3 phases of methodology for this research. The first phase in doing this research is to define the area of study, the concept, approaches and scope of POE by review precedent research and literature review of POE. The problem identification is reviewed through various sources of literature, observation, study visits and unstructured interviews. The second phase is by analysis of survey by developing and distributing questionnaire to building occupants' in one sample office building. All collected data is analyzed to get findings of the research and to achieve the research objectives. After analysis being reviewed, the author suggests and recommends ways to improve the indoor building environment. In the third phase, the author concludes all findings and provides future study recommendation.

\section{Literature Review}

POE in the 1960s and 1970s involved in individual case studies of public and student housing sector (Vischer,2002; Zimring, Rashid \& Kampschroer,2000) in Britain, France, Canada and United States. The evaluation is primarily involved collecting information about occupants and building through questionnaires, interviews, site visits, and field observation. It was then widespread to other facilities such as army barracks, hospitals, prisons, courthouses and hospital. By seeing the logical step and beneficiary results from POE, it was later applied to commercial real estate and office buildings by the mid of 1980s. Information from POE has been used by the public agencies in support of the design criteria and guidelines. POE programmes are conducted by a number of project team after construction in order to identify lessons learned by analysis of findings.

POE are typically performed within 4 to 24 months following occupancy of a new or renovated facility and are performed only once for an individual building. However, Watson (2003) in his opinion states that POE can be conducted at any time in the life of a building and it is not necessary to conduct in between the time frame. In POE, occupants ask questions and also provide answers to design professionals. As the design is applied the occupants begin to understand the implications of the spaces and facilities they asked for. Designers get a view of what users need and what is important. The consequences from the evaluation able to presents other objectives like provide design consideration for environment improvement, reduce maintenance and operation costs. Figure 1 illustrates the indoor environment audit methodology that commence with an investigation of the issues and characteristics of the indoor environment.

A POE study conducted by Kavgic et. al (2007) at a theatre in Belrade, Montana is purposely to identify where improvements could typically be made based on the results of monitoring (temperature, relative humidity, air speed and heat flux) as well as the assessment of comfort and health as perceived by occupants. The study has shown that for most of the monitored period the environmental parameters were within the standard limits of thermal comfort and Indoor Act Quality (IAQ). Another survey conducted by Wagner et. al (2007) on workplace occupant satisfaction in 16 office buildings in Germany revealed that the occupants' control of the indoor climate and moreover the perceived effect of their intervention strongly influence their satisfaction with thermal indoor conditions. These precedent research has showed the significant contribution of POE result towards improving indoor environment not only to office buildings, but also to other type of buildings i.e. residential, schools, religious, commercial etc.

\subsection{Process of $P O E$}

Generally, there are three (3) phases and steps involved in conducting POE. The phases of POE process are namely, i) planning, ii) conducting and iii) applying. 
- Planning

During the planning, all preliminaries agendas such as objectives of conducting POE are defined. This is to ensure that POE is organized and initiate the process of evaluation. It also can be called as pre evaluation phase, where it determine feasibility study of a building, review and provide analysis of building performance, define the strength and weakness of the building and identify who are the building users or occupants. This is vital in establishing research plan before evaluation starts. Strategic levels then require to proposed manpower or resources to sense of the data in terms of the questions asked in the beginning of research.

\section{- Conducting}

Data collection is the key task in conducting POE. At this phase, the building users are identified in order to develop data collection; whether based on interviews or questionnaire. This phase is where the evaluation takes place and it is important to ensure that all data collection procedures are monitored and managed. After evaluation conducted, the data is analyzed. This involved the finding and making sense of the data in terms of the questions asked in the beginning of research.

\section{- Applying}

Application of POE involves reporting the findings, recommending and planning actions. The report finding depends on the purpose to conduct. The purpose could identify problem and unsuccessful performance in facilities. Reports findings are implemented, actions are taken and the effects of the actions are measured.

\section{Analysis and Findings}

The sample building is categorized under private office building which is located at the golden triangle area in Kuala Lumpur. There are 60 questionnaires distributed to the building occupants. All of occupants of the building were desk-based and the arrangement offered a mix of single occupancy rooms, low-occupancy open plan rooms and high-occupancy larger open plan rooms.

A self-administered questionnaire which format is based on Likert-Scale is prepared for the answers rate by the respondents. The Likert-Scale consists of 5 numerical nomenclatures indicating the responses given by the respondents on each question, which are ranging from " 1 " to " 5 ". Table 1 presents the result of satisfaction and perception level in terms of indoor environment in percentage composition.

Based on summary exhibits in table 1, majority of the respondents are in comfort level in terms of building cleanliness and noise pollution. However, the highest percentage indicated as uncomfortable environment in the office is in terms of cooling system $(73 \%)$, natural day lightings $(53 \%)$, provision of air movement $(40 \%)$ and also quality of indoor ventilation (47\%). In terms of occupants comfort level in the building unit, $40 \%$ of the respondents are in medium rating only (Figure 2). Majority of the respondents indicated that their work productivity is decreased due to poor indoor environmental, which constitute to $47 \%$ out of total respondents (Figure 3 ).

Based on the survey findings, it can be concluded that visual comfort, indoor air movement and ventilation constitute the highest factor in terms of occupants' comfortability. Therefore, the author recommends several ways to mitigate the problems associated with indoor environment in office buildings:

a)

Cooling system (Air Conditioning)

Allow staff to have control of the cooling temperature. The centralized cooling system should be replaced Allow staff to have control of the cooling
to split unit as the gross floor area is not very spacious.

b) Visual Comfort (Day Lightings)

- $\quad$ Provide day lightings integrated with electric lighting controls in several area provisions. For example, provision of atrium and curtain glass walls.

- Allocate larger and higher window openings to improve daylight penetration

- $\quad$ Provide view space facing outdoor environment and to perceive natural day light

c) Indoor Air Movement and Ventilation

- $\quad$ Provide $\mathrm{CO} 2$ sensor during periods of high occupancy whereby the $\mathrm{CO} 2$ sensor alerts the system to draw air from adjacent zones to increase fresh air ventilation

- $\quad$ Provide ventilation fans in the office common areas to regulate proper air circulation

- $\quad$ Provide moisture control to prevent bad smells to office common area

In general, quality of indoor environment in office buildings can be improved by:

- $\quad$ Use recyclable or renewable materials to avoid emission of chemical or microbial contaminants. For example, materials for furniture, finishes. 


$\begin{array}{ll}- & \text { Use environmentally-products } \\ \text { service } & \text { Public awareness to practice a healthy environment and promote more campaigns through community } \\ \text { - } & \text { Emphasize energy-efficient design in office buildings }\end{array}$

\section{Research Conclusion and Recommendations}

It can be concluded that POE provides significant impact on creating change in terms of improving building environment in two ways. Firstly, by providing lessons and feedback for the owner or those involved in the environment improvement works. They can lead towards enhanced quality of indoor environment by sensitivity to changing needs of occupants. Secondly, by empowering end-users as post-occupancy evaluation that provides benchmark and a pool of analysis to show how the end product i.e. the building design and its environment management, meets the needs of its client and users. By effective implementation of POE, it enables the relevant stakeholder to shorten the learning time about the positive and negative environment changes.

By providing opportunities for improvement of various stages of building processes, and of the relationships between environment and behavior among owners, users, and designers, POE endow significant role to play in the building industry. It is suggested that POE should be implemented as a real practice in Malaysia as benchmarking towards sustainable environment. Ideally, POE must be e a continuous activity to evaluate the performance of building in certain duration of time. Continuous programmes of POE not only able to identify problems constitute to disruption in building performance, but also able to avoid emergence of defect or deterioration. By providing lesson learned derived from application of POE, it should be incorporated in the early design phase and planning for any buildings. All construction players should prioritize the application of POE as strategic level decision making to maintain sustainable environment.

\section{References}

Cheong, K.W and Chong, K.Y. (2001). Development and application of an indoor air quality audit to an air-conditioned building in Singapore. Building and Environment. Vol. 36 pp 181-188.

Hewitt, D., Higgins, C., and Heatherly, P. (2005). A market-friendly Post Occupancy Evaluation:Building Performance Report. New Buildings Institute, Inc, Washington.

Kavgic, M., Mumovic, D, Stevanovic, Z. and Yound, A. (2007). Analysis of thermal comfort and indoor air quality in a mechanically ventilated theatre. Energy and Buildings. pp 1-10.

Nicol, F. and Roaf, S. (2005). Post Occupancy Evaluation and Field Studies of Thermal Comfort. Building Research and Information. 33(4), pp 338-346.

Sekhar, S.C., Tham, K.W. and Cheong, D. (2002). Ventilation characteristics of an air-conditioned office building in Singapore. Building and Environment. Vol 37, pp 241-255.

Vischer, J. (2002). Post Occupancy Evaluation: A Multifaced Tool for Building Improvement. Federal Facilities Council. US: The National Academy Press. Chapter 3 pp. 23-34.

Watson, C. (1996). Evolving Design for Changing Values And Ways Of Life. A Paper for IAPS 14 Conference in Stockholm. Evolving Environmental Ideals; Changing Ways of Life, Values And Design Practices.

Watson, C. (2003). Review of building quality using post occupancy evaluation. Journal of Programme Education Building. Vol. 35, pp. 1-5.

Wagner, A., Gossauer, E., Moosmann, C., Gropp, Th., and Leonhart, R. (2007). Thermal comfort and workplace occupant satisfaction - Results of field studies in German low energy office buildings. Energy and Buildings. Vol. $39 \mathrm{pp}$ 758-769.

Yuan, L.J. (1987). The Malay House: Rediscovering Malaysia's Indigenous Shelter System, Penang. Institute Masyarakat, Malaysia.

Zimring, C. and Reizenstein, J. E. (1980). Post-Occupancy Evaluation: An Overview in Environment and Behavior. Vol 12: pp 429-451.

Zimring, C., Rashid, M. and Kampschroer, K. (2000). Facility Performance Evaluation. In Lawrence Federal Green Construction Guide for Specifies. US: General Services Administration. 
Table 1. Result of Satisfaction and Perception Survey from Occupants

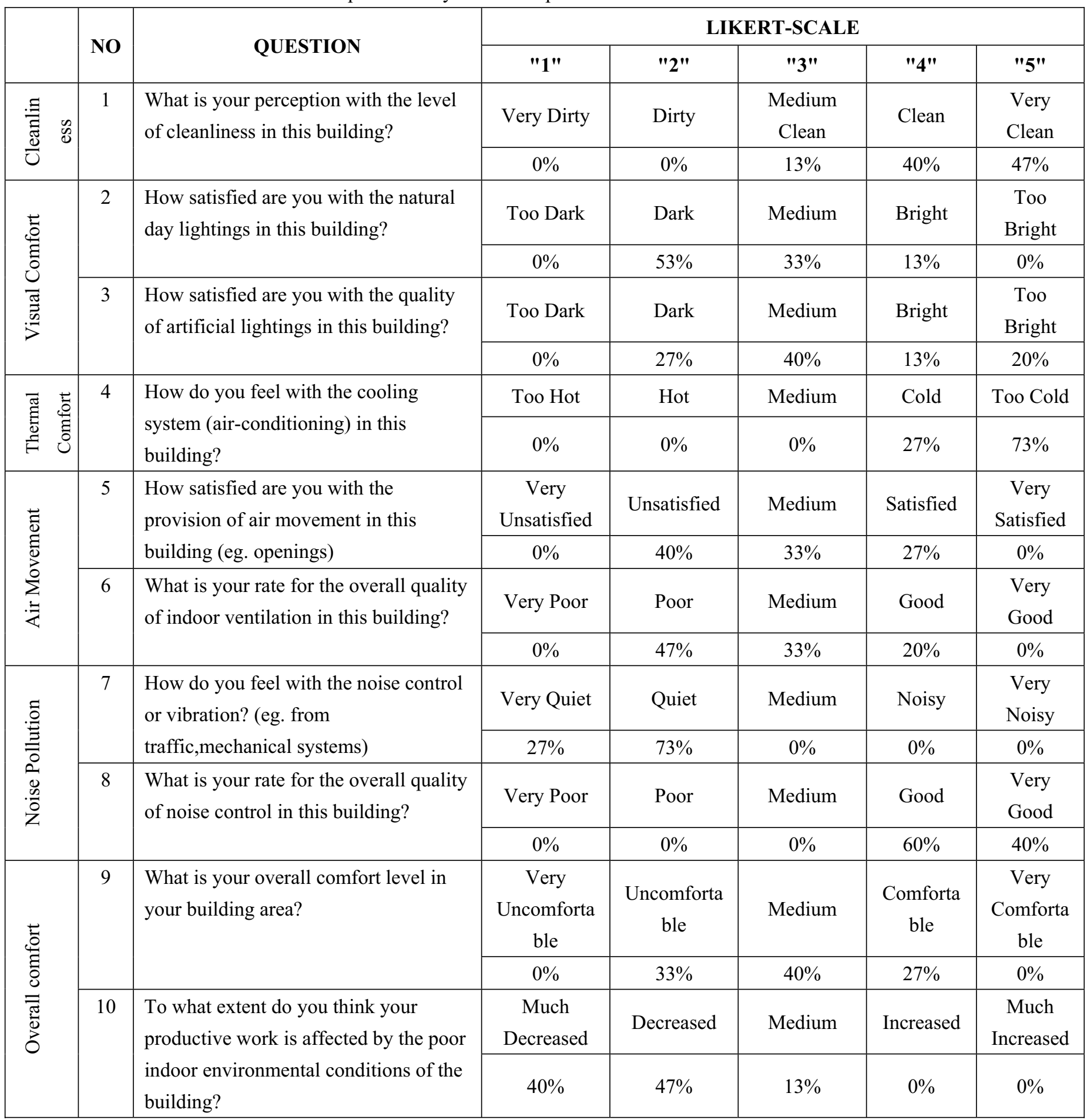




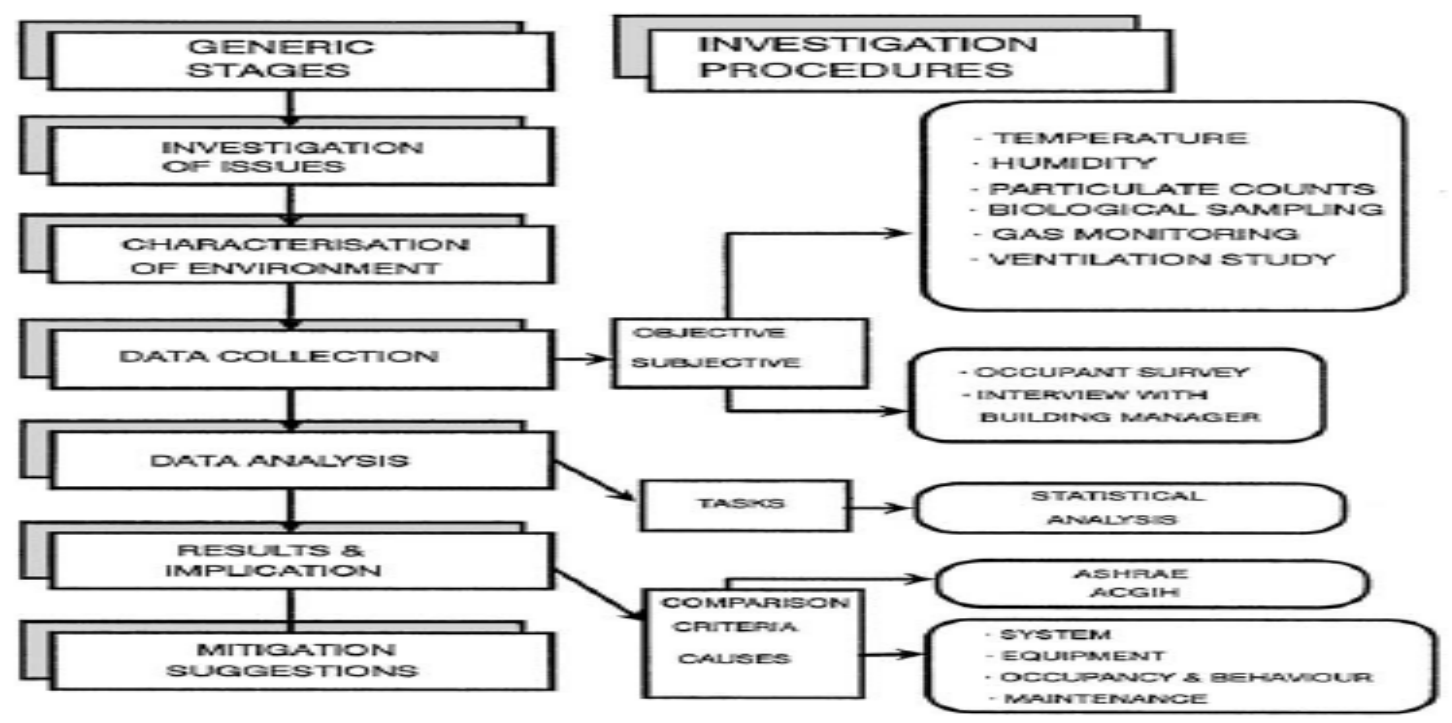

Figure 1. Indoor Environment Audit Methodology

(source: Sekhar, Tham \& Cheong, 2002)

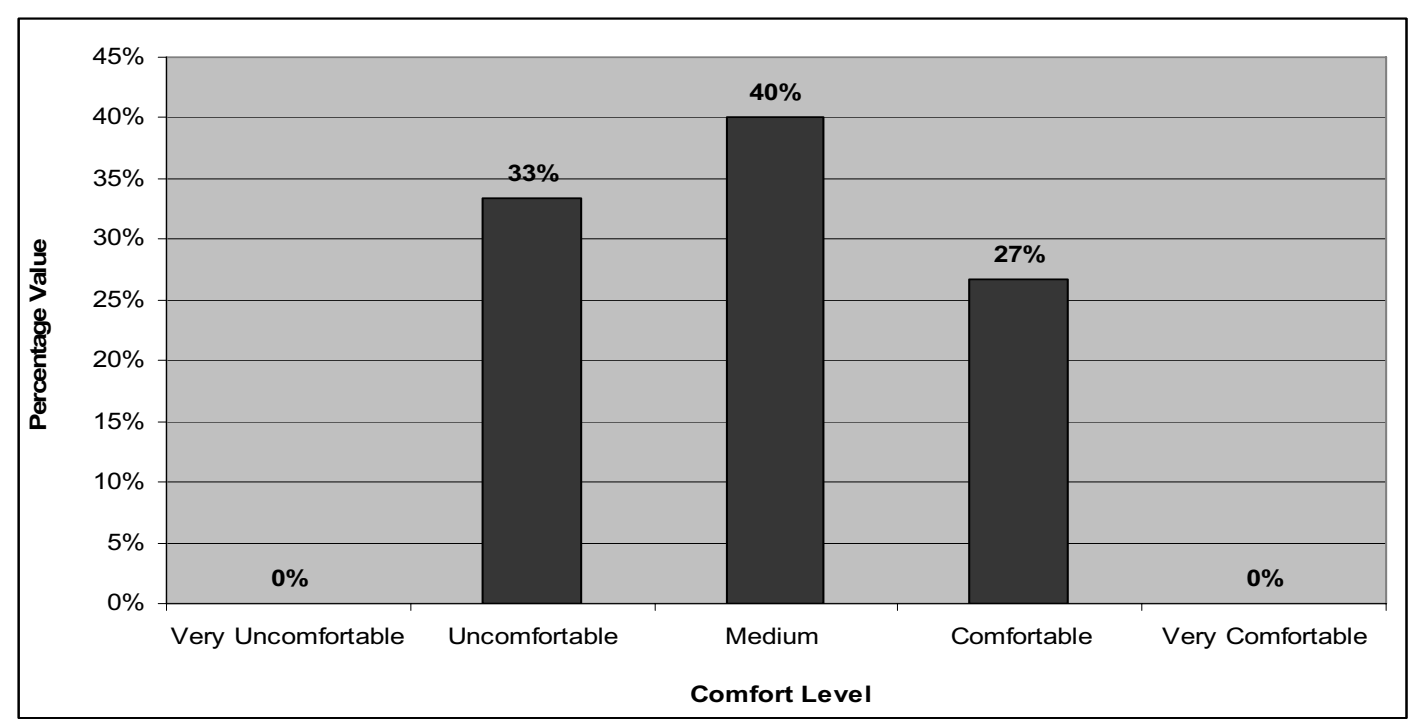

Figure 2. Assessment of Occupants' Comfort Level in Indoor Environment

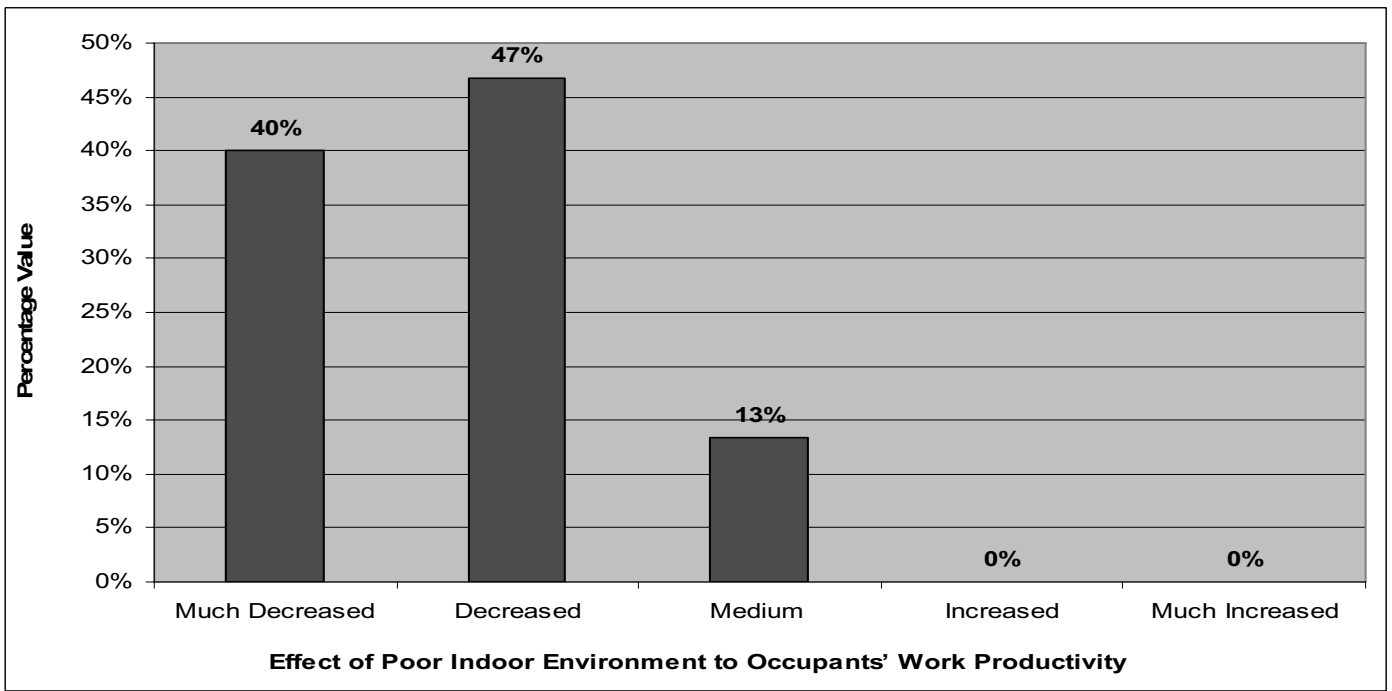

Figure 3. Assessment of Occupants' Work Productivity affected by Poor Indoor Environment 


\title{
Enterprise Social Responsibility and Enterprise Sustainable Development
}

\author{
Huiyuan Mao \\ Travel and Geographical Science College \\ Shenyang University \\ Shenyang 110044, China \\ Yunfeng Ai \\ Business Administration College \\ Northeastern University \\ Shenyang 110044, China
}

\begin{abstract}
Enterprise undertaking social responsibility is not a business posture, but is the result of market economy development in some stage, is the inner demand of enterprise and self-conscious action. Enterprise social responsibility has become a new competition after the talent, technology and management, is the important variable effected enterprise sustainable development, this paper introduces the meaning of enterprise social responsibility and enterprise sustainable development, dissertates the relationship between enterprise undertaking social responsibility and enterprise sustainable development, analyzes enterprise how to come true sustainable and build up harmonious society through undertaking social responsibility.
\end{abstract}

Keywords: Enterprise, Sustainable development, Social responsibility

According to American "Wealth" magazine report, about $62 \%$ of American enterprise's life is less than 5 years; only $2 \%$ of enterprises survives to 50 years; the average life of the middle and little enterprises is less than 7 years, commonly multinational companies have the average life of 10 to 12 years; the top 500 companies of the world have the average life of 40 to 42 years. (Li, peilin, 2006) Japan “Japanese Economic Industry" survey shows, the average life of Japan's companies is 30 years. Another data shows, China's group companies have the average of 7 to 8 years, the average life of the middle and little enterprises is only less than 3 to 4 years. It is obvious that, our country's life period is shorter comparatively, sustainable development problem of enterprise is not allowed to optimize. The status and effection of enterprise in social economic development is stronger increasingly, wheater it goes through social responsibility, relates the sustainable development of enterprise and society. In the situation of economic globalization and market competition increasingly, how to fulfill enterprise's social responsibility and come true enterprise's sustainable development, is the magnitude problem that every enterprise must think about deliberately. This paper is mainly focus on the point of enterprise social responsibility, discusses to come true the enterprise sustainable development through undertaking enterprise social responsibility.

\section{The meaning of enterprise social responsibility}

With the meaning of the corporate social responsibility(CSR), because the social development is changing all the time, different culture background, different development level's country and different development stage in the same country, all have the distinct meaning. Academia and enterprise field still haven't a uniform difinition to this conception, scholars from all around the world put forward respective perspectives from different views.

\subsection{Main viewpoint of foreign scholar}

Raymond Bauer puts forward previously:" enterprise social responsibility is to think the effection of the corporation behaviour to the society carefully." (John L.Paluszek, 1976-2000) KeithE.Davis and Robert.Blomstrom consider:" social responsibility is decision-maker thinking about himself benefits, meanwhile, also has the obligation to adopt measurement for protecting and improving social welfare." (Keith Davis and Robert L. Blomstrom, 1975) Joseph.McQuail thinks:" the thought of social responsibility advocates that the corporation not only has the obligation of economic and law aspects, besides these obligations, but also undertakes other social responsibility." (Joseph W. McGuire, 1963) Archie B.Carroll puts forward:" enterprise social responsibility is the society's expectaiton to organization with economy, law, ethic and free determination(charity)." after McQuail. (Archie B. Carrioll, 1975) 


\subsection{Main viewpoint of Inner country scholar}

Wang maolin thinks, enterprise sill need undertake the responsibility to employees, society and environment in the same time creating profit, taking charge in stockholder's benefit, including complying commercial moral, production security, professional health and protecting labour legality rights and interests etc. (Wang, maolin, 2005)

Zhang weifan thinks, enterprise social responsibility is to undertake obligation of protecting and improving social benefit in pursuing profit maximus. It is said that, enterprise should take care of more moral value and comply law regulation in commercial decision-making, as well as respect citizen, benefit community and protect environment. (Zhang weifan, 2006)

Zhang wenkui thinks, enterprise social responsibility is still to revert enterprise's original feature, namely, enterprise completes its social responsibility that it has done the right things. (Jia, cundou, Zhang, wenkui, 2006)

Deng jian thinks, recognize the conception of enterprise's social responsibility from three different aspects. The most narrow conception is that enterprise bear economic responsibility in earning profit and lawful responsibility in complying with the law and regulation in the course of operation; the conception of the middle view is, besides bearing economic responsibility in earning profit and lawful responsibility in complying with the law and regulation in the course of operation, enterprise should consider related benefits, undertake social responsibility including shareholder, employee, consumer, community, client and government etc; broad sense social responsibility not only contains economic responsibility, legal responsibility and enterprise's social responsibility in middle view, but also includes all the responsibility and behaviour accord with moral that enterprise should undertake and be capable of undertaking. At present academe mostly adopt the conception of the middle view, but now have the development tendency to the broad sense conception. (Deng, jian, Ren, wenju, 2005)

Scholars above define the conception of enterprise's social responsibility from different perspectives, although still exist some distinct points, but there's a broad recognition that enterprise should undertake social responsibility of related benefits person, society, environment and commonweal besides shareholder. Penman thinks, enterprise's social responsibility origins benefits unbalance between shareholders and related benefits persons, enterprises and society, environment in enterprise operation, in order to ensure enterprise continual operation, need keep up with the balance between enterprise's benefits and related person rights and interests. It reflects that the operation of enterprise transforms to "benefits related person" value orientation from "shareholders utmost" value orientation. Enterprise's social responsibility is that enterprise bear the obligation to protect benefits related person and promote society fairly and harmoniously besides in pursuing shareholders profits maximum.

\section{The meaning of the enterprise sustainable development}

Enterprise sustainable development, at present haven't had a uniform definition. Liu ligang defines sustainable development as: enterprise in the course of pursuing survival itself and permanent development, not only consider to come true enterprise operation aim and increase the market status, but also always hold the permanent profits increasing and ability advance in the one-up competition fields and future extending operating environment, ensure enterprise prosperous and not wane all the time. (Liu ligang, 2000) Zhong luyi considers, enterprise sustainable development is a living state of the enterprise by transcending enterprise increase deficiency or incease excess, transcending resource and environment protect constrained, transcending products life circle period, this survival state will get through continual innovation, increasing, exploiting and meeting market demand, keeping up with pursuing enterprise sustainable increasing.

Based on above viewpoint, refer to the conception of economic and social sustainable development, this paper thinks enterprise sustainable development is the state that enterprise taking social responsibility as the start, carrying out the principle of economy and ethic harmoniously, keeping up with innovation, environment protection, using resource high effectively, holding up with creating profit, meeting enterprise related benefits person rational demand, pursuing itself long prosperous and not wane(exceed average life circle in the same industry), coming true the survival state of enterprise and society development permanently and harmoniously.

\section{Social responsibility and enterprise sustainable development}

Enterprise is a open dynamic sytem which exchanges with exterior environment contiually, enterprise development can's survive without the survival resource and condition provided by social system. Enterprise need profit, but it's only the necessary condition that enterprise depend on, the worth of enterprise is at creating social wealth, not solely individual wealth, profit is the natural result after the wealth created, is the appearearce form of social wealth. Profit is important for enterprise, but enterprise overlooking social responsibility will be abandoned by society at last. It is proved, many successful century enterprises are famous in the world for undertaking social responsibility bravely. Enterprises only are brave in undertaking social responsibility, can make employees bring mighty concentration, can win better survival environment, enterprise's brand will be recognized by society, enterprise's products will be accepted by consumers, finally come true the development grandness of enterprise's economic benefit and enterprise sustainable. 
Enterprise sustainable development is weight at preserving the vitality and vigor of enterprise, this requests enterprise must take care of the full and long-term benefits of the society located, and implements responsibility and obligation completely. In many cases, enterprise need pay extra cost in engaging social responsibility activity, this means that current profits of enterprise is at loss partly or given. But consider from an another perspectives, condition is not so thus. Enterprise conducting some social responsibility activity maybe not bring direct economic performance for enterprise in one's power scale from short period, but from long-term period, this action improves enterprise's social face and living environment, in acquiring support of every social fields, also is the chance for enterprise's brand extent. From this meaning, enterprise is also self-regard as well as altruism. Most of research show, there is positive correlativity between social participation and operation performance of the company, namely, enterprise can promote the realization of economic benefit in undertaking responsibility.

\section{Enterprise coming true sustainable development through undertaking social responsibiltiy}

(1) Enterpises improve exterior environment located through undertaking social responsibiltiy. Exterior environment of enterprise usually exist in exterior of enterprise, which is the total summation of every element and power effecting enterprise's operation and development (Xu, shenghua, Chen, zihui, 2004), including economic environment, social environment, political and legal environment, natural enviroment etc. As a development better enterprise, in the first place, need propagandize sustainable development view to public actively, make public recognize the importance of sustainable development, then promote enterprise and society development together; in the other hand, understand law, regulation and policy system positively, undertake itself social responsibility initiatively, based on of it, participate in institution and implementation of policy, in order to improve social environment, then improve the exterior environment the enterprise located, acquire permanent development impetus.

(2) The consciousness of enterprise will undertake social responsibility penetrate in culture of enterprise extendly. Enterprise's culture is formed in a long period of production operation activity, enterprise members comply with value standard, behaviour criterion and moral principle of enterprise features together. Our country's traditional Ru family culture exerts a subtle influence on enterprise's culture, Confucious' highest moral standard is "humanity" "loved", emphasizes to start from self-giving motivation, shed oneself and benefit others, sacrifice one's own interests for the sake of others(Xiao, shengping, 2002), which is accordant with nowadays management thought "based on person ". Enterprise may improve employee's spirit state, encourage employee's initiative spirit, cultivate employee's responsibility consciousness for service enterprise through raising excellent tradition of collectivism, trial and strive, selfishness dedicatory, make employee's responsibility and enterprise undertaken social responsibility get to union harmoniously, provide powerful thought assurance and spirit motivity for enterprise's sustainable development.

(3) Enterprise's assignment accumulates social responsibility undertaken by enterprise. Enterprise's assignment is not the remark of concrete result of enterprise's operation activity, but is to provide a principle, orientation and philosophy for enterprise. Enterprise should undertake correspondent responsibility and perform correspondent assignment from the foundation of enterprise. Client's demand about product and the opinion about product value determine enterprise what to operate, what to produce and the future of enterprsie. Enterprise's assignment directs enterprise's strategy orientation, when enterprise meets the social responsibiltiy undertaken, enterprise will make right strategic choice, make undertaking social responsibiltiy run through enterprise's development first midst and last.

(4) Integrity is the base of enterprise's sustainable development. Enterprsie weights promise and keeps credit, will build up a good credit standing and public praise in the heart of consumers, produce economic benefit and brand benifit. Integrity may make enterprise acquire competition, carry out sustainable development. But in fact some enterprise make large benefit through implementing deceivable behaviour, appearing this situation is produced by information unsymmetry between consumer and enterprise, but, with the process of time, the degree of information asymmetry will reduce, it will become difficult if enterprise wants to win continual profit using information asymmetry again, and that enterprise must win the credit of consumer if it wants to acquire continual benefit, meanwhile, enterprise should operate with integrity in market activity, so that can acquire sustainable development.

(5) Establishing evaluation system of social responsibility undertaken by enterprise. Every enterprise has the different recognition for its social responsibility, an evaluation system should be established to measure whether enterprise undertakes social responsibility, and whether undertaking social responsibility brings economic benefit for enterprise. By the union of quality and quantity, from the fact using quantitive data evaluates the degree of enterprise undertaking social responsibility, enterprise promotes enterprise's sustainable development through undertaking social responsibility, and that enterprise's development can promote enterprise to undertake more and more social responsibility, promote enterprise better development, get to the harmonious union with society and build up harmonious society.

\section{References}

Archie B. Carrioll, (1979). "A Three-Dimensional Conceptual Modeof Corporate Social Performance," Academy of Management Re-view (Vol.4, No.4, 1979), 497-505. 
Deng, jian, Ren, wenju. (2005). Meaning discrimination of enterprise's social responsibility, [J] Marketplace Modernization, 2005, (October last ten-day publication).

Jia, cundou, Zhang, wenkui. (2006). Looking on China's social responsibility disputely, [N] China's Industrial Press Newspaper, 2006-05-18.

Joseph W. McGuire, (1963). Business and Society(New York: MGraw-Hill, 1963), 144.

Keith Davis and Robert L. Blomstrom, (1975). Business and Socity:En-vironment and Responsibility, 3rd ed.(New York:McGraw-Hill, 1975),39.

Li, peilin. (2006). Discuss enterprise's social responsibility and enterprise's sustainable development, [J] Modern Finance and Economy, 2006, 26(10)11-15.

Liu, ligang. (2000). Mode research of enterprise's sustainable development, [J] Liaoning University Transaction(Philosophy Social Science Publish), 2000, (3).

Quoted in John L.Paluszek, Business and Society: 1976-2000(NewYork:AMACOM,1976),1.

Wang, maolin. (2005). Building up harmonious society must intensify enterprise's social responsibility, [J] Pursuing Reality, 2005, (23).

Xiao, shengping. (2002). Enterprise culture, [M]Beijing: China's Weave Press, 2002.

$\mathrm{Xu}$, shenghua, Chen, zihui. (2004). Modern enterprise management. [M]Beijing; Tsinghua University Press, 2004.

Zhang weifan. (2006). Symple analysis of multi-element effect in the motion of enterprise's social responsibility [J] Group Economy Research, 2006, (August down semimonthly). 


\title{
Biofilm and Multimedia Filtration for Rainwater Treatment
}

\author{
Rasima Abdul Rasid \\ Department of Chemical and Process Engineering, Faculty of Engineering \\ Universiti Kebangsaan Malaysia (UKM) \\ 43650 UKM Bangi, Malaysia \\ E-mail: rasimarasid@yahoo.com \\ Rakmi Abdul Rahman \\ Department of Chemical and Process Engineering, Faculty of Engineering \\ Universiti Kebangsaan Malaysia (UKM) \\ 43650 UKM Bangi, Malaysia \\ E-mail: rakmi@vlsi.eng.ukm.my \\ Rasina Abdul Rasid \\ Institute of Aquaculture, University of Stirling \\ FK9 4LA Scotland, United Kingdom \\ E-mail: r.b.a.rasid@stir.ac.uk
}

This research is financed by Asian Regional Research Program me on Environmental Technology (ARRPET II) and Ministry of Science, Technology and Environment, Malaysia (IRPA 08-02-02-0003 EA094 Grant).

\begin{abstract}
This study of biofilm column and multimedia filtration which consist of granular activated carbon (GAC)-biofilm configured up-flow fluidized expanded bed (UFEB) reactor and slow down-flow packed sand bed reactor. To empathize the effectiveness of the multimedia filter, the characteristics of the process in removing the recalcitrant organic compound were investigated. This multimedia filter was run in fluidized expanded bed with hydraulic retention time (HRT) ranged from 2-8 hours. The multimedia filter showed efficient performance with a removable of $75.49 \%$ of iron $\left(\mathrm{Fe}_{2}{ }^{+}\right)$and sulphate $\left(\mathrm{SO}_{4}{ }^{2-}\right) 62.10 \%$ was removed. More than $92.59 \%$ of COD removal was achieved in this study. Besides that, this experiment also shows the good performance of ammonia $\left(\mathrm{NH}_{4}^{+}\right)$, nitrate $\left(\mathrm{NO}_{3}^{-}\right)$and nitrite $\left(\mathrm{NO}_{2}^{-}\right)$ removals, which ammonia removal is $45.16 \%$, nitrate removal range from $51.76 \%$ to $82.98 \%$ and nitrite removal up to $65.93 \%$ respectively without replenishment of external carbon source. The biomass attached to the GAC was originated from the rainwater range between $177 \mathrm{mgl}^{-1}$ and $3886 \mathrm{mgl}^{-1}$.
\end{abstract}

Keywords: Biofilm column, Multimedia filtration, Fluidized expanded bed, Recalcitrant organics

\section{Introduction}

Rainwater harvesting (RWH) is an option which has been adopted in many parts of the world where conventional water supply systems have failed to meet the needs of the people. As demand for water increased whiles the water resources is limited, there is a growing awareness to collect rainfall and make more efficient use of the rainwater. Rainwater harvesting is most applicable where other sources of water are either not available or are too expensive. Rainwater collection and utilization schemes are said to be optimal when implemented in conjunction with water demand management as well as measures to enhance aquifer recharge (Session reports 1999).

In general, the quality of roof runoff is acceptable to supply low quality domestic uses. Pollutant additions to roof runoff include organic matter, inert solids, faecal deposits from animals and birds, trace amounts of some metals, and even complex organic compounds (Forster 1991). These form the essential nutrients for growth of bacteria (WRC 1993). Factors such as type of roof material, antecedent dry period (atmospheric deposition) and surrounding environmental conditions (proximity of strong sources, such as motorways or industrial areas) have been shown to influence concentrations of heavy metals in roof runoff (Yaziz et al. 1989; Thomas \& Greene, 1993; Forster 1996). 
Biological growth may occur within the filter which is known as biofilm. The term, biofilm refers to the development of microbial communities on submerged surfaces in aqueous environments (Characklis \& Marshall, 1990). A biofilms consists of cells immobilized at a substratum and frequently embedded in an organic polymer matrix of microbial origin. Biofilm generally is very adsorptive and porous ( $>95 \%$ water) structure. This bioremoval of heavy metal processes generally fall into three categories: biosorption of metal ions onto the surface of microorganisms, chemical transformation of metal ions and intracellular uptake of metal ions by microorganisms (Dursun et al. 2003). Biofilms observed in many waters consist of a large fraction of adsorbed and entrapped materials such as solutes and inorganic particles. (e.g., clay, silt). (William \& Marcelo 2003).

\section{Methods and Materials}

A research for rainfall collection system for household conditions has been outlined in Figure 1. This research is located at Bangi, about $20 \mathrm{~km}$ from the main city Kuala Lumpur. Runoff water from the roof surface is first flow into storage tank 1 in the ground level through a pre-filter and a second filter. Then the rainwater will be stored in a second tank after a third filter, which is placed at the pipe connecting from the first tank to the second tank. Rainwater was continuously fed to the reactor A by up flow mode and into reactor B by down flow mode with varying fluid velocity by a variable speed peristaltic pump, at the inlet flow rate, Q of 24 96 Lday ${ }^{-1}$.

The multimedia filter was initially operated at 12 hours HRT for 2 months, and then changed to operated at different hydraulic retention time (HRT) ranged from 2 to 8 hours. Figure 1 shows the plant schematic and reactor configuration.

Reactor A is initially filled with about $17 \mathrm{~cm}$ height of granular activated carbon (GAC). This reactor was packed with GAC particles of $0.25-2.00 \mathrm{~mm}$ particle size, with mean diameter of $1.30 \mathrm{~mm}$ and particle density of $1200 \mathrm{kgm}^{-3}$. GAC was used as adsorbent and biomass support media. 1000 pieces of plastic media was placed in reactor A as filter media. The frame of the multimedia reactors is made of arc halite. Table 1 shows the design information for each reactor.

The reactor B is filled with gravel, coarse and fine sand bed. The fine sand bed is $0.125-0.25 \mathrm{~mm}$ in sizes were used as to remove the floc (dirt particles) from the rainwater. Water was drained from the base of the filter through $0.3 \mathrm{~cm}$ wide perforate on the top surface of the $20 \mathrm{~cm}$ PVC pipe to the opening.

\section{Results and Discussion}

Multimedia filter has been operating for 390 days, demonstrating that removal of organic ions and heavy metals can be maintained in the multimedia filter with GAC as support media, for extensive time periods without replenishment of external carbon source. The biofilm in the multimedia filter in this study was able to remove iron $\left(\mathrm{Fe}_{2}{ }^{+}\right)$up to $75.49 \%$ with an average concentration in the effluent is $0.01 \pm 0.01 \mathrm{mg} / \mathrm{L}$. The COD average concentration in the rainwater is $7.33 \pm 0.34 \mathrm{mg} / \mathrm{L}$ while the COD concentration in the effluent is $2.6 \pm 3.2 \mathrm{mg} / \mathrm{L}$. Overall the COD reduction is in the range of $37.20 \% \sim 92.59 \%$. (Refer to Figure 2)

Sulphate $\left(\mathrm{SO}_{4}{ }^{2-}\right)$ removal percentage average was $35.09 \%$. The average concentration of $\mathrm{SO}_{4}{ }^{2-}$ in the effluent is $0.7 \pm$ $0.6 \mathrm{mg} / \mathrm{L}$ while the percentage reduction range is between $17.30 \%$ and $62.10 \%$. On the other hand, the average concentration of ammonia $\left(\mathrm{NH}_{4}{ }^{+}\right)$in the effluent is $0.022 \pm 0.010 \mathrm{mg} / \mathrm{L}$. Percentage reduction of $\mathrm{NH}_{4}{ }^{+}$overall was $45.16 \%$ accomplished. (Refer to Figure 3)

Nitrate $\left(\mathrm{NO}_{3}{ }^{-)}\right.$removal within the system was apparent from the beginning of the experiment and although there was some variation in the removal efficiency, the removal percentage range between $51.76 \%$ and $82.98 \%$ with an average concentration is $1.0 \pm 0.9 \mathrm{mg} / \mathrm{L}$ in the effluent. Moreover, the average concentration of nitrite $\left(\mathrm{NO}_{2}^{-}\right)$is $0.007 \pm 0.003$ $\mathrm{mg} / \mathrm{L}$ while the percentage reduction in the range of $2.48 \% \sim 65.93 \%$ was achieved. (Refer to Figure 4)

The biomass attached to the GAC was originated from the rainwater. Figure 6 shows the significant variations of biomass concentration in reactor in the experimental runs. After changing to expanded bed operation, there was a significant loss of biomass, decreasing from $3886 \mathrm{mg} / \mathrm{L}$ to around $177 \mathrm{mg} / \mathrm{L}$. Characklis (1973) reported that high velocity would retard the primary biofilm formation. (Refer to Figure 5)

\section{Conclusion}

Based on the results of this study, it has shown that the biofilm and multimedia filters are effective, since the filtration media combine the filtration properties of several materials. It has shown in the results that with a biofilm attached to the GAC surface which consists of bacteria held in an excreted polysaccharide coating, the uptake rate and quantity of metal ions extracted from the samples can be significantly increased. This system is ideally suit from economic point of view for locations being a low cost technology requiring low initial expenditure, zero power need, no maintenance cost and self dependent operation even for areas where there is normal seasonal rains.

\section{References}

Dursun, A. Y., Uslu, G., Tepe, O., Cuci, Y., Ekiz, H. I. A. (2003). Comparative investigation on the bioaccumulation of heavy metal ions by growing Rhizopus arrhizus and Aspergillus niger. Biochemical Engineering Journal, 15, 87-92. 
Characklis, W.G. \& Marshall, K.C. (1990). Biofilms. Wiley, New York.

Forster J. (1996). Patterns of roof runoff contamination and their potential implications on practice and regulation of treatment and local infiltration. Water Science and Technology, 33(6): 39-48.

Forster J. (1991). Roof runoff pollution. In: Grottker M, Schilling W, editors. Proceedings of Second European Junior Scientist Workshop, Kastienbaum, Switzerland. pp. 145-58.

Session reports. (1999). In: Proceedings of the International Symposium on Efficient Water Use in Urban Areas, pp. 7 -25 .

Thomas PR, Greene GR. (1993). Rainwater quality from different roof catchments. Water Science and Technology, 28(3-5): 291-7.

Water Research Commission (WRC). (1993). Guidelines on the cost effectiveness of rural water supply and sanitation projects. Water Research Commission Report No. 231/1/93, Pretoria.

William, Z. \& Marcelo, D. (2003). Rainwater chemistry at the summit and southern flank of the Itatiaia massif, Southeastern Brazil. Environmental Pollution, 129: 63-68.

Yaziz MI, Gunting H, Sapari N, Ghazali AW. (1989). Variations in rainwater quality from roof catchments, Water Research, 23(6):761-5.

Table 1. Design information for Reactor A and Reactor B

\begin{tabular}{lcc}
\hline & Reaktor A & Reaktor B \\
\hline Height, cm & 110 & 80 \\
Internal diameter, cm & 15 & 12 \\
Reactor volume, $\mathrm{L}$ & 8 & 6 \\
Support media & $\begin{array}{c}\text { Granular activated carbon } \\
(\text { GAC) \& Plastic media }\end{array}$ & Gravel, Coarse and Fine Sand \\
\hline
\end{tabular}

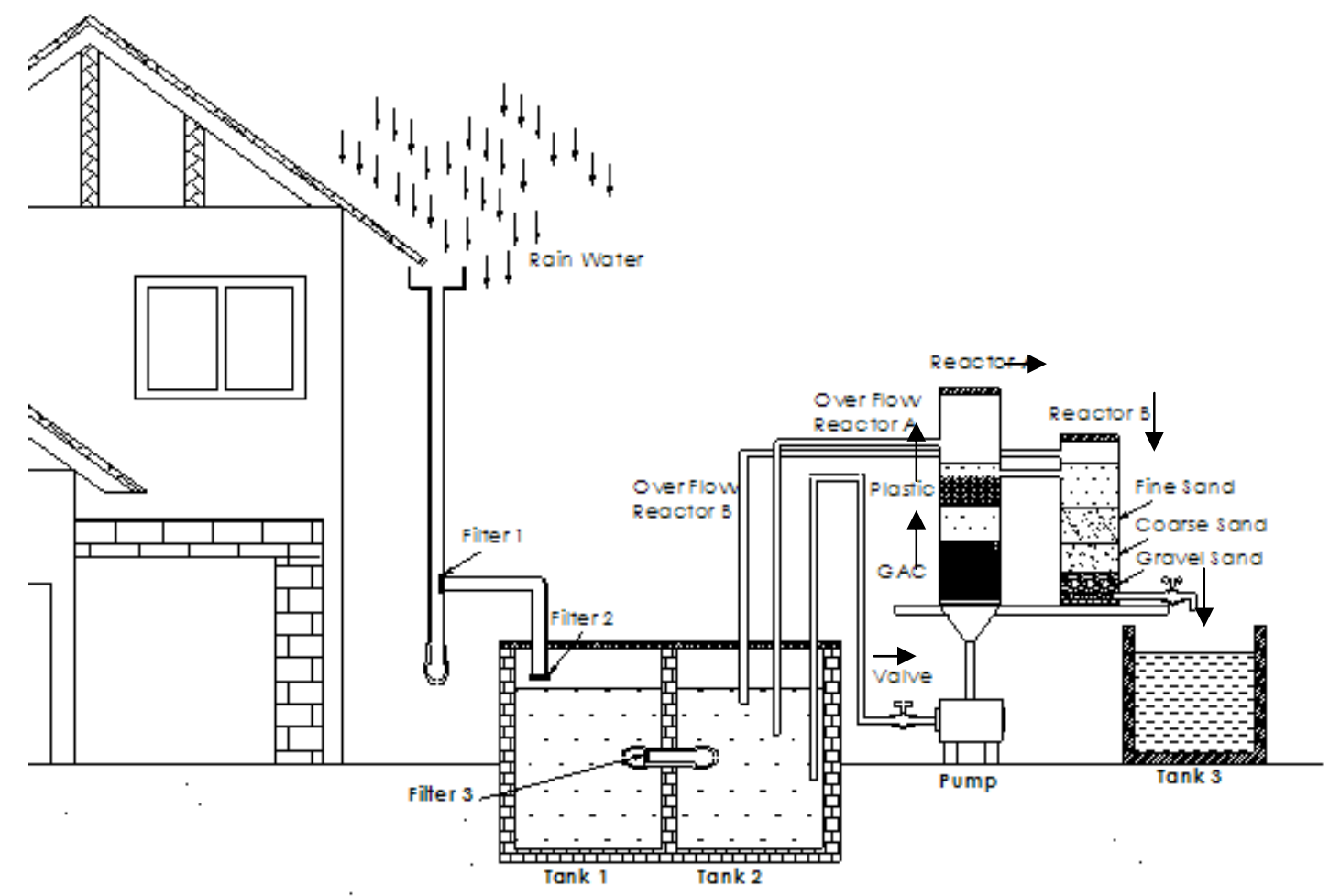

Figure 1. Plant schematic and Reactor Configuration 

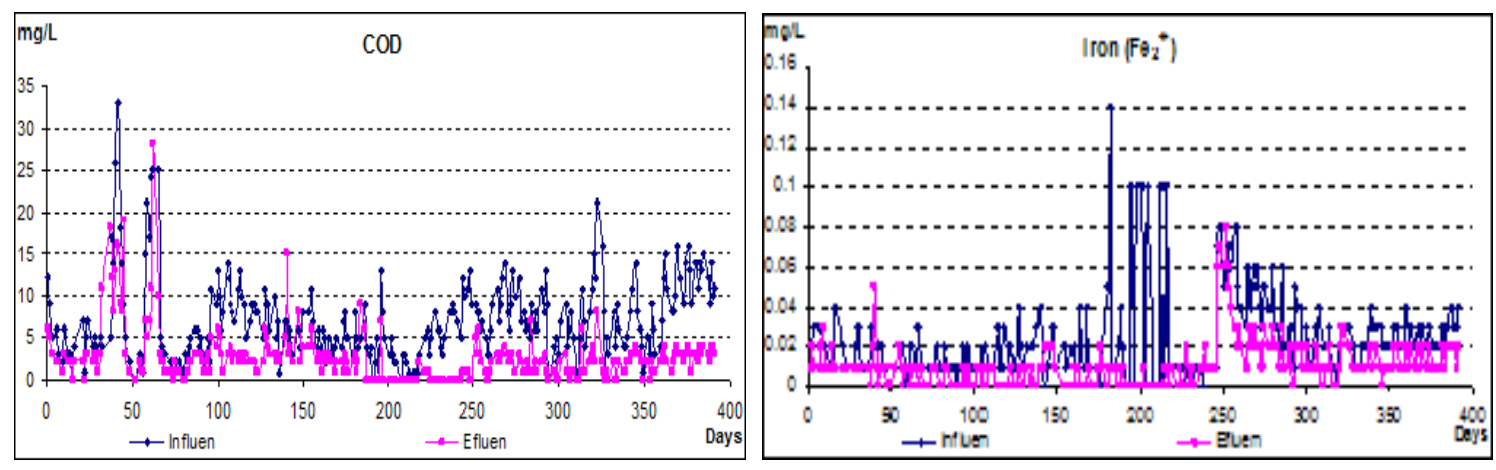

Figure 2. COD and Iron $\left(\mathrm{Fe}_{2}{ }^{+}\right)$concentration in rainwater and after filtration
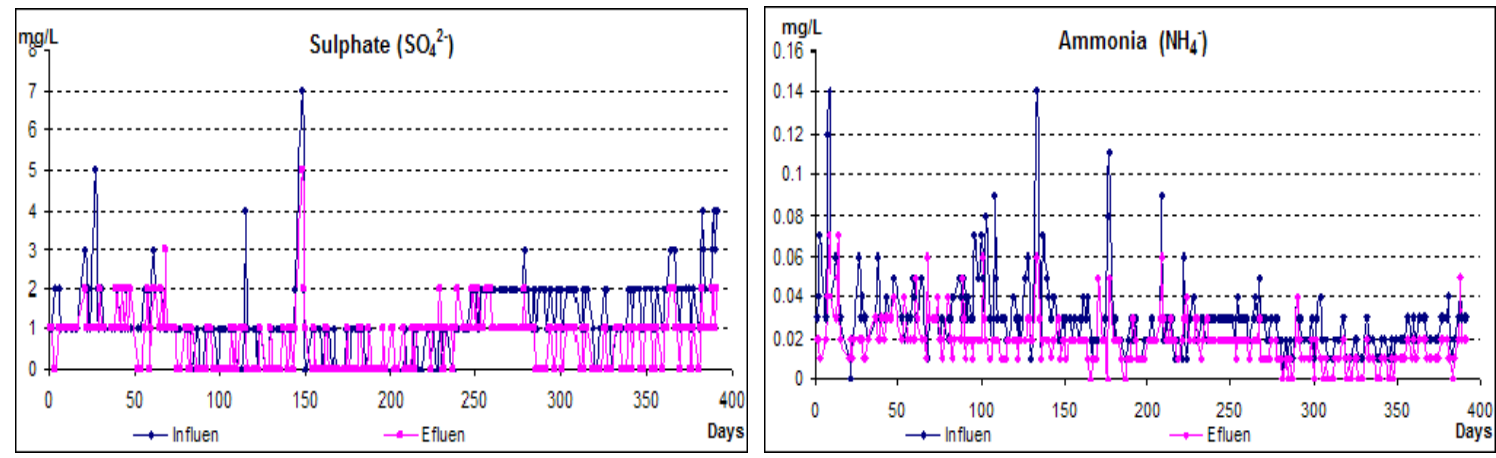

Figure 3. Sulphate $\left(\mathrm{SO}_{4}{ }^{2-}\right)$ and Ammonia $\left(\mathrm{NH}_{4}{ }^{+}\right)$concentration in rainwater and after filtration
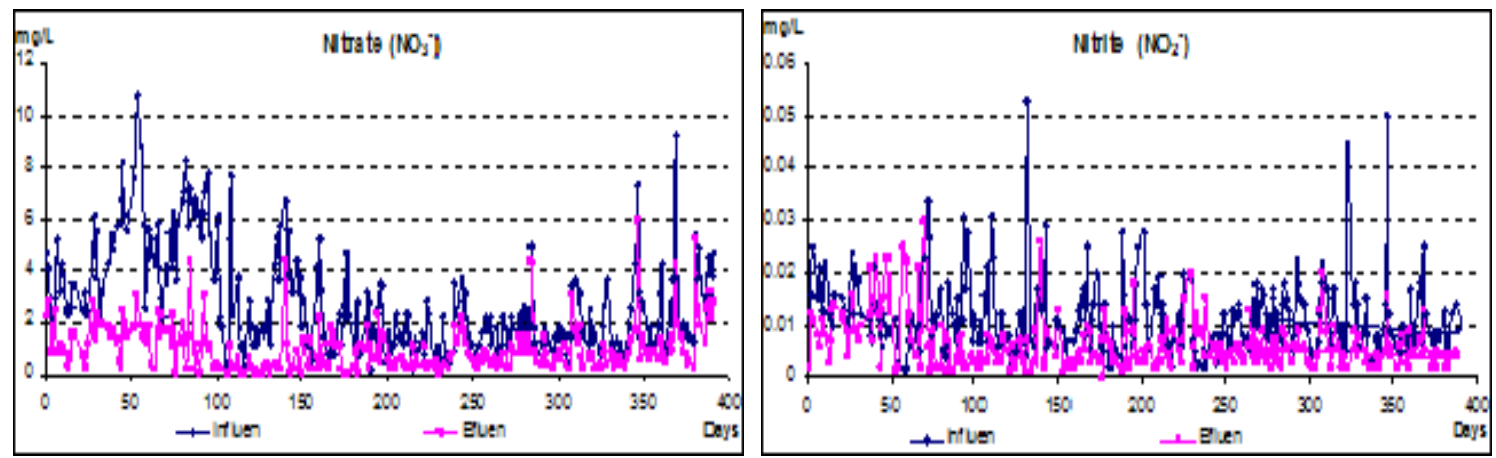

Figure 4. Nitrate $\left(\mathrm{NO}_{3}^{-}\right)$and Nitrite $\left(\mathrm{NO}_{2}^{-}\right)$concentration in rainwater and after filtration

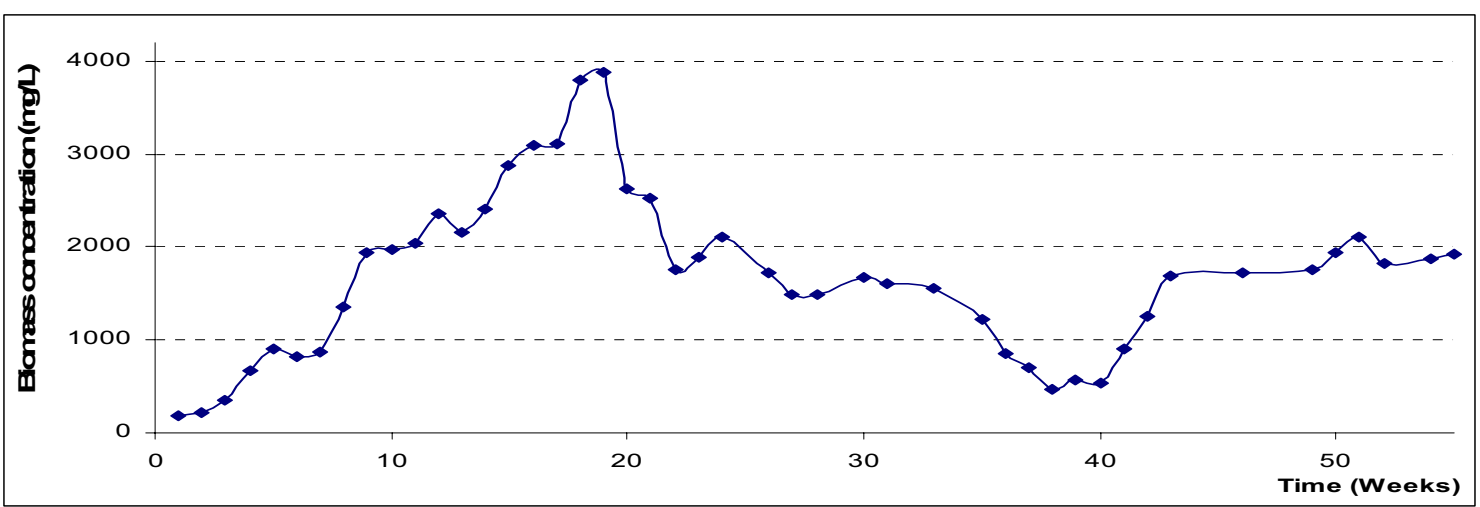

Figure 5. Biomass concentrations in GAC biofilter 


\title{
An Introduction of Building Green Schools
}

\author{
Juan Zhang \\ Applied Technology College, Xi'an Polytechnic University \\ Xi' an 710048, China \\ Zhirong Zhang \\ Applied Technology College, Xi'an Polytechnic University \\ Xi' an 710048, China \\ Yu Zheng (Corresponding author) \\ School of Management, Xi'an Polytechnic University \\ Xi'an 710048, China \\ E-mail: zyki2003@163.com
}

\begin{abstract}
Green-schools is an international environmental education program, whole school action for the environment. A school building or facility that creates a healthy environment that is conducive to learning while saving energy, resources and money. Additionally, green schools lessen environmental impacts through responsible approaches to site, reduced demand on municipal infrastructure and recycling during and after construction.
\end{abstract}

Keywords: Green schools, Benefits, Practice

\section{Definition of green schools}

Green-schools, known internationally as Eco-Schools, is an international environmental education program, environmental management system and award scheme that promotes and acknowledges long-term, whole school action for the environment.

Unlike a once-off project, it is a long-term program that introduces participants to the concept of an environmental management system. However, Green-Schools is far more than just an environmental management system. It fosters a strong sense of citizenship and leadership among participants that spreads far outside the school into the wider community. It also promotes a strong sense of teamwork among teachers, students and the wider community to reach a common high level goal. It flattens and democratizes school management structures. It brings children into the decision-making process and makes them responsible for their decision and actions. In fact it could be best described as being 'more than the sum of its parts'.

The aim of Green-Schools is to increase students' and participant awareness of environmental issues through classroom studies and to transfer this knowledge into positive environmental action in the school and also in the wider community. Schools that have successfully completed all the elements of the program are awarded the "Green-Flag" in Europe. This award has now become a well-recognized Eco-Label. The award has to be renewed every two years.

Green-Schools is an initative of, and coordinated on an international level by, FEE (Foundation for Environmental Education). There are currently over 23,000 schools in 43 countries in Europe, Africa, Asia, Oceania and South America taking part in the program.

\section{Cause of green schools}

\subsection{Litter is always caused by people}

It is waste in the wrong place which ruins the appearance of our cities, towns, villages and countryside. Litter has many forms and many sources, from a sweet wrapper or cigarette butt thrown on the street to a dumped bag of rubbish, a fly-tipped load of demolition rubble or a dog fouled public park. For example, Local Authorities spend tens of millions of money every year on cleaning the streets in Ireland and trying to prevent people from dumping their waste illegally an enormous amount of money that could be spent on better things! Estimates indicate that collecting litter is nearly ten times more extensive per ton than collecting domestic waste.

Litter such as broken bottles and cans left lying around public areas can easily result in an injury, while food litter can 
attract rats and flies, which spread disease. Litter is also lethal to wildlife, from discarded fishing lines that can maim and kill water birds, to plastic bags mistaken for food and ingested by animals such as cows, sheep, horses and some marine animals.

Recent research by TCD (Gray 2004) on the littering of minor roads in Ireland indicated that the number of litter items deposited on these roads was an average over 3,500 items per kilometer of road per year. One site surveyed had levels of littering of over 10,000 items per kilometer per year! Almost $60 \%$ of identifiable litter items were beverage containers and packaging. Furthermore, this study indicated that the roadside litter finally ends up in watercourses and on agricultural land where it causes animal injury and death, crop contamination and machinery damage.

\subsection{Litter \& Climate Change}

It is common knowledge that there is accelerated warming of the earth due to rising concentrations of heat-trapping greenhouse gases in the atmosphere which are caused by human activities. Most products we buy and use cause greenhouse gas emissions in some way, e.g. during production and distribution. They also contribute towards exhausting our natural resources. Packaging takes energy to produce, therefore by cutting down on packaging production, and also through recycling, we can reduce the amount of energy used and limit the release of further greenhouse gases in to the atmosphere.

\section{Benefits of green schools}

\subsection{A healthy, productive learning environment}

Far too often our nation's schools are only built to code and we send our children to spend eight hours a day in facilities that just barely meet health and safety standards. This must change. Every child deserves to go to a school with healthy air to breathe and conditions that encourage learning. Green schools are healthy for kids and conducive to their education. Green schools encourage: daylight and views, high indoor air quality, excellent acoustics, thermal comfort. Numerous studies have demonstrated direct benefits to student health and performance. For example, daylight improves performance, good indoor air quality improves health, acoustics increases learning potential, comfortable indoor temperatures increase occupant satisfaction

\subsection{Improved teacher retention}

Green schools aren't just good for kids. Excellent indoor air quality means improved health for everyone! Teachers deserve healthy spaces for teaching children. Good acoustics in classrooms ensure that teachers can be heard without straining their voices. Studies show that all building occupants benefit from daylight and access to views, and research indicates that teachers are happier when they have the ability to control their environments. And healthy, happy teachers save schools money. Green schools commonly report reductions in teacher absenteeism and teacher turnover. Over the lifetime of a school, that amounts to huge savings.

\subsection{Financial savings}

If all new school construction and school renovations went green starting today, energy savings alone would total $\$ 20$ billion over the next 10 years. Green schools typically cost less than $\$ 3$ per square foot more to build, an investment that is paid back within a few years of operation. Over the lifetime of the school, the savings keep adding up. Take the green schools math challenge: if a green school were to save $\$ 100,000$ per year, and a typical school facility lasts 42 years. Then over the lifetime of a school building, what could the savings amount to? Do the math: Green schools make sense for students, teachers and the bottom line.

\subsection{Hands-on learning}

Swami Chinmayananda has said: "Children are not vessels to be filled, but lamps to be lit." Students learn best when they are engaged and inspired. Imagine the learning potential when the school building itself becomes an interactive teaching tool, educating the next generation of sustainable leaders through hands-on learning. More and more green schools have the green school experience. For example, high school students learn about alternative energy from the solar panels on their roof, middle school students studying ecosystems in their constructed wetland, and kindergarteners growing the organic vegetables they eat for lunch. The school building is no longer a vessel filled with students, teachers and books, but itself an opportunity for experiential learning and discovery.

\subsection{Environmentally friendly}

Green schools do more good by doing less bad; they save more energy and use less water than traditional school buildings. Additionally, green schools lessen environmental impacts through responsible approaches to site, reduced demand on municipal infrastructure and recycling during and after construction. Like other green buildings, green schools decrease our reliance on fossil fuels, thus decreasing carbon dioxide emissions and other forms of harmful pollution. Green schools can help turn back the clock on global warming, improving the environmental outlook for the children who will one day be faced with the challenge of finding resolutions to this problem. 


\section{How to go green schools}

\subsection{School teachers}

School teachers are one of the first lines of defense in the environmental movement. In a few short years, the upcoming generation will decide the fate of this planet. And when it comes to how to teach children science, math, and geography, teachers are the best at it. The interdisciplinary skills they learn today will be the planet-saving skills they enlist tomorrow. Now, we know that's a lot to bear on teachers' shoulders, so we've put together a guide that will help teachers in the classroom — and outside it, too.

Teachers' mission is to help children develop a connection to the environment, through both learning and experience. We know that most of teachers went back-to-school in September, but we have it on good intelligence that some teachers may have spent their summers traveling and golfing, rather than working out lesson plans. We certainly don't take issue with that, and with the go green initiative's annual Earth Summit—a national conference focused on going green in the classroom-taking place in Syracuse later this month, it's a perfect time to start planning some eco-activities for students.

From hands-on projects to personal responsibility, the tips, projects, and concepts outlined in this guide take a community-based approach to learning about environmental issues. Teachers may not be able to implement a school-wide recycling or composting program, but teachers can teach the principles of zero-waste within the domain of classroom. And while teachers may not be able to get the janitorial staff to swap out for greener cleaners, they can show kids how to make their own eco-friendly cleaners from vinegar and water. Greening school doesn't have to be about getting grants for solar panels and building a rain-water collection system. Those things are great, but it can also be as simple as opening the eyes of a child to the native plants just beyond the playground, or helping a student calculate the carbon footprint of his trip to school. Whether teachers are in an urban, suburban, exurban, or rural location, and no matter if they are a public or private school employee, they can choose this call to arms. Regardless of budget or setting, there's a lot every teacher can do to inspire his students to make the world a little greener.

\subsection{Top green school teacher tips}

Instilling a sense of connectedness to nature and the environment — be it a forest, field, or urban landscape — is essential to helping fledgling Tree Huggers care about the world around them. To teach students about global issues such as climate change and endangered, look to local issues such as recycling, storm-water runoff, or air pollution. Making it personal and connecting it to community makes it real.

Carbon and environmental footprint calculators help us see how much impact we have on the world around us. If everyone in the world lived like we did, we'd need five planets worth of resources to sustain life as we need know it! Using these online tools as fun games can really drive home the point of what kind of impact each of us has. Learn about environmental footprint and check out some of our favorite carbon footprint calculators. Then create a plan to reduce your group footprint.

School-wide recycling is a brilliant move, but implementing can be tougher than teaching long division to an eight-year-old. If a school isn't recycling at-large, start a classroom-wide policy of "zero-waste". Set up recycling bins, audit how much rubbish is created in a day. Sorting trash will help kids understand how much waste they are creating in a day, and where it's all coming from. Challenge kids to pack zero-waste lunches by using reusable bottles, containers, and satchels, rather than disposable ones. Competing with another classroom to see who can reduce their waste output most is a great way to create healthy competition and less waste.

Whether teachers are in the city or the country, any classroom can bring plants into the mix. It's easy to build a self-watering plant container and get kids growing right in the classroom. They can also bring experts in the classroom, too. Field trips can get complicated and expensive; often nature centers, recycling facilities, and so on are willing to send volunteers or staff members to schools for in-house demonstrations. Explain that bringing one person to many means cutting down on carbon emissions due to transportation.

Work with community to identify group goals. From easy, inexpensive changes such as switching to greener cleaning supplies and swapping out light bulbs to major changes such building energy-efficient, green school building or getting local farm-fresh food into cafeterias, green changes often happen due to grassroots efforts. The group's ultimate goal is to unite parent-teacher associations across the country in an effort to help bring environmental programs into the school via parents, while giving teachers more time to focus on using those programs in the classroom, rather than having to organize them on their own.

\section{3 getting techie}

\subsubsection{LEED-certified green school buildings}

According to the US Green Building Council, LEED-certified and environmentally constructed schools cost less to operate - on average, up to 100,000 per year less. Studies show that carefully planned acoustics and abundant daylight 
can significantly improve students' capability to learn-and improve the well being of students and teachers. Cleaner indoor air means far fewer sick days. Plus, often, innovative design provides a hands-on learning opportunities.

\subsubsection{How green building works}

"Green building" and "sustainable development" are the hottest terms in construction right now, but what do they mean, exactly? According to the Environmental Protection Agency Web site, green building is "the practice of creating healthier and more resource-efficient models of construction, renovation, operation, maintenance and demolition". Proponents say that green building is not only environmentally friendly, but also healthier and more cost-efficient.

\subsubsection{Project based learning}

Project based learning, according the website of the same name, is a method that takes a "comprehensive approach to instruction." Students, who are often more engaged when learning hands-on, participate in various projects, using interdisciplinary skills to accomplish tasks and goals. The Project Based Learning Checklist website offers customizable project checklists for written reports, multimedia projects, oral presentations, and science projects.

\subsubsection{Green school maintenance}

Simple maintenance and facilities choices, such as using the Eco-Cube can save thousands of gallons of water each year because they allow water in urinals to be turned off, while letting naturally occurring microbes do the work instead. That saves both water and cash. Having a janitorial staff switch to greener cleaners - non-toxic commercial cleaners are increasingly available - can significantly help detoxify indoor environments by decreasing amounts of volatile organic compounds, leading to fewer sick days for teacher and kids, as well as increased productivity.

\section{Green Schools practice in Ireland}

Green-Schools in Ireland is operated and coordinated by the Environmental Education Unit of An Taisce, in partnership with Local Authorities throughout the country, is supported by the Department of Environment, Heritage and Local Government, the Department of Transport and is sponsored by Repak, Coca-Cola Bottlers Ireland Ltd., ESB Independent Energy and the Wrigley Company Ltd.

Over 3,000 primary, secondary and special schools in Ireland are currently taking part in the program and 1,460 have been awarded the Green Flag. The Irish Green-Schools program is one of the most successful within the international network. One of the main factors in the success of the Irish Green-Schools program is the partnership between the Environmental Education Unit of An Taisce and Local Authorities i.e. the financial and time contribution of the Local Authorities to the program. Each of the Local Authorities has an Environmental Education Officer (EEO). These officers provide the invaluable on the ground support to schools undertaking the program.

Green-Schools is also undertaking a pilot with East Cork Area Development (ECAD), which is funded under the National Development Plan 2000-2006, with schools on Great Island, Cobh, Co. Cork. The pilot involves the development of the role of a Local Area Green-Schools coordinator to work with schools and the wider community on Great Island.

\section{References}

Gustavson R., Lonergan C.(1998). Selection and modeling of sustainable development index: A case study of the Fraser River Basin. British Columbia. Ecological Economics.

Edith, Rob(1999). Environmental index: Typology and overview. European Environment Agency.

Costanza, R.(1997). The value of the world's ecosystem services and natural capital. Nature, 387.

Chinmayananda, From Wikipedia, the free encyclopedia[Online]. http://en.wikipedia.org.

European Conference on Ministers of Transport (ECMT, 1998). Strategic Environmental assessment in the transport sector. Paris, France.

Green-Schools in Ireland[Online]. http://www.greenschoolsireland.org.

Rapport, D. J., Costonza, R., Mcmichael, A.. J.(1998). Assessing ecosystem health. Trends in Ecology and Evolution.

U.S. Green Building Council. Build Green Schools[Online]. http://www.buildgreenschools.org. 


\title{
Study on the Application of the Double-membrane Technology
}

\section{in Dealing with Circulating Cooling Blow-off Water}

\author{
to Prepare the Boiler Feedwater
}

\author{
Lei Qu \& Liang Wang \\ The Key Lab of Hollow Fiber Membrane Materials and Membrane process of Ministry of Education \\ Tianjin Polytechnic University \\ Tianjin 300160, China \\ College of Material Science and Chemistry Engineering, Tianjin Polytechnic University, Tianjin 300160, China \\ Lin Shao \\ Tianjin Electric Power Research Institute, Tianjin 300160, China \\ Peng Qi \\ Tanggu Environmental Protection Monitoring Center Of Tianjin, Tianjin 300450, China \\ E-mail: kemboy@163.com
}

\begin{abstract}
In the article, combining with the engineering practice, we study that the membrane technology (microfiltration (MF) + reverse osmosis (RO)) is applied to pre-demineralization of the circulating cooling wastewater back to boiler feedwater by the heat power plant. The operation parameters of the reusing system were obtained through the actual test and the experimental results show that the technology which uses MF as pretreatment process of RO can meet the requirement of the RO inlet water quality with above $98 \%$ of the demineralization rate of the RO system, which has achieved good economic and social benefits.
\end{abstract}

Keywords: Membrane separation, Reclaimed water reuse, Circulating cooling blow-off water, Boiler feedwater

The heat power plant is one of main industrial consumption users, and it is one of main waste discharge users. The water consumption in the circulating cooling water system occupies above $80 \%$ of the water consumption of the whole plant, so the reuse of the circulating cooling blow-off water is imperative under the situation (Sha, 2001, P.50-52). To better use the circulating cooling blow-off water and enhance the reuse rate of the water are effective approaches to reduced the practical industrial water consumption and realize the zero draining of wastewater. To take the circulating cooling wastewater of the power plant as the boiler feedwater is one of good water saving methods, but the salt content of the circulating cooling blow-off water is always 2-5 times than the circulating complementary water, and if we take the water with high salt content as the water source of the boiler feedwater and still adopt traditional ion exchange technique, so we need frequently implementing acid and alkali regenerations and let a great lot acid and alkali waste fluids, which would enhance the running costs and pollute the environment. As a sort of new liquid separation unit operation technology, the membrane separation technique is more and more applied to the pre-demineralization system of the circulating waster water in foreign and domestic heat power plants because of its many advantages such as high efficiency, environmental protection, few floor space, low power consumption, high automatization and convenient maintenance.

\section{Inlet water quality and process flow}

\subsection{Inlet water quality}

Tianjin Chentangzhuang Heat Power Plant constructed $2 \times 300 \mathrm{MW}$ electric generating set in the third-term project, and it successfully applied the MF as the pretreatment of RO in the preparation of the boiler feedwater. The water source includes the circulating cooling wastewater from the first-term project and the second-term project, and the complementary water of the first-term circulating water and the second-term circulating water is the sea water and river water, and the weight concentration of the circulating cooling blow-off water is 2.5 . 


\subsection{Process flow}

The main water source entering into the membrane system is the circulating cooling wastewater, and the complementary water sources are the sea water and river water, and the emergent complementary water source is the tap water, so the water source supply security can be ensured when the boiler feedwater increases.

\section{Running of MF-RO system}

\subsection{MF pretreatment system}

The circulating cooling wastewater possesses many characteristics such as high turbidity and high salt content, and it can not directly enter into the membrane system and it needs the pretreatment before entering into the membrane. Sterilize the circulating wastewater by add $\mathrm{ClO}_{2}$ in the raw water box, and because the inlet temperature of the MF membrane requires $20^{\circ} \mathrm{C} \sim 35^{\circ} \mathrm{C}$, so we can properly enhance the inlet water temperature and reduce the water viscidity, enhance the fluxes of the high MF membrane and RO membrane and reduce the inlet membrane pressure (Yu, 2006, P.57-63). To ensure the proper temperature of the inlet water and the successive flocculation effect, especially in the cold winter, the raw water heater is set up in the system.

Through dynamically simulating in the former phase, the dosages of the flocculating agent and coagulant aid are confirmed in the mechanical accelerating pool. The flocculating agent is PAFC and the dosage is $50 \mathrm{mg} / \mathrm{L}$, and the coagulant aid is the polyacrylamide, and its dosage is $1 \mathrm{mg} / \mathrm{L}$. The raw water through primary turbidity removal enters into the air cleaning strainer which is the double-medium filter, and in the filter, the bottom layer is the quartz sand and the upper layer is the anthracite to eliminate the colloid and suspended substance in the raw water and reduce the inlet turbidity and fulfill the MF inlet requirement. The circulating cooling wastewater after membrane pretreatment enters into the clean water box and waits for entering into the membrane system.

The equipment before MF is the Israel ARKAL plate filter, and the filtering precision is $55 \mu$, and it can prevent the bigger grains enter into the MF system and mechanically scuff the membrane surface and ensure the long-term stable running of the MF system.

\subsection{MF unit}

The MF membrane is the UNA-602A hollow-fiber membrane made by Japan Asahi Kasei Corporation, and the filtering precision is $0.1 \mu$. Comparing with traditional products, the new-generation PVDF hollow-fiber membrane possesses many characters such as high mechanical intension, anti-oxidation, anti-pollution and high flux, and it adopts low-pressure operation, back flush, air water washing and other new technologies to make the MF membrane can keep stable performance in the wastewater medium with strong pollution.

There are many domestic power plants which use the clarifying and filtering as the RO pretreatment. The water source of Tianjin Junling cheng Power Plant was sea river water, and because the pretreatment technique was not proper, the SDI of the yielding water had exceeded 4-5 for a long time, and the import RO membrane was discarded as useless only in a half year, and the domestic RO membrane was discarded as useless only in three months. There are RP membrane damages and useless RO equipments in Shijingshan Electric Power Plant, Huaneng Dezhou Thermal Power Plant, Dagang Electric Power Plant and Hengshui Electric Power Plant all induce because of bad water quality of RO. The yielding water quality of RO pretreatment directly influence the use life, the cleaning cycle, water yield and running cost of RO. The unqualified RO pretreatment always make the RO equipments can not run normally, deteriorate the yielding water, reduce the water yield and membrane life. Many practical examples and researches indicated that one of the pollution sources of RO is the colloid grains induced by the bad RO pretreatment, and the possibility of this sort of pollution can be denoted by the index of SDI. The influences of various yielding water SDI indexes of pretreatment to the RO membrane performance are seen in Table 2.

There are 2 sets of MF equipments in the system, and the power of the single MF equipment is $150 \mathrm{~m}^{3} / \mathrm{h}$, and single MF equipment includes 56 PVDF membrane components. The crustaceous material of the hollow MF membrane UNA-620A is ABS resin, and the MF component size is $2338 \mathrm{~L} \times 165 \Phi$. The outside diameter of the hollow fiber is $1.2 \mathrm{~mm}$, and the inside diameter is $0.7 \mathrm{~mm}$, and the exterior surface of the hollow fiber is the separation layer, i.e. the exterior pressured hollow fiber membrane.

\subsection{RO unit}

The system has 2 sets of RO equipment which has one class and two stages. Each set of equipment has 21 pressure vessels which are arranged by $2: 1$, and the quantity of the membrane components are 126 . The water yield of each RO system is $100 \mathrm{~m}^{3} / \mathrm{h}$, and the design reclaimed rate is controlled in $70 \% \sim 75 \%$ regulated by the membrane component manufacture, and each RO system equips 126 US Dow BW30(LE)-440(FR) membrane components, and the effective membrane area of every membrane component is $41 \mathrm{~m}^{3}$, and they are respectively fixed in 21 pressure vessels. The RO is distributed by two parts. The first part of wastewater enters into the second part as the inlet water, and the first part yielding water and the second part yielding water combine and enter into the freshwater box, and enter into the mixed 
bed, and the second part wastewater enters into the neutralization pool. The mixed bed is regenerated in the body, and the yielding water is supplied by the demineralization box.

\section{Prevention of membrane pollution}

\subsection{Prevention of the MF membrane pollution}

After set up the yielding cycle of 1700s, implement 60s air back flush and 60s flush. When implementing back flush, the compressed air should be added to increase the shaking of the membrane and shake off the contaminations. When preparing the water, add $0.2-0.5 \mathrm{ppm} \mathrm{NaClO}$ to kill the biological colloids and microorganisms in the water. In the next day, increase the EFM dosage of $500-900 \mathrm{ppm} \mathrm{NaClO}$. When the membrane penetration pressure difference achieves $0.15-0.2 \mathrm{Mpa}$, add $1000-3000 \mathrm{ppm} \mathrm{NaClO}+1 \% \mathrm{NaOH}$, and add $2 \%$ of hydrochloric acid. Through above measures, the membrane pollution can be effectively prevented, and the continual and safe running of FM can be ensured and the safe running of the $\mathrm{RO}$ equipment can be further ensured.

\subsection{Prevention and cleaning of RO membrane pollution}

The RO membrane component material is the polyether sulphone which is the oxidated substance, and it needs adding $\mathrm{Na}_{2} \mathrm{SO}_{3}$ in the membrane raw water to eliminate $\mathrm{NaClO}$. And at the same time, we should ensure $\mathrm{SDI} \leq 3$. When the equipment stops in the short term or the equipment suddenly stops pump and when the equipment restarts, the equipment should be flushed.

In the process of RO, when any one of following instances occurs, we advise chemical cleaning.

(1) When the inlet parameter is certain, the conductance of the penetration liquid increases obviously.

(2) When the inlet water temperature is certain, and the export end pressure of the high-pressure pump increases above $8 \% \sim 10 \%$, the membrane flux can be kept invariably.

(3) When the feed-in flow velocity and temperature are certain, increase $25 \% \sim 50 \%$ of the inlet and outlet pressure difference of the RO equipment.

(4) Run for three months in the bad inlet water condition and run for six months in the normal inlet water condition, the normal cleaning should be implemented.

Otherwise, when the RO system stops, we must periodically clean the membrane to keep the RO membrane wet and prevent the growth of the microbes (Hou, 2002, P.45-47).

The cleaning methods of RO membrane can be divided into three sorts, i.e. the physical method, the chemical method and the physical-chemical method. In these three methods, the chemical method is used most extensively in the cleaning of the RO membrane, and its cleaning effect is decided by many factors such as the PH of the cleaning liquid, the temperature, the flow velocity and the cycle time, and one sort of cleaning liquid can be successful in some cleaning systems, but it can not ensure to be successful in other systems. For the chemical cleaning, according to testing and analyzing results of the contaminations, proper cleaning liquids can be selected and the cleaning liquid should be compatible with the type of the membrane and should not corrupt the system. Table 5 shows general selection principles.

The practical cleaning plans should be implemented according to many comprehensive factors such as the temperature of the $\mathrm{RO}$ membrane, the range of $\mathrm{PH}$ value and the endurance to the cleaning liquid.

\section{Conclusions}

(1) Through six months' practical running, it is feasible for the factory to use the circuiting cooling wastewater to prepare the boiler feedwater in theoretical design, and the effect is vey good, and it can reduce the pollution and increase the effect, and obtain good economic benefit and the environmental benefit. For the reclaimed water treatment, the double-membrane can be applied in not only the reclaiming of the urban living wastewater, but also the reclaiming of the industrial wastewater, and it can make the drain of the production process to be the reliable demineralization water source.

(2) MF can eliminate most suspended substances, organic things and grain substances and the yielding water turbidity is smaller than $0.1 \mathrm{NTU}$, which can largely improve the water quality of the RO inlet water and ensure the successively safe running of the RO.

(3) The application of the double-membrane reduce the demineralization pressure of the mixed bed, reduce the regeneration period of the mixed bed acid and alkali, and reduce the discharge of the acid and alkali waste liquid, and produce economic an environmental benefits.

(4) The double-membrane method with many characteristics such as high automatization degree, controlled program and few floor spaces can largely reduce operators' labor intension and further enhance the running level and the automatization degree of the whole water treatment technique. 


\section{References}

B Tansel, W Y Bao, I N Tansel. (2000). Charaeterization of fouling kineties in ultrafiltration systems by resistance in series model. Desalination. No.129. P.7-14.

Hou, Fengsong. (2002). Cleaning Membrane of Reverse Osmosis Device for Feedwater in Cogeneration Plants. North China Electric Power. No.8. P.45-47.

Sha, Zhongkui, Xie, Changxue \& Lijie. (2001). Recovery and Application of Circulating Waste Water in Thermal Power Plants. Electric Power Construction. No.22(8). P.50-52.

Yu, Zhiyong, Changyan, Zhang, Jianjun \& Zhouchen. (2006). Application of Ultra Filtration in Water Treatment. Zhejiang Electric Power. No.6. P.57-63.

Table 1. Water quality report of the circulating cooling water

\begin{tabular}{|c|c|c|c|}
\hline Item & $\mathrm{mg} / \mathrm{L}$ & Item & $\mathrm{mg} / \mathrm{L}$ \\
\hline $\mathrm{K}^{+}$ & 32.1 & total iron $\mathrm{mg} / \mathrm{L}$ & 0.79 \\
\hline $\mathrm{Na}^{+}$ & 2566 & full hardness $\mathrm{mmol} / \mathrm{L}$ & 15.56 \\
\hline $\mathrm{Ca}^{2+}$ & 129.88 & total alkalinity $\mathrm{mmol} / \mathrm{L}$ & 6.71 \\
\hline $\mathrm{Mg}^{2+}$ & 297.5 & enolphthalein alkalinity $\mathrm{mmol} / \mathrm{L}$ & 0.89 \\
\hline $\mathrm{Ba}^{2+}$ & 0.21 & all-silica & 0.83 \\
\hline $\mathrm{Sr}^{+}$ & 2.0 & turbidity & 14 \\
\hline $\mathrm{Cl}^{-}$ & 3265.16 & suspended substance $\mathrm{mg} / \mathrm{L}$ & 179 \\
\hline $\mathrm{SO}_{4}^{2-}$ & 153.59 & total dissolved solid $\mathrm{mg} / \mathrm{L}$ & 7289 \\
\hline $\mathrm{HCO}_{3}{ }^{-}$ & 250.1 & electrical conductivity $\mu \mathrm{S} / \mathrm{cm}$ & 6500 \\
\hline $\mathrm{CO}_{3}{ }^{2-}$ & 0.89 & $\mathrm{pH}$ & 8.6 \\
\hline $\mathrm{NO}_{3}^{-}$ & 6.0 & $\mathrm{COD} \mathrm{mg} / \mathrm{L}$ & 201 \\
\hline
\end{tabular}

Table 2. Influences of SDI index to the RO membrane performance

\begin{tabular}{|l|l|l|l|}
\hline Pretreatment & SDI index & $\begin{array}{l}\text { Use life of } \\
\text { membrane/ year }\end{array}$ & $\begin{array}{l}\text { Normal } \\
\text { permeation } \\
\text { rate } \%\end{array}$ \\
\hline hyperfiltration and MF & $<1$ & $7 \sim 8$ & $+40^{*}$ \\
\hline MF & $1 \sim 2$ & $3 \sim 5$ & benchmark \\
\hline $\begin{array}{l}\text { Cleaning, multiple-layer filtering } \\
\text { and exact filtering }\end{array}$ & $3 \sim 5$ & $1 \sim 2$ & $-10^{*}$ \\
\hline Ordinary tap water & $>5$ & $<1$ & $-10 \sim+20^{*}$ \\
\hline
\end{tabular}

Note: 1. "*" denotes the water yield of the membrane under the normal situation.

2. The permeation rate value is the relative value based on the normal permeation rate of MF, $+40 \%$ denotes the value is $40 \%$ higher than the MF permeation rate, and $-10 \%$ denotes the value is $10 \%$ lower than the MF permeation rate.

Table 3. The running result of 1\# FM system

\begin{tabular}{|l|l|l|l|l|l|l|l|}
\hline Date & $\begin{array}{l}\text { Inlet flux } \\
\mathrm{t} / \mathrm{h}\end{array}$ & $\begin{array}{l}\text { Inlet } \\
\text { pressure } \\
\mathrm{MPa}\end{array}$ & $\begin{array}{l}\text { Yielding } \\
\text { pressure } \\
\mathrm{MPa}\end{array}$ & $\begin{array}{l}\text { Pressure } \\
\text { difference } \\
\mathrm{MPa}\end{array}$ & $\begin{array}{l}\text { Yielding } \\
\text { water flux } \\
\mathrm{t} / \mathrm{h}\end{array}$ & $\begin{array}{l}\text { Turbidity of } \\
\text { yielding water } \\
\mathrm{NTU}\end{array}$ & $\begin{array}{l}\text { Water } \\
\text { temperature } \\
{ }^{\circ} \mathrm{C}\end{array}$ \\
\hline 10.14 & 147.56 & 0.151 & 0.082 & 0.069 & 139.36 & 0.029 & 18.3 \\
\hline 10.18 & 146.09 & 0.150 & 0.080 & 0.070 & 139.38 & 0.027 & 17.4 \\
\hline 10.23 & 154.45 & 0.140 & 0.073 & 0.067 & 144.17 & 0.030 & 16.8 \\
\hline 10.27 & 160.85 & 0.160 & 0.086 & 0.074 & 151.14 & 0.024 & 16.3 \\
\hline 11.02 & 163.77 & 0.156 & 0.080 & 0.076 & 152.45 & 0.026 & 14.5 \\
\hline
\end{tabular}


Table 4. The running result of $1 \#$ RO system

\begin{tabular}{|l|l|l|l|l|l|l|}
\hline & Inlet pressure \\
DPate & $\begin{array}{l}\text { Pressure } \\
\text { difference of } \\
\text { the first part } \\
\mathrm{MPa}\end{array}$ & $\begin{array}{l}\text { Pressure } \\
\text { difference of } \\
\text { the second } \\
\text { part } \\
\mathrm{MPa}\end{array}$ & $\begin{array}{l}\text { Yielding } \\
\text { water flux } \\
\mathrm{t} / \mathrm{h}\end{array}$ & $\begin{array}{l}\text { Yielding } \\
\text { water } \\
\text { conductance } \\
\mu \mathrm{S} / \mathrm{cm}\end{array}$ & $\begin{array}{l}\text { Demineralization } \\
\text { rate } \\
\%\end{array}$ \\
\hline 10.14 & 1.23 & 0.16 & 0.10 & 102 & 21.35 & 98.8 \\
\hline 10.18 & 1.24 & 0.16 & 0.11 & 100 & 22.65 & 98.62 \\
\hline 10.23 & 1.24 & 0.15 & 0.11 & 100 & 30.25 & 98.15 \\
\hline 10.27 & 1.23 & 0.16 & 0.12 & 103 & 29.12 & 98.23 \\
\hline 11.02 & 1.24 & 0.16 & 0.11 & 101 & 26.3 & 98.6 \\
\hline
\end{tabular}

Table 5. General cleaning principles of the membrane cleaning liquid (B Tansel, 2000, P.7-14)

\begin{tabular}{|l|l|}
\hline \multicolumn{1}{|c|}{ Contamination } & \multicolumn{1}{|c|}{ Selection principle of cleaning liquid } \\
\hline Calcium dirty & Various acids combining with EDTA \\
\hline Metal hydrate & Oxalic acid and citric acid combining with EDTA and surface active agent \\
\hline $\begin{array}{l}\mathrm{SiO} 2 \text { and other } \\
\text { colloids }\end{array}$ & $\begin{array}{l}\text { In high pH, use NH4F combining with EDTA and special cleaning liquids } \\
\text { such as } \mathrm{STP} \text { and BIZ }\end{array}$ \\
\hline $\begin{array}{l}\text { Biological } \\
\text { contaminations }\end{array}$ & $\begin{array}{l}\text { In high } \mathrm{pH} \text { use BIZ or EDTA to wash, and use } \mathrm{Cl}_{2}, \mathrm{NaHSO}_{3}, \mathrm{CH}_{2} \mathrm{O}_{2} \mathrm{H}_{2} \mathrm{O}_{2} \text { or } \\
\text { peroxyacetic acid to wash }\end{array}$ \\
\hline Organic matter & Use IPA or other special reagents combining with the surface active agent \\
\hline bacillus & Use Cl2 or formaldehyde solution to wash \\
\hline
\end{tabular}

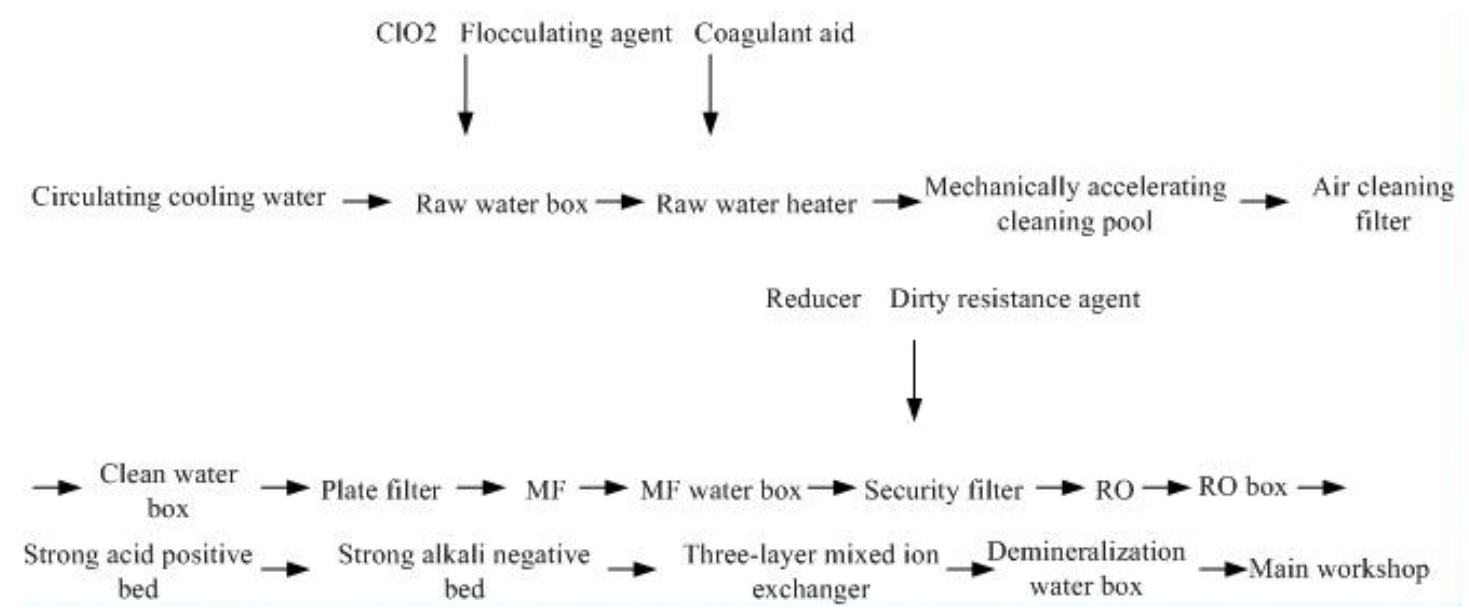

Figure 1. Process flow 


\title{
Recycling Economy and Sustainable Development
}

\author{
Hua Liu \\ Maoming University \\ Guangdong 525 000, China \\ E-mail: LiuHua-5@163.com \\ Fund: Guangdong Province Natural Science Foundation (8152500002000005) in 2008; Maoming City in 2006 IT \\ projects; Maoming College in 2008 Natural Science Foundation-funded projects.
}

\begin{abstract}
Economic development is the main theme of social progress. By recalling the economic development, the necessity and inevitability of sustainable development is fully demonstrated. With the acceleration of economic globalization, the influence for sustainable development is increasing. There is a complex opposite and united relationship between economic globalization and sustainable development. People are seeking a way to eliminate confrontation and get united. In social practice, we found that the recycling economy is the best way to achieve sustainable development, and it is an important embodiment of the economic, social and ecological sustainability.
\end{abstract}

Keywords: Economy, Sustainable Development, Economic Globalization, Recycling Economy

"Person" is the center of social development, "material" is the centre of economic development, but the economic development is the basis of social development. Economy, the main line of social development, requires higher demands of the environmental conditions continuously. The relationship between economy and environment has become more complex. In order to strive after the sustainable development of economy and society, the research about economy and sustainable development is very necessary. That is because a good economic situation is based on the ecological sustainable development ability, and environmental industry is about to become an important component of the economic cycle and a new point of economic growth (Mao Hanying, 1995). This article will discuss the relationship between economy and sustainable development in three aspects.

\section{The Process of Economic Development and The Introduction of Sustainable Development}

The history of human society experienced three periods: the primitive economy, the agricultural economy and the industrial economy. Nowadays, a part of the developed countries have completed the process of industrialization, and entered a period of intellectual economy. The influences of human economic activities on the environment are different from each stages of economic development, the knowledge of economy and environment is also different.

\subsection{The Original Economic Period (Primitive Society)}

The level of productive forces is extremely low, and labor force is the only production factor. Human just use the environment by taking animals, wild fruit and other things as essential means of subsistence, through metabolism to achieve the energy and material exchange with the environment, and through natural purification to achieve ecological balance of nature. Basically, this period human had no impact on the environment and no understanding about the relationship between human and environment.

\subsection{The Agricultural Economy Period (Slave Society, Feudal Society)}

Agriculture is the main economic sector, which plays a decisive role. The major activities of human are going around the land. Crop farming is the leading factor of agriculture. Labor, land and simple tools become production factors. Although the level of productivity had a substantial increase than the primitive society, it is still very low in general. Human economic activity has small damage to the environment, and the awareness of the relationship between human and environment is not much either.

\subsection{The Industrial Economy Period (Capitalist Society, Socialist Society)}

Since the 18th century, industry plays a decisive role in the economy growth. Manufacturing industry becomes a leading sector, and human economic activities are going around the resources. With the advancement in technology, the productivity level has increased significantly. With the increase in material wealth, human's damage to the environment has become increasingly heavier. Although the awareness of the relationship between human beings and the environment is gradually deepened, the traditional concept of development still rules the understanding of "development". That is, the development is defined according to the economic growth, GDP and national income's 
growth. Accordingly, a series of problems are broken out, such as the energy crisis, shortage of resources, environmental pollution and ecological damage, etc. (Zhou Wenzong, 2005)

Since the 1960s, mankind has experienced a series of major pollution incidents. Environmental pollution and ecological damage brought about huge losses to the economic and social development, and also a threat to the survival of mankind. Suffering the pain and threatening human positively reflect and conclude, and begin to be suspicious and contemptuous of the traditional model of economic development. This is the first jump of the awareness of "economic development and environment". Since the 1980s, countries around the world started to research the development problems from the economic, political, social and other aspects. Thus forming a new "social development concept", that is, the economic development embodies that the economic growth, social progress, and the environment improvement are acting at the same time. This new "social concept of development" gradually evolved into a "coordinated development concept" in practice. That is, a new idea of the natural ecological and socio-economic coordinated development. In 1980, the World Conservation Union, the United Nations Environment Program and the World Wildlife Fund jointly issued the "World Conservation Program". And the idea of sustainable development was proposed in the program. Taking the United Nations Conference on Environment and Development in 1992 as the hallmark, human began to tend to the road from the separation of the environment and human development to the combination of economic development and environmental protection.

Sustainable development is brought forward and reached a global consensus, which is the most important progress of the human development concept, which is a leap of awareness about the relationship between man and nature, as well as the human socio-economic activity. At the same time, it's the second jump of the awareness about "environment and development". Sustainable development, first of all, is a transformation about the purpose which changes from making the economic growth as the core to a comprehensive social development. The transformation from the exploitation the mainly from natural resources to human resources is followed. What it stresses is the harmony and unity at the economic, social, ecological and other aspects . As a landmark of the new epoch-making concept of development, not only the revolution of ideology, but also a socio-economic changes, the sustainable development is impacting on the socio-economic development historical process of countries around the world. (Wang Lei, 2007)

\section{Economic Globalization Impacts on Sustainable Development}

In the late 1980s and early 1990s, as "sustainable development" concept was quickly accepted by the world, "economic globalization" wave was sweeping across the world. About the effect "economic globalization" on "sustainable development", it is difficult to make a simple answer. As the two sides of globalization (the economic globalization and the globalization of environmental problems), There are many complex relations. Economic globalization is a campaign process of the world economy. It mainly refers that production factors move freely in the global scale to achieve rational distribution of resources. And the factors of production flow global mainly through trade, investment and financial activities to achieve. At present, the trend of economic globalization is further accelerating, which promoting the free flowing of the production factors in the world scale, and eliminating all kinds of barriers and obstacles to make the national economic correlation and dependence more and more strengthen. Global economic integration is the inevitable result of the world's productive forces and the international division of labor developing to more advanced stage . However, if we can not properly deal with the relationship between economic globalization and the protection of the ecological environment, then, it will exacerbate environmental problems of globalization, thereby impeding the achievement of sustainable development.

\subsection{Sustainable Development and Economic Globalization are two Co-restraint and Co-promote Important Aspects Nowadays.}

On one hand, economy is the foundation. Sustainable development requires economic growth to provide material wealth; On the other hand, sustainable development is the principle. Economic development needs sustainable development principle for guidance. Therefore, the strategy of sustainable development to improve the ecological environment around the world and through globalization and to promote further economic growth are two sides of the unity of opposite.

\subsection{The Economic Globalization and Sustainable Development is Unified in Essence.}

Their basic objective is improving human quality of life continuously through the rational allocation of resources. There are strong coherence and complementarities between these two aspects. Economic globalization offers the support and cooperation of the global scope for the implementation of the sustainable development strategy. It has promoted the optimal allocation of resources and the rationalization of production in the global scope, improving the efficiency of resource using, reducing environmental pollution caused by the low efficiency of development resources and production relatively. Moreover, economic globalization will popularize the cost-effective, market-oriented view to all over the world, which contributing to promoting the cost of resources and the value of environment. In addition, economic globalization will further promote and enhance international cooperation in environmental issues and establish 
environmental industries. In short, economic globalization on a beneficial effect on sustainable development can be summarized as the following three points:

(1) Economic globalization makes the distribution and using of resources more effective, improving the utilization rate, thus promoting production growth and reducing pressures on the environment.

(2) Economic globalization is conducive to economic development, and laid the material foundation for improving the environment.

(3) Economic globalization provides a realistic way for solving the global environmental issues. For example, the World Trade Organization, the World Bank and other global economic organizations are by virtue of their special status to promote the implementation of the strategy of sustainable development, and helping to resolve the environmental problems of economic globalization process. (Zhang Kun, 2003)

\subsection{There are not only United and Favorable Side but also Opposite and Negative Side between Economic Globalization and Sustainable Development.}

Economic globalization stressed that we should realize the increase of the "quantity" of human wealth through the effective allocation of resources, while sustainable development stressed that the effective allocation of resources to the environment, with a focus on human life "quality" of improvement. In addition, economic globalization has also widened the gap between developed and developing countries, which makes the developing countries at a disadvantage in the competition of global resources and markets and exploited by developed countries. The developed countries occupy the monopoly of high-tech industries, shifting the serious pollution and high energy-consuming industries to developing countries so that the pollution is spreading to the international scope. Which is not conducive to the achievement of sustainable development. Specifically, economic globalization on the disadvantage effect on sustainable development can be summarized as the following four aspects:

(1) Economic globalization lead to the spread of environmental pollution. The internationalization of production makes the pollution internationalized.

(2) Economic globalization brings the economic growth, to a certain extent, also constitutes a pressure on the environment at the same time. Economic growth must cost more energy, transport increased, increasing pollution and shortage of resources.

(3) Economic globalization has intensified the conflicts in the south and north sides on environmental issues. On the one hand, the developed countries plundered resources, transferred the hazardous production processes, so that the resources of developing countries are destroyed, and the environment is damaged; On the other hand, the developed countries take the environment as an excuse to limit developing countries exporting products to achieve the purpose of exploitation and monopoly. In addition, the developed countries also stressed the international character of environmental problems, required that solutions to environmental problems must be overcome national borders, leading to the sovereignty of developing countries being challenged. All of these are exacerbated the contradictions between the south and north side on environmental issues.

(4) Economic globalization is widening gap between rich and poor, exacerbated the unfair, which is inconsistent with sustainable development. There are not only the mutually beneficial, and promote role but also disadvantageous effect between economic globalization and sustainable development.

How to take measures to promote and use the advantageous and united side, and to avoid and eliminate the disadvantageous and confrontation side, it is an important subject human society have to face.

\section{Recycling Economy is the Embodiment of Sustainable Development}

With the rapid development of ecology since the 1960s, people have a wish to imitate the natural ecological system. In accordance with the natural ecosystem material recycling and energy flow law human reconstruct the economic system, making the economic system harmonious integrated into natural ecosystems in the process of the material cycle, and establishing a new economic shape - circular economy. By the 1990s, with the sustainable development of globalization, the developed countries develop recycling economy and establish recycling-oriented society as an important way for sustainable development (Zhu Guohong, 1995).

\subsection{Recycling Economy is Essentially a Kind of Ecological Economy}

Recycling economy mainly uses the bionomics law to guide socio-economic activities, taking clean production and comprehensive utilization of resources, ecological design and sustainable consumption and so on to be integrated, to achieve the in-house recycling of material and energy. It performs an economic mode of pollution performance for low emissions or zero emission on environment way.

Compared recycling economy to traditional economy, their difference is: The traditional economy is the economy which is made of materials, energy one-way flow by "resources - products - pollution discharges". In this economy, 
whether industrial model or agricultural model, can not bring about the sustainable development of mankind. Because the natural world is treated as a "natural storage" and " garbage can". Human thought that natural resources are infinite, inexhaustible, and can be unrestricted and free to obtain more and more things. At the same time, human thought that the ability of the nature to accept waste is unlimited, it's free to discharge more and more waste to the environment. This one-time and extensive mode of operation is at the cost of the environment and resources to seek the social development, which will inevitably lead to the destruction of resources and the serious consequences of environmental pollution. The recycling economy is an economic development model on the basis of a continuous cycle of the material. It requires the economic activities have to according to the model of the natural ecological system to organize the material circulation process of "resources - production - renewable resources", which can make the entire economic system and the process of production and consumption are basically have little or no waste. And, the environmental industries have a certain status in the recycling economy. Clearly, the traditional economy depends on changing resources into waste to achieve economic growth, while the recycling economy depends on recycling resources to promote economic growth. It fundamentally eliminates the contradictions and conflicts between the environment and economic development, achieving the dual function of the waste utilization and environmental protection, which is the perfect embodiment of sustainable development between the economy and the environment.

3.2 The Development of Recycling Economy is an important way to Achieve Sustainable Development. It is the Fundamental Means of the Environment Protection and Reducing Pollution, too

The development of recycling economy is the protection of the environment, which concrete expresses in its $3 \mathrm{R}$ principles. Recycling economy makes "Reduce, Reuse, Recycle" as the code of conduct of the socio-economic activities. Reduction of principle (Reduce) requires with fewer raw materials and energy inputs to achieve the established purpose of production or consumption purposes. At the beginning of the economic activities we should take attention to save resources and reduce pollution. Re-use principle (Reuse) requires that products and packaging should be repeatedly used to avoid the proliferation of one-time items. Recycling principles (Recycle) requires that productions can become available resources rather than useless waste after the completion of its function.

The recycling economy, this new form of the advanced economies, is a set of economic, technological and social integration in the systems engineering. In developed countries the recycling economy is becoming a trend and has been successful in the social practice. But in developing countries, it is only a concept, with very little production practice, the more countries are in the test (Xia Huanlong, 2006). China actively develops the recycling economy to promote the economic, social, and ecological sustainable developments by establishing regulations, implementing green accounting, and developing green technology and green consumption to achieve the recycling economy.

\section{References}

Mao, Hanying, (1995). the relations between people and geography and regional sustainable development. [M] Beijing: China Science and Technology Press, 1995.

Wang Lei, (2007). University leapfrog development: new needs of the knowledge economy era. [J] Guide of scientific and technological innovation. 2007 (31):180-182.

Xia Huanlong, (2006). the relationship between man and nature in harmony evolution [J] Shanghai School of Business Journal. 2006, 12 (1): 8-9.

Zhang Kun, (2003). theory and practice of recycling economy. [M] Beijing: China Environmental Science Press, 2003.

Zhou, Wenzong, (2005). Ecological industries and industrial ecology. [M]. Beijing: Chemical Industry Publishing House.

Zhu Guohong, (1995). relations between the people. [J] population and economy. 1995, 88 (1):18-24. 
A journal archived in Library and Archives Canada

A journal indexed in CANADIANA (The National Bibliography)

A journal indexed in AMICUS

A journal included in Google Scholar

A journal included in LOCKSS

A journal included in PKP Open Archives Harvester

A journal listed in Journalseek

A peer-reviewed journal in environment and sustainable development

\section{Journal of Sustainable Development}

Three Times a Year

Publisher Canadian Center of Science and Education

Address 4915 Bathurst St. Unit \#209-309, Toronto, ON. M2R 1 X9

Telephone 1-416-208-4027

Fax 1-416-208-4028

E-mail JSD@ccsenet.org

Website www.ccsenet.org

Printer William Printing tne

Price CAD $\$ 20.00$

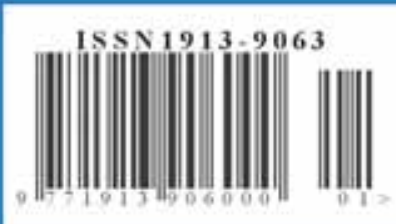

